\title{
Sustainability Standards, Welfare Impacts, and Risk Attitudes Among Coffee Farmers in Uganda
}

\author{
Dissertation \\ to obtain the Ph.D. degree \\ in the International Ph.D. Program for Agricultural Sciences in Göttingen (IPAG) \\ at the Faculty of Agricultural Sciences, \\ Georg-August-University Göttingen, Germany
}

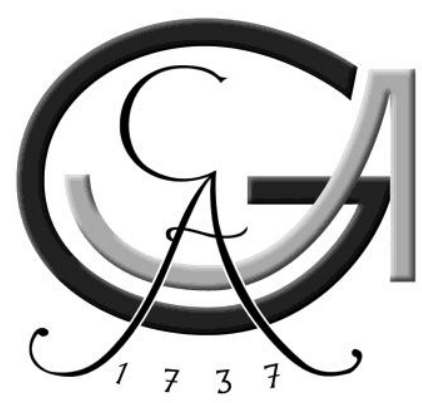

presented by

\section{Brian Chiputwa}

born in Harare, Zimbabwe

Göttingen, May 2014 
D7

\section{Committee of supervisors}

1. Name of supervisor: Prof. Dr. Matin Qaim

2. Name of co-supervisor: Prof. Dr. Bernhard Brümmer

Date of dissertation: July $24^{\text {th }}, 2014$ 


\section{Summary}

Agriculture is still the most important sector in driving economic growth and poverty reduction in developing countries. In recent times, global agricultural food systems around the world are undergoing a rapid transformation with modern retailers, private standards, and vertically integrated supply chains gaining in importance. This transformation, which is partly driven by changes in consumer preferences, has led to a sharp increase in the production and trade of high-value foods such as fruits, vegetables, milk, meat, eggs, and fish. At the same time, the demand for luxury commodities such as coffee, tea, and cocoa that fulfill sustainability standards is also growing. In response, the number of sustainability standards is also growing, with the most common being Organic, Fairtrade, Rainforest Alliance, UTZ Certified, and CAFÉ Practices. The main emphasis of sustainability standards is on production systems that advance social equity and economic prosperity of producers, while maintaining or improving environmental quality. But what are the implications for smallholders in developing countries.

Several studies have explored the impacts of different sustainability standards on for different crops in developing countries. Some of these studies are qualitative in nature. Other studies used quantitative techniques, but without accounting for non-random selection of farmers into certification schemes, means that the impact estimates may be biased. For sustainability standards in the coffee sector in particular, there are still only very few studies that properly control for selection bias; those that do, mostly assess the impact of only one standard, without comparing different standards and certification schemes. Furthermore, gender and nutrition effects of high-value food trade and modernization of supply chains remain almost unexplored. This is despite the high levels of malnutrition among smallholder farming communities and the fact that sustainability standards have a social component that goes beyond mere income effects.

The first objective of this dissertation is to analyze the impacts of three sustainability standards - Fairtrade, UTZ, and Organic — on the living standard and poverty of smallholder coffee farmers. The second objective is to estimate the nutrition impacts and nutrition impact pathways of sustainability standards among smallholder coffee farmers in Uganda. Since compliance with sustainability standards involves making investment decisions and investment decisions involve risk, the third objective of this study involves measuring risk attitudes of farmers. The specific objective is to compare different risk elicitation methods regarding consistency of risk attitude measures as well as inconsistency 
rates in the response behavior. The analyses of these objectives rely on two datasets that were collected in 2012. The first dataset consists of a comprehensive household survey comprising of 419 smallholder coffee farmers in Uganda. The second dataset consists of data collected from a framed field experiment that elicited risk preferences of 332 farmers, which is a sub-sample of the 419 farmers interviewed in the household survey.

To analyze the first objective, we use survey data and propensity score matching with multiple treatments to control for selection bias. We find that farmers complying with all three sustainability standards have significantly higher living standards. However, disaggregation by certification scheme, Fairtrade certification improves living standards by $30 \%$ and significantly reduces the likelihood of being poor by $50 \%$. However, we also show that participation in UTZ and Organic certifications is not associated with higher living standards or lower poverty rates. Much of these differences in results are due to Fairtrade farmers receiving higher prices through a minimum guarantee system, having better bargaining power, and adding value to their certified coffee compared to the other two schemes. We conclude that overly general statements about the effects of standards on smallholder livelihoods may be misleading.

For the second objective, again we use household survey data to analyze the impact of sustainability oriented certification on household nutrition, while controlling observed and unobserved factors using an instrumental variable approach. In addition, we have used structural equation modeling to identify the main nutrition impact pathways. Econometric results reveal that compliance with sustainability certification standards increases household calorie consumption by $19 \%$ and supply of micronutrients including iron and zinc by at least $35 \%$. Furthermore, using structural equation modeling, we find that income and gender are the two main pathways to nutritional gains from sustainable certification. Participation in sustainability oriented certification leads to improved household nutrition through increased income and through improved bargaining power of women.

We use experimental data to analyze the third objective of this research. The objective is to compare two innovative experimental methods that can be used in eliciting individual risk attitudes. The two methods were modified from the original lottery-choice experiments by replacing probabilities expressed in percent with images of bags of colored balls to represent probabilities of different payoffs in order to apply them to individuals in a rural developing country setting. The results show that both methods reveal high proportions of farmers who are classified as risk averse, which is consistent with literature on risk among 
smallholder farmers in developing countries. We also find that observed inconsistency rates in the response behavior are relatively low compared to other studies in this field. The main policy highlight from this objective is that different risk elicitation methods may lead to different risk classification categories, which consequently may result in different policy recommendations. 


\section{Acknowledgements}

First and foremost, I would like to express my heartfelt gratitude and appreciation to my major supervisor, Prof. Dr. Matin Qaim, for his professional guidance, mentorship, and encouragement during the course of this work. I feel honored, have learnt a lot and will forever be grateful for this opportunity. I am sincerely grateful to Dr. David Spielman, my IFPRI counterpart for his mentorship and academic advice. You went beyond your way in assisting and I am grateful. I would like to acknowledge my committee members Dr. Bernhard Bruemmer and Stephan von Cramon-Taubadel for their willingness to serve in my committee. Also many thanks to Profs. Bernhard Bruemmer and Xiahou Yu for useful comments in the early versions of this work.

I would also like to thank the German Research Foundation (DFG) through the GlobalFood Research Training Group (RTG) for providing me the financial support and opportunity to pursue Doctoral studies in Goettingen. To all my friends and officemates in the GlobalFood RTG, it's been a happy three years for me to have met and interacted with such a diverse group of interesting people. As they say, we meet to part and part to meet.

Hanna, Christine, Simon and my special one Natalia, I will forever cherish the special moments we shared together, both academic and otherwise. Goettingen was always a lot of fun with you guys around.

Many thanks also go to my enumerators in Uganda: UTZ-Balaam, Fake-Brian, RadioUganda-Nakato, Stella, Manager-Emma and Jackie for their assistance and hard work in ensuring that I get good quality data. Not forgetting Bosco, our ever careful driver and navigator in the treacherous roads of Uganda.

My sincere gratitude also goes to the Hanns Neumann Foundation, National Coffee Farmers' Organization in Uganda (NUCAFE) and Kibinge Farmers Association for their assistance and networks in the build-up to this work. Moreover, I would also like to acknowledge and thank all interviewed farmers for their willingness to take time out of their busy schedules to respond to the many questions we had. Finally, I would like to express my gratitude to my family, who provided so much support and encouragement during my long stay away from my motherland.

I cannot conclude this note without thanking Hanna, my best friend, confidante, colleague and partner for the love, support, comfort, patience and lovely memories. You will forever be dear to my heart. To our unborn child, I am anxiously counting down the days. 


\section{Table of Contents}

I. General Introduction ......................................................................................................1

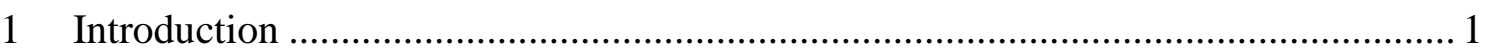

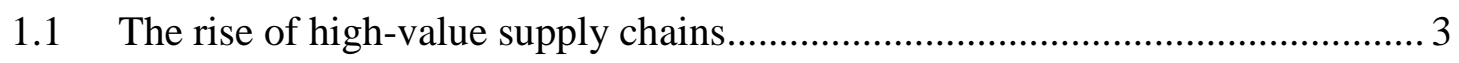

1.2 Implications of high-value supply chains on smallholders .............................. 4

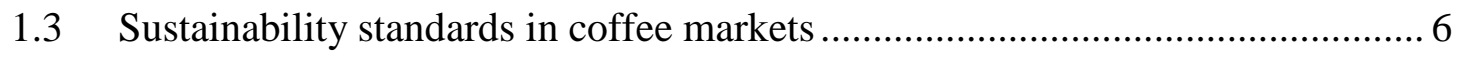

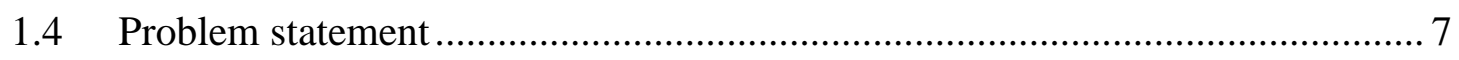

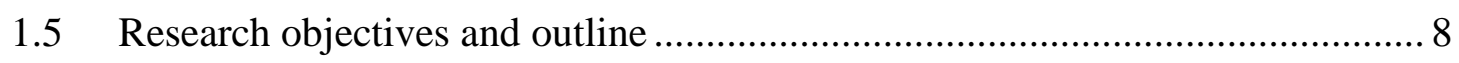

II. Food Standards, Certification, and Poverty among Coffee Farmers in Uganda.... 10

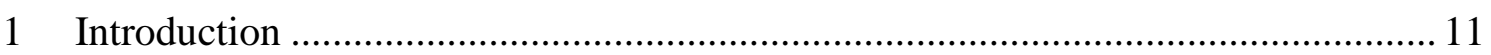

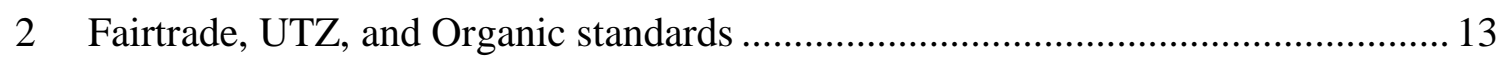

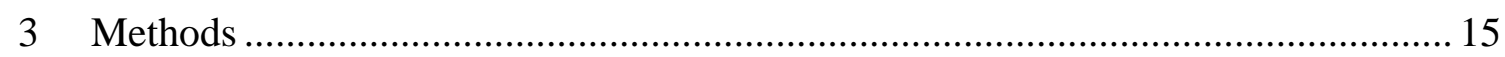

3.1 Modeling farmers' choice of certification scheme...................................... 15

3.2 Modeling the impact of certification.......................................................... 16

3.3 Propensity score matching with multiple treatments .................................. 17

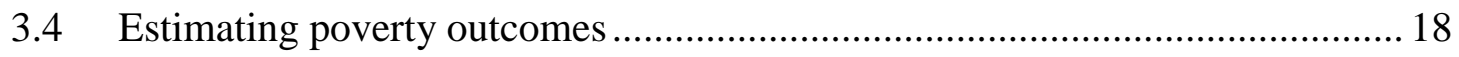

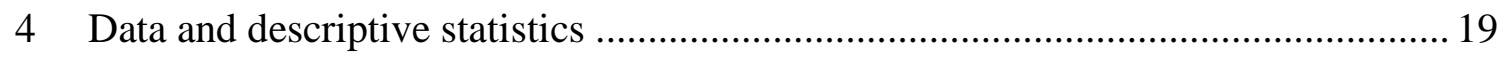

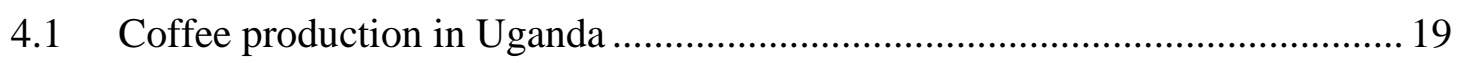

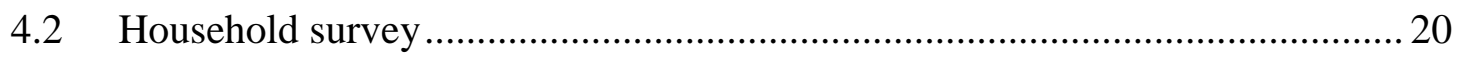

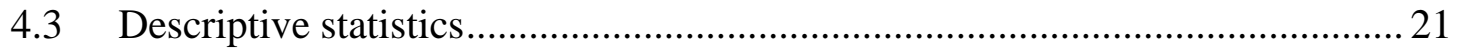

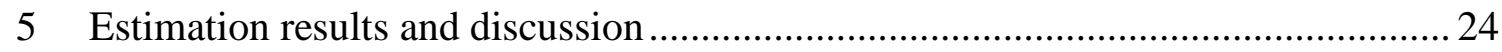

5.1 Factors influencing the certification decision .............................................. 24

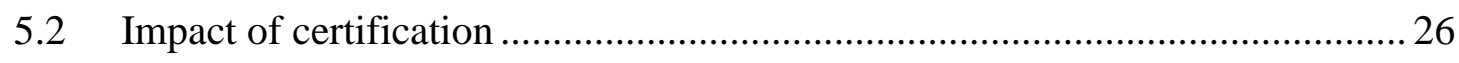

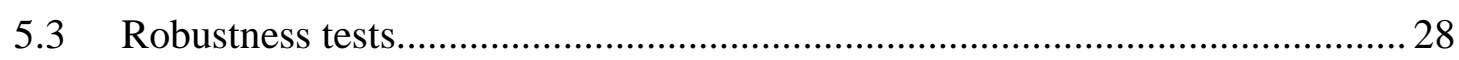

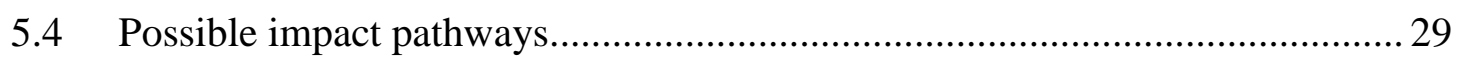

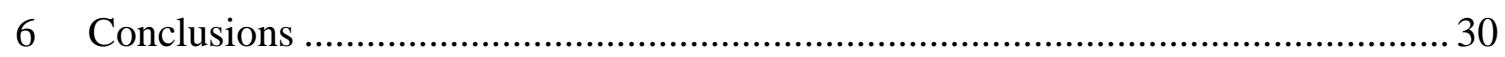

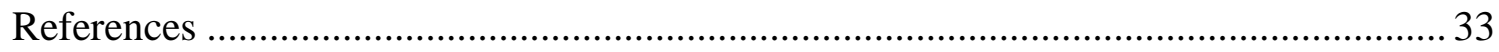

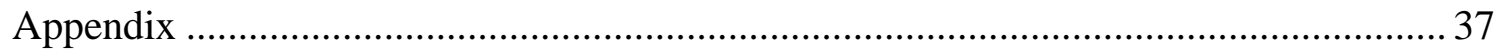

III. Sustainability Standards, Gender, and Nutrition among Coffee Farmers in Uganda 39

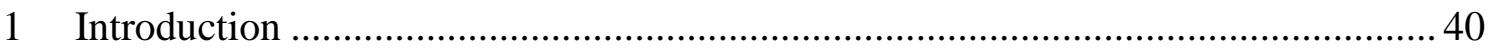

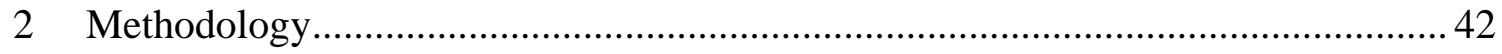

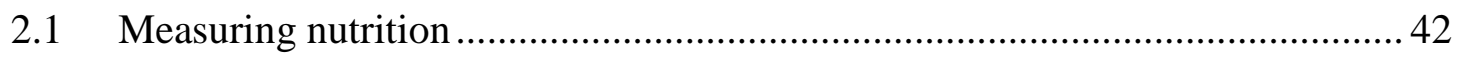

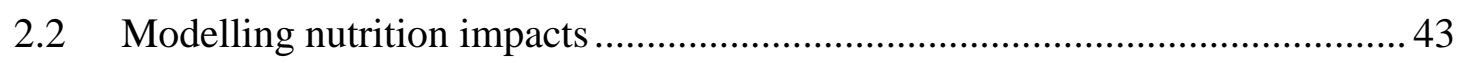

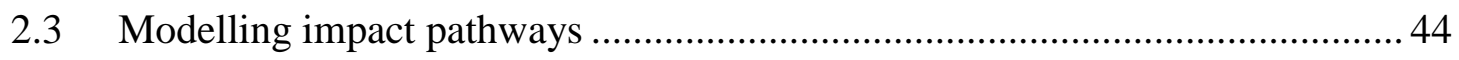

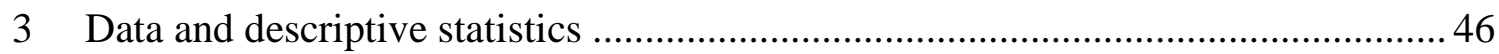




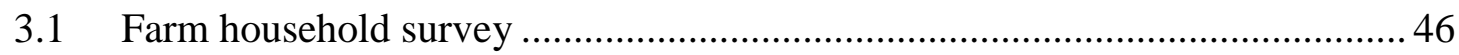

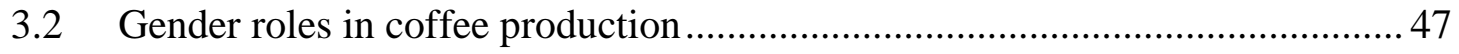

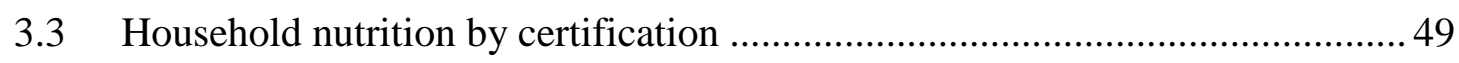

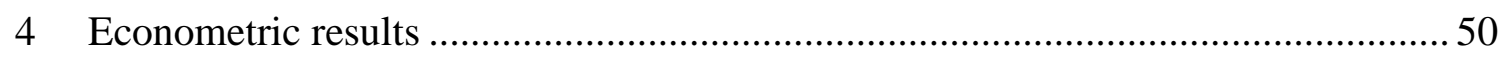

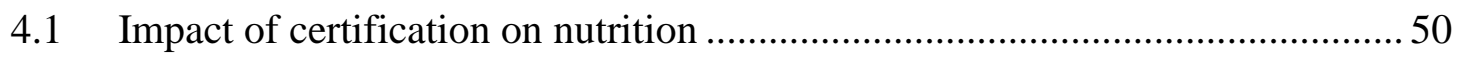

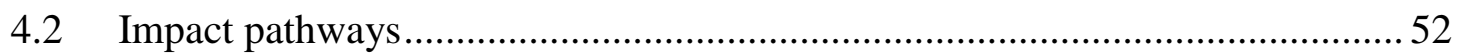

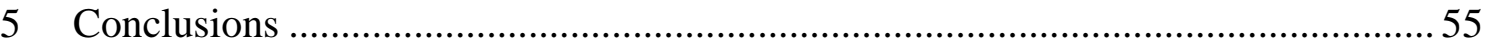

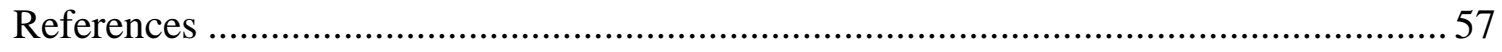

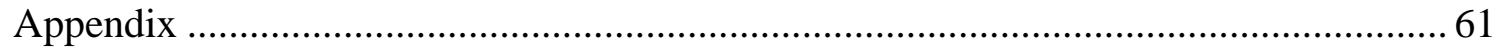

IV. Do Changing Probabilities or Payoffs in Lottery-Choice Experiments Affect the

Results? Evidence from Rural Uganda............................................................................ 64

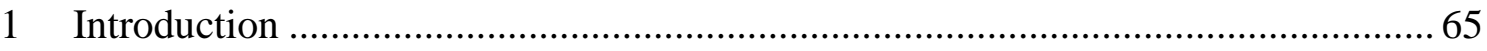

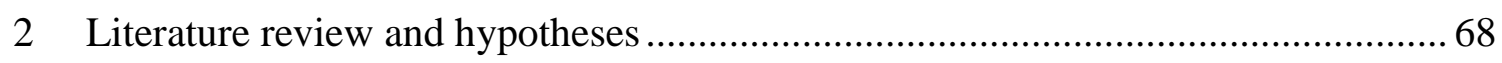

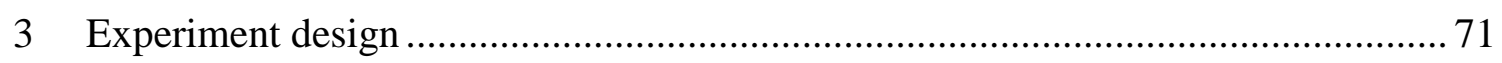

3.1 The Holt and Laury lottery and its modification ........................................... 71

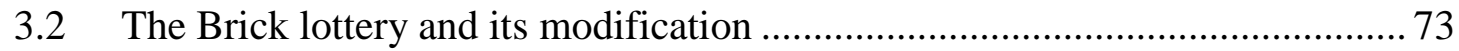

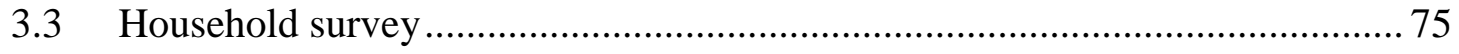

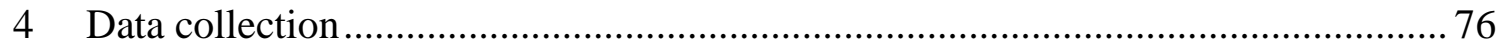

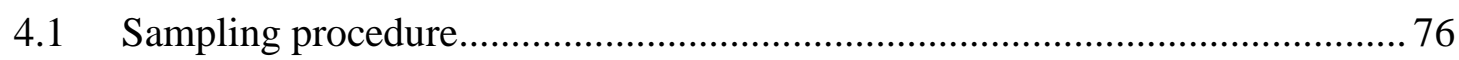

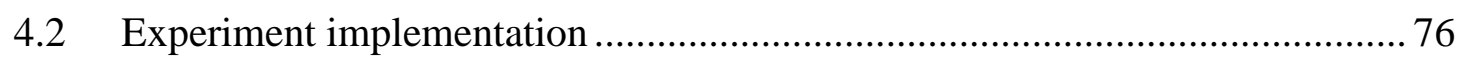

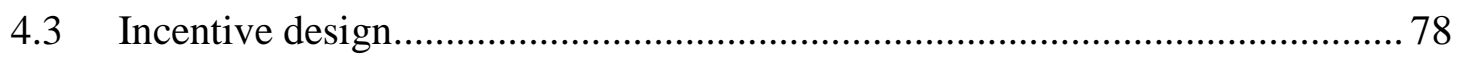

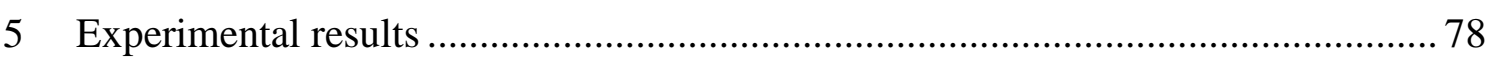

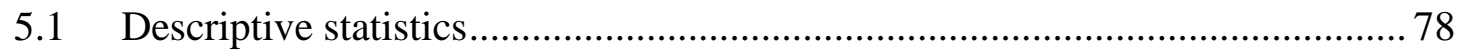

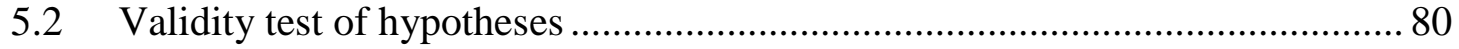

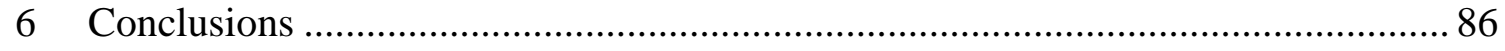

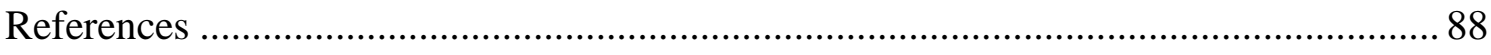

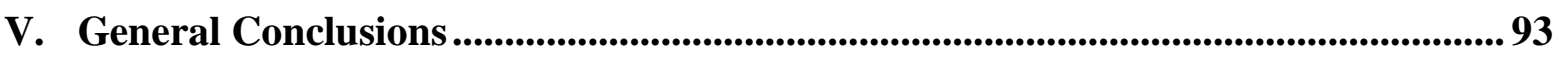

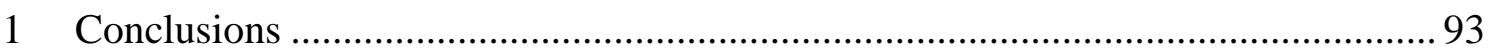

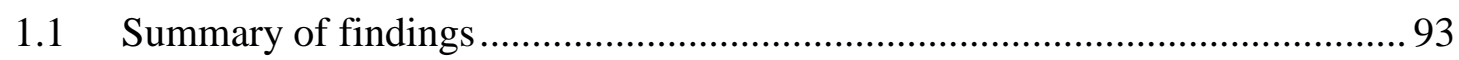

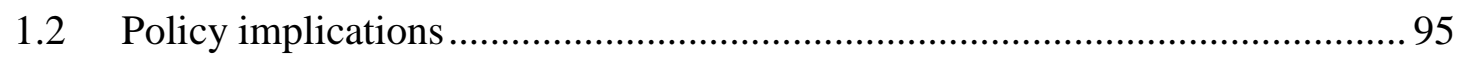

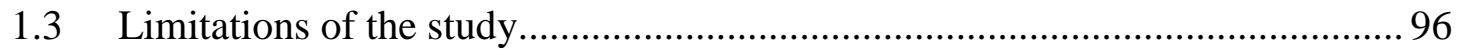

List of publications..................................................................................................................................... 98

Declaration on the proportion of own work performed ...................................................99

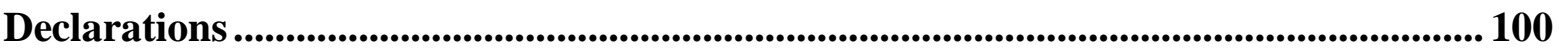

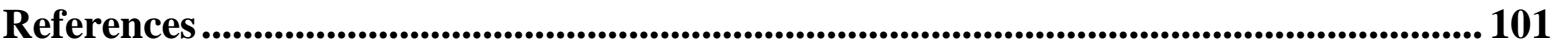

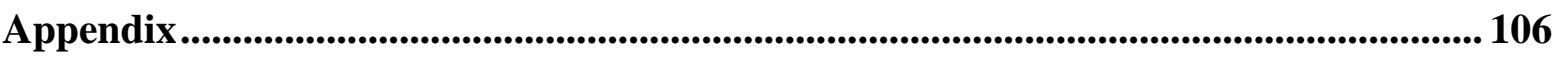




\section{General Introduction}

\section{Introduction}

Agriculture is still the most important sector in driving economic growth and poverty reduction in developing countries. Eighty-percent of the estimated 500 million farms are managed by smallholders who contribute almost $80 \%$ of food supplies in Africa and Asia (IFAD \& UNEP, 2013). Agriculture is inherently risky and associated with uncertainty over changes in the climate, high input prices, volatile output prices, institutional changes and increasing liberalization of global trade, with severe implications for smallholder vulnerability (Hurley, 2010; Vargas Hill, 2009). In recent times, global poverty and foodinsecurity in developing countries has been in the spotlight. Despite supplying a large share of global food supply, smallholders make up the majority of the 842 million people experiencing chronic hunger and undernourishment (FAO, IFAD, \& WFP, 2013). Although there have been modest successes, the progress in hunger reduction falls short of the Millennium Development Goals (MDGs), which had targeted to halve the proportion of people under extreme hunger and poverty between 1990 and 2015. Growth in the smallholder sector plays a key role in contributing to poverty reduction in developing countries.

Over the last couple of decades, major growth and structural changes in global agricultural food value chains have occurred. Trade liberalization, reduction in import barriers in industrialized countries and foreign direct investment have further contributed to agricultural economies opening up and increased economic integration of transition and developing countries. This trend has seen a sharp increase in the production and trade of high-value non-staple foods such as fruits, vegetables, milk, meat, eggs, and fish (Maertens \& Swinnen, 2009; Reardon \& Timmer, 2005; Swinnen, 2007). As a result, domestic agricultural food systems in developing countries are rapidly changing with the expansion of modern food supply chains with major implications for economic development. Supermarkets are also rapidly spreading across developing countries (Reardon, Timmer, Barrett, \& Berdegue, 2003). At the same time, food production and trade are now increasingly being governed by stringent public and private standards regarding food quality and safety (Henson \& Jaffee, 2006). In more recent times, there has been a rapid proliferation of sustainability standards, which are also private and voluntary standards, but with an emphasis on production systems that advance social equity and economic 
prosperity of producers while maintaining or improving the environmental quality (Blackmore, Keeley, with Pyburn, R., E., Chen, \& Yuhui, 2012). The most common and widely adopted sustainability standards are Organic, Fairtrade, Rainforest Alliance, UTZ Certified, and CAFÉ Practices. Despite these stringent standards, the share of high-value products traded from Asia and Latin America has doubled from 20\% of agricultural exports since 1980 to around $40 \%$, although the rates are slower in Africa (Swinnen, 2014).

It is generally agreed that global supply chains have had a profound effect on the way food is produced and traded, although there is still on-going debate on the implications for smallholder welfare in developing countries. Despite fears that high-value supply chains can contribute to the exclusion of poor farmers in developing countries due to the strict standards, modern supply chains are regarded as an important way of linking smallholder farmers to more stable and lucrative international markets. Smallholder farmers might potentially benefit from higher prices, improved quality, access to inputs, extension, and credit (Asfaw, Mithöfer, \& Waibel, 2010a; Maertens, Colen, \& Swinnen, 2009).

Agriculture is inherently a risky sector. Investment decisions in farming are often made under risk and uncertain future returns. The growth in demand for high-value products and opening of agricultural economies has increased concern for the risks faced by smallholder farmers (Hill, 2009). On one hand, adopting private standards can be regarded as a riskreducing measure for smallholders because often they come with guaranteed output markets and product prices. On the other hand, participation in sustainability oriented certification, also involves investing in specialized pattern of production and such investments usually represent fundamental decisions for smallholder farmers as they are associated with uncertain future returns stemming from international price fluctuations and other vagaries of nature like crop and livestock diseases. Therefore understanding the risk attitudes and risk bearing capabilities of smallholders is therefore important policy.

This research in this dissertation uses data collected from smallholder coffee farmers in Uganda and comprises of three analytical chapters. The dissertation focusses on analyzing the impact of participating in sustainability certification standards on smallholder welfare. Since participation in sustainability oriented certification is also linked with risk attitudes, this dissertation also analyzes risk attitudes of farmers using innovative experimental designs. 
The first manuscript will analyze the impacts of three sustainability standards — Fairtrade, UTZ, and Organic - on the living standards and poverty levels among coffee farmers in Uganda. The second manuscript analyzes the nutrition impact of complying with sustainability standards and identifies the main nutrition impact pathways. The third manuscript will compare two different lottery designs used to elicit individual risk attitudes of coffee farmers in Uganda.

\subsection{The rise of high-value supply chains}

Due to the growing demand for high-value agricultural products, modern retailers, private standards, and vertically integrated supply chains are gaining in importance (Henson, Masakure, \& Boselie, 2005; Reardon, Barrett, Berdegué, \& Swinnen, 2009). Vertical integration of supply chains has resulted in private traders, international retailers, supermarkets, agribusinesses, and food processing companies increasingly engaging with smallholders in developing countries through contract farming (Swinnen \& Maertens, 2007). Contract farming is an arrangement with producers that is governed by private standards, which are a pre-defined set of rules or requirements that have to be complied with in order to have access to certain segments of a market. The growing demand for high-value products has been triggered by both demand and supply side factors.

On the demand side, one of the major driving forces causing a shift towards high-value products is the change in consumer preferences and lifestyles. Some factors that have contributed to this change include rapid economic and income growth, higher living standards, higher education levels, increased urbanization and evolving lifestyles (Mergenthaler, Weinberger, \& Qaim, 2009; Narrod et al., 2009). In addition, there have been growing fears among consumers over the need to secure food safety and quality. A series of heavily publicized foodborne disease outbreaks and incidents resulting from natural, accidental, and deliberate contamination of food, have been described by the World Health Organization (WHO) as one of the major global public health threats of the 21 st century (WHO, 2007). This has raised attention among consumers, governments and food retailers on the need to monitor and control food production and distribution systems (Liu, Byers, \& Giovannucci, 2008). Additionally, consumers in industrialized countries are increasingly becoming concerned with the possible social and environmental consequences of trade and food production systems. Thus, there is a segment of consumers willing to pay higher premiums for ethically produced goods in an effort to help poor farmers in developing countries out of poverty. Ethical consumers in this case are motivated by pure 
altruism and the 'warm glow' that comes with making a voluntary donation (Elfenbein \& McManus, 2010).

On the supply side, private voluntary standards were first introduced by big retailers and supermarkets in developed countries to respond to consumer concerns that included food safety and quality, traceability, health impact, human rights, animal welfare, labor standards and environmental, social and economic impacts (Ellis \& Keane, 2008; Henson \& Humphrey, 2010; Reardon, Henson, \& Berdegue, 2007). In recent years, compliance with private standards is increasingly becoming a requirement for producers in developing countries, mainly because their domestic regulatory and control systems for ensuring food safety and quality are considered as weak. Therefore, large international retailers in conjunction with non-governmental organizations and independent certification bodies have established certification programs to accompany their standards. Furthermore, since most of the high-value foods traded are perishables like fresh fruits and vegetables, retail chains try to protect their reputation and market share by putting great emphasis on freshness, quality, and safety (Henson \& Humphrey, 2010).

Certification is now being used as a mechanism that reduces information asymmetries by making the attributes and origin of a commodity apparent to consumers and ensuring a larger degree of coordination, traceability, and monitoring along the commodity chain. Better coordination over the production process and control of input supplies and distribution can lead to cost savings and greater efficiency (Muradian \& Pelupessy, 2005). Certified products usually display a logo or label that sends a signal to consumers that the product has complied with a certain standard.

\subsection{Implications of high-value supply chains on smallholders}

Although the increasing demand for high-value commodities is mostly driven by changing consumer preferences, it has far-reaching consequences on local producers and communities in developing countries. With modern supply chains becoming increasingly international, farmers who want to participate have to upgrade their production and processing systems, in order to comply with the stringent food quality and safety standards. Despite being regarded as voluntary, private standards are almost becoming mandatory, because many international buyers now consider them as a pre-requisite to do business in developing countries. These trends have many implications on the welfare of smallholders around the world. 
On the one hand, there are growing concerns that due to tight product and production systems, smallholders might be excluded from high-value supply chains. A couple of reasons can explain why smallholders may not be able to consistently meet the highly stringent food standards. Smallholders are faced with many constraints that include (i) lack of access to production assets (land, labor and credit), (ii) existence of imperfect and incomplete markets, (iii) poor access to information, technology, extension and physical infrastructure, and (iv) smallholders are increasingly becoming vulnerable to a spectrum of challenges driven by adverse climatic conditions, declining productivity, high transaction costs, and price volatility (Minten \& Reardon, 2008; Reardon et al., 2009; Swinnen, 2007). These constraints have been observed to cause smallholder farmers to be more risk averse and to pursue more subsistence-oriented objectives, further exacerbating their food insecurities and poverty (Dercon, 2009).

In addition, other factors that might contribute to the exclusion of smallholders include high costs of obtaining initial certification and compliance. These costs may introduce a bias towards larger farms who can better exploit economies of scale and have the ability to supply in bulk (Muradian \& Pelupessy, 2005). Vertically integrated supply chains may lead to producers being highly dependent on one or a few large buyers or retailers, thereby creating monopsony power that can also lead to unfavorable contract conditions (Swinnen $\&$ Vandeplas, 2012). Under such conditions, the risk of high-value product supply is often shifted unilaterally towards farmers.

On the other hand, high-value supply chains also present opportunities for smallholders in developing countries. Through vertically integrated chains, international retailers, agribusiness firms and supermarkets enter into contract farming with smallholder farmers. Smallholder agriculture is characterized by product and price risks. Vertically integrated chains can be regarded as a market based risk management strategy, if market power can be avoided. Ideally, high-value supply chains and contracts ensure guaranteed access to output markets, fixed and stable prices and timely payments for farmers. Furthermore, farmers may benefit from the technical and institutional support that is sometimes provided in vertically integrated supply chains, thus reducing transaction costs, increasing productivity, and improving access to information and technology (Carletto, Kirk, Winters, \& Davis, 2010; Henson et al., 2005; Maertens \& Swinnen, 2009; Rao, Brummer, \& Qaim, 2012). Vertically integrated supply chains also create employment opportunities for rural communities especially in the processing and handling of high-value products (Rao \& 
Qaim, 2013). Women account for a large share of this type of employment, resulting in modern supply chains having a positive impact on gender dynamics at the household and community level (Maertens \& Swinnen, 2012).

\subsection{Sustainability standards in coffee markets}

Sustainability standards are also increasingly being used by retailers and manufacturers, especially for luxury foods such as coffee, tea, or cocoa, to promote sustainability production systems among producers and to fulfill objectives for corporate social responsibility. Coffee ranks as one of the highly traded commodities on the international market, both in terms of volumes and value. It is estimated that the majority of the 25 million global producers of coffee are smallholder farmers in developing countries whose livelihoods are directly dependent on coffee production (Calo \& Wise, 2005; Fairtrade, 2013). Consistent with global trends of high-value supply chains, the proportion of sustainability coffees is increasing, especially among consumers in Europe and the United States. In response to changing consumer preferences, major European retailers as well as other international organizations have developed private voluntary standards that differentiate and certify coffee produced under sustainability environmental and social conditions. The striking emergence and growth of sustainability coffee standards have seen them transform rapidly from being a niche market into the mainstream and growing at rates faster than any industry in recent years. In 2009, sustainably certified coffees accounted for about $8 \%$ of all global coffee sales, and this figure is projected to surge to $20-25 \%$ by 2015 (Pierrot, Giovannucci, \& Kasterine, 2010). Sustainability standards for coffee are viewed as instruments that reduce information asymmetries by making non-visible product and process attributes apparent to consumers and ensuring a larger degree of coordination, traceability, and monitoring along the commodity chain (Jena, Chichaibelu, Stellmacher, \& Grote, 2012; Muradian \& Pelupessy, 2005). Due to the distinct production and marketing systems, certification schemes like Fairtrade, UTZ, and Organic are seen as an important instrument in addressing chronic poverty through improved crop yields and product quality as well as cushioning farmers from volatile coffee prices (Beuchelt \& Zeller, 2011; Calo \& Wise, 2005; Jena et al., 2012). The Netherlands is leading the trend with $40 \%$ of the coffee consumed being certified, followed by the United States with a share of 16\% (Pierrot et al., 2010) 


\subsection{Problem statement}

Global trade, liberalization and the emergence of sustainability standards in high-value supply chains are transforming the way food systems in developing countries operate. There are growing debates and interests among researchers and policy makers on the likely impacts of smallholder participation in high-value supply chains, as well as on how behavioral aspects of farmers towards risk and uncertainty affects their production and marketing decision under different policy conditions. This dissertation analyzes the welfare impacts of farmers' compliance with sustainability standards using a household survey of coffee farmers in Uganda. In addition, it compares the results of two experimental designs that are commonly used in eliciting risk preferences. In the section below, we identify some gaps in the extant literature that motivated this dissertation.

There is a growing body of literature analyzing the direct and indirect effects of different sustainability standards on the welfare of smallholder farmers in developing countries for different crops like coffee (e.g., Arnould, Plastina, \& Ball, 2009; Blackman \& Naranjo, 2012; Bolwig, Gibbon, \& Jones, 2009; Jena et al., 2012; Ruben \& Fort, 2012), cocoa (e.g., Jones \& Gibbon, 2011), banana (e.g., Fort \& Ruben, 2008; Ruben \& van Schendel, 2008; Zúñiga-Arias \& Segura, 2008) and horticultural export crops like fresh fruits and vegetables (e.g., Asfaw, Mithöfer, \& Waibel, 2010b; Carletto et al., 2010; Colen, Maertens, \& Swinnen, 2012; Maertens \& Swinnen, 2009). However, the number of standards is growing, especially for luxury commodities such a coffee, tea and cocoa. Different standards may have different impacts. For sustainability standards in the coffee sector, there are still only very few studies that properly control for selection bias; those that do, mostly assess the impact of only one standard, without comparing between different standards and certification schemes. We are not aware of any studies that compared the income and poverty effects of different sustainability standards in the same setting, using quantitative techniques and controlling for selection bias. Furthermore, the gender and nutrition effects of high-value food trade and modernization of supply chains remain almost unexplored. This is despite the high levels of malnutrition among smallholder farming communities and the fact that sustainability standards have a social component that goes beyond mere income effects.

In recent years, there is a growing number of empirical studies that explore the relationship between farmers' preferences for risk and time and how they affect household decision making, which we classify into two broad categories. Researchers in the past have used 
various techniques to measure risk and time preferences, including (i) the use of actual production data (e.g., Antle, 1983, 1987; Di Falco, Chavas, \& Smale, 2007; Di Falco \& Chavas, 2009; Just \& Pope, 1979) and (ii) experimental approaches that include examples that are hypothetical (e.g Binswanger, 1980; Brick, Visser, \& Burns, 2012; Holt \& Laury, 2002) or that involve real pay-offs (Mosley \& Verschoor, 2005; Tanaka, Camerer, \& Nguyen, 2010; Yesuf \& Bluffstone, 2009). Despite the growing number of elicitation methods, there are only very few studies comparing different risk elicitation methods. This is particularly important since previous investigations have shown that results on risk attitudes are often affected by the method used. This may also have implications for policy recommendations.

\subsection{Research objectives and outline}

The broad objectives of this dissertation are to analyze the welfare impacts of sustainability standards and experimentally compare two risk elicitation methods using data from smallholder farmers in Uganda. The specific research objectives that will be addressed in three manuscripts of this dissertation are as follows:

1. To analyze and compare impacts of three sustainability oriented certification schemes - namely, Fairtrade, UTZ, and Organic - on household living standards and poverty.

2. To analyze the impact of sustainability oriented certification on household undernutrition and dietary quality and identify the main nutrition impact pathways.

3. To compare the performance of two experimental methods in eliciting risk attitudes and how well they are understood by farmers.

The analyses of these objectives rely on two datasets. To analyze objective 1 and 2 , we use a comprehensive household survey data collected in Uganda from 419 coffee farmers. The household questionnaire used is attached in the Appendix at the end of the dissertation. To analyze objective 3, we will use data collected from a framed field experiment that elicited risk preferences from 332 farmers, which is a sub-sample of the 419 farmers from the household survey. The instructions used to conduct the experiment are also contained in the Appendix at the end of the dissertation. The rest of the dissertation is organized as follows: Chapter II presents the first manuscript titled "Food Standards, Certification, and Poverty among Coffee Farmers in Uganda”, employs propensity score matching (PSM) techniques to estimate the differential impacts of Fairtrade, UTZ, and Organic standards on 
the living standard and poverty of coffee farmers. Chapter III presents the second manuscript titled "Sustainability Standards, Gender, and Nutrition among Coffee Farmers in Uganda”. This study applies an instrumental variable approach to estimate the nutrition impacts and impact pathways of sustainability standards among coffee farmers in Uganda. Chapter IV presents the third manuscript titled "Do Changing Probabilities or Payoffs in Lottery-Choice Experiments Affect the Results? Evidence from Rural Uganda”. It uses experimental methods to compare different risk elicitation methods regarding the consistency of risk attitude measures as well as inconsistency rates on the response behavior. Chapter V summarizes the main findings and concludes with some policy implications and possible directions for further research. 


\title{
II. Food Standards, Certification, and Poverty among Coffee Farmers in Uganda ${ }^{1}$
}

\begin{abstract}
Private standards are gaining in importance in global markets for high-value foods. We analyze and compare impacts of three sustainability oriented standards - Fairtrade, Organic, and UTZ - on the livelihoods of smallholder coffee farmers in Uganda. Using survey data and propensity score matching with multiple treatments, we find that Fairtrade certification increases household living standards by $30 \%$ and significantly reduces the prevalence and depth of poverty. For the other two certification schemes, no significant impacts are found. Institutional factors that may explain differential impacts are discussed. Overly general statements about the effects of standards on smallholder livelihoods may be misleading.
\end{abstract}

\section{Key words}

Coffee, smallholder farmers, Organic, Fairtrade, impact, Uganda, Africa.

\section{JEL classification}

I32, L15, O12, Q13, Q17.

\footnotetext{
${ }^{1}$ This chapter was published in the GlobalFood Discussion Paper Series No. 27 (2013). The co-authors of this article are Matin Qaim and David Spielman.
} 


\section{Introduction}

Food systems around the world are undergoing a rapid transformation, with modern retailers, private standards, and vertically integrated supply chains gaining in importance (Henson, Masakure, \& Boselie, 2005; Reardon, Barrett, Berdegué, \& Swinnen, 2009). This transformation is partly driven by changing consumer preferences, induced by rising living standards and growing concerns about food safety and the environmental and social consequences of agricultural production (Mergenthaler, Weinberger, \& Qaim, 2009; Narrod et al., 2009). What do these trends imply for smallholder farmers in developing countries? On the one hand, farmers may profit from higher prices that are paid for highquality products. They may also benefit from technical and institutional support that is sometimes provided in integrated supply chains. On the other hand, smallholders may find it difficult to meet the high standards, or they might be exploited by agribusiness companies through monopsony situations or unfavorable contracts.

A growing body of literature has studied related questions in different developing countries. One literature strand has analyzed the impacts of new supermarket procurement channels on smallholder productivity and household welfare (e.g., Hernandez, Reardon, \& Berdegué, 2007; Neven, Odera, Reardon, \& Wang, 2009; Rao \& Qaim, 2011; Rao, Brümmer, \& Qaim, 2012). Another literature strand has studied the direct and indirect effects of GlobalGAP and other private standards in horticultural export channels on smallscale producers (e.g., Maertens \& Swinnen, 2009; Asfaw, Mithöfer, \& Waibel, 2010; Carletto, Kirk, Winters, \& Davis, 2010; Colen, Maertens, \& Swinnen, 2012). Most of these studies show that poor rural households can benefit from modern supply chains through own participation as producers or through labor markets.

However, the number of standards is growing, and different standards may have different impacts. Hence, overly general statements about the welfare effects of standards for smallholder farmers may not be justified. Especially for luxury foods - such as coffee, tea, or cocoa - retailers and manufacturers are increasingly using sustainability oriented standards and labels to differentiate their products and fulfill objectives of corporate social responsibility. This trend is supported by non-governmental organizations and independent certification bodies (Liu, Byers, Giovannucci et al., 2008). For coffee, the global market share of products with sustainability certification - such as Organic, Fairtrade, UTZ, or Rainforest Alliance - has doubled from 4\% in 2006 to $8 \%$ in 2009; it is expected to grow to over $20 \%$ in the next couple of years (ITC, 2011). Especially in rich and emerging 
countries, a rising share of consumers is willing to pay more for foods that are labeled to be sustainably produced. For coffee and other tropical products, this also involves consumer perceptions to contribute to improved livelihoods of smallholder farmers (Basu \& Hicks, 2008; Elfenbein \& McManus, 2010). However, actual evidence about producer benefits is mixed (ITC, 2011).

Several studies have explored the impacts of different sustainability standards on coffee producers in developing countries. Impacts of Fairtrade, Organic, and other certification schemes were analyzed in Nicaragua (Utting-Chamorro, 2005; Bacon, 2005; Valkila \& Nygren, 2009; Beuchelt \& Zeller, 2011), Mexico (Jaffee, 2008; Barham, Callenes, Gitter, Lewis, \& Weber, 2011), and other countries in Latin America (Raynolds, Murray, \& Taylor, 2004). Some of these studies are qualitative in nature. Others used quantitative techniques but without accounting for non-random selection of farmers into certification schemes, so the impact estimates may be biased. There are also a few quantitative studies that tried to control for selection bias, but most of these studies focused on only one certification scheme. Arnould, Plastina, \& Ball (2009) evaluated the impact of Fairtrade certification on coffee farmers in Peru, Guatemala, and Nicaragua, using a multi-stage sampling procedure. Ruben \& Fort (2012) also focused on Fairtrade, evaluating impacts in Peru with propensity score matching techniques. Bolwig, Gibbon \& Jones (2009) analyzed impacts of Organic certification in Uganda, and Wollni \& Zeller (2007) looked at specialty coffees in Costa Rica; both studies used Heckman selection models. Jena et al. (2012) evaluated the impact of coffee certification on smallholder farmers in Ethiopia; their sample included Fairtrade and Organic farmers, but the results were not disaggregated by certification scheme. We are not aware of studies that compared impacts of different certification schemes in the same context, using quantitative techniques and controlling for selection bias. Such comparison could help to better understand how differences in the institutional design of standards and certification schemes affect smallholder livelihoods.

Here, we address this research gap by analyzing and comparing impacts of three sustainability oriented certification schemes - namely, Fairtrade, UTZ, and Organic - on household living standards and poverty among smallholder coffee producers in Uganda. We use household survey data collected in 2012 and employ a propensity score matching approach with multiple treatments to control for observed heterogeneity between different groups of farmers. We also test for the potential role of unobserved heterogeneity. The 
estimation results suggest that there are indeed significant differences in impacts between certification schemes.

\section{Fairtrade, UTZ, and Organic standards}

Fairtrade, UTZ, and Organic are among the most important sustainability oriented standards in the global coffee market. Recent trends in the global trade of coffee under these standards are shown in Figure 1. All three are relevant for smallholder farmers in developing countries, and all three have social and environmental objectives. For smallholders to be certified under any of these standards, they need to be organized in farmer groups or cooperatives.

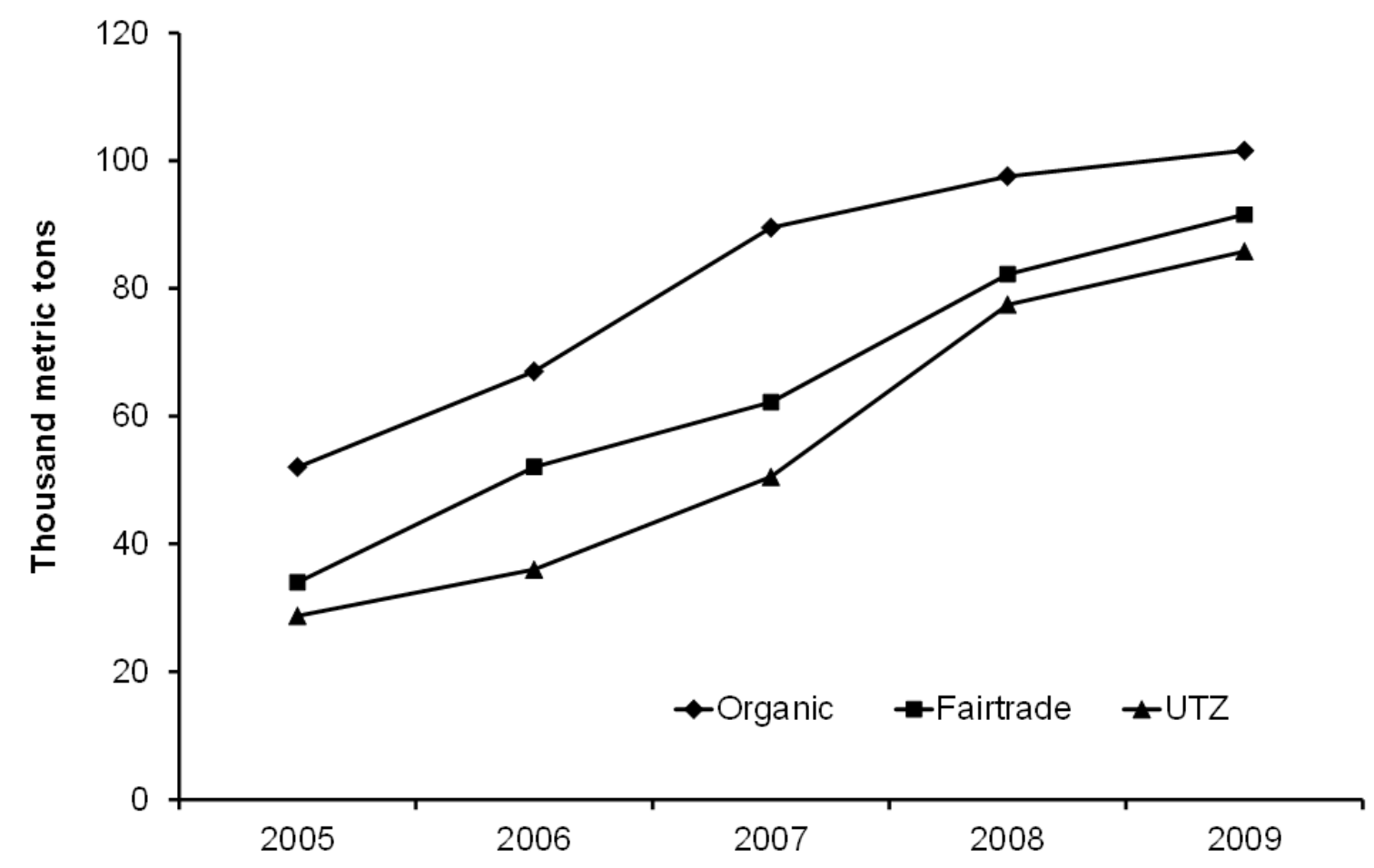

Figure 1: Global import quantities of Organic, Fairtrade, and UTZ Certified coffee Source: Own graphical presentation based on data from ITC (2011).

Fairtrade certification and labeling systems for coffee were launched in 1988 by the Fairtrade Labeling Organization (FLO) with the aim of improving the livelihoods of smallholder producers and cushioning them from volatile market prices. Fairtrade certification can only be attained by smallholder producer organizations that are farmer managed, transparent, and founded on democratic principles. Democratic principles require that leaders are elected by all members of the organization. The Fairtrade label guarantees producers a minimum floor price, whenever the international free market price falls below 
a certain threshold. In addition, a Fairtrade premium is paid to the producer organization to be used for capacity building, community development, and related projects. Producers have to ensure good labor conditions for workers, including payment of minimum wages, no child labor, and measures to reduce occupational health hazards. There are also specific rules for environmental protection, including practices for sustainability soil and water management and safe use of pesticides and fertilizers (Fairtrade, 2011). The most important markets for Fairtrade coffee are the United States, United Kingdom, Germany, France, and the Netherlands (ITC, 2011).

The UTZ labeling system (formerly known as UTZ Kapeh) is a more recently founded standard. It was established in 1999 by the Ahold Coffee Company, a Dutch roaster, but is now used by other European coffee companies and restaurant chains as well. The primary focus of UTZ is on traceability and sustainability production processes, based on Good Agricultural Practice (GAP) as specified by GlobalGAP. The GlobalGAP standard requires producers to comply with the labor laws concerning wages and working hours, and to handle agrochemicals responsibly, as stipulated by the International Labor Organization. The UTZ label does not guarantee a minimum price to producers, nor does it provide any premium or protection against price volatility. It is mandatory for UTZ certified farmers to be trained in GAP. The idea is that this training will contribute to higher coffee yields, better quality, and thus higher prices. The official website says: "Through the UTZprogram farmers grow better crops, generate more income and create better opportunities while safeguarding the environment and securing the earth's natural resources" (UTZ Certified, 2013). Blackmore et al. (2012) argue that the certification process is less bureaucratic for UTZ than for other sustainability oriented standards, which may be one reason for the rapid expansion of this standard. The Netherlands is the biggest consumer of UTZ certified coffee; around $30 \%$ of all coffee consumed in the Netherlands has the UTZ label (ITC, 2011).

The Organic standard follows the principles of health, ecology, fairness, and care. Certified farmers have to use production methods based on traditional and scientific knowledge that maximize farm soil fertility and enhance biodiversity. The use of inorganic inputs such as synthetic fertilizers and chemical pesticides is strictly prohibited. Organic certification requires farmers to strictly follow organic production guidelines for a minimum period of three years (referred to as the conversion period) before getting full certification, thus making it one of the most stringent among the voluntary standards (Coulibaly \& Liu, 
2006). Prices paid for Organic coffee are usually higher than for uncertified coffee. The international guidelines for Organic farming are set by the International Federation of Organic Agriculture Movements (IFOAM), an organization based in Germany with affiliated organizations in over 100 countries. In addition, some countries and companies use their own organic standards, which are similar to the IFOAM guidelines but may differ in certain details.

A fundamental difference between the three standards is that Fairtrade and Organic provide price bonuses in comparison to free market prices, while UTZ does not. Fairtrade provides a minimum guaranteed price that is above the average cost of production and independent of the prevailing international price, while the Organic price is usually above the prevailing international price, but not necessarily above the average cost of production. Hence, the social sustainability component has a higher weight in Fairtrade than in the other two standards.

\section{Methods}

\subsection{Modeling farmers' choice of certification scheme}

We model farmers' participation in a particular certification scheme in a random utility framework. Utility, $U$, is determined by a set of socioeconomic variables and contextual factors, $X$, which also influence the farmers' ability and willingness to participate in certification. The farmer is assumed to maximize utility

$$
\operatorname{MAX} U=f(X) \text {. }
$$

We postulate that coffee farmer $i$ will participate in a certified coffee market $j$ if and only if the utility $U_{i j}$ derived is greater than the utility $U_{i m}$ that results from accessing an alternative market $m$. This relationship can be represented by latent variable $I^{*}$ as

$$
I^{*}=U_{i j}>U_{i m} \quad \forall m \neq j
$$

where $I^{*}$ is representing the benefits of participating in certified coffee market $j$ as opposed to market $m$. While $I^{*}$ itself is unobserved, we can observe the type of marketing channel the farmer participates in. The probability that a farmer participates in certified market $j$ can be denoted by $\operatorname{Pr}(I=1)$; if the farmer does not participate in market $j, I^{*}$ takes a value of zero. The utility maximizing behavior of farmers can be represented as 


$$
U_{i}=\left\{\begin{array}{ll}
I^{*} & \text { if } I_{i j} \geq 0 \\
0 & \text { if } I_{\text {im }}<0
\end{array} \quad \forall m \neq j\right.
$$

If we assume a linear relationship, $I^{*}$ can be written as

$$
I_{i j}=\beta_{j} X_{i}+u_{i j}
$$

where $\beta$ is a vector of coefficients to be estimated, and $u$ is a vector of random disturbances of the unobserved factors affecting the participation decision.

\subsection{Modeling the impact of certification}

In theory, impacts of a program should be evaluated by estimating the average treatment effect on the treated (ATT) as follows

$$
E\left(W_{i} \mid I=1\right)=E\left(Y_{i 1} \mid I=1\right)-E\left(Y_{i 0} \mid I=1\right),
$$

where $W_{i}$ denotes the unbiased welfare effect for households $i$ that participate in the program, $I=1$. In our case, $I=1$ means that households participate in a particular certification scheme. $Y_{i 1}$ is the outcome variable of interest (e.g., income, poverty) with certification, while $Y_{i 0}$ is the outcome variable when the same households were not certified. Unfortunately, the same households are not observed with and without certification, so in reality one has to compare certified and uncertified households that are not identical as follows

$$
E\left(W_{i} \mid I=1\right)=E\left(Y_{i 1} \mid I=1\right)-E\left(Y_{i 0} \mid I=0\right)
$$

where $E\left(Y_{i 0} \mid I=0\right)$ is the outcome for households not participating in certification. Equations (5) and (6) lead to identical results when there is no systematic difference between participating and non-participating households, except for the certification scheme itself. Yet, whenever participating and non-participating households differ in terms of observed or unobserved characteristics, equation (6) will lead to biased impact estimates, where the bias $B$ can be represented as

$$
B=E\left(Y_{i 0} \mid I=1\right)-E\left(Y_{i 0} \mid I=0\right) .
$$

A good method to avoid estimation bias is an experiment where households are randomly assigned to treatment and control groups, thus ensuring that there are no systematic differences. In our case, such random assignment was not possible. Our study builds on observational data, where households self-selected into certification. We use a propensity 
score matching approach to reduce selection bias $B$ when evaluating the impact of different certification schemes.

\subsection{Propensity score matching with multiple treatments}

We use generalized propensity scores to control for pre-treatment differences between certified and uncertified households in estimating the ATT. Propensity score matching (PSM) is often used to evaluate impacts of a binary treatment variable (e.g., Fischer \& Qaim, 2012; Ruben \& Fort, 2012). However, in our case there are different certification schemes $j$ that farmers can participate in, so that the treatment variable can take more than two values. In particular, with three certification schemes and one control group, the treatment variable can have four possible values. We define $j=0$ for farm households that are not certified under any scheme, $j=1$ for households with Fairtrade certification, $j=2$ for households with UTZ certification, and $j=3$ for households with Organic certification. We follow theoretical foundations by Imbens (2000) and Lechner (2001) and empirical applications by Gerfin \& Lechner (2002) and Lechner (2002) for estimating propensity scores with multiple treatments. For each marketing channel, we predict the individual probability of participation using an unconditional multinomial probit model. Predicted propensity scores of participation can be written as

$$
\hat{P}_{j}(x), j \in J=\{0,1, \ldots 3\} .
$$

Following Lechner (2002), the resulting pairwise propensity scores are

$$
\hat{P}_{j \mid m j}(x)=\frac{\hat{P}_{j}(x)}{\hat{P}_{j}(x)+\hat{P}_{m}(x)} \quad \forall m \neq j ; \quad j, m \in J=\{0,1, . .3\},
$$

where $\hat{P}_{j \mid m j}(x)$ is the predicted conditional propensity score of a household participating in channel $j$ as opposed to an alternative channel $m$. We want to evaluate the impact of certification in comparison to no certification. In addition, we are interested in how each certification scheme compares to no certification, and how the different schemes compare against each other. Thus, there are seven pairwise comparisons, namely certified vs. noncertified, Fairtrade, UTZ, and Organic vs. non-certified, as well as Fairtrade vs. UTZ, Fairtrade vs. Organic, and UTZ vs. Organic.

Following Lechner (2001, 2002), estimation of ATT with multiple treatments can be extended to

$$
\mathrm{ATT}^{j} \mid m=E\left\{Y_{j}-Y_{m} \mid J=j\right\}, \quad \forall m \neq j, \quad j \in J=\{0,1, \ldots 3\}
$$


In our case $\mathrm{ATT}^{j}{ }^{\mid m}$ estimates the expected average effects of participating in marketing channel $j$ compared to the alternative channel $m$.

As in any PSM analysis, an algorithm to match treated and control households has to be chosen. We use nearest neighbor matching (NNM) and kernel matching (KM), two commonly used algorithms for empirical analysis (Caliendo \& Kopeinig, 2008). NNM involves choosing a partner from the control group for matching with each treated household or individual based on propensity scores. We match each treated household with the three nearest neighbors (with replacement) in terms of propensity score distances. To avoid the possibility of bad matches, we impose a maximum caliper restriction of 0.1 . KM uses non-parametric techniques to compare treated and control households based on kernel-weighted averages (Caliendo \& Kopeinig, 2008). For the KM, we specified a default bandwidth of 0.06 .

It should be stressed that PSM builds on the conditional independence assumption (CIA), which is also called selection on observables (Rosenbaum \& Rubin, 1983). This means that the method only controls for observed heterogeneity between treated and control households. Estimates of the ATT may still be biased when there is unobserved heterogeneity. We test for the influence of such hidden bias by calculating Rosenbaum bounds (DiPrete \& Gangl, 2004; Becker \& Caliendo, 2007).

\subsection{Estimating poverty outcomes}

We are interested in analyzing how sustainability certification affects the living standard and poverty of coffee-producing households in Uganda. We use household per capita expenditure on food and non-food consumption items as our measure of living standard. This also includes the market value of home-produced goods. In evaluating poverty outcomes, we make use of the FGT (Foster, Greer, \& Thorbecke 1984) class of poverty measures, which are calculated as

$$
F G T_{\alpha}=\frac{1}{N} \sum_{i=1}^{q}\left(\frac{z-q_{i}}{z}\right)^{\alpha} \quad \text { with } \alpha \geq 0,
$$

where $N$ is the total number of households in the sample, $z$ is the poverty line, $q_{i}$ is per capita expenditure of household $i ; q$ is the number of households below the poverty line, and $\alpha$ is the poverty aversion parameter. We calculate two measures, (i) the head count index, when $\alpha=0$, and (ii) the poverty gap index, when $\alpha=1$. For the calculations, we use the international poverty line of $\$ 1.25$ a day in terms of purchasing power parity (PPP). 
Expenditures by households in Ugandan shillings (UGX) are converted to international dollars by using the PPP exchange rate (World Bank, 2013). ${ }^{2}$

\section{Data and descriptive statistics}

\subsection{Coffee production in Uganda}

Uganda is one of the top coffee producers in Africa, accounting for approximately $2.5 \%$ of global coffee production. Coffee is also the most important export crop in Uganda. Eightyfive percent of the coffee grown in the country is Robusta, which is indigenous to Uganda, while the rest is Arabica (World Bank, 2011). It is estimated that in Uganda the coffee sector employs more than 3.5 million people directly and indirectly. The crop is mostly grown by smallholders; an estimated $90 \%$ of the coffee in Uganda is produced by farm households with less than 7 acres of total land (GAIN, 2012). In smallholder production systems, coffee is often intercropped with staples like banana, maize, and cassava; coffee is the main source of cash income, while the other crops are predominantly grown for subsistence consumption.

Prior to 1991, the Ugandan coffee market was centrally controlled by a marketing board. Coffee producers were organized in cooperatives, and through these cooperatives the marketing board paid farmers a fixed price upon delivery, and a premium based on quality at a later stage. The fixed prices were often below world market levels, and the quality premium was often paid with significant delays. The system was liberalized in 1991. The Uganda Coffee Development Authority (UCDA) was established to monitor and regulate the market, and to promote value addition and competitiveness among local farmers. But the UCDA is not directly involved in purchasing or marketing coffee; this is left to independent private traders and companies. As a result of liberalization, market efficiency and prices that farmers received for their coffee increased, while poverty rates in coffeegrowing regions decreased (Baffes, 2006).

Farmers in Uganda sell their coffee in different forms, depending on technical ability, availability of labor, financial needs, and other factors. When farmers urgently need cash already before the harvest, they sometimes decide to sell their coffee to middlemen when it is still at the flowering stage in the field. Prices received by farmers for such coffee sales are very low. Alternatively, when the coffee turns red, it can be harvested and sold as fresh

\footnotetext{
${ }^{2}$ The PPP exchange rate is 744.62 UGX per dollar. In 2012 , the official market exchange rate was around 2600 UGX per dollar.
} 
red cherries. If the cherries are dried in the sun to a moisture content of about $12 \%$, they can be sold as 'kiboko'. The sun-dried cherries can also be milled, by separating the husk from the bean, using a hulling machine. After milling, the coffee is sold as green beans. Green beans are then further graded by size, shape, and quality and exported to various international destinations for roasting (Fafchamps \& Hill, 2005).

\subsection{Household survey}

We carried out a structured survey of coffee-producing households in Uganda between July and September 2012. For the selection of households to be interviewed, we used a multi-stage sampling procedure. At first, we contacted the main coffee associations in Uganda to obtain lists of existing farmer cooperatives, including information on their location, the number of cooperative members, and certification details. Based on these lists and visits to many of the locations, we purposively selected three cooperatives. These three cooperatives had similar agro-ecological and infrastructure conditions. All three are located in the Central Region of Uganda; two of them in Luwero District, and the third in Masaka District. In all three cooperatives, farmers produce Robusta coffee. Luwero and Masaka are among the top four districts that account for over $50 \%$ of Uganda's Robusta coffee production.

All three cooperatives selected had acquired UTZ certification around the year 2007; two of them had added a second certification scheme shortly thereafter. At the time of the survey, one cooperative had only UTZ, the second had UTZ plus Fairtrade, and the third UTZ plus Organic certification. We could not identify farmers that are only certified under Fairtrade or Organic without also having UTZ certification. This may be considered a drawback for the evaluation of individual standards. However, we evaluate the impact of each standard not only in comparison to uncertified farmers but also in comparison to farmers with other standards, so the combination in two of the cooperatives is not a problem. As Fairtrade and Organic standards both have stronger requirements than the UTZ, we refer to the UTZ-Fairtrade combination as "Fairtrade" and to the UTZ-Organic combination as "Organic" below.

Farmers have to be member of a cooperative to participate in the certification schemes, but not all members of the three cooperatives actually participated in certification. Hence, participation is an individual decision. Cooperative management provided us with lists of all members, including details on the location of each farm household and their 
participation in certification schemes. In each cooperative we randomly selected two parishes, and in each parish we randomly selected three villages. In these villages, we randomly selected households for the interviews. In total, we interviewed 108 Fairtrade farmers, 101 Organic farmers, and 62 UTZ farmers. In addition, 148 control farmers were randomly selected from the lists of non-certified farmers in the same villages.

The farmers were interviewed with a structured questionnaire by a small team of local enumerators that were carefully selected, trained, and supervised by the researchers. The questionnaire covered all economic activities of households with a detailed breakdown for coffee production and marketing. We also captured the household demographic composition, food and non-food consumption, and a variety of household contextual characteristics. Food consumption data were collected through a 7-day recall. As the timing of the survey was shortly after the main harvest, consumption levels may be somewhat higher than during other times of the year. Yet, as all farmers were surveyed during a relatively short period, this should not lead to any bias in the impact assessment.

\subsection{Descriptive statistics}

Table 1 shows descriptive statistics of sample farmers with a disaggregation by certification scheme. There are a few significant differences between certified and noncertified farmers. Certified farms have larger households, older household heads, longer experience with coffee cultivation, and better access to credit and agricultural extension. They also have larger farms and shorter distances to all-weather roads and input shops. Furthermore, we observe a few significant differences between farmers in different certification schemes. On average, Fairtrade farmers are better educated, own larger houses, and have better access to credit than UTZ and Organic farmers. They are also more likely to have a leadership position in the cooperative or any other local association, which we use as a proxy for diplomatic skills and social standing. On the other hand, UTZ farmers have better infrastructure conditions, whereas Organic farmers have somewhat larger landholdings. 
Table 1: Summary statistics by certification scheme

\begin{tabular}{|c|c|c|c|c|c|}
\hline & \multicolumn{2}{|c|}{ Pooled sample } & \multicolumn{3}{|c|}{ By certification scheme } \\
\hline & $\begin{array}{c}\text { Non- } \\
\text { certified } \\
(\mathrm{N}=148)\end{array}$ & $\begin{array}{l}\text { Certified } \\
(\mathrm{N}=271)\end{array}$ & $\begin{array}{l}\text { Fairtrade } \\
(\mathrm{N}=108)\end{array}$ & $\begin{array}{c}\text { UTZ } \\
(\mathrm{N}=62)\end{array}$ & $\begin{array}{l}\text { Organic } \\
(\mathrm{N}=101)\end{array}$ \\
\hline \multicolumn{6}{|l|}{ Household characteristics } \\
\hline \multirow[t]{2}{*}{ Male household head (dummy) } & 0.791 & 0.738 & 0.806 & 0.694 & 0.693 \\
\hline & $(0.41)$ & $(0.44)_{* * * *}$ & $(0.40)_{* * *}$ & $(0.46)_{* * *}$ & $(0.46)_{* * *}$ \\
\hline \multirow[t]{2}{*}{ Age of household head (years) } & 47.378 & $55.432^{* * * *}$ & $55.824^{* * *}$ & $56.258^{* * *}$ & $54.505^{* * *}$ \\
\hline & $(15.44)$ & $(12.82)$ & $(11.96)$ & $(13.05)$ & $(13.60)$ \\
\hline \multirow[t]{2}{*}{ Education of household head (years) } & 6.534 & 6.590 & $7.787^{* *}$ & $6.710^{d}$ & $5.238^{* * i}$ \\
\hline & $(3.33)$ & $(3.78)$ & $(3.66)$ & $(3.57)$ & $(3.63)$ \\
\hline \multirow[t]{2}{*}{ Cellphone ownership (dummy) } & 0.750 & 0.775 & $0.907^{* *} \mathbf{b}$ & 0.758 & $0.644^{\mathrm{i}}$ \\
\hline & $(0.43)$ & $(0.42)$ & $(0.29)$ & $(0.43)$ & $(0.48)$ \\
\hline \multirow[t]{2}{*}{ Household size (members) } & 5.919 & $6.919^{* *}$ & $6.731^{*}$ & 6.452 & $7.406^{* * *}$ \\
\hline & $(3.07)$ & $(3.23)$ & $(2.55)$ & $(2.95)$ & $(3.94)$ \\
\hline \multirow[t]{2}{*}{ Labor capacity (worker equivalents) } & 3.370 & $4.200^{* * * *}$ & $4.246^{* * * *}$ & 3.821 & $4.384^{* * *}$ \\
\hline & $(1.78)$ & $(2.19)$ & $(1.80)$ & $(1.82)$ & $(2.70)$ \\
\hline \multirow[t]{2}{*}{ Number of rooms } & 4.128 & $4.613^{* *}$ & $5.296^{* * * * c}$ & $4.435^{\mathrm{d}}$ & $3.990^{i}$ \\
\hline & $(1.48)$ & $(1.51)$ & $(1.53)$ & $(1.25)$ & $(1.33)$ \\
\hline \multirow[t]{2}{*}{ Years resident in community } & 34.074 & $40.321^{*}$ & $44.194^{* * a}$ & 37.855 & $37.693^{h}$ \\
\hline & $(32.79)$ & $(17.33)$ & $(16.15)$ & $(17.88)$ & $(17.59)$ \\
\hline \multirow[t]{2}{*}{ Years growing coffee } & 16.662 & $26.786^{* * *}$ & $26.787^{* * *}$ & $25.597^{* * * *}$ & $27.515^{* * *}$ \\
\hline & $(12.75)$ & $(15.59)$ & $(15.33)$ & $(16.50)$ & $(15.40)$ \\
\hline \multirow[t]{2}{*}{ Leadership position (dummy) } & 0.372 & $0.513^{* *}$ & $0.685^{* * * \mathbf{b}}$ & 0.484 & $0.347^{\mathrm{i}}$ \\
\hline & $(0.48)$ & $(0.50)$ & $(0.47)$ & $(0.50)$ & $(0.48)$ \\
\hline \multirow[t]{2}{*}{ Access to extension (dummy) } & 0.486 & $0.598^{*}$ & $0.667^{\text {*** }}$ & $0.677^{* d}$ & $0.475^{\mathrm{h}}$ \\
\hline & $(0.50)$ & $(0.49)$ & $(0.47)$ & $(0.47)$ & $(0.50)$ \\
\hline \multirow[t]{2}{*}{ Access to savings account (dummy) } & 0.182 & $0.347^{* * * *}$ & $0.444^{* * *}$ & $0.323^{*}$ & $0.257^{\mathrm{h}}$ \\
\hline & $(0.39)$ & $(0.48)$ & $(0.50)$ & $(0.47)$ & $(0.44)$ \\
\hline \multirow[t]{2}{*}{ Access to credit (dummy) } & 0.291 & $0.487^{* * * *}$ & $0.657^{* * * \mathbf{b}}$ & 0.403 & $0.356^{i}$ \\
\hline & $(0.46)$ & $(0.50)$ & $(0.48)$ & $(0.49)$ & $(0.48)$ \\
\hline \multicolumn{6}{|l|}{ Farm characteristics } \\
\hline \multirow[t]{2}{*}{ Total land owned (acres) } & 4.533 & $6.220^{* * *}$ & $5.857^{* *}$ & $5.378^{\mathrm{d}}$ & $7.126^{* * *}$ \\
\hline & $(3.30)$ & $(4.70)$ & $(3.37)$ & $(3.53)$ & $(6.20)$ \\
\hline \multirow[t]{2}{*}{ Farm altitude (m) } & 1210.02 & $1168.85^{* * *}$ & $1249.65^{* * *} \mathrm{c}$ & $1140.13^{* * * \mathbf{f}}$ & $1100.07^{* * * *_{\mathrm{i}}}$ \\
\hline & $(47.70)$ & $(71.65)$ & $(24.75)$ & $(22.64)$ & $(23.52)$ \\
\hline \multirow[t]{2}{*}{ Distance to input market $(\mathrm{km})$} & 5.712 & $4.009^{* *}$ & 4.484 & 3.677 & $3.705^{*}$ \\
\hline & $(8.32)$ & $(3.87)$ & $(4.74)$ & $(3.21)$ & $(3.10)$ \\
\hline \multirow[t]{2}{*}{ Distance to output market (km) } & 4.135 & 3.523 & 3.521 & $2.863^{d}$ & $3.930^{\mathrm{g}}$ \\
\hline & $(6.19)$ & $(3.02)$ & $(3.10)$ & $(2.46)$ & $(3.19)$ \\
\hline \multirow[t]{2}{*}{ Distance to all-weather road (km) } & 18.793 & $14.998^{* *}$ & $15.450^{* \mathrm{c}}$ & $4.959^{* * * * \mathbf{f}}$ & $20.675^{i}$ \\
\hline & $(15.40)$ & $(8.31)$ & $(6.71)$ & $(3.31)$ & $(6.01)$ \\
\hline \multicolumn{6}{|l|}{ Living standard and poverty } \\
\hline Per capita expenditure (UGX/day) & 3,176 & $3,579^{*}$ & $4,010^{* * * \mathbf{b}}$ & 3,154 & $3,380^{\mathrm{g}}$ \\
\hline & $(1,582)$ & $(1,821)$ & $(1,902)$ & $(1,666)$ & $(1,743)$ \\
\hline Poverty headcount index & 0.26 & 0.21 & $0.14^{* a}$ & 0.26 & $0.25^{\mathrm{g}}$ \\
\hline & $(0.44)$ & $(0.41)$ & $(0.35)$ & $(0.44)$ & $(0.43)$ \\
\hline
\end{tabular}

Notes: Mean values are shown with standard deviations in parentheses. Mean values across schemes are tested for statistically significant differences; ${ }^{*} \mathrm{p}<0.1,{ }^{* *} \mathrm{p}<0.05,{ }^{* * *} \mathrm{p}<0.01$ when compared to non-certified farmers; ${ }^{\mathbf{a}} \mathrm{p}<0.1,{ }^{\mathbf{b}}$ $\mathrm{p}<0.05,{ }^{\mathrm{c}} \mathrm{p}<0.01$ for differences between Fairtrade and UTZ; ${ }^{\mathrm{d}} \mathrm{p}<0.1,{ }^{\mathrm{e}} \mathrm{p}<0.05,{ }^{\mathrm{f}} \mathrm{p}<0.01$ for differences between UTZ and Organic; ${ }^{\mathbf{g}} \mathrm{p}<0.1,{ }^{\mathbf{h}} \mathrm{p}<0.05,{ }^{\mathbf{i}} \mathrm{p}<0.01$ for differences between Organic and Fairtrade. ${ }^{\#}$ Worker equivalents were calculated by weighting household members; less than 9 years $=0 ; 9$ to 15 years or above 49 years $=0.7 ; 16$ to $49=1$.

Considering household consumption expenditures and poverty levels, which are shown in the lower part of Table 1, Fairtrade farmers seem to be better off than all other groups. This is also visualized in Figure 2, which depicts cumulative distribution functions (CDFs) of 
per capita expenditure for certified and non-certified farmers in our sample. A Kolmogorov-Smirnov test confirms that the Fairtrade distribution stochastically dominates the CDF of uncertified farmers $(\mathrm{p}<0.01)$ and that of UTZ farmers $(\mathrm{p}<0.05)$. The pooled $\mathrm{CDF}$ for certified farmers dominates that of non-certified farmers at $10 \%$ significance level. Figure 3 shows the poverty headcount index and the poverty gap. Fairtrade farmers are less likely to be poor, and those below the poverty line are less likely to be very poor.

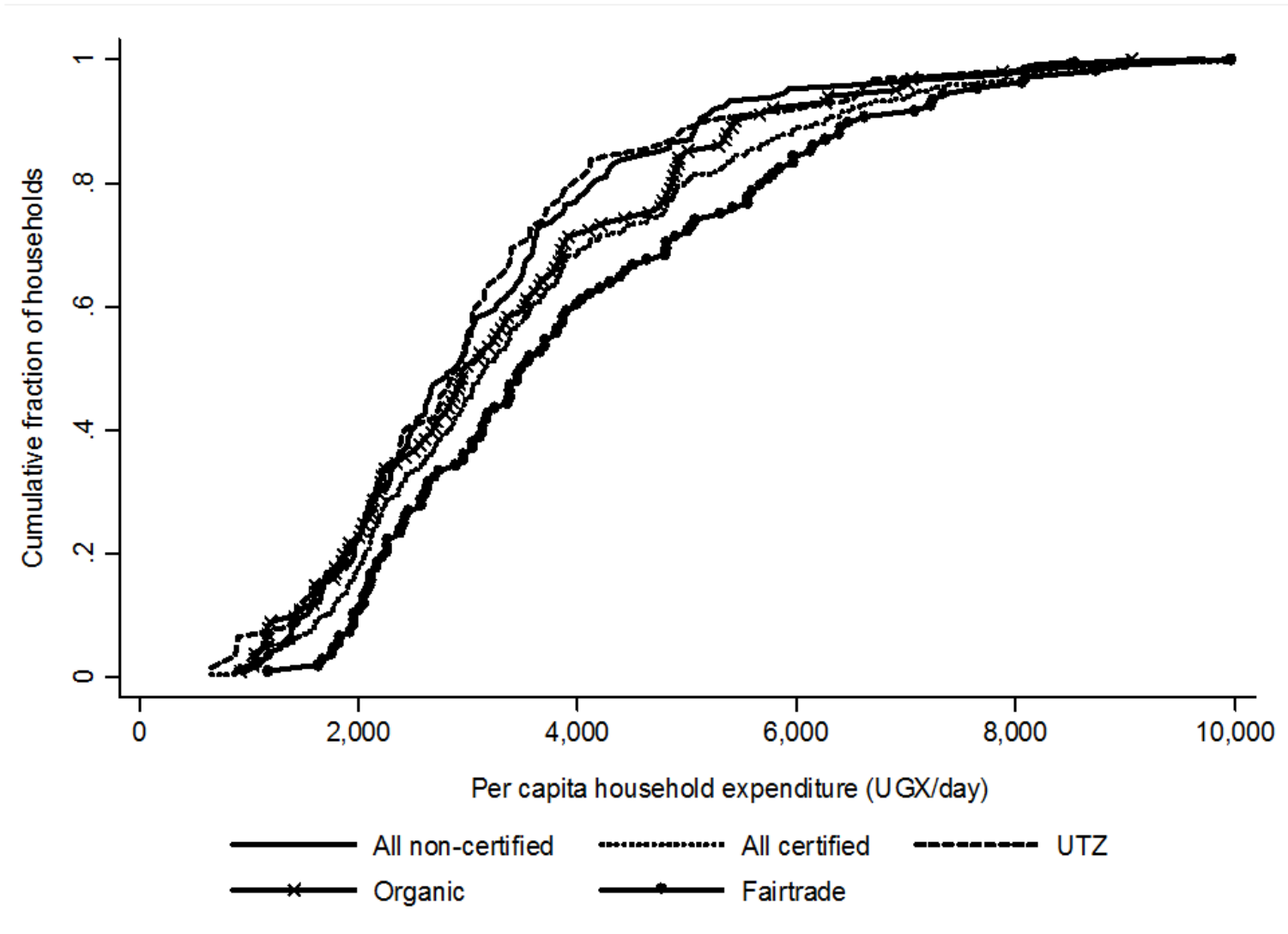

Figure 2: Cumulative distribution of per capita expenditure by certification scheme 


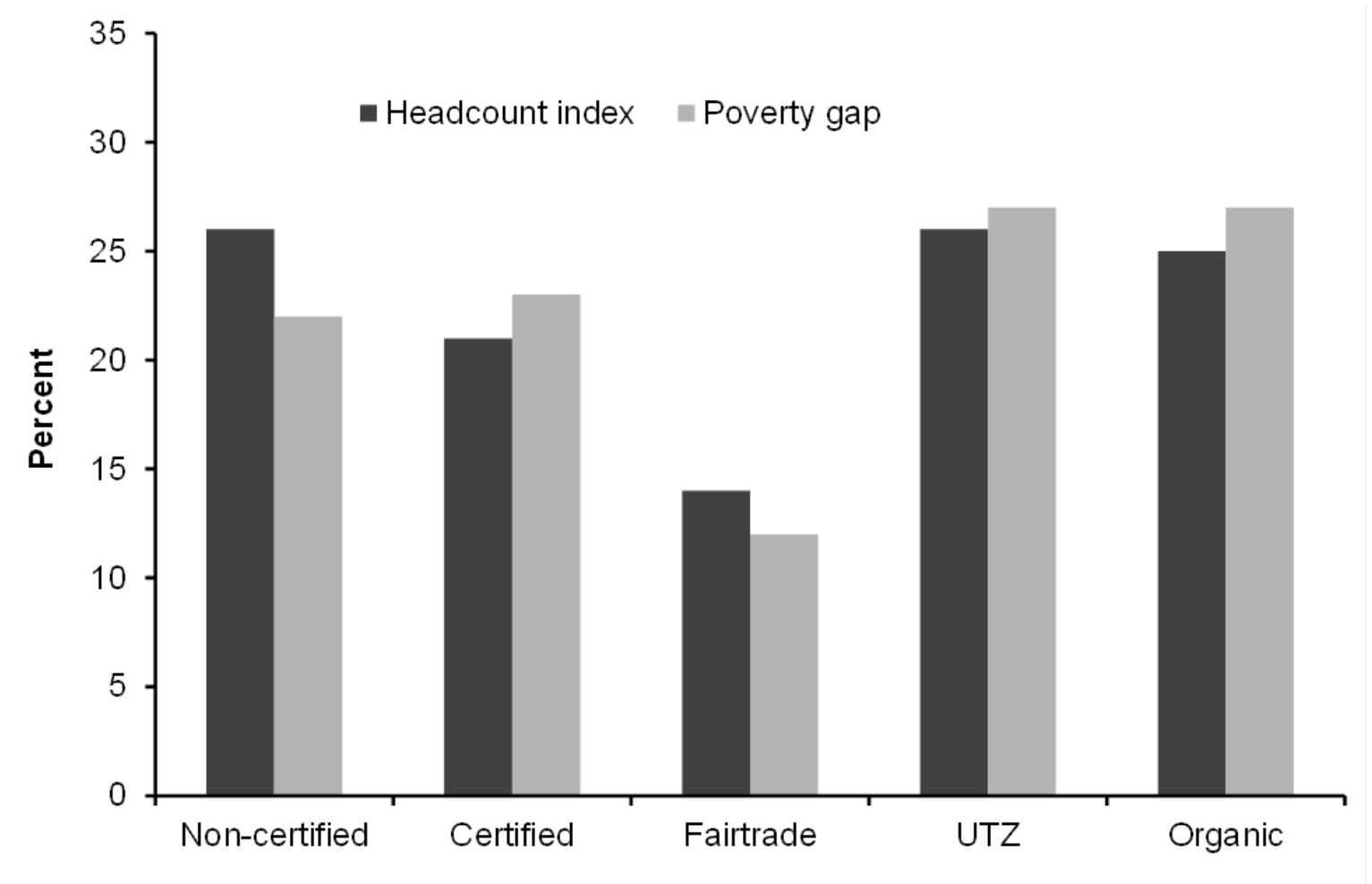

Figure 3: Poverty indicators by certification scheme

These descriptive statistics suggest that there are systematic differences between participants and non-participants in certified markets and also between participants in different certification schemes. However, without estimating treatment effects we do not know whether the observed differences in household living standards are impacts of certification or the result of other factors. This will be analyzed in the next section.

\section{$5 \quad$ Estimation results and discussion}

\subsection{Factors influencing the certification decision}

We start this analysis by analyzing the factors that influence household decisions to participate in a particular certification scheme. We estimate a multinomial probit model for the three certification schemes and take non-certified farmers as the base category. As described above, this multinomial probit is also employed to calculate propensity scores. Hence, we include a broad range of explanatory variables. Estimation results are shown in Table 2. For the calculation of propensity scores it does not matter if the explanatory variables are endogenous. However, to the extent possible we tried to use exogenous variables. For the more durable assets such as size of the house and landholding we preferred values lagged by five years, as this was the time when the certification schemes started in the study region. Thus, we avoid possible reverse causality. Interestingly, lagged 
size of the landholding does not influence participation in any of the three schemes, suggesting that certification is scale-neutral in this local context. However, the size of the house, which we use as a proxy of wealth, increases the likelihood of Fairtrade and UTZ certification.

Table 2: Multinomial probit estimates for participation in certification schemes

\begin{tabular}{|c|c|c|c|}
\hline Variables & Fairtrade & UTZ & Organic \\
\hline \multicolumn{4}{|l|}{ Household characteristics } \\
\hline \multirow[t]{2}{*}{ Male household head (dummy) } & -0.142 & 0.158 & 0.893 \\
\hline & $(0.384)$ & $(0.501)$ & $(0.634)$ \\
\hline \multirow[t]{2}{*}{ Age of household head (years) } & 0.104 & 0.127 & $0.270^{* *}$ \\
\hline & $(0.077)$ & $(0.093)$ & $(0.115)$ \\
\hline \multirow[t]{2}{*}{ Age of household head squared } & -0.001 & -0.001 & $-0.002^{* *}$ \\
\hline & $(0.001)$ & $(0.001)$ & $(0.001)$ \\
\hline \multirow{2}{*}{ Education of household head (years) } & 0.067 & 0.073 & -0.036 \\
\hline & $(0.050)$ & $(0.071)$ & $(0.083)$ \\
\hline \multirow[t]{2}{*}{ Cellphone ownership (dummy) } & 0.106 & 0.334 & 0.284 \\
\hline & $(0.467)$ & $(0.475)$ & $(0.586)$ \\
\hline \multirow[t]{2}{*}{ Labor capacity (worker equivalents) } & 0.061 & 0.172 & $0.243^{*}$ \\
\hline & $(0.087)$ & $(0.119)$ & $(0.135)$ \\
\hline \multirow[t]{2}{*}{ Number of rooms ( 5 years ago) } & $0.276^{* * * *}$ & $0.289^{* *}$ & -0.096 \\
\hline & $(0.100)$ & $(0.132)$ & $(0.211)$ \\
\hline \multirow[t]{2}{*}{ Years resident in community } & 0.006 & 0.008 & 0.004 \\
\hline & $(0.005)$ & $(0.011)$ & $(0.009)$ \\
\hline \multirow[t]{2}{*}{ Years growing coffee } & $0.038^{* * * *}$ & 0.017 & 0.029 \\
\hline & $(0.013)$ & $(0.020)$ & $(0.024)$ \\
\hline \multirow[t]{2}{*}{ Leadership position (dummy) } & $0.853^{* * * *}$ & 0.554 & -0.695 \\
\hline & $(0.326)$ & $(0.466)$ & $(0.653)$ \\
\hline \multirow[t]{2}{*}{ Access to extension (dummy) } & 0.389 & $1.477^{* * * *}$ & $1.357^{* *}$ \\
\hline & $(0.312)$ & $(0.484)$ & $(0.584)$ \\
\hline \multirow{2}{*}{ Access to savings account (dummy) } & 0.200 & 0.312 & 0.536 \\
\hline & $(0.364)$ & $(0.558)$ & $(0.666)$ \\
\hline \multirow[t]{2}{*}{ Access to credit (dummy) } & $0.985^{* * * *}$ & 0.631 & 0.854 \\
\hline & $(0.303)$ & $(0.443)$ & $(0.523)$ \\
\hline \multicolumn{4}{|l|}{ Farm characteristics } \\
\hline \multirow[t]{2}{*}{ Total land owned 5 years ago (acres) } & -0.017 & -0.089 & 0.059 \\
\hline & $(0.042)$ & $(0.069)$ & $(0.071)$ \\
\hline \multirow[t]{2}{*}{ Farm altitude $(\mathrm{m})$} & $0.018^{* * * *}$ & $-0.044^{* * *}$ & $-0.076^{* * *}$ \\
\hline & $(0.004)$ & $(0.009)$ & $(0.010)$ \\
\hline \multirow[t]{2}{*}{ Distance to input market $(\mathrm{km})$} & -0.030 & 0.038 & -0.069 \\
\hline & $(0.027)$ & $(0.071)$ & $(0.071)$ \\
\hline \multirow[t]{2}{*}{ Distance to output market $(\mathrm{km})$} & 0.039 & 0.076 & $0.092^{*}$ \\
\hline & $(0.037)$ & $(0.088)$ & $(0.053)$ \\
\hline \multirow[t]{2}{*}{ Distance to all-weather road $(\mathrm{km})$} & $-0.058^{* * *}$ & $-0.161^{* * *}$ & $0.061^{* *}$ \\
\hline & $(0.015)$ & $(0.037)$ & $(0.025)$ \\
\hline \multirow[t]{2}{*}{ Constant } & $-28.25^{* * *}$ & $42.27^{* * *}$ & $75.17^{* * *}$ \\
\hline & $(5.239)$ & $(9.834)$ & (10.94) \\
\hline Log likelihood & -178.7 & & \\
\hline Chi-square & $200.0^{* * * *}$ & & \\
\hline Observations & 419 & & \\
\hline
\end{tabular}

Notes: Coefficient estimates are shown with standard errors in parentheses. The base category consists of farmers without any certification. $* \mathrm{p}<0.1, * * \mathrm{p}<0.05, * * * \mathrm{p}<0.01$. 
Farmers with local leadership positions are more likely to be Fairtrade certified, while access to extension seems to be more important for UTZ and Organic certification. Organic production involves knowledge-intensive agronomic practices, so farmers with access to extension may find it easier to participate. Organic practices are often more laborintensive, too. Hence, households with a larger family labor capacity have an advantage. And, in organic production external inputs such as chemical fertilizers and pesticides are replaced with household resources, which may explain why farms further away from roads and markets are more likely to be certified in the Organic scheme. For them, it is more difficult to access such external inputs anyway. In contrast, better road access increases the likelihood of participation in Fairtrade and UTZ certification.

Based on this multinomial probit model, we predict propensity scores for the PSM analysis. Figures A1 and A2 in the appendix show the propensity score distributions for each of the seven pairwise comparisons. Regions of common support are identified by eliminating observations in the treatment and control groups that do not find matches due to too low or too high propensity scores ("untreated off-support" and "treated offsupport"). These eliminated observations are not included in the calculation of the treatment effects below.

\subsection{Impact of certification}

Table 3 shows the average treatment effects of certification on household expenditure and poverty levels for the different matching comparisons. On average, the ATTs are somewhat larger with nearest neighbor matching than with kernel matching, although the significance levels are almost identical. Looking at the first comparison between certified and non-certified farmers, we find that certification increases consumption expenditure by UGX 369-479 per capita and day (PPP \$ 0.50-0.64). This effect is significant and implies an increase in living standard by $12-15 \%$ when compared to mean expenditure levels of non-certified households. However, the effects on household poverty are not statistically significant. These results are similar to the findings of Jena et al. (2012) in Ethiopia; they also concluded that certification somewhat increased household expenditures among smallholder coffee producers, but without a significant effect on poverty. 
Table 3: Average treatment effects on the treated for household expenditure and poverty

\begin{tabular}{|c|c|c|c|c|c|}
\hline & \multicolumn{2}{|c|}{ Nearest neighbor matching } & \multicolumn{2}{|c|}{ Kernel matching } & \multirow[b]{2}{*}{$\Gamma$} \\
\hline & ATT & S.E. & ATT & S.E. & \\
\hline \multicolumn{6}{|l|}{ Certified vs. non-certified } \\
\hline Per capita expenditure (UGX) & $478.99^{* *}$ & 191.88 & $369.44^{* *}$ & 180.24 & 1.9 \\
\hline Poverty headcount index & -0.08 & 0.05 & -0.05 & 0.05 & 1.5 \\
\hline Poverty gap index & 0.01 & 0.04 & 0.01 & 0.04 & 1.3 \\
\hline \multicolumn{6}{|l|}{ Fairtrade vs. non-certified } \\
\hline Per capita expenditure (UGX) & $1028.58^{* * *}$ & 239.84 & $871.27^{* * *}$ & 229.69 & 1.6 \\
\hline Poverty headcount index & $-0.15^{* *}$ & 0.06 & $-0.13^{* *}$ & 0.05 & 2.0 \\
\hline Poverty gap index & $-0.09^{*}$ & 0.04 & $-0.11^{* *}$ & 0.04 & 1.5 \\
\hline \multicolumn{6}{|l|}{ UTZ vs. non-certified } \\
\hline Per capita expenditure (UGX) & -51.70 & 269.70 & 36.72 & 254.52 & 1.2 \\
\hline Poverty headcount index & -0.02 & 0.08 & -0.03 & 0.07 & 1.3 \\
\hline Poverty gap index & 0.05 & 0.07 & 0.05 & 0.07 & 1.1 \\
\hline \multicolumn{6}{|l|}{ Organic vs. non-certified } \\
\hline Per capita expenditure (UGX) & 242.42 & 286.99 & 0.55 & 252.84 & 1.3 \\
\hline Poverty headcount index & -0.04 & 0.08 & 0.02 & 0.07 & 1.4 \\
\hline Poverty gap index & 0.06 & 0.05 & 0.07 & 0.06 & 1.1 \\
\hline \multicolumn{6}{|l|}{ Fairtrade vs. UTZ } \\
\hline Per capita expenditure (UGX) & $984.83^{* * *}$ & 318.74 & $850.20^{* * *}$ & 286.93 & 1.8 \\
\hline Poverty headcount index & -0.07 & 0.07 & -0.07 & 0.07 & 1.4 \\
\hline Poverty gap index & $-0.21^{* *}$ & 0.06 & $-0.22^{* * *}$ & 0.06 & 2.3 \\
\hline \multicolumn{6}{|l|}{ Fairtrade vs. Organic } \\
\hline Per capita expenditure (UGX) & $619.75^{*}$ & 334.15 & 484.8 & 331.01 & 1.4 \\
\hline Poverty headcount index & -0.08 & 0.08 & -0.07 & 0.08 & 1.1 \\
\hline Poverty gap index & $-0.19^{* *}$ & 0.08 & $-0.24^{* *}$ & 0.1 & 2.3 \\
\hline \multicolumn{6}{|l|}{ UTZ vs. Organic } \\
\hline Per capita expenditure (UGX) & 97.53 & 405.28 & -106.55 & 343.34 & 1.2 \\
\hline Poverty headcount index & 0.15 & 0.11 & 0.13 & 0.09 & 1.1 \\
\hline Poverty gap index & -0.17 & 0.18 & 0.03 & 0.13 & 1.1 \\
\hline
\end{tabular}

Notes: ATT: average treatment effect on the treated; S.E.: bootstrapped standard errors; $\Gamma$ : Rosenbaum bounds (critical levels of hidden bias). ${ }^{*} \mathrm{p}<0.1 ;{ }^{* *} \mathrm{p}<0.05 ;{ }^{* * *} \mathrm{p}<0.01$. 
Disaggregating by certification scheme, we find that the positive impact on household expenditure is entirely driven by Fairtrade certification. Participation in Fairtrade increases per capita expenditure by $27-33 \%$, while the effects for UTZ and Organic are both insignificant. Likewise, we find significant poverty-reducing effects for Fairtrade, but not for UTZ and Organic. Participation in Fairtrade reduces the poverty headcount index by $0.13-0.15$, implying a $50 \%$ reduction of the poverty rates among non-certified households. Fairtrade also reduces the poverty gap by $9-11$ percentage points. These results confirm that differentiating impacts by certification scheme is important.

How do the three certification schemes compare with each other in terms of living standard effects? Fairtrade farmers have significantly higher household expenditures than both UTZ and Organic farmers. The differences in the poverty headcount index between certification schemes are not statistically significant. Interestingly, however, Fairtrade farmers below the poverty line have a much lower poverty gap than their colleagues in the UTZ and Organic schemes. Comparing UTZ with Organic, none of the effects is statistically significant. These patterns underline that Fairtrade is more beneficial for smallholder coffee farmers in Uganda than the other two certification schemes. The results also suggest that the combination of treatments in two of the cooperatives is unlikely to confuse the impact assessment. As discussed above, Fairtrade farmers actually have UTZ plus Fairtrade certification, whereas Organic farmers have UTZ plus Organic certification. Our estimates show that participation in UTZ alone has no significant effect on living standard. Hence, it seems justified to attribute the combined UTZ-Fairtrade effects primarily to the Fairtrade standard. This does not rule out that UTZ certification may facilitate participation in more stringent standards, such as Fairtrade or Organic.

\subsection{Robustness tests}

As discussed in section 3, PSM controls for selection bias in impact assessment that is caused by observed heterogeneity between treatment and control groups. While we have used a broad set of farm, household, and contextual variables to calculate the propensity scores, it is still possible that there are unobserved factors that could be jointly correlated with the decision to participate in certification and household living standard. Such unobserved heterogeneity could bias the estimated treatment effects. To test the robustness of our results we calculate Rosenbaum bounds for hidden bias (DiPrete \& Gangl, 2004; Becker \& Caliendo, 2007). Assume two matched individuals with the same observed covariates that differ in their odds of participating in a certification scheme solely by the 
difference in unobserved factors. The Rosenbaum bound $(\boldsymbol{\Gamma})$ measures how big the difference in unobserved factors that drive the participation decision would have to be, in order to render the estimated ATT insignificant.

The Rosenbaum bounds are shown in the last column of Table $3 .^{3}$ For the significant ATTs, the values for $\Gamma$ range between 1.5 and 2.3. The lower bound of 1.5 (for the Fairtrade poverty gap effect) implies that matched farmers with the same observed covariates would have to differ in terms of unobserved covariates by a factor of $1.5(50 \%)$, in order to invalidate the inference of a significant treatment effect. The upper bound of 2.3 implies that unobserved covariates could even differ by a factor of $2.3(130 \%)$. Based on these results we conclude that the impact estimates are quite robust to possible hidden bias.

\subsection{Possible impact pathways}

We have shown that Fairtrade certification is associated with significant benefits for smallholder coffee producers in Uganda, while UTZ and Organic certification is not. What are the reasons for these differences in impact between certification schemes? Differences in prices that farmers receive for their coffee may play a role. In section 2, we discussed that the three standards involve different pricing schemes. Fairtrade provides minimum support prices to farmers plus a Fairtrade premium to the cooperative, while Organic coffee is supposed to fetch a bonus on top of international market prices. In Table 4, we show average coffee prices received by sample farmers in different marketing channels. As coffee prices can fluctuate considerably, we asked farmers to report prices received over a period of two years. These price data are not normally distributed; we show median prices that better reflect the average than arithmetic means. Prices received by farmers for certified coffee are significantly higher than for non-certified coffee. This is in line with expectations and with studies conducted in other settings (e.g., Bacon, 2005; Wollni \& Zeller, 2007). However, further disaggregation by certification scheme reveals that this pattern is primarily driven by the high prices in the Fairtrade scheme. In fact, average prices received for UTZ and Organic coffee are not significantly different from prices received for non-certified coffee. This also confirms farmers' subjective perceptions. Especially Organic farmers in our sample pointed out that there is usually no difference in prices between certified Organic and uncertified channels. An advantage of selling to

\footnotetext{
${ }^{3}$ The Rosenbaum bounds shown in Table 3 refer to the nearest neighbor matching algorithm. We did the same calculations also for the kernel matching algorithm with almost identical results.
} 
traders in uncertified channels is that farmers get cash on the spot, while sales in the Organic channels are through the cooperative and associated with payment delays.

Table 4: Median prices received for coffee under different certification schemes

\begin{tabular}{lcc}
\hline Certification scheme & Median coffee price $(\mathrm{UGX} / \mathrm{kg})$ & Interquartile range \\
\hline All non-certified & 1550 & 1150 \\
All certified & $2000^{\mathrm{a}}$ & 1350 \\
Fairtrade & $3233^{\mathrm{a}, \mathrm{c}, \mathrm{d}}$ & 1783 \\
UTZ & $1750^{\mathrm{b}}$ & 762 \\
Organic & $1500^{\mathrm{b}}$ & 900 \\
\hline
\end{tabular}

Notes: Median coffee prices received by farmers were calculated over the last two seasons. The interquartile range is analogous to the standard deviation for the median. Median prices between schemes are tested for statistically significant differences using the Kruskal-Wallis test; ${ }^{\mathbf{a}} \mathrm{p}<0.01$ when compared to non-certified; ${ }^{\mathbf{b}} \mathrm{p}<0.01$ when compared to Fairtrade; ${ }^{\mathbf{c}} \mathrm{p}<0.01$ when compared to UTZ; ${ }^{\mathbf{d}} \mathrm{p}<0.01$ when compared to Organic.

Table 4 shows that the average price received for Fairtrade coffee is more than double the price of uncertified coffee. This is not only due to price bonuses for certified coffee, but also to differences in processing and sales channels. Many non-certified farmers sell their coffee as fresh red cherries or as 'kiboko'. UTZ and Organic producers also sell primarily in the 'kiboko' stage. In contrast, farmers in the Fairtrade cooperative mostly sell their coffee after milling in the green bean stage. Hence, Fairtrade farmers benefit from value addition at the cooperative level. Such value addition, including capacity building and technological upgrading, is especially promoted through the Fairtrade premium. Obviously, other cooperatives could also engage in further processing, but this is not specifically supported in any of the other schemes. Furthermore, there is an important institutional difference in the local context. The Fairtrade cooperative is entirely managed by its farmer members, and it owns the certification documents itself. The cooperative independently sells the coffee directly to exporters in Kampala, where it can negotiate prices. In contrast, the certification process for the UTZ and Organic cooperatives was partly funded by local export companies. Thus, the certification documents are owned by these companies, who buy the coffee from certified farmers and determine prices and processing stages.

\section{Conclusions}

Global food systems are undergoing a rapid transformation, with high-value market segments, private standards, and certification schemes gaining in importance. Smallholder farmers in developing countries may potentially benefit from these trends when they can 
be linked successfully to the emerging international value chains. Especially for luxury foods from tropical regions - such as coffee, tea, and cocoa - manufacturers and retailers use an increasing number of sustainability oriented standards and labels that also promise to improve the livelihoods of farmers. Several recent studies have analyzed the impacts of sustainability oriented standards on farmers in developing countries, but no previous research has compared the effects of different standards in the same setting with rigorous quantitative evaluation techniques. This can be important to better understand how differences in standard design and certification practices can affect outcomes at the local level. In this article, we have addressed this research gap and have analyzed and compared the impact of three standards, namely Fairtrade, UTZ, and Organic, on the livelihoods of coffee farmers in Uganda. For the analysis, we have used data from a household survey in Central Uganda and a propensity score matching approach with multiple treatments.

Estimation results show that farm households in all three certification schemes combined have significantly higher living standards than their matched counterparts in non-certified channels. Poverty effects are not statistically significant for the combined sample of certified households. However, disaggregation by certification scheme has revealed important differences. Fairtrade certification causes a $30 \%$ increase in per capita consumption expenditures, primarily through higher prices received in the Fairtrade channel. Fairtrade certification cuts the likelihood of being poor by $50 \%$ and also significantly reduces the poverty gap. Participation in UTZ and Organic certification schemes is not associated with significant impacts on living standards and poverty. In fact, average prices received by UTZ and Organic farmers are not different from those received by non-certified farmers. These results confirm that differentiating by certification scheme is important. Overly broad statements about the impact of certification in general may be misleading.

The differences in impact can be explained by various factors. First, Fairtrade guarantees farmers a minimum support price and pays an additional Fairtrade premium to the cooperative for capacity building and related community projects. Such social premiums are not paid in UTZ and Organic certification schemes. Second, farmers in the Fairtrade cooperative have more freedom how to market their coffee. The cooperative owns the certification documents itself and can sell to any buyer; thus it is in a better position to negotiate prices. In contrast, the UTZ and Organic certification documents are owned by specific exporters, to which participating farmers have to sell their coffee. Third, and 
related to the previous point, the Fairtrade cooperative sells most of the coffee from its members in milled form as green beans; member farmers benefit from this value addition at the cooperative level. UTZ and Organic farmers, on the other hand, sell most of their coffee in unprocessed form, as specified by the exporters that own the certification documents. Some of these factors are specific to the particular cooperatives analyzed here. Therefore, one should not extrapolate these findings to other settings without further analysis. We should also stress that our study is not an attempt to holistically assess all possible impacts of certification. We focused on socioeconomic implications for smallholder producers in terms of living standard and poverty. Especially the Organic standard places higher priority on aspects of environmental sustainability, which we did not analyze here.

Nevertheless, there are some broader lessons that can be learned from our results. First, when provided with institutional support, smallholder farmers and cooperatives can participate in certified markets and comply with stringent food quality and food safety standards. The cooperatives investigated in this study, in one of the poorest countries in the world, were certified around the year 2007 and have since managed to fully comply with the different international standards. This is encouraging and disproves pessimistic views that smallholder farmer will not be able to participate in high-value markets on a sustained basis. Second, the impact of standards and certification on farmer livelihoods may differ significantly by certification scheme. Hence, it is worthwhile to take a closer look. Better understanding impact differences and factors that contribute to these differences may be relevant for all actors along the supply chain, including for consumers who may wish to make more informed purchase decisions. Such understanding may also help improve the design of standards and certification systems from a social perspective. Third, the impacts of standards and certification systems depend to a large extent on institutional factors at the local level, including cooperative performance and management capacity. Certification may be a prerequisite for entering international high-value chains, but this alone is not a sufficient condition for improved livelihoods and poverty reduction. 


\section{References}

Arnould, E. J., Plastina, A., \& Ball, D. (2009). Does Fair Trade deliver on its core value proposition? Effects on income, educational attainment, and health in three countries. Journal of Public Policy \& Marketing, 28(2), 186-201.

Asfaw, S., Mithöfer, D., \& Waibel, H. (2009). EU food safety standards, pesticide use and farm-level productivity: the case of high-value crops in Kenya. Journal of Agricultural Economics, 60(3), 645-667.

Asfaw, S., Mithöfer, D., \& Waibel, H. (2010). Agrifood supply chain, private-sector standards, and farmers' health: evidence from Kenya. Agricultural Economics, 41, 251-263.

Bacon, C. M. (2005). Confronting the coffee crisis: can fair trade, organic, and specialty coffees reduce small-scale farmer vulnerability in northern Nicaragua? World Development, 33(3), 497-511.

Baffes, J. (2006). Restructuring Uganda's coffee industry: why going back to basics matters. Development Policy Review, 24(4), 413-436.

Barham, B., Callenes, M., Gitter, S., Lewis, J., \& Weber, J. (2011). Fair trade/organic coffee, rural livelihoods, and the "agrarian question": southern Mexican coffee families in transition. World Development, 39(1), 134-145.

Basu, A., \& Hicks, R. (2008). Label performance and the willingness to pay for Fair Trade coffee: a cross-national perspective. International Journal of Consumer Studies, $5(32), 823-42$.

Becker, S., \& Caliendo, M. (2007). Mhbounds-sensitivity analysis for average treatment effects. The Stata Journal, 7(1), 71-83.

Beuchelt, T.D., \& Zeller, M. (2011). Profits and poverty: certification's troubled link for Nicaragua's organic and Fairtrade coffee producers. Ecological Economics, 70(7), 1316-1324.

Blackmore, E., Keeley, J., with Pyburn, R., M., E., Chen, L., \& Yuhui. (2012). Pro-poor certification: assessing the benefits of sustainability certification for small-scale farmers in Asia. Natural Resource Issues 25, London: International Institute of Environment and Development.

Bolwig, S., Gibbon, P., \& Jones, S. (2009). The economics of smallholder organic contract farming in tropical Africa. World Development, 37(6), 1094-1104.

Caliendo, M., \& Kopeinig, S. (2008). Some practical guidance for the implementation of propensity score matching. Journal of Economic Surveys, 22(1), 31-72. 
Carletto, C., Kirk, A., Winters, P. C., \& Davis, B. (2010). Globalization and smallholders: the adoption, diffusion, and welfare impact of non-traditional export crops in Guatemala. World Development, 38(6), 814-827.

Colen, L., Maertens, M., \& Swinnen, J. (2012). Private standards, trade and poverty: GlobalGAP and horticultural employment in Senegal. The World Economy, 35(8), 1073-1088.

Coulibaly, A. L., \& Liu, P. (2006). Regulations, Standards and Certification for Agricultural Exports. A Practical Manual for Producers and Exporters in East Africa. Rome: Food and Agricultural Organization of the United Nations.

DiPrete, T., \& Gangl, M. (2004). Assessing bias in the estimation of causal effects: Rosenbaum bounds on matching estimators and instrumental variables estimation with imperfect instruments. Sociological Methodology, 34, 271-310.

Elfenbein, D. W., \& McManus, B. (2010). A greater price for a greater good? Evidence that consumers pay more for charity-linked products. American Economic Journal: Economic Policy, 2(2), 28-60.

Fafchamps, M., \& Hill, R. (2005). Selling at the farmgate or traveling to market. American Journal of Agricultural Economics, 87(3), 717-734.

Fairtrade (2011). Fairtrade Standard for Small Producer Organizations. Retrieved on 6 December 2013 from http://www.fairtrade.net.

Fischer, E., \& Qaim, M. (2012). Linking smallholders to markets: determinants and impacts of farmer collective action in Kenya. World Development, 40(6), 1255-1268.

Foster, J., Greer, J., \& Thorbecke, E. (1984). A class of decomposable poverty measures. Econometrica, 52(3), 761-766.

GAIN. (2012). Uganda Coffee Annual Report 2012. Kampala: Global Agricultural Information Network, USDA Foreign Agricultural Services.

Gerfin, M., \& Lechner, M. (2002). A microeconometric evaluation of the active labour market policy in Switzerland. Economic Journal, 482(112), 854-893.

Henson, S., Masakure, O., \& Boselie, D. (2005). Private food safety and quality standards for fresh produce exporters: the case of Hortico Agrisystems, Zimbabwe. Food Policy, 30(4), 371-384.

Hernandez, R., Reardon, T., \& Berdegue, J. (2007). Supermarkets, wholesalers, and tomato growers in Guatemala. Agricultural Economics, 36(3), 281-290.

Imbens, G. (2000). The role of the propensity score in estimating dose-response functions. Biometrika, 87(3), 706-710.

ITC (2011). Trends in the Trade of Certified Coffees. Technical Paper, Geneva: International Trade Center, World Trade Organization and United Nations. 
Jaffee, D. (2008). "Better, but not great": the social and environmental benefits and limitations of Fair Trade for indigenous coffee producers in Oaxaca, Mexico. In R. Rueben (ed.). The Impact of Fair Trade. Wageningen: Wageningen Academic Publishers, pp. 195-222.

Jena, P. R., Chichaibelu, B. B., Stellmacher, T., \& Grote, U. (2012). The impact of coffee certification on small-scale producers' livelihoods: a case study from the Jimma Zone, Ethiopia. Agricultural Economics, 43(4), 429-440.

Lechner, M. (2001). Identification and estimation of causal effects of multiple treatments under the conditional independence assumption. In M. Lechner \& F. Pfeiffer (eds.). Econometric Evaluation of Labour Market Policies. ZEW Economic Studies 13, Heidelberg: Physica Verlag, pp. 43-58.

Lechner, M. (2002). Program heterogeneity and propensity score matching: an application to the evaluation of active labor market policies. Review of Economics and Statistics, 84(May), 205-220.

Liu, P., Byers, A., \& Giovannucci, D. (2008). Value-Adding Standards in the North American Food Market - Trade Opportunities in Certified Products for Developing Countries. Rome: Food and Agriculture organization of the United Nations.

Maertens, M., \& Swinnen, J. F. M. (2009). Trade, standards, and poverty: Evidence from Senegal. World Development, 37(1), 161-178.

Mergenthaler, M., Weinberger, K., \& Qaim, M. (2009). The food system transformation in developing countries: a disaggregate demand analysis for fruits and vegetables in Vietnam. Food Policy, 34(5), 426-436.

Narrod, C., Roy, D., Okello, J., Avendaño, B., Rich, K., \& Thorat, A. (2009). Publicprivate partnerships and collective action in high value fruit and vegetable supply chains. Food Policy, 34(1), 8-15.

Neven, D., Odera, M. M., Reardon, T., \& Wang, H. L. (2009). Kenyan supermarkets, emerging middle-class horticultural farmers, and employment impacts on the rural poor. World Development, 37(11), 1802-1811.

Rao, E. J. O., Brümmer, B., \& Qaim, M. (2012). Farmer participation in supermarket channels, production technology, and efficiency: the case of vegetables in Kenya. American Journal of Agricultural Economics, 94(4), 891-912.

Rao, E. J. O., \& Qaim, M. (2011). Supermarkets, farm household income, and poverty: insights from Kenya. World Development, 39(5), 784-796.

Raynolds, Laura T., Murray, D., \& Leigh Taylor, P. (2004). Fair trade coffee: building producer capacity via global networks. Journal of International Development, 16(8), 1109-1121. 
Reardon, T., Barrett, C. B., Berdegué, J. A., \& Swinnen, J. F. M. (2009). Agrifood industry transformation and small farmers in developing countries. World Development, 37(11), 1717-1727.

Rosenbaum, P. R., \& Rubin, D. B. (1983). The central role of the propensity score in observational studies for causal effects. Biometrika, 70(1), 41.

Ruben, R., \& Fort, R. (2012). The impact of Fair Trade certification for coffee farmers in Peru. World Development, 40(3), 570-582.

Utting-Chamorro, K. (2005). Does fair trade make a difference? The case of small coffee producers in Nicaragua. Development in Practice, 15(3), 584-599.

UTZ Certified (2013). https://www.utzcertified.org (retrieved on 6 December 2013).

Valkila, Joni, \& Nygren, A. (2009). Impacts of Fair Trade certification on coffee farmers, cooperatives, and laborers in Nicaragua. Agriculture and Human Values, 27(3), 321333.

Wollni, M., \& Zeller, M. (2007). Do farmers benefit from participating in specialty markets and cooperatives? The case of coffee marketing in Costa Rica1. Agricultural Economics, 37(2-3), 243-248.

World Bank. (2011). Ugandan Coffee Supply Chain Risk Assessment. Washington, DC: World Bank.

World Bank. (2013). World Development Indicators. Washington, DC: World Bank. 


\section{Appendix}
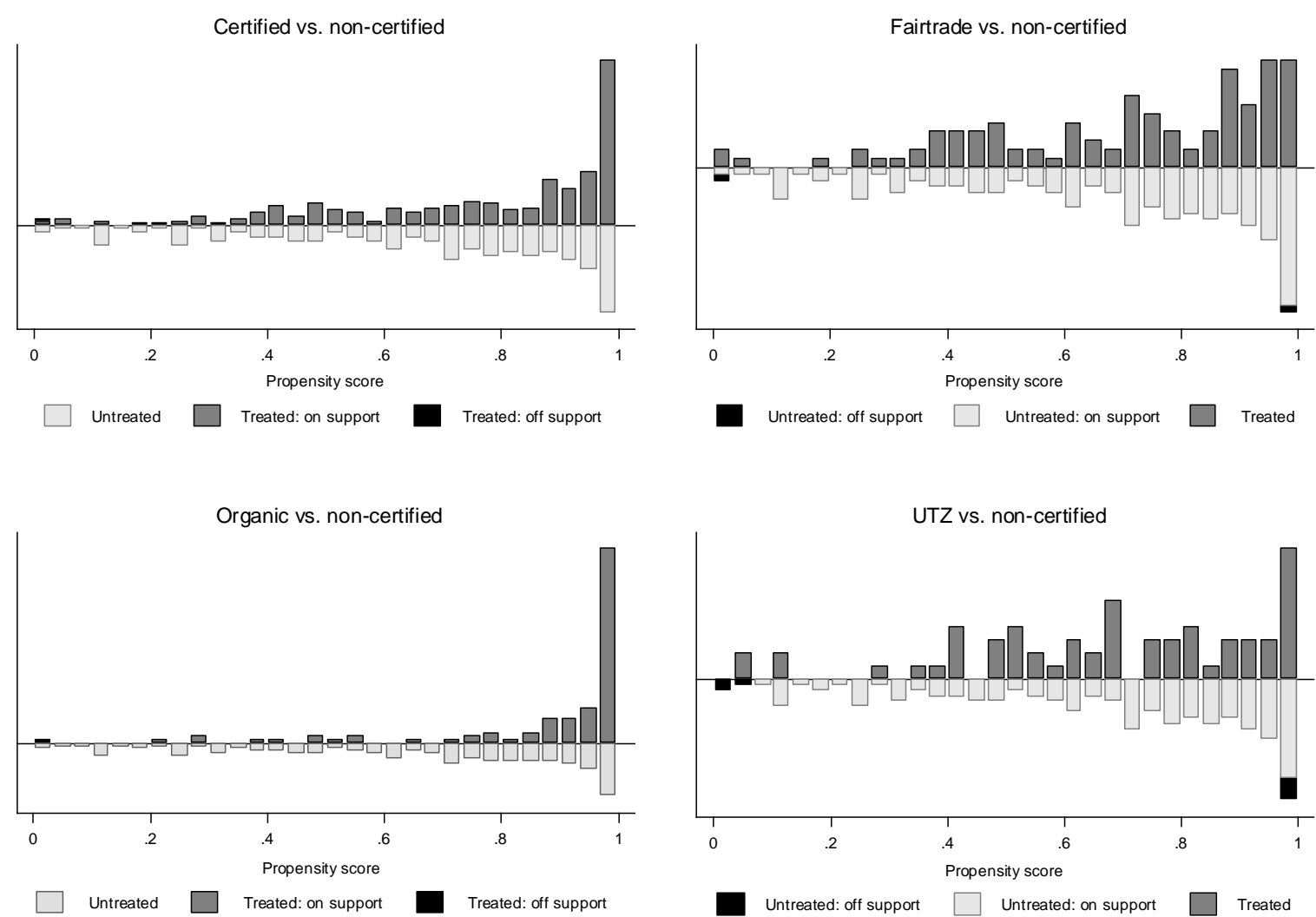

Figure A1: Propensity score distribution and common support for certified and noncertified farmers 

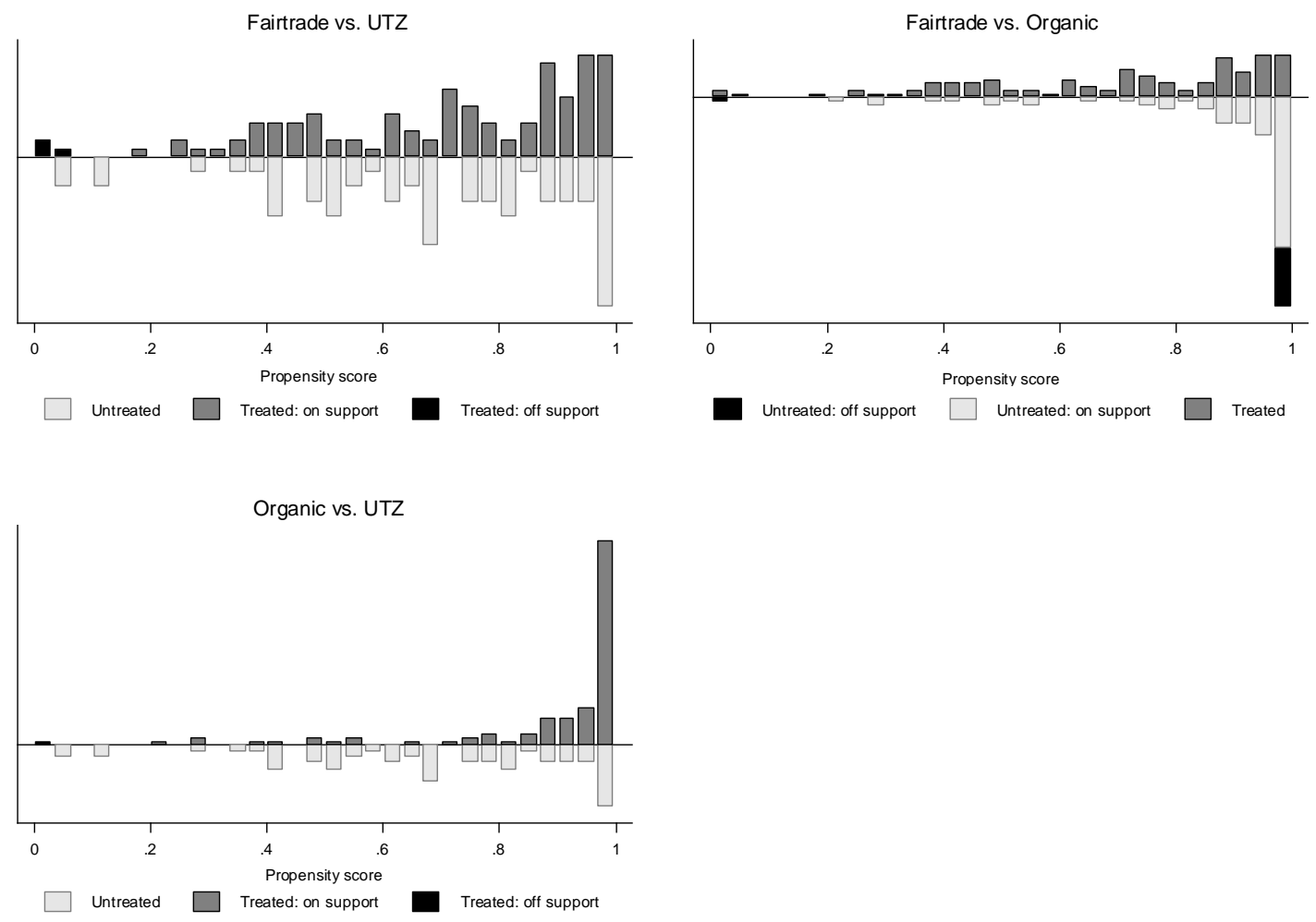

Figure A2: Propensity score distribution and common support for farmers in different certification schemes. 


\title{
III. Sustainability Standards, Gender, and Nutrition among Coffee Farmers in Uganda ${ }^{1}$
}

\begin{abstract}
Sustainability standards are gaining in importance in global markets for high-value foods. While previous research has shown that participating farmers in developing countries may benefit through income gains, nutrition impacts have hardly been analysed. We use survey data from smallholder coffee farmers in Uganda - certified under Fairtrade, Organic, and UTZ - to analyse impacts on food security and dietary quality. Estimates of instrumental variable models and simultaneous equation systems show that certification increases calorie and micronutrient consumption, mainly through higher incomes and improved gender equity. In certified households, women have greater control of coffee production and monetary revenues from sales.
\end{abstract}

\section{Key words}

Private standards, smallholder farmers, nutrition impact, gender, Uganda.

\section{JEL classification}

I32, L15, O12, Q13, Q17.

\footnotetext{
${ }^{1}$ This chapter is an updated version of the original manuscript and is published in the GlobalFood Discussion Paper Series No. 52 (2014). The co-author of this article is Matin Qaim.
} 


\section{Introduction}

Global food systems are undergoing a rapid transformation, with high-value market segments, private standards, and certification schemes gaining in importance (Berdegué et al., 2005; Reardon \& Timmer, 2012). This transformation is partly driven by changing consumer preferences resulting from rising incomes, urbanization, and growing concerns for food safety and environmental and social consequences of agricultural production (Mergenthaler, Weinberger, \& Qaim, 2009; Narrod et al., 2009). To address these concerns, various sustainability standards were introduced. In rich and emerging countries, market shares of products with sustainability labels are growing. Especially for high-value foods imported from developing countries - such as coffee, tea, cocoa, or tropical fruits voluntary sustainability standards like Fairtrade, Organic, UTZ, or Rainforest Alliance are increasingly used for product differentiation (Henson \& Humphrey, 2010; Holzapfel \& Wollni, 2014). Many of these standards involve smallholder farmers. Hence, this trend towards "sustainable consumption" in rich countries may contribute to poverty reduction and rural development in poor countries.

There is a growing body of literature looking at the impact of sustainability standards on smallholder farmers in developing countries. Many of these studies have analysed the effects of participating in Fairtrade and Organic certification schemes for producers of coffee (Arnould, Plastina, \& Ball, 2009; Bolwig, Gibbon, \& Jones, 2009; Blackman \& Naranjo, 2012; Jena et al., 2012; Ruben \& Fort, 2012; Chiputwa, Spielman, \& Qaim, 2015), cocoa (Jones \& Gibbon, 2011), and tropical fruits (Ruben, 2008; Kleemann, Abdulai, \& Buss, 2014). Most of these studies have analysed impacts in terms of output price levels and farm profits, some have also looked at household income and poverty. While the concrete results differ, and the specific institutional context plays an important role, a general conclusion is that smallholder farmers can indeed raise their income levels through participation in sustainability certification.

One question that has received much less attention in the existing literature is whether sustainability standards can also help to improve food security and nutrition among smallholder farmers. Undernutrition is still a widespread problem in many developing countries, and a large proportion of the undernourished people are smallholder farmers. Against this background, it is critical to better understand the linkages between agriculture and nutrition and to include nutrition dimensions into impact evaluation of agricultural 
programs (Hoddinott, 2012; Haddad, 2013; IFPRI, 2014). So far, little is known about the nutrition impacts of the food system transformation in developing-country farm households (Gomez \& Ricketts, 2013). Income gains resulting from participation in high-value markets may contribute to improved nutrition. However, there is also evidence that agricultural commercialization can change gender roles within the farm household, often resulting in a lower share of the income being controlled by women (von Braun and Kennedy, 1994; Njuki et al., 2011). Since women tend to spend more on food and healthcare than men (Hoddinott \& Haddad, 1995; Quisumbing \& Maluccio, 2003), this shift in income control towards male household members might possibly lead to negative effects for dietary quality and nutrition.

We are aware of only one study that has looked into the effects of sustainability standards on food cosumption in farm households with a quantitative approach: using data from a small sample of farmers in Kenya, Becchetti \& Costantino (2008) showed that Fairtrade certification is positively associated with food expenditures and dietary quality. Becchetti \& Costantino (2008) used a relatively simple dietary quality index, and they did not analyze the causal chain behind the observed differences in diets between certified and non-certified households. Other studies looked at gender effects of standards, yet without linking these to dietary or nutrition outcomes (Utting-Chamorro, 2005; Lyon, Bezaury, \& Mutersbaugh, 2010; Maertens \& Swinnen, 2012). Some of the sustainability standards consider the promotion of gender equity as an important element (Lyon et al., 2010), which may have implications for income control and nutrition.

We contribute to this literature by analysing the nutrition impacts and impact pathways of sustainability standards among smallholder farmers in Uganda, where undernutrition is a sizeable problem. In particular, we use data from a comprehensive survey of smallholder coffee growers. In addition to uncertified farmers as a control group, the sample contains farmers who are certified under three different sustainability standards, namely Fairtrade, Organic, and UTZ. We use detailed food recall data to analyse impacts on household calorie and micronutrient consumption. Instrumental variable models are employed to control for possible selection bias. We also develop and estimate simultaneous equation systems to better understand causal chains, with a particular emphasis on income and gender effects. 


\section{Methodology}

\subsection{Measuring nutrition}

To analyse nutrition impacts of sustainability standards, we first need to identify appropriate indicators of nutrition. The most precise indicators of nutritional status are clinical measures (e.g., blood samples) and anthropometric data (Masset et al., 2012, IFPRI, 2014). However, clinical and anthropometric measures are less suitable to assess patterns of food security and dietary quality, which is what we concentrate on here. To analyse dietary patterns, data from household food consumption recalls are frequently used, which can be converted to calorie and nutrient values using food composition tables (Ecker \& Qaim, 2011; Fiedler et al., 2012). We follow this approach and use calorie consumption levels to assess food security. Furthermore, we use the consumption of important micronutrients to assess dietary quality. Micronutrient consumption is also a good proxy for dietary diversity, because fruits, vegetables, and animal products contain larger quantities of micronutrients than typical staple foods. We focus on iron, zinc, and vitamin A, because deficiencies in these micronutrients cause large public health problems in developing countries (Stein et al., 2008; IFPRI, 2014).

Details of the household survey are provided further below. Here, we only describe how the food consumption data were collected and used to derive the nutrition indicators. We conducted a food recall, asking survey respondents to report quantities of all foods consumed by the household during the last 7 days from own production, purchases, or any other source. To increase the accuracy of the responses, the food recall was carried out with the person in the households responsible for food preparation. The survey questionnaire included a breakdown of over 100 different food items. The reported food quantities consumed were converted to edible portions. These edible portions were then converted to quantities of calories and micronutrients, using recent food composition tables for Uganda (Hotz et al., 2012).

To enable comparison across households of different size and composition, consumption levels at the household level were divided by the number of adult equivalents (AE) living in each household. We define a food-secure household as one whose calorie consumption per $\mathrm{AE}$ is greater than or equal the minimum daily requirement of $2400 \mathrm{kcal}$ for adult men. The recommended dietary threshold levels used for the three micronutrients are 18.27 
$\mathrm{mg} /$ day/AE for iron, $15 \mathrm{mg} /$ day/AE for zinc, and $625 \mu \mathrm{g} \mathrm{RE} /$ day/AE for vitamin A (FAO, WHO, \& UNU, 2001).

While using household food consumption data has advantages to assess food security and dietary quality, the approach also has a few limitations (Bouis, 1994; de Haen, Klasen, \& Qaim, 2011; Fiedler et al., 2012). First, by using a single 7-day recall we cannot account for seasonal variation in food consumption. The timing of our survey was shortly after the main harvest season, so that consumption levels may be somewhat higher than during other times of the year. Second, we are not able to account for intra-household food distribution. Third, the 7-day recall data measure consumption levels, which are only a proxy for actual food and nutrient intakes. Food wasted in the household or portions given to guests or fed to pets cannot always be fully accounted for, which may result in overestimated consumption levels. However, while these issues reduce the accuracy of the dietary assessments, they are unlikely to bias the impact estimates systematically, because they apply equally to certified and non-certified households.

\subsection{Modelling nutrition impacts}

We want to evaluate the impact of farmer participation in sustainability-oriented certification schemes on household nutrition. For this purpose, we start with a reducedform model as follows:

$$
N_{i}=\alpha_{0}+\alpha_{1} C_{i}+\alpha_{2} X_{i}+\varepsilon_{1},
$$

where, $N_{i}$ is the nutrition indicator. In different regressions, we use household consumption of calories and micronutrients per AE as indicators of food security and dietary quality, as explained above. $C_{i}$ is the certification treatment variable, which we define in two different ways: (i) We use a treatment dummy that takes a value of one for certified farm households and zero otherwise. (ii) We use a continuous treatment variable measuring the number of years that a farm households has been certified already (duration); for non-certified households this variable takes a value of zero. $X_{i}$ is a vector of farm, household, and contextual variables that may influence nutrition, such as asset ownership, characteristics of the household and the household head, and infrastructure conditions. $\varepsilon_{1}$ is a random error term. 
To evaluate whether certification has an impact on household nutrition, we are particularly interested in the coefficient $\alpha_{1}$. A positive and significant coefficient would imply that certification contributes to improved nutrition and vice versa. However, one problem in estimating equation (1) is that $C_{i}$ is likely endogenous. We use a sample where farm household decided themselves whether or not to participate in a certification scheme. It is possible that this decision is systematically correlated with unobserved factors that also influence nutrition, in which case the estimated treatment effect would suffer from nonrandom selection bias. We deal with this problem by using an instrumental variable (IV) approach. The challenge is to identify a valid instrument that is correlated with the treatment variable but uncorrelated with the nutrition outcomes.

Following Wollni \& Zeller (2007), who analysed welfare effects of farmer participation in specialty markets for coffee in Costa Rica, we use altitude of the farm as an instrument for $C_{i}$. Altitude has an influence on coffee quality (Decazy et al., 2003; Avelino et al., 2005). Since coffee quality matters for exporters in certified markets, certification is correlated with farm altitude. On the other hand, altitude has no direct influence on household nutrition. One might expect that coffee quality may influence sales prices and incomes also in non-certified markets. However, altitude differences in our sample are relatively small; most farms are located within a range of 1100-1300 m above sea level. Coffee sales prices and household incomes of non-certified farms are not correlated with altitude, so that the conditions for a valid instrument are fulfilled.

\subsection{Modelling impact pathways}

This The reduced-form model in equation (1) is useful to analyse whether sustainability certification has an impact on household nutrition, but it cannot explain impact pathways. We hypothesise that participation in certification affects nutrition primarily through two pathways, namely through effects on income and gender roles within the household. Concerning the income pathway, several studies have shown that sustainability standards like Fairtrade and Organic can contribute to significant income gains through price premiums, reduced risk, and, in some cases, positive productivity effects (Arnould et al., 2009; Bolwig et al., 2009; Jena et al., 2012; Ruben \& Fort, 2012). Holding other things constant, income gains are likely to improve food security and dietary quality.

Concerning the gender pathway, certification may also affect the roles of men and women within the household and thus food availability and nutrition. Previous research showed 
that agricultural commercialization is often associated with women in farm households losing control of production and income (von Braun \& Kennedy, 1994; Njuki et al., 2011; Fischer \& Qaim, 2012). However, sustainability standards explicitly try to strengthen women's role, so that loss of income control may possibly be prevented. For example, the promotion of gender equity and ensuring that women's work is properly valued and equally rewarded is one of the ten key principles of the Fairtrade standard (Fairtrade, 2009). Similarly, the UTZ code of conduct promotes policies of non-discrimination and gender equity by providing gender training and awareness programs to its members and extension workers (UTZ, 2009). A few studies show that sustainability standards improve women's incomes, autonomy, and access to information and cooperative networks (Riisgaard et al., 2009; Lyon et al., 2010; Bassett, 2010).

To formally analyse the two impact pathways, we develop a system of simultaneous equations as follows:

$$
\begin{gathered}
N_{i}=\beta_{0}+\beta_{1} I_{i}+\beta_{2} G_{i}+\beta_{3} X_{i}+\varepsilon_{2} \\
I_{i}=\theta_{0}+\theta_{1} C_{i}+\theta_{2} Y_{i}+\varepsilon_{3} \\
G_{i}=\omega_{0}+\omega_{1} C_{i}+\omega_{2} Z_{i}+\varepsilon_{4} \\
C_{i}=\gamma_{0}+\gamma_{1} A_{i}+\gamma_{2} L_{i}+\varepsilon_{5}
\end{gathered}
$$

where $N_{i}$ is the nutrition indicator of household $i$, as defined above, $I_{i}$ is per capita income, and $G_{i}$ is gender, which we measure in terms of a dummy that takes a value of one when revenue from coffee sales is controlled by a male household member. We hypothesise that income and gender are both endogenous and influenced by certification $C_{i}$, as shown in equations (3) and (4). $C_{i}$ is also endogenous, so that in equation (5) we use farm altitude, $A_{i}$, as a valid instrument. $X_{i}, Y_{i}, Z_{i}$, and $L_{i}$ are vectors of socioeconomic controls that are expected to influence nutrition, income, gender, and certification. $\varepsilon_{2}, \varepsilon_{3}, \varepsilon_{4}$, and $\varepsilon_{5}$ are random error terms that may be correlated. We employ a mixed-process maximum likelihood procedure to estimate this system of simultaneous equations (Roodman, 2011). 


\section{Data and descriptive statistics}

\subsection{Farm household survey}

We carried out a structured survey of coffee-producing households in Uganda between July and September 2012. For the selection of households to be interviewed, we used a multi-stage sampling procedure. At first, we contacted the main coffee associations in Uganda to obtain lists of existing farmer cooperatives, including information on their location, the number of cooperative members, and certification details. Based on these lists and visits to many of the locations, we purposively selected three cooperatives for inclusion in the study. These cooperatives have similar agro-ecological and infrastructure conditions. All three are located in the Central Region of Uganda; two of them in Luwero District, and the third in Masaka District. In all three cooperatives, farmers produce only Robusta coffee. Luwero and Masaka are among the top four districts that account for over $50 \%$ of Uganda's Robusta coffee production.

All three selected cooperatives had acquired UTZ certification around the year 2007; two of them had added a second certification scheme shortly thereafter. At the time of the survey, one cooperative had only UTZ; the second had UTZ plus Fairtrade, and the third had UTZ plus Organic certification. Farmers have to be member of a cooperative to participate in the certification schemes, but not all members of the three cooperatives actually participated in certification. Hence, all three cooperatives comprise certified and uncertified farm households, based on individual household decisions whether or not to participate in the certification schemes. Cooperative management provided us with lists of all members, including details on the location of each farm household and their participation in certification schemes. In each cooperative, we randomly selected two parishes, and in each parish, we randomly selected three villages. In these villages, we randomly selected households for the interviews.

In total, we interviewed 271 certified households. Of these, 108 households were certified under UTZ and Fairtrade, 101 under UTZ and Organic, and 62 only under UTZ. In addition to these certified households, we randomly selected a control group of 148 noncertified farm households in the same villages. Some of these control households were cooperative members while others were not. The total sample size is 419 .

All farm households in the sample were interviewed with a structured questionnaire by a small team of local enumerators that were carefully selected, trained, and supervised by the 
researchers. The questionnaire covered all economic activities of households with a detailed breakdown for coffee production and marketing. Table 1 shows descriptive statistics of sampled households, disaggregated by certification status.

We find a few significant differences between certified and non-certified households. The heads of certified households are older and have longer experience with coffee cultivation. Certified farmers also have more land and larger houses, measured in terms of the number of rooms. They are located closer to all-weather roads than non-certified farmers and have slightly higher incomes. We proxy income by per capita expenditure levels, which is considered a better indicator of household living standard in the development economics literature. As explained above, we use altitude as an instrument for certification status. Certified farms are located in somewhat lower altitudes than non-certified farms. This difference is statistically significant but relatively small in magnitude..

Table 2. Summary statistics by certification status

\begin{tabular}{|c|c|c|c|c|c|}
\hline & \multicolumn{2}{|c|}{$\begin{array}{l}\text { Non-certified } \\
(\mathrm{N}=148)\end{array}$} & \multicolumn{2}{|l|}{$\begin{array}{l}\text { Certified } \\
(\mathrm{N}=271)\end{array}$} & \multirow[t]{2}{*}{ Difference } \\
\hline & Mean & S.D. & Mean & S.D. & \\
\hline \multicolumn{6}{|l|}{ Household and farm characteristics } \\
\hline Male household head (dummy) & 0.791 & 0.408 & 0.738 & 0.441 & \multirow{5}{*}{$* * *$} \\
\hline Age of household head (years) & 47.378 & 15.444 & 55.432 & 12.816 & \\
\hline Education of household head (years) & 6.534 & 3.329 & 6.590 & 3.785 & \\
\hline Cellphone ownership (dummy) & 0.750 & 0.434 & 0.775 & 0.418 & \\
\hline Household size (AE) & 4.848 & 2.930 & 5.360 & 2.683 & \\
\hline Number of rooms & 4.128 & 1.481 & 4.613 & 1.508 & $* *$ \\
\hline Years growing coffee & 16.662 & 12.745 & 26.786 & 15.590 & \multirow{2}{*}{$\begin{array}{l}* * * \\
* * *\end{array}$} \\
\hline Total land owned (acres) & 4.533 & 3.296 & 6.220 & 4.702 & \\
\hline Number of rooms ( 5 years ago) & 3.757 & 1.519 & 4.557 & 2.237 & $* * *$ \\
\hline Per capita expenditure per day (UGX) & 3176.39 & 1582.18 & 3579.32 & 1821.21 & \multirow[t]{2}{*}{$*$} \\
\hline Total land owned 5 years ago (acres) & 4.344 & 3.496 & 5.995 & 5.287 & \\
\hline Farm altitude $(\mathrm{m})$ & 1210.03 & 47.698 & 1168.85 & 71.652 & \multirow{2}{*}{$\begin{array}{l}* * * \\
* *\end{array}$} \\
\hline Distance to all-weather road $(\mathrm{km})$ & 18.793 & 15.401 & 14.998 & 8.307 & \\
\hline \multicolumn{6}{|l|}{ Control of coffee activities: } \\
\hline Males control production (dummy) & 0.574 & 0.496 & 0.369 & 0.483 & \multirow{2}{*}{$\begin{array}{l}* * * \\
* *\end{array}$} \\
\hline Males controls revenue (dummy) & 0.601 & 0.491 & 0.439 & 0.497 & \\
\hline
\end{tabular}

Notes: UGX, Ugandan Shillings; AE, adult equivalent; S.D., standard deviation. Differences in mean values are tested for statistically significant differences; *,**,*** denote significance at $10 \%, 5 \%$ and $1 \%$ levels, respectively.

\subsection{Gender roles in coffee production}

To better understand intra-household relations and decision making, respondents were asked to identify who in the household is the primary decision maker for coffee production activities (e.g. weeding, harvesting) and in control of coffee revenues (e.g., who keeps it and decides how it is spent). The decisions were categorized as being made by (i) male- 
head (alone), (ii) the female spouse or head (alone), and (iii) jointly (i.e. household head with the spouse and/or any other male or female member of the family). The lower part of Table 2 shows descriptive statistics for these gender role responses. In certified households, women have significantly more control of coffee production activities and revenues than in non-certified households. In 56 per cent of the certified households, women control coffee revenues either alone or together with a male household member (Figure 2). This is a first indication that certification may have a positive influence on women's empowerment, although this comparison is not yet proof of causality.

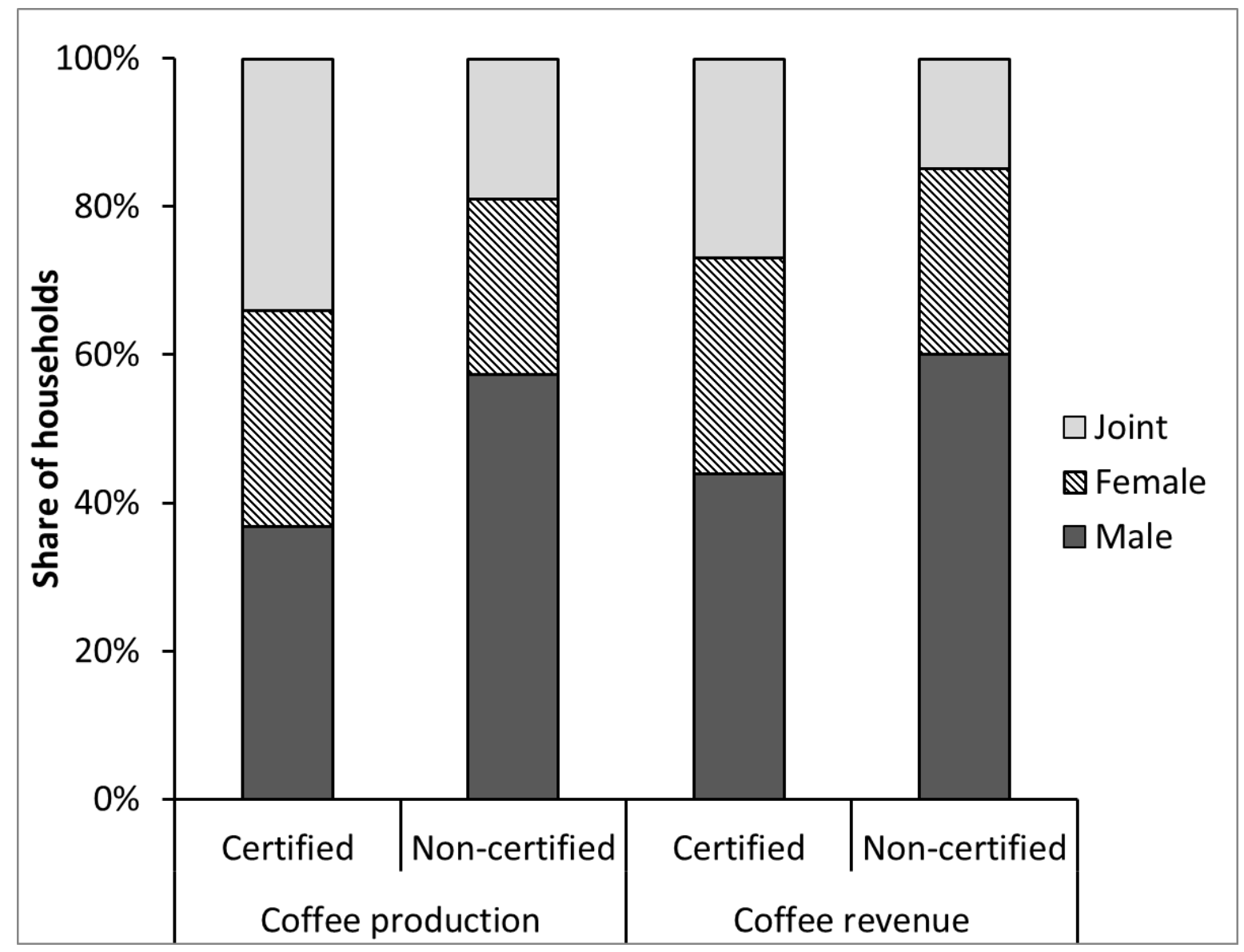

Figure 2. Male and female control of coffee production and revenues for certified and noncertified households

To further examine potential effects of sustainability certification on gender roles, we analyse the relationship between the duration of being certified and gender control of coffee production and revenues in Figure 3. This is possible with the cross-section survey data, because households in the sample were certified at different points in time. The 
longer households have been certified, the less likely it is that males alone control coffee production and revenues. This supports the hypothesis that certification contributes to profound behavioural changes towards gender equity in participating households.

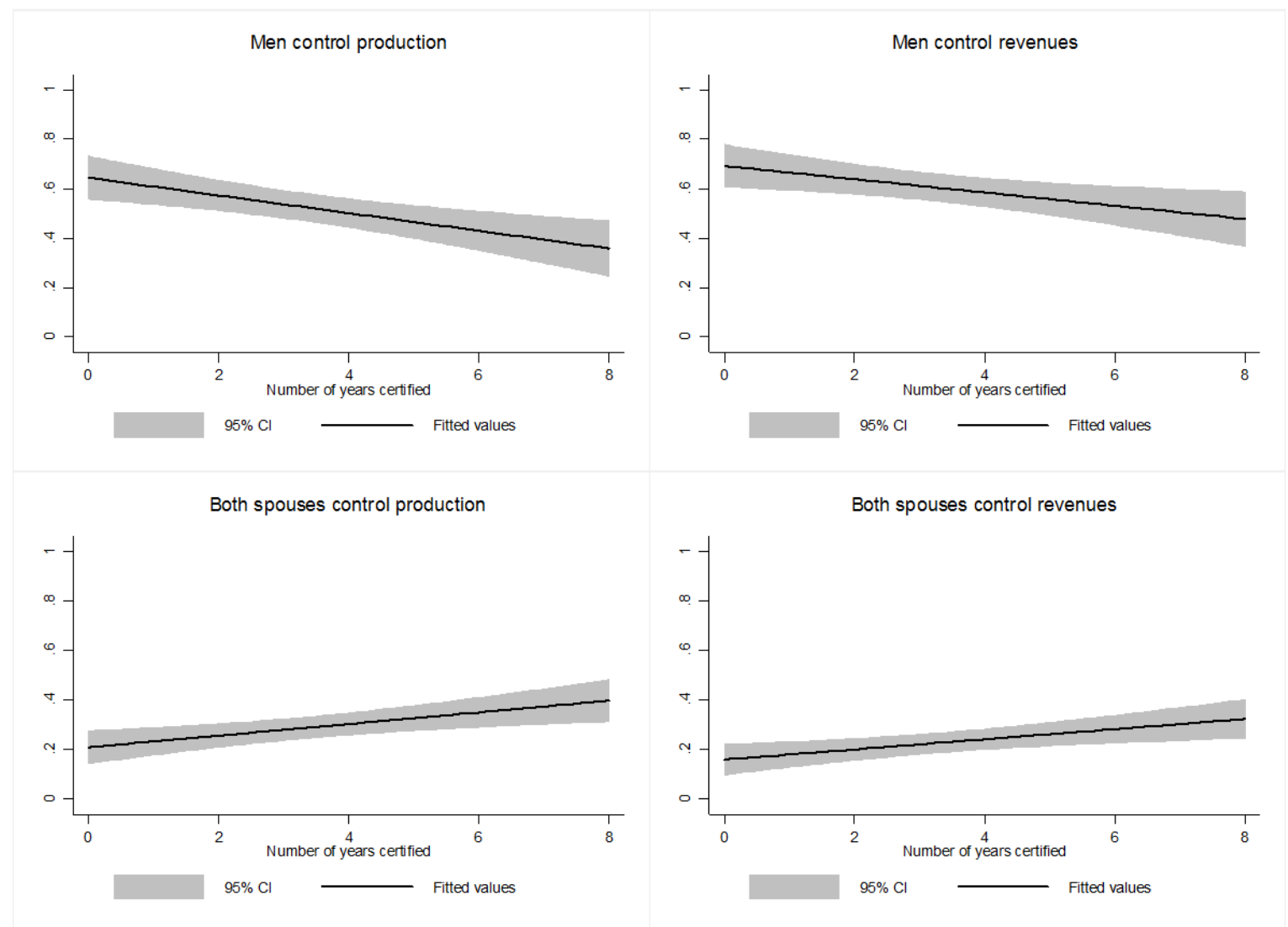

Figure 3. Relationship between duration of certification and gender control of coffee production and revenues

Notes: Fitted values are predictions based on simple linear regressions with proportion of male control or both spouses as dependent variable and length of certification as independent variables (CI confidence interval). 0 years represent non-certified farmers.

\subsection{Household nutrition by certification}

Next, we compare nutritional indicators between certified and non-certified households.

Table 3 shows levels of consumption, deficiency, and depth of deficiency for calories, iron, zinc, and vitamin A. The numbers confirm that food insecurity and micronutrient malnutrition are widespread problems among coffee farmers in Uganda, affecting more than 40 per cent of the households. Notable differences are observed between certified and non-certified households. Certified households have higher mean calorie and micronutrient consumption levels. They also have lower levels of nutritional deficiencies. Whether or not these differences can be interpreted as causal effects of certification will be analysed in the next section. 
Table 3. Households' calorie and micronutrient consumption

\begin{tabular}{|c|c|c|c|c|c|}
\hline & \multicolumn{2}{|c|}{ Non-certified } & \multicolumn{2}{|l|}{ Certified } & \multirow[b]{2}{*}{ Difference } \\
\hline & Mean & S.D. & Mean & S.D. & \\
\hline \multicolumn{6}{|l|}{ Calories: } \\
\hline Daily consumption (kcal/AE) & 2867.710 & 1408.336 & 3151.453 & 1353.307 & $*$ \\
\hline Prevalence of deficiency $(\%)$ & 0.439 & 0.498 & 0.354 & 0.479 & \\
\hline Depth of deficiency $(\%)$ & 0.289 & 0.204 & 0.217 & 0.148 & $*$ \\
\hline \multicolumn{6}{|l|}{ Iron: } \\
\hline Daily consumption (mg/AE) & 20.722 & 10.770 & 23.266 & 11.324 & $*$ \\
\hline Prevalence of deficiency (\%) & 0.486 & 0.502 & 0.395 & 0.490 & \\
\hline Depth of deficiency $(\%)$ & 0.344 & 0.225 & 0.248 & 0.152 & $* * *$ \\
\hline \multicolumn{6}{|l|}{ Zinc: } \\
\hline Daily consumption (mg/AE) & 10.661 & 5.974 & 12.263 & 6.392 & $*$ \\
\hline Prevalence of deficiency $(\%)$ & 0.784 & 0.413 & 0.745 & 0.436 & \\
\hline Depth of deficiency $(\%)$ & 0.460 & 0.220 & 0.379 & 0.192 & $* * *$ \\
\hline \multicolumn{6}{|l|}{ Vitamin A: } \\
\hline Daily consumption ( $\mu \mathrm{g}$ RE/AE) & 1203.388 & 1218.732 & 1266.426 & 1148.831 & \\
\hline Prevalence of deficiency $(\%)$ & 0.358 & 0.481 & 0.303 & 0.460 & \\
\hline Depth of deficiency $(\%)$ & 0.455 & 0.276 & 0.437 & 0.269 & \\
\hline
\end{tabular}

Descriptive statistics in this section have shown that certification is associated with men having less control for coffee incomes and higher consumption of calories and supply of micronutrients. This suggests that certification might have a positive impact on household food security and nutrition. However, these differences are merely descriptive in nature and do not prove causal relationships as there could be systematic differences that affect both certification and household nutrition. Therefore, to address this endogeneity problem, we use an instrumental variable (IV) approach to properly analyze the treatment effects of certification while controlling for other factors in the next section.

\section{$4 \quad$ Econometric results}

\subsection{Impact of certification on nutrition}

We start this analysis by specifying and estimating the reduced-form model in equation (1). In separate regressions, we use the consumption of calories, iron, zinc, and vitamin A per $\mathrm{AE}$ as dependent variables. Certification is used as the treatment variable on the right-hand side, together with a vector of controls. As control variables, we include gender, age, and education of the household head, household size, and infrastructure conditions, which may all affect nutrition. Furthermore, we include two asset variables - farm size and number of rooms in the house - as proxies for household wealth. Wealth may be influenced by certification, which could lead to issues of reverse causality. We use values lagged by five years, thus referring to 2007 (the other values refer to 2012 when the survey was 
conducted). Most households in the sample were not certified before 2007; hence, we reduce possible issues of reverse causality.

As explained above, we specify the treatment variable in two different ways, as a certification dummy and as a continuous variable measuring the number of years that a farm household has been certified. Table 4 shows the estimation results for the models with the certification dummy. These estimates are based on an IV estimator, using farm altitude as instrument for certification. For comparison, OLS results are shown in Table A1, whereas first-stage results of the IV models are shown in Table A2 in the Appendix. The Durbin-Wu-Hausman test statistics are significant for all models, suggesting that the IV models are preferred due to the endogeneity of the certification dummy.

Table 4. Impact of certification status on calorie and micronutrient consumption

\begin{tabular}{|c|c|c|c|c|}
\hline & $\begin{array}{l}\text { Calorie } \\
\text { consumption } \\
\text { (kcal/AE) } \\
\end{array}$ & $\begin{array}{l}\text { Iron } \\
\text { consumption } \\
(\mathrm{mg} / \mathrm{AE}) \\
\end{array}$ & $\begin{array}{l}\text { Zinc } \\
\text { consumption } \\
(\mathrm{mg} / \mathrm{AE}) \\
\end{array}$ & $\begin{array}{l}\text { Vitamin A } \\
\text { consumption } \\
(\mu \mathrm{g} \mathrm{RE} / \mathrm{AE})\end{array}$ \\
\hline \multicolumn{5}{|l|}{ Second stage } \\
\hline Household certified (dummy) & $\begin{array}{l}540.909^{*} \\
(327.795)\end{array}$ & $\begin{array}{l}7.274^{* * *} \\
(2.418)\end{array}$ & $\begin{array}{l}5.137^{* * *} \\
(1.217)\end{array}$ & $\begin{array}{l}441.029 \\
(307.128)\end{array}$ \\
\hline Male household head (dummy) & $\begin{array}{l}-140.605 \\
(149.889)\end{array}$ & $\begin{array}{l}-1.656 \\
(1.265)\end{array}$ & $\begin{array}{l}-0.295 \\
(0.727)\end{array}$ & $\begin{array}{l}-140.829 \\
(142.071)\end{array}$ \\
\hline Age of household head (years) & $\begin{array}{l}6.347 \\
(5.248)\end{array}$ & $\begin{array}{l}0.030 \\
(0.043)\end{array}$ & $\begin{array}{l}0.015 \\
(0.024)\end{array}$ & $\begin{array}{l}-0.379 \\
(4.960)\end{array}$ \\
\hline Education of household head (years) & $\begin{array}{l}-30.377^{*} \\
(18.165)\end{array}$ & $\begin{array}{l}-0.325^{* *} \\
(0.153)\end{array}$ & $\begin{array}{l}-0.189^{* *} \\
(0.088)\end{array}$ & $\begin{array}{l}-37.720^{* *} \\
(17.217)\end{array}$ \\
\hline Household size (AE) & $\begin{array}{l}-201.577^{* * *} \\
(22.849)\end{array}$ & $\begin{array}{l}-1.388^{* * * *} \\
(0.192)\end{array}$ & $\begin{array}{l}-0.758^{* * *} \\
(0.110)\end{array}$ & $\begin{array}{l}-33.124 \\
(21.651)\end{array}$ \\
\hline Number of rooms (5 years ago) & $\begin{array}{l}55.714^{*} \\
(32.243)\end{array}$ & $\begin{array}{l}0.119 \\
(0.270)\end{array}$ & $\begin{array}{l}-0.141 \\
(0.155)\end{array}$ & $\begin{array}{l}25.484 \\
(30.542)\end{array}$ \\
\hline Total land owned 5 years ago (acres) & $\begin{array}{l}8.465 \\
(13.929)\end{array}$ & $\begin{array}{l}0.003 \\
(0.117)\end{array}$ & $\begin{array}{l}0.086 \\
(0.067)\end{array}$ & $\begin{array}{l}-3.292 \\
(13.193)\end{array}$ \\
\hline Distance to all-weather road $(\mathrm{km})$ & $\begin{array}{l}12.603^{* *} \\
(5.914)\end{array}$ & $\begin{array}{l}0.123^{* *} \\
(0.049)\end{array}$ & $\begin{array}{l}0.078^{* * * *} \\
(0.028)\end{array}$ & $\begin{array}{l}-0.426 \\
(5.593)\end{array}$ \\
\hline Constant & $\begin{array}{l}3227.684^{* * * *} \\
(327.200)\end{array}$ & $\begin{array}{l}24.106^{* * *} \\
(2.758)\end{array}$ & $\begin{array}{l}11.863^{* * *} \\
(1.583)\end{array}$ & $\begin{array}{l}1420.629^{* * * *} \\
(310.105)\end{array}$ \\
\hline Observations & 419 & 419 & 419 & 419 \\
\hline Log likelihood & -3789 & -1781 & -1540 & -3762 \\
\hline Wald Chi-squared & 105.60 & 83.70 & 82.61 & 16.22 \\
\hline Durbin-Wu-Hausman Chi-squared & $4.01^{*}$ & $7.19^{* * *}$ & $15.57^{* * *}$ & $4.70^{* *}$ \\
\hline
\end{tabular}

The results in Table 3 show that certification has a positive and significant effect on the consumption of calories, iron, and zinc. Controlling for other factors, certified households consume $541 \mathrm{kcal}$ more per AE and day, which implies a 19 per cent increase over mean consumption levels of non-certified households. Certified households also consume 7.3 $\mathrm{mg} / \mathrm{AE}$ more iron and $5.1 \mathrm{mg} / \mathrm{AE}$ more zinc, representing increases relative to noncertified households of 35 per cent and 48 per cent, respectively. Also for vitamin A, we 
in Uganda

observe a positive effect of certification, although this coefficient is not statistically significant. These results suggest that participation in sustainability certification improves food security and dietary quality among coffee farmers in Uganda. This is similar to what has been shown for horticultural farm households in Kenya by Becchetti \& Costantino (2008), who had used simpler measures of dietary quality.

The results in Table 5 use the same reduced-form models, but now with the duration of certification as a continuous treatment variable. Also for these models, the Durbin-WuHausman test statistics suggest that the IV estimator is preferred over OLS. As can be seen, each additional year that a household is certified increases the consumption of calories and all three micronutrients. In these models, the effect for vitamin $\mathrm{A}$ is significant as well. It appears that certification does not only lead to a one-time positive shift, but to steady improvements in nutrition, which may be related to induced behavioural changes within the coffee-producing households.

Table 5. Impact of certification duration on calorie and micronutrient consumption

\begin{tabular}{|c|c|c|c|c|}
\hline & $\begin{array}{l}\text { Calorie } \\
\text { consumption } \\
(\mathrm{mg} / \mathrm{AE}) \\
\end{array}$ & $\begin{array}{l}\text { Iron } \\
\text { consumption } \\
(\mathrm{mg} / \mathrm{AE}) \\
\end{array}$ & $\begin{array}{l}\text { Zinc } \\
\text { consumption } \\
(\mathrm{mg} / \mathrm{AE}) \\
\end{array}$ & $\begin{array}{l}\text { Vitamin A } \\
\text { consumption } \\
(\mu \mathrm{g} \text { RE/AE) }\end{array}$ \\
\hline \multicolumn{5}{|l|}{ Second stage } \\
\hline \multirow[t]{2}{*}{ Number of years certified } & $111.421^{*}$ & $1.530^{* * *}$ & $1.202^{* * *}$ & $105.236^{*}$ \\
\hline & $(58.189)$ & $(0.519)$ & $(0.302)$ & $(56.897)$ \\
\hline \multirow[t]{2}{*}{ Male household head (dummy) } & -111.271 & -1.248 & 0.045 & -110.718 \\
\hline & $(164.769)$ & $(1.404)$ & $(0.812)$ & $(167.292)$ \\
\hline \multirow[t]{2}{*}{ Age of household head (years) } & 6.591 & 0.033 & 0.012 & -0.713 \\
\hline & $(4.945)$ & $(0.042)$ & $(0.025)$ & $(5.104)$ \\
\hline \multirow[t]{2}{*}{ Education of household head (years) } & -27.347 & -0.284 & -0.160 & $-35.228^{* *}$ \\
\hline & $(19.916)$ & $(0.176)$ & $(0.105)$ & $(16.489)$ \\
\hline \multirow[t]{2}{*}{ Household size (AE) } & $-205.155^{* * *}$ & $-1.439^{* * *}$ & $-0.805^{* * * *}$ & $-37.346^{*}$ \\
\hline & $(25.976)$ & $(0.232)$ & $(0.140)$ & $(21.170)$ \\
\hline \multirow[t]{2}{*}{ Number of rooms ( 5 years ago) } & $64.004^{*}$ & 0.230 & -0.068 & 31.655 \\
\hline & $(38.022)$ & $(0.359)$ & $(0.175)$ & $(28.794)$ \\
\hline \multirow[t]{2}{*}{ Total land owned 5 years ago (acres) } & 6.520 & -0.025 & 0.057 & -5.891 \\
\hline & $(15.166)$ & $(0.122)$ & $(0.083)$ & $(9.816)$ \\
\hline \multirow[t]{2}{*}{ Distance to all-weather road $(\mathrm{km})$} & $10.822^{*}$ & $0.100^{*}$ & $0.064^{* *}$ & -1.559 \\
\hline & $(5.773)$ & $(0.051)$ & $(0.029)$ & $(4.907)$ \\
\hline \multirow[t]{2}{*}{ Constant } & $3179.127^{* * *}$ & $23.422^{* * *}$ & $11.257^{* * *}$ & $1366.514^{* * *}$ \\
\hline & $(336.352)$ & $(2.895)$ & $(1.670)$ & $(370.882)$ \\
\hline Observations & 419 & 419 & 419 & 419 \\
\hline Wald Chi-squared & 76.98 & 54.19 & 49.48 & 16.54 \\
\hline Durbin-Wu-Hausman Chi-squared & $5.351^{* *}$ & $8.005^{* * *}$ & $15.84^{* * *}$ & $5.048^{* *}$ \\
\hline
\end{tabular}

\subsection{Impact pathways}

Results from the reduced-form models revealed that sustainability certification and the duration of certification are both positively associated with higher calorie and 
micronutrient consumption in coffee-producing households. We now turn to the analysis of possible impact pathways, estimating the simultaneous equation system shown in equations (2) to (5). Again, we use two different treatment variables, namely the certification dummy and the duration of certification as a continuous variable. The main results for the dummy specification are summarised in Table 6 (full results are shown in Table A3 in the Appendix).

Table 6. Impact pathways of certification status on calorie and micronutrient consumption

\begin{tabular}{lllll}
\hline & $\begin{array}{l}\text { Calorie } \\
\text { consumption } \\
(\mathrm{mg} / \mathrm{AE})\end{array}$ & $\begin{array}{l}\text { Iron } \\
\text { consumption } \\
(\mathrm{mg} / \mathrm{AE})\end{array}$ & $\begin{array}{l}\text { Zinc } \\
\text { consumption } \\
(\mathrm{mg} / \mathrm{AE})\end{array}$ & $\begin{array}{l}\text { Vitamin A } \\
\text { consumption } \\
(\mu \mathrm{gE} / \mathrm{AE})\end{array}$ \\
\hline $\begin{array}{l}\text { Main pathways } \\
\text { Per capita expenditure per day(UGX) }\end{array}$ & $\begin{array}{l}0.306^{* * *} \\
(0.034)\end{array}$ & $\begin{array}{l}0.002^{* * *} \\
(0.000)\end{array}$ & $\begin{array}{l}0.002^{* * *} \\
(0.000)\end{array}$ & $\begin{array}{l}0.045 \\
(0.034)\end{array}$ \\
Male controls revenue (dummy) & $-664.215^{* * *}$ & $-6.525^{* * *}$ & $-2.346^{* *}$ & $-557.335^{* * *}$ \\
& $(198.861)$ & $(1.687)$ & $(0.930)$ & $(198.880)$ \\
Per capita expenditure per day $(\boldsymbol{U G} \boldsymbol{G})$ & & $4521.814^{* * *}$ & $4546.756^{* * *}$ & $4496.279^{* * *}$ \\
Household certified (dummy) & $\begin{array}{l}4513.056^{* * *} \\
\text { Male controls revenue (dummy) }\end{array}$ & $\begin{array}{l}454.917) \\
(544.884)\end{array}$ & $(544.798)$ & $(544.950)$ \\
Household certified (dummy) & $-0.657^{* * *}$ & $-0.669^{* * *}$ & $-0.680^{* * *}$ & $-0.661^{* * *}$ \\
Household certified (dummy) & $(0.127)$ & $(0.127)$ & $(0.127)$ & $(0.128)$ \\
Farm altitude (m) & $-0.001^{* * *}$ & $-0.001^{* * *}$ & $-0.001^{* * *}$ & $-0.001^{* * *}$ \\
& $(0.000)$ & $(0.000)$ & $(0.000)$ & $(0.000)$ \\
\hline
\end{tabular}

Notes: UGX, Ugandan Shillings; AE, Adult equivalent; RE, retinol equivalent. Coefficients are shown with standard errors in parentheses. *, $* *, * * *$ denote significance at $10 \%, 5 \%$ and $1 \%$ levels, respectively.

The first two rows in Table 6 show how household expenditure (income) and gender roles affect calorie and micronutrient consumption. Each additional UGX (Ugandan shilling) of daily per capita expenditure increases calorie consumption by $0.306 \mathrm{kcal} / \mathrm{AE}$; that is, an additional 1000 UGX (about 0.38 US\$) increases calorie consumption by $306 \mathrm{kcal}$ per day. Per capita expenditure levels also have a positive impact on iron and zinc consumption, whereas the effect for vitamin A is not statistically significant. Other studies with data from rural households in Africa have also shown that vitamin A consumption is often less responsive to income changes than iron or zinc consumption (Ecker \& Qaim, 2011). On the other hand, gender roles within the household have a significant effect on all nutrition indicators, including vitamin A. If a male household member controls the revenue from coffee sales (as compared to female or joint control), calorie consumption is reduced by $664 \mathrm{kcal}$, equivalent to 23 per cent of mean calorie consumption levels. Iron, zinc, and vitamin A consumption are also reduced considerably through male control of coffee revenues. This is consistent with the literature showing that men and women often spend 
income on different types of goods, as discussed above (Hoddinott \& Haddad, 1995; Quisumbing \& Maluccio, 2003).

The other rows in Table 6 show that certification significantly affects household expenditure (income) and gender roles, confirming the two main hypothesised impact pathways. Per capita expenditure levels and women's empowerment are positively influenced through certification. When a household is certified, the probability that a male alone controls coffee revenues is reduced by 0.66 . This is a very strong effect that may be explained by two factors. First, as discussed above, some of the sustainability standards promote gender equity through special training, awareness building, and other gender mainstreaming activities. Second, certified coffee production with stricter standards increases the demand for labour, so that female household members become increasingly involved in the coffee crop. More female labour spent on coffee production seems to improve women's bargaining power and their influence on decision-making.

Table 7 summarises the results for the simultaneous equation system using the duration of certification as continuous treatment variable (full results are shown in Table A4 in the Appendix). These estimates are consistent with the findings so far. Each additional year that a household is certified increases per capita expenditures by about 500 UGX per day and reduces the probability of male revenue control by 0.09 . These results point at learning effects of producing successfully in certified markets and at a positive trend towards women empowerment. 
Table 7. Impact pathways of certification duration on calorie and micronutrient consumption

\begin{tabular}{|c|c|c|c|c|}
\hline & $\begin{array}{l}\text { Calorie } \\
\text { consumption } \\
\text { (mg/AE) }\end{array}$ & $\begin{array}{l}\text { Iron } \\
\text { consumption } \\
\text { (mg/AE) }\end{array}$ & $\begin{array}{l}\text { Zinc } \\
\text { consumption } \\
\text { (mg/AE) }\end{array}$ & $\begin{array}{l}\text { Vitamin A } \\
\text { consumption } \\
(\mu \mathrm{g} \text { RE/AE) }\end{array}$ \\
\hline \multicolumn{5}{|l|}{ Main pathway } \\
\hline Per capita expenditure (UGX) & $\begin{array}{l}0.310^{* * *} \\
(0.034)\end{array}$ & $\begin{array}{l}0.002^{* * * *} \\
(0.000)\end{array}$ & $\begin{array}{l}0.002^{* * * *} \\
(0.000)\end{array}$ & $\begin{array}{l}0.043 \\
(0.034)\end{array}$ \\
\hline Male controls revenue (dummy) & $\begin{array}{l}-665.098^{* * *} \\
(198.959)\end{array}$ & $\begin{array}{l}-6.573^{* * *} \\
(1.688)\end{array}$ & $\begin{array}{l}-2.409^{* * *} \\
(0.930)\end{array}$ & $\begin{array}{l}-557.986^{* * *} \\
(198.909)\end{array}$ \\
\hline Per capita expenditure per day $(U G X)$ & & & & \\
\hline Number of years certified & $\begin{array}{l}500.387^{* * *} \\
(81.421)\end{array}$ & $\begin{array}{l}501.219^{* * *} \\
(81.420)\end{array}$ & $\begin{array}{l}508.781^{* * *} \\
(81.396)\end{array}$ & $\begin{array}{l}497.385^{* * *} \\
(81.408)\end{array}$ \\
\hline Male controls revenue (dummy) & & & & \\
\hline Number of years certified & $\begin{array}{l}-0.090^{* * * *} \\
(0.020)\end{array}$ & $\begin{array}{l}-0.093^{* * *} \\
(0.020)\end{array}$ & $\begin{array}{l}-0.095^{* * *} \\
(0.020)\end{array}$ & $\begin{array}{l}-0.089^{* * *} \\
(0.020)\end{array}$ \\
\hline $\begin{array}{l}\text { Number of years certified } \\
\text { Farm altitude }(\mathrm{m})\end{array}$ & $\begin{array}{l}-0.012^{* * * *} \\
(0.002)\end{array}$ & $\begin{array}{l}-0.012^{* * *} \\
(0.002)\end{array}$ & $\begin{array}{l}-0.012^{* * *} \\
(0.002)\end{array}$ & $\begin{array}{l}-0.012^{* * * *} \\
(0.002)\end{array}$ \\
\hline
\end{tabular}

Notes: UGX, Ugandan Shillings; AE, adult equivalent; RE, retinol equivalent. Coefficients are shown with standard errors in parentheses. $*, * *, * * *$ denote significance at $10 \%, 5 \%$ and $1 \%$ levels, respectively.

\section{Conclusions}

Global food systems are undergoing a rapid transformation, with voluntary sustainability standards and certification schemes gaining in importance. Smallholder farmers in developing countries may potentially benefit from such standards. Previous research had analysed impacts of smallholder participation in sustainability-oriented certification schemes in terms of output prices, profits, and incomes. Impacts on household nutrition have hardly been evaluated. We have addressed this shortcoming, using survey data from smallholder coffee farmers in Uganda who participate in Fairtrade, Organic, and UTZ certification schemes. Our contribution to the existing literature is twofold. First, we have analysed impacts on household food security and dietary quality, building on various indicators constructed from comprehensive food consumption data. Second, we have developed and estimated systems of simultaneous equations to analyse impact pathways with a particular focus on income and gender roles within farm households. The approaches developed may also be useful for impact evaluation in other contexts, thus contributing to the broader research direction on agriculture-nutrition linkages.

The empirical results suggest that sustainability standards in the coffee market have positive impacts on food security and dietary quality for smallholder farmers in Uganda. Controlling for other factors, participation in the certification schemes has increased household consumption of calories, iron, and zinc by 19 per cent, 35 per cent, and 48 per 
cent, respectively. In terms of impact pathways, we have shown that sustainability certification increases household incomes and improves gender equity. Both these factors contribute to improved nutrition.

The gender effects are particularly noteworthy. Agricultural commercialization often contributes to women losing control of farm production and revenues, sometimes with negative marginal effects for household nutrition. The reason is that women tend to spend a greater share of their income on family nutrition and health than men. Our results demonstrate that this loss of female control can be prevented and even reversed when measures to promote gender equity are integrated into market linkage initiatives. Sustainability standards vary in their concrete measures and approaches, but their codes of conduct generally emphasise zero tolerance to discrimination, marginalisation, and unfair treatment of family members and workers employed on certified farms.

In addition to the structured survey that we implemented, we conducted several focus group discussions with certified and non-certified farmers, separately for men and women. These discussions confirm the results from the quantitative analysis. Spouses of male farmers often stated that intra-household gender relations have changed indeed through certification; many had received training courses on coffee production, marketing, and gender issues. Cooperatives with certification are also hiring more women as extension workers and foster equal representation of women in the leadership structure. In some cases, payments for coffee delivered to the cooperative are only made if both spouses are present. This improves transparency and women's involvement in decisions on how to spend the income. The econometric results suggest that women's empowerment further increases with the duration of certification, pointing at positive and profound behavioural changes.

Of course, the results from certified coffee farmers in Uganda should not simply be generalized. Nevertheless, we cautiously conclude that sustainability standards can contribute to improved livelihoods of smallholder farm households, including higher incomes, better nutrition, and improved gender equity. One shortcoming of our analysis is that it builds on cross-section data, so that not all possible biasing factors may be eliminated completely. Follow-up research with panel data may help to further increase the robustness of the results on impacts, impact pathways, and impact dynamics.. 


\section{References}

Arnould, E. J., Plastina, A., \& Ball, D. (2009). Does Fair Trade deliver on its core value proposition? Effects on income, educational attainment, and health in three countries. Journal of Public Policy \& Marketing, 28(2), 186-201.

Avelino, J., Barboza, B., Araya, J. C., Fonseca, C., Davrieux, F., Guyot, B., \& Cilas, C. (2005). Effects of slope exposure, altitude and yield on coffee quality in two altitude terroirs of Costa Rica, Orosi and Santa María de Dota. Journal of the Science of Food and Agriculture, 85, 1869-1876.

Bassett, T. (2010). Slim pickings: Fairtrade cotton in West Africa. Geoforum, 41, 44-55.

Becchetti, L., \& Costantino, M. (2008). The effects of Fair Trade on affiliated producers: An impact analysis on Kenyan farmers. World Development, 36(5), 823-842.

Berdegué, J. A., Balsevich, F., Flores, L., \& Reardon, T. (2005). Central American supermarkets' private standards of quality and safety in procurement of fresh fruits and vegetables. Food Policy, 30(3), 254-269.

Blackman, A., \& Naranjo, M. (2012). Does eco-certification have environmental benefits? Organic coffee in Costa Rica. Ecological Economics, 83(12), 58-66.

Bolwig, S., Gibbon, P., \& Jones, S. (2009). The economics of smallholder organic contract farming in tropical Africa. World Development, 37(6), 1094-1104.

Bouis, H. E. (1994). The effect of income on demand for food in poor countries: Are our food consumption databases giving us reliable estimates? Journal of Development Economics, 44(1), 199-226.

Chiputwa, B., Spielman, D.J., \& Qaim, M. (2015). Food standards, certification, and poverty among coffee farmers in Uganda. World Development, 66, 400-412.

de Haen, H., Klasen, S., \& Qaim, M. (2011). What do we really know? Metrics for food insecurity and undernutrition. Food Policy, 36, 760-769.

Decazy, F., Avelino, J., Guyot, B., Perriot, J. J., Pineda, C., \& Cilas, C. (2003). Quality of different Honduran coffees in relation to several environments. Journal of Food Science, 68, 2356-2361.

Ecker, O., Qaim, M. (2011). Analyzing nutritional impacts of policies: An empirical study for Malawi. World Development, 39, 412-428.

Fairtrade. (2009). Generic Fairtrade standards for small producers' organizations. Retrieved from http://www.fairtrade.net/fileadmin/user_upload/content/2009/standards/documents/04 -10_EN_Generic_Fairtrade_Standards_SPO_Aug_09_EN_amended_version_0410.pdf 
FAO, WHO, \& UNU. (2001). Human energy requirements. Rome: Food and Agriculturlal Organization, World Health Organization, United Nations University.

Fiedler, J. L., Lividini, K., Bermudez, O. I., \& Smitz, M. F. (2012). Household consumption and expenditures surveys (HCES): A primer for food and nutrition analysis. Food and Nutrition Bulletin, (33), S170-S184.

Fischer, E., \& Qaim, M. (2012). Gender, agricultural commercialization, and collective action in Kenya. Food Security, 4, 441-453.

Gomez, M.I., \& Ricketts, K.D. (2013). Food value chain transformations in developing countries: selected hypotheses on nutritional implications. Food Policy, 42, 139-150.

Haddad, L. (2013). From nutrition plus to nutrition driven: How to realize the elusive potential of agriculture for nutrition? Food and Nutrition Bulletin, 34, 39-44.

Hoddinott, J. \& Haddad, L. (1995). Does female income share influence household expenditures? Evidence from Cote D'Ivoire. Oxford Bulletin of Economics and Statistics, 57(1), 77-96.

Henson, S., \& Humphrey, J. (2010). Understanding the complexities of private standards in global agri-food chains as they impact developing countries. Journal of Development Studies, 46(9), 1628-1646.

Hoddinott, J. (2012). Agriculture, health, and nutrition: Toward conceptualizing the linkages. In S. Fan \& R. Pandya-Lorch (Eds.), Reshaping Agriculture for Nutrition and Health (pp. 13-20). Washington, DC: International Food Policy Research Institute.

Holzapfel, S., \& Wollni, M. (2014). Is GlobalGAP certification of small-Scale farmers sustainable? Evidence from Thailand. Journal of Development Studies, 50, 731-747.

Hotz, C., Abdelrahman, L., Sison, C., Moursi, M., \& Loechl, C. (2012). A food composition table for Central and Eastern Uganda. Washington, DC: International Food Policy Research Institute and International Center for Tropical Agriculture.

IFPRI (2014). Global Nutrition Report 2014: Actions and Accountability to Accelerate the World's Progress on Nutrition. Washington, DC: International Food Policy Research Institute.

Jena, P. R., Chichaibelu, B. B., Stellmacher, T., \& Grote, U. (2012). The impact of coffee certification on small-scale producers' livelihoods: A case study from the Jimma Zone, Ethiopia. Agricultural Economics, 43, 429-440.

Jones, S., \& Gibbon, P. (2011). Developing agricultural markets in sub-Saharan Africa: Organic cocoa in rural Uganda. Journal of Development Studies, 47, 1595-1618.

Kleemann, L., Abdulai, A., \& Buss, M. (2014). Certification and access to export markets: Adoption and return on investment of organic-certified pineapple farming in Ghana. World Development, 64, 79-92. 
Lyon, S., Bezaury, J. A., \& Mutersbaugh, T. (2010). Gender equity in fairtrade-organic coffee producer organizations: Cases from Mesoamerica. Geoforum, 41(1), 93-103.

Maertens, M., \& Swinnen, J. F. M. (2012). Gender and modern supply chains in developing countries. Journal of Development Studies, 48(10), 1412-1430.

Masset, E., Haddad, L., Cornelius, A., \& Isaza-Castro, J. (2012). Effectiveness of agricultural interventions that aim to improve nutritional status of children: Systematic review. British Medical Journal, 344, d8222-d8222.

Mergenthaler, M., Weinberger, K., \& Qaim, M. (2009). The food system transformation in developing countries: A disaggregate demand analysis for fruits and vegetables in Vietnam. Food Policy, 34(5), 426-436.

Narrod, C., Roy, D., Okello, J., Avendaño, B., Rich, K., \& Thorat, A. (2009). Publicprivate partnerships and collective action in high value fruit and vegetable supply chains. Food Policy, 34(1), 8-15.

Njuki, J., Kaaria, S., Chamunorwa, A., \& Chiuri, W. (2011). Linking smallholder farmers to markets, gender and intra-household dynamics: Does the choice of commodity matter? European Journal of Development Research, 23(3), 426-443.

Quisumbing, A. R., \& Maluccio, J. A. (2003). Resources at marriage and intrahousehold allocation: Evidence from Bangladesh, Ethiopia, Indonesia, and South Africa. Oxford Bulletin of Economics and Statistics, 65(3), 283-328.

Reardon, T., \& Timmer, C.P. (2012). The economics of the food system revolution. Annual Review of Resource Economics, 4, 225-264.

Riisgaard, L., Michuki, G., \& Gibbon, P. (2009). The performance of voluntary standard schemes from the perspective of small producers in East Africa. Copenhagen: Danish Institute for International Studies for Traidcraft.

Roodman, D. M. (2011). Fitting fully observed recursive mixed-process models with cmp. Stata Journal, 11(2), 159-206.

Ruben, R., \& Fort, R. (2012). The impact of Fair Trade certification for coffee farmers in Peru. World Development, 40(3), 570-582.

Ruben, R. (Ed.) (2008). The Impact of Fair Trade. Wageningen: Wageningen Academic Publishers.

Stein, A.J., Meenakshi, J.V., Qaim, M., Nestel, P., Sachdev, H.P.S., Bhutta, Z.A. (2008). Potential impacts of iron biofortification in India. Social Science \& Medicine, 66, 1797-1808.

Utting-Chamorro, K. (2005). Does fair trade make a difference? The case of small coffee producers in Nicaragua. Development in Practice, 15(3), 584-599. 
UTZ (2009). UTZ Certified position paper on gender. Retrieved from https://www.utzcertified.org/attachments/article/2174/UTZ_Gender_position_paper.p df

von Braun, J., \& Kennedy, E. (Eds.) (1994). Agricultural Commercialization, Economic Development, and Nutrition. Baltimore, MD: The Johns Hopkins University Press.

Wollni, M., \& Zeller, M. (2007). Do farmers benefit from participating in specialty markets and cooperatives? The case of coffee marketing in Costa Rica1. Agricultural Economics, 37(2-3), 243-248. 


\section{Appendix}

Table A1. Impact of certification on calorie and micronutrient consumption (OLS results)

\begin{tabular}{lllll}
\hline & $\begin{array}{l}\text { Calorie } \\
\text { consumption } \\
(\mathrm{mg} / \mathrm{AE})\end{array}$ & $\begin{array}{l}\text { Iron } \\
\text { consumption } \\
(\mathrm{mg} / \mathrm{AE})\end{array}$ & $\begin{array}{l}\text { Zinc } \\
\text { consumption } \\
(\mathrm{mg} / \mathrm{AE})\end{array}$ & $\begin{array}{l}\text { Vitamin A } \\
\text { consumption } \\
(\mu \mathrm{gE} / \mathrm{AE})\end{array}$ \\
\hline Household certified (dummy) & $\begin{array}{l}283.117^{*} \\
(147.263)\end{array}$ & $\begin{array}{l}2.658^{* * *} \\
(1.187)\end{array}$ & $\begin{array}{l}1.644^{* * *} \\
(0.671)\end{array}$ & $\begin{array}{l}-0.749 \\
(136.665)\end{array}$ \\
Male household head (dummy) & -149.478 & -1.815 & -0.415 & -156.034 \\
& $(160.556)$ & $(1.316)$ & $(0.729)$ & $(160.079)$ \\
Age of household head (years) & $8.430^{*}$ & $0.068^{*}$ & $0.043^{* *}$ & 3.191 \\
& $(4.675)$ & $(0.038)$ & $(0.022)$ & $(4.629)$ \\
Education of household head (years) & -29.014 & $-0.301^{*}$ & $-0.171^{*}$ & $-35.384^{* *}$ \\
& $(19.870)$ & $(0.170)$ & $(0.100)$ & $(16.120)$ \\
Household size (AE) & $-198.464^{* * *}$ & $-1.332^{* * *}$ & $-0.716^{* * *}$ & -27.789 \\
& $(24.359)$ & $(0.204)$ & $(0.117)$ & $(19.401)$ \\
Number of rooms (5 years ago) & 61.838 & 0.229 & -0.058 & 35.979 \\
& $(38.536)$ & $(0.350)$ & $(0.161)$ & $(26.737)$ \\
Total land owned 5 years ago (acres) & 11.278 & 0.053 & 0.124 & 1.529 \\
& $(14.868)$ & $(0.117)$ & $(0.081)$ & $(9.716)$ \\
Distance to all-weather road (km) & $10.580^{*}$ & $0.087^{*}$ & $0.051^{*}$ & -3.892 \\
& $(5.817)$ & $(0.051)$ & $(0.027)$ & $(4.927)$ \\
Constant & $3258.140^{* * *}$ & $24.652^{* * *}$ & $12.275^{* * *}$ & $1472.821^{* * *}$ \\
& $(325.108)$ & $(2.628)$ & $(1.446)$ & $(359.014)$ \\
\hline Observations & 419 & 419 & 419 & 419 \\
Log likelihood & -3574.6 & -1567.8 & -1329.4 & -3548.1 \\
\hline Notes: AE, adult equivalent; RE, retinol equivalent. Coefficients are shown with robust standard errors in parentheses. *, \\
$* * * *$ denote significance at 10\%, 5\% and 1\% levels, respectively. & & & \\
& & & & \\
& & & &
\end{tabular}

Table A2. First-stage results with farm altitude as instrument for certification status

\begin{tabular}{|c|c|c|c|c|}
\hline & $\begin{array}{l}\text { Calorie } \\
\text { consumption } \\
\text { (mg/AE) }\end{array}$ & $\begin{array}{l}\text { Iron } \\
\text { consumption } \\
\text { (mg/AE) }\end{array}$ & $\begin{array}{l}\text { Zinc } \\
\text { consumption } \\
(\mathrm{mg} / \mathrm{AE})\end{array}$ & $\begin{array}{l}\text { Vitamin A } \\
\text { consumption } \\
(\mu \mathrm{g} \mathrm{RE} / \mathrm{AE})\end{array}$ \\
\hline \multicolumn{5}{|l|}{ Household certified (dummy) } \\
\hline Farm altitude $(\mathrm{m})$ & $\begin{array}{l}-0.008^{* * *} \\
(0.001)\end{array}$ & $\begin{array}{l}-0.008^{* * *} \\
(0.001)\end{array}$ & $\begin{array}{l}-0.009^{* * *} \\
(0.001)\end{array}$ & $\begin{array}{l}-0.008^{* * *} \\
(0.001)\end{array}$ \\
\hline Male household head (dummy) & $\begin{array}{l}0.011 \\
(0.173)\end{array}$ & $\begin{array}{l}0.024 \\
(0.174)\end{array}$ & $\begin{array}{l}0.032 \\
(0.173)\end{array}$ & $\begin{array}{l}0.029 \\
(0.174)\end{array}$ \\
\hline Age of household head (years) & $\begin{array}{l}0.025^{\text {*** }} \\
(0.005)\end{array}$ & $\begin{array}{l}0.026^{* * *} \\
(0.005)\end{array}$ & $\begin{array}{l}0.026^{* * *} \\
(0.005)\end{array}$ & $\begin{array}{l}0.025^{\text {*** }} \\
(0.005)\end{array}$ \\
\hline Education of household head (years) & $\begin{array}{l}0.048^{* * *} \\
(0.022)\end{array}$ & $\begin{array}{l}0.050^{* * *} \\
(0.022)\end{array}$ & $\begin{array}{l}0.053^{* * *} \\
(0.021)\end{array}$ & $\begin{array}{l}0.047^{* * *} \\
(0.022)\end{array}$ \\
\hline Household size (AE) & $\begin{array}{l}0.012 \\
(0.025)\end{array}$ & $\begin{array}{l}0.013 \\
(0.025)\end{array}$ & $\begin{array}{l}0.013 \\
(0.025)\end{array}$ & $\begin{array}{l}0.012 \\
(0.026)\end{array}$ \\
\hline Number of rooms ( 5 years ago) & $\begin{array}{l}0.221^{\text {**** }} \\
(0.052)\end{array}$ & $\begin{array}{l}0.215^{\text {*** }} \\
(0.052)\end{array}$ & $\begin{array}{l}0.216^{\text {*** }} \\
(0.052)\end{array}$ & $\begin{array}{l}0.218^{* * *} \\
(0.052)\end{array}$ \\
\hline Total land owned 5 years ago (acres) & $\begin{array}{l}0.014 \\
(0.019)\end{array}$ & $\begin{array}{l}0.013 \\
(0.019)\end{array}$ & $\begin{array}{l}0.010 \\
(0.019)\end{array}$ & $\begin{array}{l}0.013 \\
(0.019)\end{array}$ \\
\hline Distance to all-weather road $(\mathrm{km})$ & $\begin{array}{l}-0.021^{* * *} \\
(0.006)\end{array}$ & $\begin{array}{l}-0.021^{* * * *} \\
(0.006)\end{array}$ & $\begin{array}{l}-0.021^{* * * *} \\
(0.006)\end{array}$ & $\begin{array}{l}-0.021^{* * * *} \\
(0.006)\end{array}$ \\
\hline Constant & $\begin{array}{l}7.755^{\text {**** }} \\
(1.378)\end{array}$ & $\begin{array}{l}8.051^{* * *} \\
(1.361)\end{array}$ & $\begin{array}{l}8.522^{* * *} \\
(1.348)\end{array}$ & $\begin{array}{l}7.758^{* * *} \\
(1.355)\end{array}$ \\
\hline Observations & 419 & 419 & 419 & 419 \\
\hline Log likelihood & -3789.4 & -1780.9 & -1540.0 & -3762.1 \\
\hline Chi-square & 105.6 & 83.70 & 82.61 & 16.22 \\
\hline
\end{tabular}

Notes: AE, adult equivalent; RE, retinol equivalent. Coefficients are shown with robust standard errors in parentheses. *, $* *, * * *$ denote significance at $10 \%, 5 \%$ and $1 \%$ levels, respectively. 
Table A3. Impact pathways of certification status on calorie and micronutrient consumption

\begin{tabular}{|c|c|c|c|c|}
\hline & $\begin{array}{l}\text { Calorie } \\
\text { consumption } \\
(\mathrm{mg} / \mathrm{AE})\end{array}$ & $\begin{array}{l}\text { Iron } \\
\text { consumption } \\
\text { (mg/AE) }\end{array}$ & $\begin{array}{l}\text { Zinc } \\
\text { consumption } \\
\text { (mg/AE) }\end{array}$ & $\begin{array}{l}\text { Vitamin A } \\
\text { consumption } \\
\text { ( } \mu \mathrm{g} \text { RE/AE) }\end{array}$ \\
\hline \multicolumn{5}{|l|}{ Main pathways } \\
\hline \multirow[t]{2}{*}{ Per capita expenditure per day(UGX) } & $0.306^{* * *}$ & $0.002^{* * *}$ & $0.002^{* * *}$ & 0.045 \\
\hline & $(0.034)$ & $(0.000)$ & $(0.000)$ & $(0.034)$ \\
\hline \multirow[t]{2}{*}{ Male controls coffee revenue (dummy) } & $-664.215^{* * *}$ & $-6.525^{* * *}$ & $-2.346^{* *}$ & $-557.335^{* * *}$ \\
\hline & $(198.861)$ & $(1.687)$ & $(0.930)$ & $(198.880)$ \\
\hline \multirow[t]{2}{*}{ Age of household head (years) } & $10.990^{* * *}$ & $0.078^{* * *}$ & $0.052^{* * * *}$ & 2.425 \\
\hline & $(4.177)$ & $(0.036)$ & $(0.019)$ & $(4.157)$ \\
\hline \multirow[t]{2}{*}{ Education of household head (years) } & $-50.154^{* * *}$ & $-0.475^{* * *}$ & $-0.293^{* * *}$ & $-35.948^{* * *}$ \\
\hline & $(16.678)$ & $(0.142)$ & $(0.078)$ & $(16.600)$ \\
\hline \multirow[t]{2}{*}{ Household size (AE) } & $-143.113^{* * *}$ & $-0.984^{* * *}$ & $-0.429^{* * *}$ & -26.626 \\
\hline & $(21.302)$ & $(0.181)$ & $(0.099)$ & $(21.203)$ \\
\hline \multirow[t]{2}{*}{ Constant } & $2822.138^{* * *}$ & $22.227^{* * * *}$ & $8.979^{* * * *}$ & $1612.469^{* * *}$ \\
\hline & $(330.871)$ & $(2.813)$ & $(1.544)$ & $(329.669)$ \\
\hline \multicolumn{5}{|l|}{ Per capita expenditure per day(UGX) } \\
\hline \multirow[t]{2}{*}{ Household certified (dummy) } & $4513.056^{* * *}$ & $4521.814^{* * * *}$ & $4546.756^{* * *}$ & $4496.279^{* * *}$ \\
\hline & $(544.917)$ & $(544.884)$ & $(544.798)$ & $(544.950)$ \\
\hline \multirow[t]{2}{*}{ Male household head (dummy) } & $797.429^{* * * *}$ & $797.627^{\text {**** }}$ & $799.837^{* * * *}$ & $794.281^{* * * *}$ \\
\hline & $(249.419)$ & $(249.419)$ & $(249.415)$ & $(249.413)$ \\
\hline \multirow[t]{2}{*}{ Age of household head (years) } & $-35.859^{* * * *}$ & $-35.935^{\text {***** }}$ & $-36.183^{* * * *}$ & $-35.728^{* * * * *}$ \\
\hline & $(8.738)$ & $(8.738)$ & $(8.737)$ & $(8.738)$ \\
\hline \multirow[t]{2}{*}{ Education of household head (years) } & $56.040^{*}$ & $55.985^{*}$ & $55.627^{*}$ & $56.194^{*}$ \\
\hline & $(30.261)$ & $(30.261)$ & $(30.260)$ & $(30.261)$ \\
\hline \multirow[t]{2}{*}{ Household size (AE) } & $-247.584^{* * * *}$ & $-247.686^{* * *}$ & $-248.186^{* * *}$ & $-247.360^{* * * *}$ \\
\hline & $(37.944)$ & (37.944) & (37.944) & (37.944) \\
\hline \multirow[t]{2}{*}{ Total land owned (acres) } & -7.789 & -7.909 & -7.582 & -7.413 \\
\hline & $(24.496)$ & (24.494) & $(24.487)$ & $(24.494)$ \\
\hline \multirow[t]{2}{*}{ Constant } & $2779.785^{* * *}$ & $2779.556^{* * *}$ & $2777.872^{* * *}$ & $2781.876^{* * * *}$ \\
\hline & $(525.447)$ & $(525.447)$ & $(525.446)$ & $(525.446)$ \\
\hline \multicolumn{5}{|l|}{ Male controls coffee revenue (dummy) } \\
\hline \multirow[t]{2}{*}{ Household certified (dummy) } & $-0.657^{* * *}$ & $-0.669^{* * *}$ & $-0.680^{* * *}$ & $-0.661^{* * *}$ \\
\hline & $(0.127)$ & $(0.127)$ & $(0.127)$ & $(0.128)$ \\
\hline Age of household head (years) & 0.002 & 0.002 & 0.002 & 0.002 \\
\hline & $(0.002)$ & $(0.002)$ & $(0.002)$ & $(0.002)$ \\
\hline Education of household head (years) & $0.016^{* * *}$ & $0.016^{* *}$ & $0.016^{* *}$ & $0.016^{* *}$ \\
\hline & $(0.007)$ & $(0.007)$ & $(0.007)$ & $(0.007)$ \\
\hline Household size (AE) & 0.001 & 0.001 & 0.001 & 0.001 \\
\hline & $(0.009)$ & $(0.009)$ & $(0.009)$ & $(0.009)$ \\
\hline Constant & $0.703^{* * *}$ & $0.704^{* * * *}$ & $0.704^{* * * *}$ & $0.703^{* * *}$ \\
\hline & $(0.124)$ & $(0.124)$ & $(0.124)$ & $(0.124)$ \\
\hline Household certified (dummy) & & & & \\
\hline Farm altitude $(\mathrm{m})$ & $-0.001^{* * *}$ & $-0.001^{* * *}$ & $-0.001^{* * *}$ & $-0.001^{* * *}$ \\
\hline & $(0.000)$ & $(0.000)$ & $(0.000)$ & $(0.000)$ \\
\hline Male household head (dummy) & $-0.194^{* * *}$ & $-0.194^{* * * *}$ & $-0.194^{* * * *}$ & $-0.192^{* * *}$ \\
\hline & $(0.049)$ & $(0.049)$ & $(0.049)$ & $(0.049)$ \\
\hline Age of household head (years) & $0.008^{* * *}$ & $0.008^{* * *}$ & $0.008^{* * *}$ & $0.008^{* * * *}$ \\
\hline & $(0.002)$ & $(0.002)$ & $(0.002)$ & $(0.002)$ \\
\hline Education of household head (years) & $0.015^{* *}$ & $0.015^{* *}$ & $0.015^{* *}$ & $0.015^{* * *}$ \\
\hline & $(0.006)$ & $(0.006)$ & $(0.006)$ & $(0.006)$ \\
\hline Household size (AE) & $0.014^{*}$ & $0.014^{*}$ & $0.014^{*}$ & $0.014^{*}$ \\
\hline & $(0.008)$ & $(0.008)$ & $(0.008)$ & $(0.008)$ \\
\hline Total land owned 5 years ago (acres) & 0.006 & 0.006 & 0.006 & 0.006 \\
\hline & $(0.004)$ & $(0.004)$ & $(0.004)$ & $(0.004)$ \\
\hline Number of rooms ( 5 years ago) & $0.030^{* * *}$ & $0.029^{* * * *}$ & $0.028^{* * * * *}$ & $0.030^{* * * *}$ \\
\hline & $(0.009)$ & $(0.009)$ & $(0.009)$ & (0.009) \\
\hline Distance to all-weather road $(\mathrm{km})$ & $-0.003^{*}$ & $-0.003^{*}$ & -0.003 & $-0.003^{*}$ \\
\hline & $(0.002)$ & $(0.002)$ & $(0.002)$ & $(0.002)$ \\
\hline Constant & $1.275^{* * * *}$ & $1.290^{* * * *}$ & $1.322^{* * * *}$ & $1.289^{* * * *}$ \\
\hline & $(0.361)$ & $(0.361)$ & $(0.361)$ & $(0.361)$ \\
\hline
\end{tabular}

Notes: UGX, Ugandan Shillings; AE, adult equivalent; RE, retinol equivalent. Coefficients are shown with standard errors in parentheses. *, **, *** denote significance at $10 \%, 5 \%$ and $1 \%$ levels, respectively. 
Table A4. Impact pathways of certification duration on calorie and micronutrient consumption

\begin{tabular}{|c|c|c|c|c|}
\hline & $\begin{array}{l}\text { Calorie } \\
\text { consumption } \\
(\mathrm{mg} / \mathrm{AE})\end{array}$ & $\begin{array}{l}\text { Iron } \\
\text { consumption } \\
(\mathrm{mg} / \mathrm{AE}) \\
\end{array}$ & $\begin{array}{l}\text { Zinc } \\
\text { consumption } \\
(\mathrm{mg} / \mathrm{AE}) \\
\end{array}$ & $\begin{array}{l}\text { Vitamin A } \\
\text { consumption } \\
(\mu \mathrm{g} \mathrm{RE} / \mathrm{AE})\end{array}$ \\
\hline \multicolumn{5}{|l|}{ Main pathway } \\
\hline \multirow[t]{2}{*}{ Per capita expenditure per day(UGX) } & $0.311^{* * *}$ & $0.002^{* * *}$ & $0.002^{* * * *}$ & 0.044 \\
\hline & $(0.034)$ & $(0.000)$ & $(0.000)$ & $(0.034)$ \\
\hline \multirow[t]{2}{*}{ Male controls coffee revenue (dummy) } & $-659.761^{* * * *}$ & $-6.499^{* * *}$ & $-2.397^{* * *}$ & $-549.158^{* * *}$ \\
\hline & (199.044) & $(1.689)$ & $(0.930)$ & $(198.984)$ \\
\hline \multirow{2}{*}{ Age of household head (years) } & $10.991^{* * *}$ & $0.078^{* * *}$ & $0.052^{* * * *}$ & 2.463 \\
\hline & $(4.177)$ & $(0.036)$ & $(0.019)$ & $(4.157)$ \\
\hline \multirow[t]{2}{*}{ Education of household head (years) } & $-50.710^{* * *}$ & $-0.482^{* * *}$ & $-0.298^{* * *}$ & $-35.922^{* *}$ \\
\hline & $(16.677)$ & $(0.142)$ & $(0.078)$ & $(16.599)$ \\
\hline \multirow[t]{2}{*}{ Household size (AE) } & $-142.338^{* * *}$ & $-0.974^{* * *}$ & $-0.421^{* * *}$ & -26.709 \\
\hline & $(21.301)$ & $(0.181)$ & $(0.099)$ & $(21.201)$ \\
\hline \multirow[t]{2}{*}{ Constant } & $2803.677^{* * *}$ & $21.998^{* * * *}$ & $8.847^{* * * *}$ & $1610.003^{* * * *}$ \\
\hline & $(330.895)$ & $(2.813)$ & $(1.543)$ & $(329.662)$ \\
\hline \multicolumn{5}{|l|}{ Per capita expenditure per day(UGX) } \\
\hline \multirow[t]{2}{*}{ Number of years certified } & $591.266^{* * *}$ & $592.245^{* * *}$ & $600.202^{* * *}$ & $587.966^{* * *}$ \\
\hline & $(82.935)$ & $(82.934)$ & $(82.907)$ & $(82.918)$ \\
\hline \multirow[t]{2}{*}{ Male household head (dummy) } & $714.522^{* * *}$ & $714.580^{* * * *}$ & $719.767^{* * *}$ & $710.541^{* * *}$ \\
\hline & $(239.115)$ & $(239.116)$ & $(239.111)$ & $(239.103)$ \\
\hline \multirow[t]{2}{*}{ Age of household head (years) } & $-19.381^{* *}$ & $-19.423^{* *}$ & $-19.755^{* * *}$ & $-19.274^{* *}$ \\
\hline & $(7.658)$ & $(7.658)$ & $(7.658)$ & $(7.658)$ \\
\hline \multirow[t]{2}{*}{ Education of household head (years) } & $93.798^{* * *}$ & $93.792^{* * *}$ & $93.605^{* * *}$ & $93.817^{* * * *}$ \\
\hline & $(28.501)$ & $(28.501)$ & $(28.501)$ & $(28.501)$ \\
\hline \multirow[t]{2}{*}{ Household size (AE) } & $-240.304^{* * *}$ & $-240.403^{* * *}$ & $-241.317^{* * *}$ & $-240.005^{* * *}$ \\
\hline & $(36.177)$ & $(36.177)$ & $(36.176)$ & $(36.177)$ \\
\hline \multirow[t]{2}{*}{ Total land owned (acres) } & -2.615 & -2.617 & -2.645 & -2.117 \\
\hline & $(23.894)$ & $(23.892)$ & $(23.881)$ & $(23.890)$ \\
\hline \multirow[t]{2}{*}{ Constant } & $2636.900^{* * *}$ & $2636.446^{* * *}$ & $2629.927^{* * *}$ & $2640.669^{* * *}$ \\
\hline & $(501.673)$ & $(501.673)$ & $(501.670)$ & $(501.669)$ \\
\hline \multicolumn{5}{|l|}{ Male controls coffee revenue (dummy) } \\
\hline \multirow[t]{2}{*}{ Number of years certified } & $-0.097^{* * *}$ & $-0.100^{* * *}$ & $-0.102^{* * *}$ & $-0.096^{* * *}$ \\
\hline & $(0.020)$ & $(0.020)$ & $(0.020)$ & $(0.020)$ \\
\hline Age of household head (years) & 0.000 & 0.000 & 0.000 & 0.000 \\
\hline & $(0.002)$ & $(0.002)$ & $(0.002)$ & $(0.002)$ \\
\hline Education of household head (years) & 0.010 & 0.010 & 0.010 & 0.010 \\
\hline & $(0.007)$ & $(0.007)$ & $(0.007)$ & $(0.007)$ \\
\hline Household size (AE) & 0.001 & 0.001 & 0.002 & 0.001 \\
\hline & $(0.009)$ & $(0.009)$ & $(0.009)$ & $(0.009)$ \\
\hline Constant & $0.736^{* * *}$ & $0.737^{* * *}$ & $0.738^{* * * *}$ & $0.736^{* * * *}$ \\
\hline & $(0.123)$ & $(0.123)$ & $(0.123)$ & $(0.123)$ \\
\hline Number of years certified & & & & \\
\hline Farm altitude $(\mathrm{m})$ & $-0.010^{* * *}$ & $-0.010^{* * *}$ & $-0.011^{* * *}$ & $-0.010^{* * *}$ \\
\hline & $(0.002)$ & $(0.002)$ & $(0.002)$ & $(0.002)$ \\
\hline Male household head (dummy) & $-1.136^{* * * *}$ & $-1.134^{* * *}$ & $-1.130^{* * *}$ & $-1.124^{* * * *}$ \\
\hline & $(0.288)$ & $(0.288)$ & $(0.288)$ & $(0.288)$ \\
\hline Age of household head (years) & $0.033^{* * * *}$ & $0.033^{* * *}$ & $0.033^{* * * *}$ & $0.033^{* * * *}$ \\
\hline & $(0.009)$ & $(0.009)$ & $(0.009)$ & $(0.009)$ \\
\hline Education of household head (years) & $0.064^{*}$ & $0.065^{*}$ & $0.066^{*}$ & $0.064^{*}$ \\
\hline & $(0.037)$ & $(0.037)$ & $(0.037)$ & $(0.037)$ \\
\hline Household size (AE) & $0.086^{*}$ & $0.086^{*}$ & $0.085^{*}$ & $0.086^{*}$ \\
\hline & $(0.045)$ & $(0.045)$ & $(0.045)$ & $(0.045)$ \\
\hline Total land owned 5 years ago (acres) & 0.033 & 0.031 & 0.034 & 0.032 \\
\hline & $(0.025)$ & $(0.025)$ & $(0.025)$ & $(0.025)$ \\
\hline Number of rooms ( 5 years ago) & $0.157^{* * *}$ & $0.154^{* * *}$ & $0.147^{* * * *}$ & $0.158^{* * * *}$ \\
\hline & $(0.056)$ & $(0.056)$ & $(0.056)$ & $(0.056)$ \\
\hline Distance to all-weather road $(\mathrm{km})$ & -0.006 & -0.006 & -0.006 & -0.008 \\
\hline & $(0.009)$ & $(0.009)$ & $(0.009)$ & $(0.009)$ \\
\hline Constant & $12.933^{* * *}$ & $13.105^{* * *}$ & $13.303^{* * *}$ & $13.019^{* * *}$ \\
\hline & $(2.220)$ & $(2.219)$ & $(2.219)$ & $(2.216)$ \\
\hline
\end{tabular}




\title{
IV. Do Changing Probabilities or Payoffs in Lottery-Choice Experiments Affect the Results? Evidence from Rural Uganda ${ }^{1}$
}

\begin{abstract}
This study compares risk attitudes of smallholder farmers elicited from two different lottery designs (i) with fixed payoffs and changing probabilities and (ii) with fixed probabilities and changing payoffs. We utilize experimental data collected from 332 randomly selected smallholder farmers in Uganda. Both methods reveal high proportions of farmers who are classified as risk averse. However, comparing the different risk attitude categories shows that the two elicitation methods yield significantly different results. Furthermore, we find relatively low inconsistency rates in the response behavior for the two methods compared to other studies in the past. Specific socio-demographic and socioeconomic characteristics also affect farmers' risk attitudes.
\end{abstract}

\section{Key words}

Elicitation of risk attitude, inconsistency rates, laboratory experiment in the field, Uganda.

\section{JEL classification}

C91, C93, D81, O13.

\footnotetext{
${ }^{1}$ This chapter is joint work with Hanna Ihli and Oliver Musshoff. Hanna Ihli is the first author. My contribution to this research was in terms of contributing the socioeconomic data. I was also involved in the data analysis and the interpretation of the results. This chapter also appears in Hanna Ihli's Doctoral Dissertation at the University of Goettingen titled: "Decision Making under Uncertainty in Developed and Developing Countries: An Experimental Analysis of Farmers' Risk Attitude and Investment Behavior".
} 


\section{Introduction}

The majority of people in developing countries rely on agriculture as their main source of livelihood and often perform in precarious and risky conditions. In agricultural production, where farmers' crop yields and incomes are dependent on various exogenous factors such as weather conditions and price fluctuations respectively, risk is ubiquitous in farming decisions (Menapace et al. 2012). Ultimately, risk plays a significant role in almost every important economic farm decision such as crop selection (Price and Wetzstein 1999), technology adoption (Purvis et al. 1995), conservation intervention (Winter-Nelson and Amegbeto 1998), and crop insurance markets (Hill and Viceisza 2012). However, people naturally differ in the way they make risky decisions, and these differences are often described as differences in risk attitude. Therefore, understanding the risk attitude of economic agents provides useful insights in understanding their economic behavior (Reynaud and Couture 2012). From a policy-maker's perspective, it is imperative to understand farmers' risk attitudes in order to gain insight of how risk affects the decision behavior and to predict this behavior under different policy conditions (Bhattamishra and Barrett 2010). Harrison (2011) notes that welfare evaluation of any proposed policy with risky outcomes should consider people's risk attitudes. As a result, many researchers have studied individual risk attitudes, and a variety of methods have been used for testing risk attitudes in laboratory and field settings.

There is extensive literature regarding the elicitation of individuals' risk attitudes in both developed and developing countries. A variety of methods has evolved for testing these attitudes, including lottery choice task decisions (eg., Holt and Laury 2002), selfassessment questions (e.g., Dohmen et al. 2011), hypothetical gambles (e.g., Anderson and Mellor 2009), and willingness to pay analyses (e.g., Kahneman et al. 1990). Studies that explored risk attitudes of individuals in a developed country setting include among others Holt and Laury (2002), Eckel and Grossman (2002, 2008), Dave et al. (2010), and Reynaud and Couture (2012). The studies conducted by Binswanger (1980), Humphrey and Verschoor (2004), Jacobson and Petrie (2009), Yesuf and Bluffstone (2009), and Harrison et al. (2010) examined risk attitudes of individuals in a developing country context. A troubling result of previous investigations is that often risk attitudes of an individual vary significantly across different elicitation methods (Isaac and James 2000; Andersen et al. 2006; Dave et al. 2010; Reynaud and Couture 2012). Several reasons have 
been offered to explain this behavior, including context dependency (Reynaud and Couture 2012), differences in cognitive abilities of subjects and task complexity (Anderson and Mellor 2009), and non-expected utility preferences (Starmer 2000). Furthermore, several developing country field studies utilizing complex risk attitude elicitation methods, including lottery choice task decisions, reported relatively high inconsistency rates in individuals' response behavior, which may indicate a low level of comprehension (e.g., Galarza 2009; Jacobson and Petrie 2009; Doerr et al. 2011; Engle-Warnick et al. 2011). As a result, inconsistent subjects are usually excluded from the analysis, which often means excluding a large portion of the data. These problems show that there is a danger that risk attitudes are not estimated correctly and consequently might result in different policy recommendations. Therefore, a valid measure of risk attitudes is a critical input for properly designing effective policy instruments in the agricultural sector as well as for an adequate single-farm decision support. It can support quantifying optimal portfolios, introducing efficient risk prevention policies and designing optimal insurance instruments (Gollier 2001; Harrison et al. 2005a).

In the last decade, the Holt and Laury lottery (HLL hereafter) has virtually become the standard method for the elicitation of subjective risk attitudes. It has been used in a great variety of contexts and with different subject groups, including convenience groups such as students (e.g., Andersen et al. 2006; Deck et al. 2008; Abdellaoui et al. 2011) and real decision-makers such as managers (e.g., Masclet et al. 2009; Holm et al. 2012). Brick et al. (2012) applied a similar design to that of Holt and Laury (2002) but differs in that, instead of changing probabilities and fixing payoffs, probabilities are fixed and payoffs change (BL hereafter). Brick et al. (2012) assumed that people have more difficulties with varying probabilities than with varying amounts of payoffs and thus modified the HLL accordingly.

The objectives of this study are twofold: First, we compare two different risk attitude elicitation methods to answer the questions of how the choice of method affects the results and how well these methods are understood by individuals in a rural, developing country setting. Specifically, we evaluate the consistency of risk measures in the two elicitation methods as well as the inconsistency rates in the response behavior. Our risk attitude elicitation methods are based on the well-known incentive-compatible lotteries used in Holt and Laury (2002) and Brick et al. (2012), in which subjects were given a series of choices between two systematically varied options. The two methods differ in the variation 
of probabilities and the fixing of payoffs or vice versa. In our experiment, both risk attitude elicitation methods are modified from the original lottery-choice experiments by replacing probabilities expressed in percent with images of bags of colored balls to represent probabilities of different payoffs and henceforth are described as modified HLL and modified BL. Conducting a standard HLL and BL with individuals in a rural developing country setting might not be appropriate; thus, we incorporated a modification aiming to reduce inconsistency rates and to provide more reliable measures of risk attitudes. Second, we identify and compare influencing socio-demographic and socio-economic factors of risk attitudes across the two elicitation methods. This allows us to check the robustness of explanatory factors of risk attitudes and examine whether these factors vary depending on the elicitation method. Specifically, this study focuses on a sample of smallholder farmers in Uganda, a setting in which the importance of risk in influencing economic behavior of poor households has been documented (Hill 2009, 2010). To achieve these objectives, we combine data generated from lottery-choice experiments with comprehensive household survey data which were collected in Uganda from July to August 2012.

Our study contributes to the extant literature by addressing the following two aspects: First, to the best of our knowledge, this study is the first to compare the effects of changing probabilities while keeping payoffs constant or vice versa on risk attitudes based on the Holt and Laury (2002) and Brick et al. (2012) experimental designs, using the same sample of subjects. This comparison may add to the knowledge on which method may work better in a developing country context. Second, our work extends the previous research by proposing an adequately experimental design to measure risk attitudes of people with a limited level of education, which may be used as an appropriate elicitation tool within a developing country context.

The remainder of this paper is structured as follows: Section 2 presents the relevant literature from which the research hypotheses are derived. In Section 3, we explain the two risk attitude elicitation methods used to measure the risk attitudes. The sampling procedure, incentive design, and the experimental implementation are described in detail in Section 4. We present and discuss our findings in Section 5, and lastly, Section 6 concludes this paper. 


\section{Literature review and hypotheses}

The existing literature on risk behavior suggests various methods to measure risk attitude, but only few studies compare different elicitation methods, in particular, for data collected in developing countries among resource-poor farmers. Binswanger (1980) measured the risk attitudes of Indian farmers by using two different methods, a hypothetical questionnaire and an experimental gambling method with real payoffs, and discovered inconsistencies in the measures of risk aversion in the two methods. Reynaud and Couture (2012) compared two different risk elicitation methods, namely the Holt and Laury (2002) and the Eckel and Grossman (2008) lottery tasks, on a sample of French farmers. They found that the risk preference measures were affected by the type of method used and demonstrated that risk attitudes were context-dependent. However, both lotteries applied were not incentive-compatible. Charness and Viceisza (2011) compared three distinct nonincentivized elicitation methods, the Holt and Laury (2002) lottery tasks, an adaptation of a simple binary method initially proposed by Gneezy and Potters (1997), and a willingnessto-risk scale pioneered by Dohmen et al. (2011) using a sample drawn from the rural population in Senegal. The results indicated that the simple binary method had substantially more predictive power compared to the HLL, which revealed a relatively low level of understanding. The willingness-to-risk question generated results that were unlikely to be accurate according to patterns in other risk attitude elicitation studies. Dave et al. (2010) used two different elicitation methods with different degrees of difficulty and also came to a similar conclusion. They analyzed how and when a simpler but coarser risk attitude elicitation method may be preferred to a more complex but finer one. They found that the more complex method had superior predictive accuracy, but had the disadvantage that participants made inconsistent choices. Andersen et al. (2006) examined the properties of the multiple price list method as well as some variants on the basic design and found that the elicitation of risk attitudes was sensitive to procedures, subject pools, and the format of the multiple price list tables. They recruited a sample from Denmark. MaartNoelck and Musshoff (2013) applied the incentive-compatible HLL and two psychometric methods on a sample of German students and German and Kazakhstani farmers and found that students responded consistently across all three elicitation methods, whereas German farmers, and especially Kazakhstani farmers, were more inconsistent. Thus far, it has not been investigated how risk attitudes assessed by two different risk attitude elicitation methods differing in the variation of probabilities or payoffs based on Holt and Laury 
(2002) and Brick et al. (2012) compare to each other in a within-sample experiment. Therefore, we analyze the consistency of risk measures across the two different elicitation methods which we have used and adapted to individuals in a rural developing setting. We formulate the following hypothesis:

H1 'Modified HLL vs. modified BL': There is a consistency between the risk attitude determined in the modified HLL and the response behavior in the modified BL.

Risk attitudes measured in lottery choice task decisions are usually based on the point at which participants switch from the safe option to the risky one. A common problem with such designs is that when participants fail to understand a task, they tend to switch back and forth between the lottery options as they move down the decision rows. This makes a risk measure based on a switching point from risky to safe lottery option problematic. Multiple switching behaviors have been observed in numerous studies using the HLL, but were especially prevalent in a developing country context. Galarza (2009) observed an inconsistency rate of $52 \%$ in a study conducted with Peruvian cotton farmers. Jacobson and Petrie (2009) found that approximately 55\% of Rwandan participants made at least one inconsistent switch. The experiment was conducted with a random sample of the adult population in Rwanda. Brick et al. (2012) found that about $41 \%$ of the sample of South African fishers showed multiple switching behaviors, and Charness and Viceisza (2011) found that $51 \%$ of the participating farmers in Senegal switched lotteries at least twice. De Brauw and Eozenou (2011) found an inconsistency rate of 14\% among Mozambican farmers, which matched with most case studies of developed countries which had lower inconsistency rates. Holt and Laury (2002) found an inconsistency rate of $13 \%$ for students in the United States, and Dave et al. (2010) found an inconsistency rate of $8.5 \%$ for an adult population in Canada. The relatively large proportion of participants in developing countries that made inconsistent choices in lottery choice task decisions could indicate that the HLL might not be the most appropriate within this setting. Therefore, we analyze the inconsistency rates of the two elicitation methods and evaluate whether the modified BL is better able to reduce inconsistencies in the response behavior compared to the modified HLL following the argumentation of Brick et al. (2012). Our hypothesis is:

$H 2$ 'Inconsistency rates of modified BL vs. modified HLL': The modified BL outperforms the modified HLL in reducing the inconsistency rates in the response behavior.

Individuals' characteristics naturally vary and may also have an impact on the risk attitudes (Doss et al. 2008). In our study, we focus on specific socio-demographic (age, gender, 
education, household size and number of dependents, and district) and socio-economic characteristics (wealth, farm size, access to a savings account, and access to credit) of respondents to examine whether these factors influence their risk attitudes and whether these factors are consistent across the two elicitation methods. In the extant literature, there is no consensus, which socio-demographic and socio-economic characteristics have an influence on risk attitudes. Although some studies find that risk attitudes differ significantly based on specific characteristics, other studies find no significant relationship. Table 1 provides a summary of the variables and their impact on the risk attitude from other studies. Our last hypothesis is as follows:

H3 'Farmer-specific effects for risk attitude': Socio-demographic and socio-economic variables have a significant effect on the risk attitude of farmers.

Table 1 Overview of socio-demographic and socio-economic variables and their impact on risk attitude

\begin{tabular}{|c|c|c|}
\hline \multirow{2}{*}{\multicolumn{2}{|c|}{$\begin{array}{l}\text { Variable } \quad \text { Study } \\
\text { Socio-demographic variables }\end{array}$}} & Impact \\
\hline & & \\
\hline \multirow[t]{2}{*}{ Age } & e.g., Nielsen et al. (2013) & $\begin{array}{l}+ \text { Older individuals are more risk } \\
\text { averse than younger ones }\end{array}$ \\
\hline & e.g., Maart-Noelck and Musshoff (2013) & - No significant effect \\
\hline \multirow[t]{2}{*}{ Gender } & e.g., Croson and Gneezy (2009) & $\begin{array}{l}+ \text { Women are more risk averse than } \\
\text { men }\end{array}$ \\
\hline & e.g., Mosley and Verschoor (2005) & - No significant effect \\
\hline \multirow[t]{2}{*}{ Education } & e.g., Harrison et al. (2007) & $\begin{array}{l}+ \text { Individuals with higher education } \\
\text { are more risk averse than those with } \\
\text { less education }\end{array}$ \\
\hline & e.g., Reynaud and Couture (2012) & - No significant effect \\
\hline \multirow[t]{2}{*}{$\begin{array}{l}\text { Household } \\
\text { size }\end{array}$} & e.g., Miyata (2003) & $\begin{array}{l}+ \text { Individuals with larger households } \\
\text { are more risk averse }\end{array}$ \\
\hline & e.g., Maart-Noelck and Musshoff (2013) & - No significant effect \\
\hline \multirow[t]{2}{*}{$\begin{array}{l}\text { Number of } \\
\text { dependents }\end{array}$} & e.g., Hallahan et al. (2004) & $\begin{array}{l}+ \text { Individuals with a larger number of } \\
\text { dependents are more risk averse }\end{array}$ \\
\hline & e.g., Picazo-Tadeo and Wall (2011) & - No significant effect \\
\hline \multicolumn{3}{|c|}{ Socio-economic variables } \\
\hline \multirow[t]{2}{*}{ Wealth } & e.g., Cohen and Einav (2007) & $\begin{array}{l}+ \text { Wealthier individuals are more risk } \\
\text { averse }\end{array}$ \\
\hline & e.g., Tanaka et al. (2010) & - No significant effect \\
\hline \multirow[t]{2}{*}{ Farm size } & e.g., Wik et al. (2004) & $\begin{array}{l}+ \text { Individuals with more land are } \\
\text { more risk averse }\end{array}$ \\
\hline & e.g., Reynaud and Couture (2012) & - No significant effect \\
\hline $\begin{array}{l}\text { Access to a } \\
\text { savings } \\
\text { account }\end{array}$ & e.g., Jacobson and Petrie (2009) & $\begin{array}{l}+ \text { Individuals with access to a savings } \\
\text { account are less risk averse }\end{array}$ \\
\hline $\begin{array}{l}\text { Access to } \\
\text { credit }\end{array}$ & e.g., Eswaran and Kotwal (1990) & $\begin{array}{l}+ \text { Individuals with access to credit are } \\
\text { less risk averse }\end{array}$ \\
\hline
\end{tabular}

Source: Author's own illustration. 


\section{Experiment design}

This section provides an overview of how the experiment was designed. Both risk attitude elicitation methods were chosen in a randomly determined order. A complete set of instructions for the experiment is included in Appendix 1. The experiment was preceded by a household survey that collected information on household demographics and economic characteristics.

\subsection{The Holt and Laury lottery and its modification}

In the Holt and Laury (2002) experiment, participants had to make 10 choices between two systematically varied options, namely option A (the relatively safer option) or option B (the relatively riskier option). In our design, option A offered the chance to either win UGX 6,000 or UGX 4,800 with a certain probability, while option B offered the chance to win UGX 11,550 or UGX 300 with the same probability (see Table 2). The payoffs in the safer option have a lower range than those in the riskier option. We use the rate of 1:3,000 (which corresponds to the exchange rate) to get the equivalent payoffs in Ugandan shillings compared to the original task. The earnings are held constant across the choice tasks, whereas the probabilities of the earnings vary in intervals of $10 \%$ between the choice tasks. The expected values of the options change as participants move from one to the next choice task. Up to the fourth choice task, the expected value of the safer option A is higher than the expected value of the riskier option B. From the fifth task, the expected value of option B exceeded the expected value of option A.

Participants were asked to make 10 choices of either option A or option B, one for each choice task. The switching point from the safer to the riskier option allowed us to determine their individual risk attitude. A risk seeking participant would switch to option $\mathrm{B}$ in the first three decision rows, while a risk averse participant would switch to option B between the decision rows five to nine. In turn, a risk neutral participant would always decide in favor of the option with the higher expected value. Therefore, the person would switch from choosing option A to option B in row five. A HLL-value (= number of safe choices) between one and three expresses risk preference, a HLL-value of four implies risk neutrality, and a HLL-value between five and 10 expresses risk aversion of the participant. Following Holt and Laury (2002), a power risk utility function with a constant relative risk aversion (CRRA) defined over the lottery prize was used to calculate a range of relative risk aversion compatible with each choice. The risk utility function is of the form $U(x)=$ 
$\left(x^{1-r}\right) /(1-r)$ where $x$ is the lottery prize and $r$ is the latent risk coefficient. Using this utility function, we can calculate the implied bounds of an individual's CRRA coefficient. For instance, a participant who chose option A six times before switching to option B reveals a CRRA coefficient interval between 0.15 and 0.41 . Positive values of the CRRA coefficient denote risk aversion $(r>0)$, a value of zero indicates risk neutralitiy $(r=0)$, and negative values denote risk seeking $(r<0)$.

Table 2 Payoff matrix of the Holt and Laury lottery

\begin{tabular}{|c|c|c|c|c|c|c|}
\hline Task & Option A & Option B & $\mathbf{E} \mathbf{V}^{\mathbf{A}}$ & $\mathbf{E V}^{\mathbf{B}}$ & $\begin{array}{c}\text { CRRA } \\
\text { ranges }^{\text {a }}\end{array}$ & $\begin{array}{c}\text { Risk } \\
\text { aversion } \\
\text { class }^{b}\end{array}$ \\
\hline \multirow[t]{2}{*}{1} & With $10 \%$ prize of 6,000 & With $10 \%$ prize of 11,550 & 4,920 & 1,425 & $\mathrm{r}<-1.71$ & Extremely \\
\hline & With $90 \%$ prize of 4,800 & With $90 \%$ prize of 300 & & & & RL \\
\hline \multirow[t]{2}{*}{2} & With $20 \%$ prize of 6,000 & With $20 \%$ prize of 11,550 & 5,040 & 2,550 & $-1.71<\mathrm{r}$ & Highly \\
\hline & With $80 \%$ prize of 4,800 & With $80 \%$ prize of 300 & & & $<-0.95$ & $\mathrm{RL}$ \\
\hline \multirow[t]{2}{*}{3} & With $30 \%$ prize of 6,000 & With $30 \%$ prize of 11,550 & 5,160 & 3,675 & $-0.95<\mathrm{r}$ & Very \\
\hline & With $70 \%$ prize of 4,800 & With $70 \%$ prize of 300 & & & $<-0.49$ & $\mathrm{RL}$ \\
\hline \multirow[t]{2}{*}{4} & With $40 \%$ prize of 6,000 & With $40 \%$ prize of 11,550 & 5,280 & 4,800 & $-0.49<\mathrm{r}$ & RL \\
\hline & With $60 \%$ prize of 4,800 & With $60 \%$ prize of 300 & & & $<-0.14$ & \\
\hline \multirow[t]{2}{*}{5} & With $50 \%$ prize of 6,000 & With $50 \%$ prize of 11,550 & 5,400 & 5,925 & $-0.14<\mathrm{r}$ & $\mathrm{RN}$ \\
\hline & With $50 \%$ prize of 4,800 & With $50 \%$ prize of 300 & & & $<0.15$ & \\
\hline \multirow[t]{2}{*}{6} & With $60 \%$ prize of 6,000 & With $60 \%$ prize of 11,550 & 5,520 & 7,050 & $0.15<\mathrm{r}$ & Slightly \\
\hline & With $40 \%$ prize of 4,800 & With $40 \%$ prize of 300 & & & $<0.41$ & RA \\
\hline \multirow[t]{2}{*}{7} & With $70 \%$ prize of 6,000 & With $70 \%$ prize of 11,550 & 5,640 & 8,175 & $0.41<\mathrm{r}$ & RA \\
\hline & With $30 \%$ prize of 4,800 & With $30 \%$ prize of 300 & & & $<0.68$ & \\
\hline \multirow[t]{2}{*}{8} & With $80 \%$ prize of 6,000 & With $80 \%$ prize of 11,550 & 5,760 & 9,300 & $0.68<r$ & Very \\
\hline & With $20 \%$ prize of 4,800 & With $20 \%$ prize of 300 & & & $<0.97$ & $\mathrm{RA}$ \\
\hline \multirow[t]{2}{*}{9} & With $90 \%$ prize of 6,000 & With $90 \%$ prize of 11,550 & 5,880 & 10,425 & $0.97<\mathrm{r}$ & Highly \\
\hline & With $10 \%$ prize of 4,800 & With $10 \%$ prize of 300 & & & $<1.37$ & RA \\
\hline \multirow[t]{2}{*}{10} & With $100 \%$ prize of 6,000 & With $100 \%$ prize of 11,550 & 6,000 & 11,550 & $1.37<\mathrm{r}$ & Extremely \\
\hline & With $0 \%$ prize of 4,800 & With $0 \%$ prize of 300 & & & & RA \\
\hline
\end{tabular}

Source: Author's own illustration according to Holt and Laury (2002).

Notes: Prizes are displayed in Ugandan shillings (UGX). At the time of the experiments, the exchange rate was approximately $€ 1$ to UGX 3,000, so prizes range from approximately $€ 0.1$ to $€ 3.85$. The fourth and fifth columns show the expected values (EV) of the respective option.

${ }^{a}$ Constant relative risk aversion coefficient assuming a power risk utility function.

${ }^{\mathrm{b}} \mathrm{RL}, \mathrm{RN}$, and RA respectively for risk lover, neutral, and averse.

Pretests have shown that to conduct a standard HLL with individuals in a rural developing setting like Uganda would not have been feasible. Therefore, we incorporated a modification in order to develop an easy to apply and effective method to elicit the risk attitude. The standard HLL is modified in this experimental design by replacing probabilities expressed in percent with images of bags of colored balls (green, blue, red, and yellow) representing probabilities of different payoffs (UGX 300,UGX 4,800, UGX 6,000, and UGX 11,550). Each ball measures a 10\% probability and each bag includes 10 balls. The different payoffs are represented in a different color. Apart from using images of bags and balls, the lottery-choice experiment was absolutely identical to 
the standard HLL, i.e. the same number of tasks and the implied CRRA ranges. The choice tasks were presented all at once to the participants. Figure 1 shows the 10 choice tasks the participants faced in this lottery.
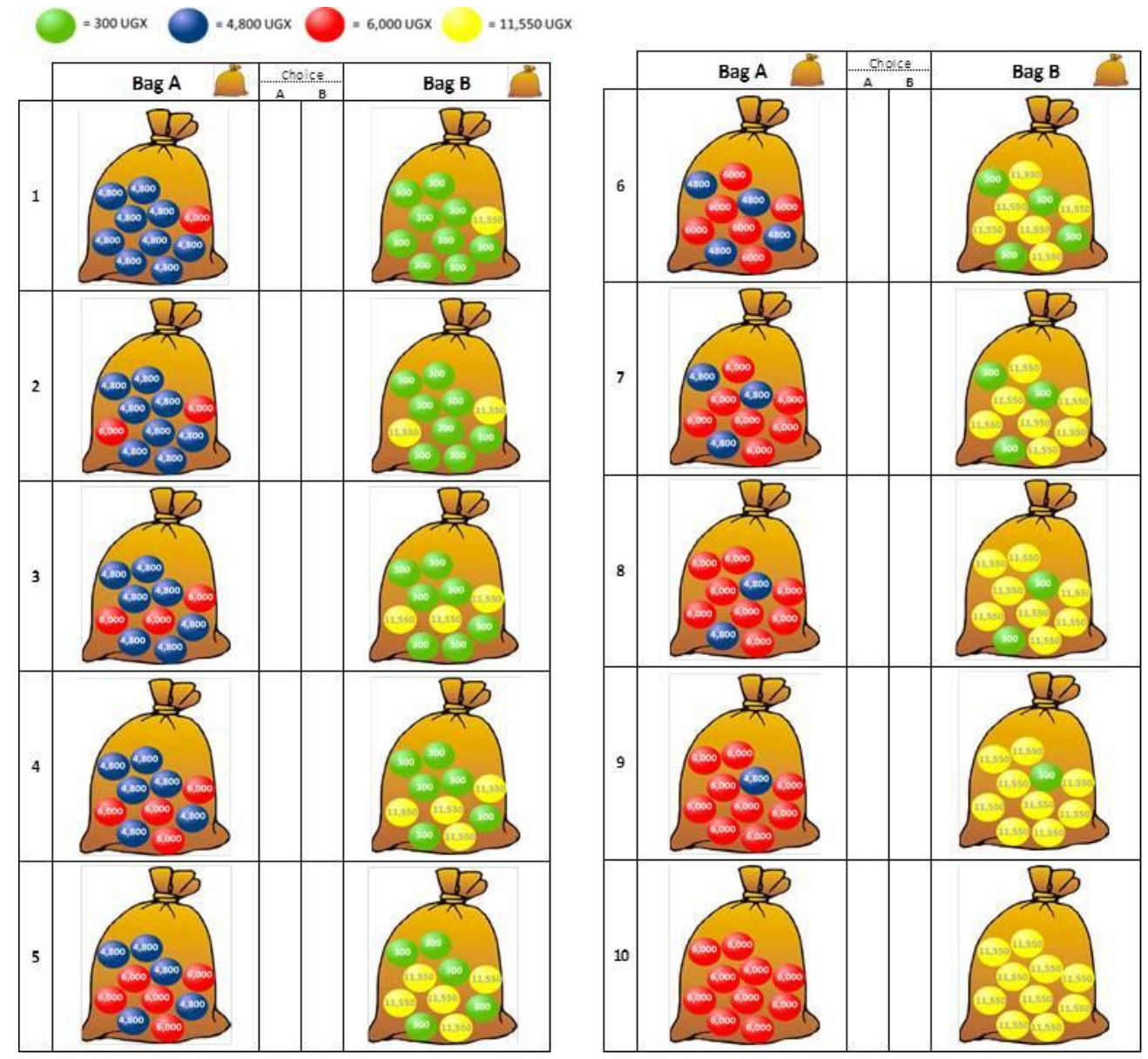

Source: Author's own illustration.

Fig. 4 Graphical display of the modified Holt and Laury lottery (in Ugandan shillings)

\subsection{The Brick lottery and its modification}

The experimental design used in Brick et al. (2012) is similar to that of Holt and Laury (2002), but with one main difference. Instead of keeping payoffs constant and varying the probabilities of receiving the high and low outcomes, the probabilities are constant and the payoffs are varied. We use the rate of 1:500 to get the equivalent payoffs in Ugandan shillings compared to the original task and to adjust to the payoffs of the HLL. For each choice task, participants were asked to choose between option A and option B. Fixed probabilities of $100 \%$ and $50 \%$ were used in the experiment. In the first task, for example, option A offered a $100 \%$ chance to win UGX 10,000, while option B offered a $50 \%$ chance to either win UGX 10,000 or UGX 0 (see Table 3). The payoff associated with option A declines systematically throughout the eight tasks from UGX 10,000 to UGX 1,000, while 
the payoff for option B remains unchanged and is fixed at UGX 10,000 and UGX 0. A highly risk seeking participant would choose option B in the first choice task, while a highly risk averse participant would choose option A in the eighth choice task. A risk neutral participant would switch from choosing option A to option B after row three.

Table 3 Payoff matrix of the Brick lottery

\begin{tabular}{|c|c|c|c|c|c|c|}
\hline $\begin{array}{c}\text { Tas } \\
\mathbf{k}\end{array}$ & Option A & Option B & $\mathbf{E V}^{\mathrm{A}}$ & $\mathbf{E} \mathbf{V}^{\mathbf{B}}$ & $\begin{array}{l}\text { CRRA } \\
\text { ranges }^{a}\end{array}$ & $\begin{array}{c}\text { Risk } \\
\text { aversion } \\
\text { class }^{\mathrm{b}}\end{array}$ \\
\hline 1 & With $100 \%$ prize of 10,000 & $\begin{array}{l}\text { With } 50 \% \text { prize of } 10,000 \\
\text { With } 50 \% \text { prize of } 0\end{array}$ & 10,000 & 5,000 & $\mathrm{r}<-1.41$ & $\begin{array}{l}\text { Highly } \\
\text { RL }\end{array}$ \\
\hline 2 & With $100 \%$ prize of 7,500 & $\begin{array}{l}\text { With } 50 \% \text { prize of } 10,000 \\
\text { With } 50 \% \text { prize of } 0\end{array}$ & 7,500 & 5,000 & $\begin{array}{l}-1.41<\mathrm{r} \\
<-0.36\end{array}$ & $\begin{array}{l}\text { Very } \\
\text { RL }\end{array}$ \\
\hline 3 & With $100 \%$ prize of 6,000 & $\begin{array}{l}\text { With } 50 \% \text { prize of } 10,000 \\
\text { With } 50 \% \text { prize of } 0\end{array}$ & 6,000 & 5,000 & $\begin{array}{l}-0.36<\mathrm{r} \\
<0\end{array}$ & RL \\
\hline 4 & With $100 \%$ prize of 5,000 & $\begin{array}{l}\text { With } 50 \% \text { prize of } 10,000 \\
\text { With } 50 \% \text { prize of } 0\end{array}$ & 5,000 & 5,000 & $\begin{array}{l}0<\mathrm{r} \\
<0.24\end{array}$ & $\mathrm{RN}$ \\
\hline 5 & With $100 \%$ prize of 4,000 & $\begin{array}{l}\text { With } 50 \% \text { prize of } 10,000 \\
\text { With } 50 \% \text { prize of } 0\end{array}$ & 4,000 & 5,000 & $\begin{array}{l}0.24<\mathrm{r} \\
<0.42\end{array}$ & $\begin{array}{l}\text { Slightly } \\
\text { RA }\end{array}$ \\
\hline 6 & With $100 \%$ prize of 3,000 & $\begin{array}{l}\text { With } 50 \% \text { prize of } 10,000 \\
\text { With } 50 \% \text { prize of } 0\end{array}$ & 3,000 & 5,000 & $\begin{array}{l}0.42<\mathrm{r} \\
<0.57\end{array}$ & RA \\
\hline 7 & With $100 \%$ prize of 2,000 & $\begin{array}{l}\text { With } 50 \% \text { prize of } 10,000 \\
\text { With } 50 \% \text { prize of } 0\end{array}$ & 2,000 & 5,000 & $\begin{array}{l}0.57<\mathrm{r} \\
<0.70\end{array}$ & $\begin{array}{l}\text { Very } \\
\text { RA }\end{array}$ \\
\hline 8 & With $100 \%$ prize of 1,000 & $\begin{array}{l}\text { With } 50 \% \text { prize of } 10,000 \\
\text { With } 50 \% \text { prize of } 0\end{array}$ & 1,000 & 5,000 & $\mathrm{r}<0.70$ & $\begin{array}{l}\text { Highly } \\
\text { RA }\end{array}$ \\
\hline
\end{tabular}

Source: Author's own illustration according to Brick et al. (2012).

Notes: Prizes are displayed in Ugandan shillings (UGX). At the time of the experiments, the exchange rate was approximately $€ 1$ to UGX 3,000 , so prizes range from approximately $€ 0.33$ to $€ 3.33$. The fourth and fifth columns show the expected vales (EV) of the respective option.

${ }^{a}$ Constant relative risk aversion coefficient assuming a power risk utility function.

${ }^{\mathrm{b}} \mathrm{RL}, \mathrm{RN}$, and RA respectively for risk lover, neutral, and averse.

In our version of the lottery, we use images of bags of colored balls (red, blue, and green) representing probabilities of different payoffs (UGX 0, UGX 10,000, and between UGX 10,000 and UGX 1,000). Each ball measures a $100 \%$ or a $50 \%$ probability and each bag includes one or two balls. The different payoffs are represented in a different color, except for the varying value of the green ball. Apart from using images of bags and balls, the lottery-choice experiment was absolutely identical to the standard BL, i.e. the same number of tasks and the implied CRRA ranges. The choice tasks were presented all at once to the participants. Figure 2 shows the eight choice tasks presented to participants. 

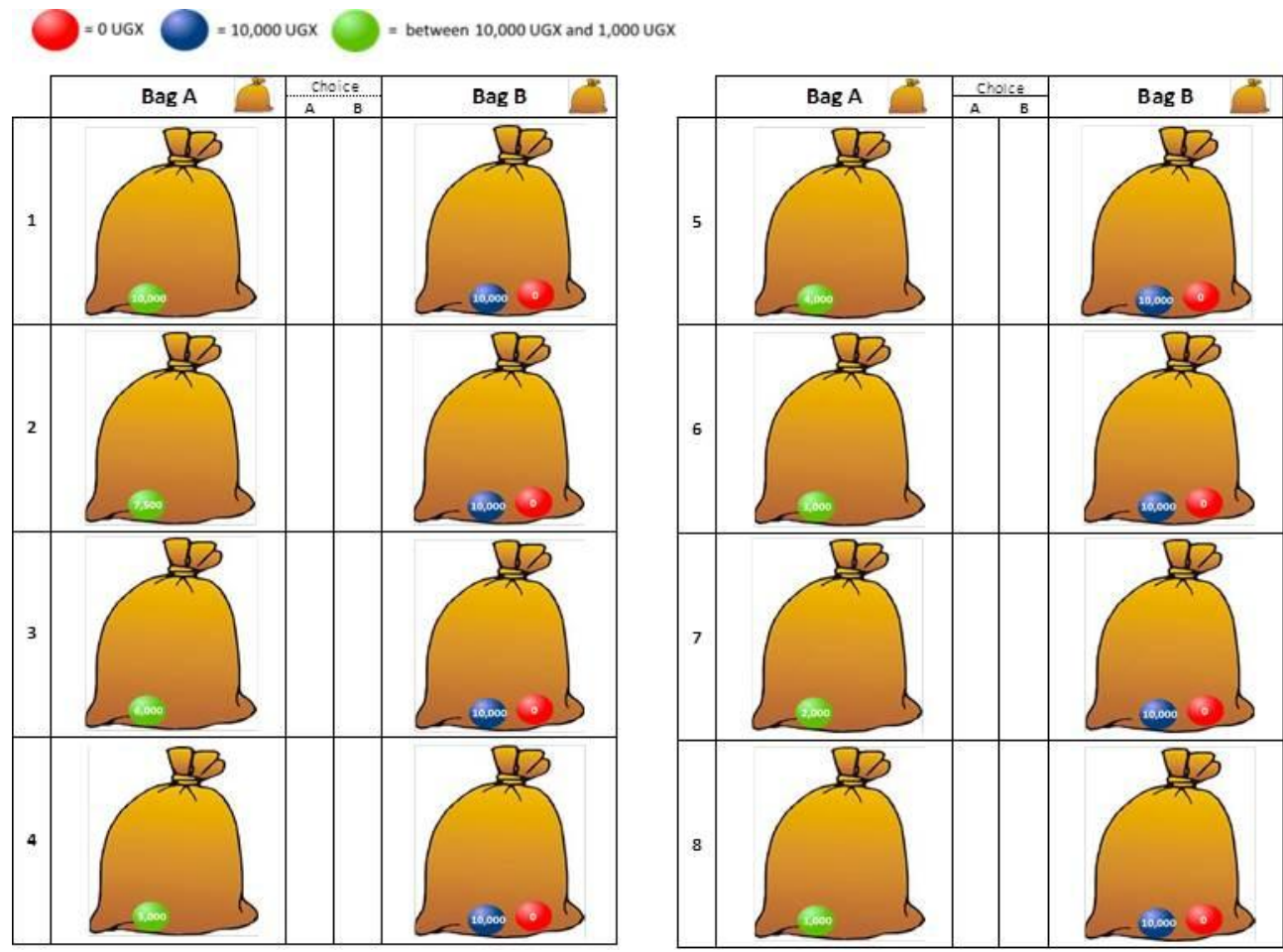

Source: Author's own illustration.

Fig. 2 Graphical display of the modified Brick lottery (in Ugandan shillings)

\subsection{Household survey}

In addition to the lottery-choice experiments, participants attended a household survey during which they completed a comprehensive questionnaire capturing information on the household demographic composition and economic activities. The main variables collected through the survey were age, gender, education, household size, number of dependents, district, per capita household expenditure as a proxy variable for wealth, total land owned, access to savings account, and access to credit.

A participant's ability to reason with numbers and probabilities may affect the understanding and choice among risky lotteries, and hence, the opportunity to obtain an accurate measurement of risk attitudes (Dave et al. 2010). Therefore, we included three additional tasks, adapted from Viceisza (2011) and Charness and Viceisza (2011), to assess farmers' ability to process percentage and probabilistic information and to explore the relationship between their decision behavior and the test score in the quiz: (i) 'Imagine, we toss a coin and 'heads' comes up. What comes up if we toss the coin again?' Participants were faced with three possible answers: heads, tails, one cannot predict exactly. (ii) 'If the chance of winning a prize is $10 \%$, how many people out of 100 would be expected to get the prize?' Participants had to name the appropriate value. (iii) 'When you draw the red 
ball, you win! Look at the two boxes and mark the correct sentence.' One box contains two red and two blue balls, while the other box contains four red and four blue balls. Participants have to decide whether the chance of winning is higher if they choose the first box, the second box, or the chance of winning is equal regardless of which box they choose.

\section{Data collection}

\subsection{Sampling procedure}

Data used in this study was obtained from experiments and a household survey of 332 smallholder farmers randomly selected from two districts of Masaka and Luwero in Uganda from July to August 2012. These two districts, located in the Central Region, have been broadly classified as having similar agro-climatic conditions and farming systems. For the selection of smallholder farmers to be interviewed, we used a multi-stage sampling procedure. At first, we randomly selected parishes and villages. Within each selected village, smallholder farmers were then randomly selected using updated, village-level household lists. The farmers were then recruited via the local extension service to participate in a household survey and an experiment. The invitation to attend our experiment was provided orally by the recruiters and contained the date, time, and place of the study, a brief and general purpose of the study, and the type of compensation that could be expected. None of the farmers refused to participate in the household survey and the experiment, which means that our sample does not have a selection bias. The household survey took place one day prior to the actual experiments. Our participants were either the household head or the spouse because they are those most likely to be faced with risky choices and important economic decisions.

\subsection{Experiment implementation}

The 332 smallholder farmers were allocated randomly to groups for the experimental sessions. In total, we conducted 56 sessions during the course of 30 days. Two sessions were held each day and each session involved a group of six farmers. ${ }^{2}$ All participants played both lottery-choice experiments and the order in which they were faced with the two experiments was randomly determined. In the experiment, choices made by

\footnotetext{
${ }^{2}$ However, four farmers were excluded from the analysis. One farmer left before completing all tasks, and three farmers participated in the household survey but were not able to undertake (or arrived too late to participate) the experiment.
} 
participants were not time constrained. On average, the complete session lasted between 60 and 90 minutes. The experimental sessions were held in several villages and conducted in classrooms of local schools or in a meeting room at the main gathering place of a farmers' group or association. All of the sessions were held in locations which were familiar to the farmers and usually within walking distance or accessible by bicycle. The rooms were equipped with tables and chairs and were spaced out to prevent conferring among the participants. A team of seven local enumerators that were carefully selected conducted all of the experimental sessions. One of the enumerators served as the experimenter, and the author served as the assistant experimenter. The other enumerators were placed next to the participants to record their choices in case participants were illiterate. Each participant had their own enumerator. All sessions were conducted in Luganda, one of the main indigenous Bantu languages in south central Uganda. Prior to the first session, the enumerators were trained on the experiment protocol and how to carefully avoid giving specific instructions about how to answer.

Each experiment session consisted of registration, instruction, practice, decision making, and payment. In the beginning of the experiment, each participant received a personal number, which randomly determined his/her seat that remained to be the individual's location throughout the session. The experiment instructions were read aloud to all participants as a group by the experimenter and supported by posters of graphical examples displayed on a large board at the front of the room to improve the understanding. During the presentation of the instructions, participants were encouraged to ask questions about any unclear issues. To further facilitate comprehension, we used real bags of colored balls representing probabilities of the different payoffs. Each choice task in the experiment was conducted in the following way: The assistant experimenter placed the appropriate balls in the bags, while the experimenter explained the values attached to each ball. The participants then considered their decision and made their choice by pointing to the preferred bag on the sheet in front of them, and their enumerator recorded the choice. Participants were informed about all parameters and assumptions underlying the experiment, and they had to answer some control questions to ensure that they entirely understood the instructions. Our overall impression was that our version of the instructions was well understood by the participants because of the various interview techniques applied, such as visual, oral, and written explanations, as well as the practical implementation with real bags and colored balls. Further support of respondents' 
comprehension of the instructions is seen, for example, in the unproblematic answering of the control questions during the experiment.

\subsection{Incentive design}

The decisions in the lottery-choice experiments were related to real earnings to ensure incentive compatibility of the experiment and to motivate participants to take the tasks more seriously. Participants were informed at the beginning of the experiment that when they have completed all decision tasks in the respective lottery, one task would be selected at random and played out for real money. This random lottery incentive system is commonly used in lottery-choice risk experiments (Humphrey and Verschoor 2004). Nevertheless, there is an ongoing controversial debate on the use of monetary incentives as rewards for participants in experiments and the practice of paying only some participants for only some of their decisions. Camerer and Hogarth (1999) found that using high financial incentives for a fraction of participants rather than providing small incentives for each of the participants often improves participants' performance during the experiment. We chose one participant at random for payment for each lottery-choice experiment of our payment design; hence we had two winners per session. The earning of the participant was based on his/her preference expressed between various mutually exclusive options in the two lotteries. Each decision task had exactly the same probability to be drawn. The potential earning varied between UGX 300 and UGX 11,550 for the modified HLL and between UGX 0 and UGX 10,000 for the modified BL. The average payoffs of the two lotteries were UGX 6,674 (approximately $€ 2.2$ ) and UGX 5,687 (approximately $€ 1.9$ ). Furthermore, all participants received a show-up fee of UGX 5,000 as a compensation for their time. This compares to one day of casual farm labor wage in this area. Participants were paid in cash by the assistant experimenter at the end of the experiment.

\section{Experimental results}

\subsection{Descriptive statistics}

Table 4 below presents descriptive statistics on socio-demographic and socio-economic characteristics of participants in the experiment. On average, participants were aged 50.21 years. Of all participants, 39\% were female. The education level of the household head was on average 6.67 years of schooling. The average household size and dependency ratio were 6.56 and 1.51, respectively. Of all participants, 57\% were from Masaka district, while $43 \%$ of them were from Luwero district. In order to assess whether farmers have a basic 
comprehension of probabilities, we conducted a short quiz composed of three simple questions before the experimental session started. On average, each farmer answered two out of the three questions correctly. The average annual per capita household expenditure was approximately UGX 516,855. The mean farm size for each farmer was about 5.73 acres. Of all participants, $28 \%$ indicated to have access to a savings account, while $43 \%$ claimed to be able to access financial credit for agricultural activities whenever they need it.

Table 4 Descriptive statistics of respondent characteristics $(\mathrm{N}=332)$

\begin{tabular}{|c|c|c|c|}
\hline Variable name & Variable definition & Mean & Std. dev. \\
\hline \multicolumn{4}{|c|}{ Socio-demographic characteristics } \\
\hline Age & Age in years & 50.21 & 14.28 \\
\hline Gender & Dummy $=1$ if female, 0 otherwise & 0.39 & - \\
\hline Education & Years of formal schooling & 6.67 & 3.60 \\
\hline Household size & Number of household members & 6.56 & 3.10 \\
\hline Dependency ratio & $\begin{array}{l}\text { Ratio of dependent (less than } 15 \\
\text { years of age or greater than } 64 \text { ) to } \\
\text { nondependent household members }\end{array}$ & 1.51 & 1.18 \\
\hline District & $\begin{array}{l}\text { Dummy }=1 \text { if from Masaka, } 0= \\
\text { Luwero }\end{array}$ & 0.57 & - \\
\hline Probability test score & $\begin{array}{l}\text { number of probability questions } \\
\text { correctly answered }\end{array}$ & 2.05 & 0.78 \\
\hline \multicolumn{4}{|c|}{ Socio-economic characteristics } \\
\hline Household expenditure & $\begin{array}{l}\text { Annual per capita household } \\
\text { expenditure in } \mathrm{UGX}^{\mathrm{a}}\end{array}$ & 516.855 & 392.949 \\
\hline Total land owned & Total land owned in acres ${ }^{b}$ & 5.73 & 4.53 \\
\hline Access to a savings account & $\begin{array}{l}\text { Dummy }=1 \text { if access to a savings } \\
\text { account, } 0 \text { otherwise }\end{array}$ & 0.28 & - \\
\hline Access to credit & $\begin{array}{l}\text { Dummy = } 1 \text { if access to credit, } 0 \\
\text { otherwise }\end{array}$ & 0.43 & - \\
\hline
\end{tabular}

Source: Survey data.

${ }^{\text {a }}$ At the time of the experiments, the exchange rate was approximately $€ 1$ to UGX 3,000.

${ }^{\mathrm{b}} 1$ acre $=0.40$ hectare.

Figure 3 presents the distribution of safe choices before switching to the risky lottery option by elicitation method. ${ }^{3}$ The individual risk attitudes vary between risk seeking and strong risk aversion. The histogram of the modified HLL shows a high peak at 5 (the average value in the range), while there is a high peak at 4 (the average value in the range) and a very high peak at 8 in the histogram of the modified BL. The latter one may be explained by the fact that in lottery option B participants had a $50 \%$ chance of receiving nothing, and thus rather chose the safer option A eight times.

\footnotetext{
${ }^{3}$ For the participants who showed an inconsistent behavior (i.e. participants who switched at least twice), we assumed the HLL-value at which the participant switched for the first time.
} 

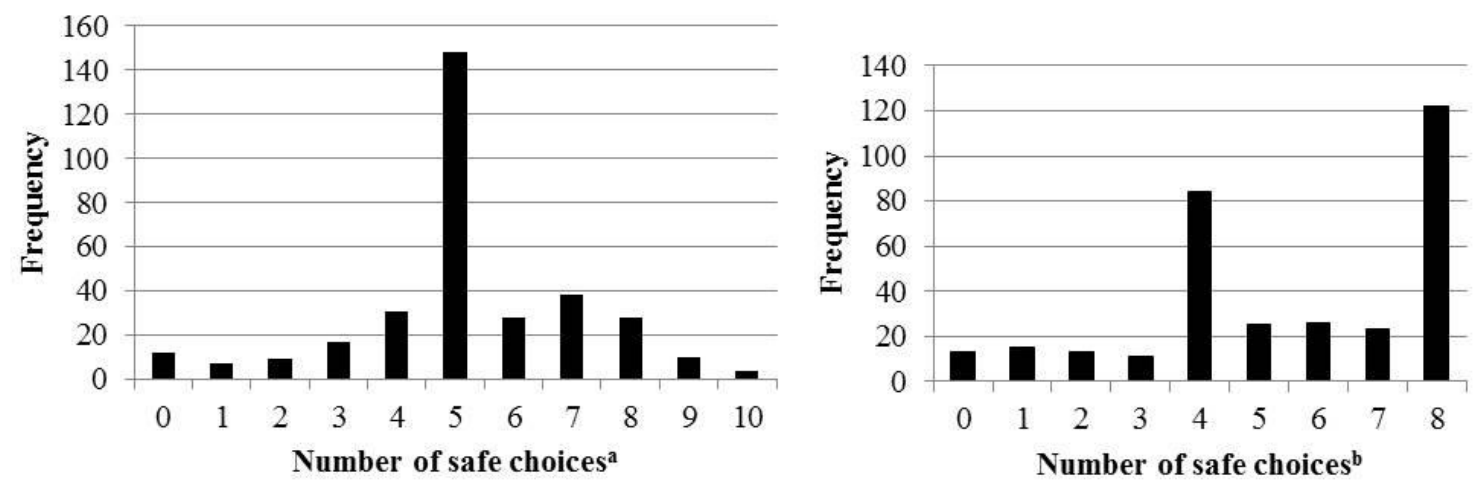

Source: Survey data.

${ }^{\text {a }}$ Number of safe choices in the HLL: range of 0-3 = risk seeking (CRRA range: -1.71 to -0.14 ), $4=$ risk neutral (CRRA range: -0.14 to 0.15 ), range of $5-10=$ risk averse (CRRA range: 0.15 to 1.37 ).

${ }^{\mathrm{b}}$ Number of safe choices in the BL: range of $0-3=$ risk seeking (CRRA range: -1.41 to 0 ), $4=$ risk neutral (CRRA range: 0 to 0.24 ), range of 5-8 = risk averse (CRRA range: 0.24 to 0.70 ).

Fig. 3 Distribution of safe choices in the modified HLL (left figure: $\mathrm{N}=332$ ) and modified BL (right figure: $\mathrm{N}=332$ )

\subsection{Validity test of hypotheses}

\section{Test of H1 'Modified HLL vs. modified BL'}

Table 5 presents the summary statistics of the two risk attitude elicitation methods. The two lotteries reveal that there are slightly more risk-seeking (15.66\%) (52), more risk neutral (25.30\%) (84), and less risk averse (59.04\%) (196) participants in the modified BL than compared to the modified HLL with $13.55 \%$ (45) risk seeking, 9.34\% (31) risk neutral, and $77.11 \%$ (256) risk averse participants. The results of the chi-square tests show that there is a significant difference in the proportions of the categories of risk neutral $(\mathrm{p}<$ $0.01)$ and risk averse participants $(\mathrm{p}<0.01)$ in the two elicitation methods, while there is no significant difference in the category of risk seeking participants. Due to the non-normal distribution of the number of safe choices, it is more appropriate to use the Wilcoxon ranksum test to examine whether there is a statistically difference between the two elicitation methods. ${ }^{4}$ The results reveal that there is a statistically significant difference $(p<0.10){ }^{5}$ An additional analysis, which excludes participants who showed an inconsistent response

\footnotetext{
${ }^{4}$ In order to test whether the distribution of the safe choices are normally distributed and to check robustness, we conduct three different tests, namely the Shapiro Francia, the Shapiro Wilk, and the Skewness Kurtosis. All three tests show that the distribution of safe choices in the modified HLL and the modified BL are nonnormally distributed $(\mathrm{p}<0.05)$. This finding compels us to use non-parametric test statistics to compare whether the two distributions are significantly different from each other (Gardner 1975).

${ }^{5}$ For making possible the comparison between the two risk attitude elicitation methods, given the differences in the number of tasks in each method and the implied CRRA ranges, the number of safe choices are converted into percentages of safe choices.
} 
behavior (e.g., a multiple switching behavior), generates similar results. Here, we excluded 19 participants of the modified HLL and 25 participants of the modified BL. Thus, we reject $H 1$ 'Modified $H L L$ vs. modified $B L$ '. Essentially, this means that risk attitude measures are affected by the type of method used. Although we found inconsistencies in the individual risk attitude across the two elicitation methods, the tendency of participants being risk averse is the same, which corroborates empirical findings of other studies conducted in developing countries (e.g., Jacobson and Petrie 2009; Yesuf and Bluffstone 2009; Harrison et al. 2010).

Table 5 Summary statistics of the two risk attitude elicitation methods

\begin{tabular}{lllll}
\hline & Risk category & \multicolumn{1}{c}{ Modified HLL } & \multicolumn{1}{c}{ Modified BL } & $\begin{array}{c}\text { Test of } \\
\text { significance }\end{array}$ \\
\hline $\begin{array}{l}\text { Risk category } \\
(\%)\end{array}$ & Risk seeking & $13.55(0.02)$ & $15.66(0.02)$ & $\chi^{2}=0.59$ \\
& Risk neutral & $9.34(0.02)$ & $25.30(0.02)$ & $\chi^{2}=29.9^{* * *}$ \\
& Risk averse & $77.11(0.02)$ & $59.04(0.03)$ & $\chi^{2}=24.9^{* * *}$ \\
\hline \multirow{2}{*}{$\begin{array}{l}\text { Distribution } \\
\text { of safe choices }\end{array}$} & Mean & 52.04 & 68.83 & \\
$(\%)$ & Std. dev. & 19.58 & 30.27 & $\mathrm{z}^{\mathrm{b}}=-1.75^{*}$ \\
& Median & 50 & 75 & \\
& Skewness & -0.37 & -0.55 & \\
\hline
\end{tabular}

Source: Survey data.

Notes: $\mathrm{N}=332$. Standard errors are indicated in parentheses. $* \mathrm{p}<0.10, * * \mathrm{p}<0.05, * * * \mathrm{p}<0.01$.

${ }^{a}$ Due to the difference in scale value, the number of safe choices in the modified HLL (range of 0-10) and the modified BL (range of 0-8) are converted into percentages of safe choices for comparison.

${ }^{\mathrm{b}}$ Based on the Wilcoxon rank-sum (Mann-Whitney) test.

\section{Test of $\mathrm{H} 2$ 'Inconsistency rates of modified $B L$ vs. modified $H L L$ '}

To analyze whether the modified BL is better able to reduce inconsistency rates in the response behavior compared to the modified HLL, individuals are classified into four groups as shown in Table 6. With respect to the modified HLL, the first group encompasses participants who first choose option A and at some point switch to option B. The second group comprises participants who always choose option B. We assume that participants in these two groups understood the lottery and therefore consider them as to be consistent. The third group comprises participants who always choose option A. This group is considered as to be inconsistent as we think that participants did not completely understand the lottery, since they should have switched to option B at the latest in decision task 10. In the fourth group there are participants who switch at least twice. With respect to the modified BL, the first group also encompasses participants who first choose option A and at some point switch to option B. The second group comprises participants who always choose option A and the third group comprises participants who always choose option B. 
Although the third group is consistent in their response behavior, we think that participants did not completely understand the lottery, since they should have chosen option A at least in the first decision task, which offered a $100 \%$ chance to win UGX 10,000. Hence, this group is considered as being inconsistent. The last group comprises participants who switch at least twice. Also in the modified BL, the first two groups are classified as to be consistent, while the last two groups are classified as to be inconsistent in our analysis.

Table 6 Classification of groups by consistency and inconsistency rate $(\mathrm{N}=332)$

\begin{tabular}{lclc}
\hline & Group & \multicolumn{1}{c}{ Description } & Modified HLL \\
\hline \multirow{2}{*}{ Consistent } & 1 & Switch once & 303 \\
& 2 & Always choose option B & 10 \\
\multirow{2}{*}{ Inconsistent } & 3 & Always choose option A & 4 \\
& 4 & Switch at least twice & 15 \\
\hline \multirow{2}{*}{ Consistent } & Group & \multicolumn{1}{c}{ Description } & Modified BL \\
& 1 & Switch once & 185 \\
\multirow{2}{*}{ Inconsistent } & 2 & Always choose option A & 122 \\
& 3 & Always choose option B & 10 \\
\hline
\end{tabular}

Source: Survey data.

According to this classification scheme, 313 of 332 participants $(94.3 \%)$ appear to have understood the modified HLL. Another 4 participants (1.2\%) always chose option A, and 15 participants (4.5\%) switched at least twice. In the modified BL, 307 of 332 participants (92.5\%) appear to have understood the lottery. Another 10 participants (3.0\%) always chose option B, and 15 participants $(4.5 \%)$ switched at least twice. In both risk attitude elicitation methods, the inconsistency rates of 5.7\% in the modified HLL and $7.5 \%$ in the modified BL are relatively low compared to other studies in this field (Galarza 2009; Jacobson and Petrie 2009; Brick et al. 2012; Charness and Viceisza 2011). The relatively low rates of inconsistency may be an indication that our design of the modified HLL and the modified BL was well understood by the participants in Uganda. The inconsistency rates are even slightly lower in the modified HLL compared to the modified BL. Against the assumption of Brick et al. (2012) that people have more difficulties with varying probabilities than with varying amounts of payoffs, we do not find any evidence in our results given the relatively low rates of inconsistency in both methods. On this basis, we reject $H 2$ 'Inconsistency rates of modified BL vs. modified HLL'. 


\section{Test of H3 'Farmer-specific effects for risk attitude'}

The interval and ordered probit regression models are used to analyze how sociodemographic and socio-economic factors affect risk attitudes. The interval regression model uses the midpoint CRRA coefficients of the modified HLL and the modified BL as the dependent variable, while the ordered probit regression model uses the number of times a participant chose the safe option in the respective lottery as the dependent variable. We use two regression models as a robustness check of the regression results of each of the two models. Table 7 presents the results of two interval and two ordered probit regression models.

First, the results show that the effects of socio-demographic and socio-economic factors on risk attitudes are the same across the two regression models, confirming robustness of our results. For example, education, district, quiz test score, and winner modified BL all significantly have an effect on risk attitudes in the interval and ordered probit models. Second, all statistically significant explanatory variables (except for quiz test scores in the interval regression) of risk attitude vary across the two elicitation methods. For example, education has a statistically significant negative effect on risk aversion in the modified BL but shows no significant effect in the modified HLL. Third, the results offer insights into characteristics significant in increasing or decreasing risk aversion as well as their relative impact. The coefficients of district indicate that participants from the Masaka district are substantially less risk averse in the modified HLL than compared to participants from the Luwero district. Participants who correctly answered more questions in the quiz are significantly more risk averse in both elicitation methods in the interval regression. Annual per capita household expenditure has a positive impact on risk aversion for both elicitation methods. Age, gender, household size, dependency ratio, total land owned, access to a savings account, and access to credit show no significant effects.

The extant literature offers conflicting evidence on how individual characteristics influence risk attitude. For example, we found that risk aversion decreases with education, which is contradictory to other studies (e.g., Harrison et al. 2007), although deviating from other studies, which did not find a significant impact (e.g., Reynaud and Couture 2012). Previous studies found a positive relationship between risk aversion and wealth (e.g., Cohen and Einav 2007), whereas others do not find a relationship (e.g., Tanaka et al. 2010). We found that a proxy for wealth such as the annual per capita household expenditure is positively associated with risk aversion. Moreover, some of the socio-demographic (age, gender, 
household size, and dependency ratio) and socio-economic characteristics (total land owned, access to a savings account, and access to credit) are not significant, which is interesting because many studies found an effect (Eswaran and Kotwal 1990; Miyata 2003; Hallahan et al. 2004; Wik et al. 2004; Croson and Gneezy 2009; Jacobson and Petrie 2009; Nielsen et al. 2013). Although we found a significant effect of several socio-demographic and socio-economic factors on risk attitude, these factors are not consistent across the two elicitation methods. On this basis, we fail to reject $H 3$ 'Farmer-specific effects for risk attitude'.

Besides testing the effects of socio-demographic and socio-economic characteristics on individuals' risk attitudes, we test for a potential 'order effect' in the experiment to check whether farmers show different decision behavior when they are faced with the two lottery-choice experiments in a different order. Some participants were at first faced with the modified HLL and then with the modified BL or vice versa. According to Harrison et al. (2005b) prior experience with one task may influence participants' behavior in a subsequent task. However, it may also indicate a 'learning effect', meaning that participants acquire routines in one task and apply them to later decisions even if they are related to another task (Scheufele and Bennett 2013). We also included a binary indicator for winning in the first lottery-choice experiment in order to test whether there is an impact on the second lottery-choice experiment. Order in the experiment is not statistically significant in the regression models. However, a participant who first played the modified BL and won is more risk averse in the subsequent modified HLL. This indicates that conducting various successive experiments should be done with caution as prior experience with one task affects behavior in a subsequent task, which was also found by Harrison et al. (2005b). 
Table 7 Results of the interval and ordered probit regression with the individual risk attitude as the dependent variable $(\mathrm{N}=332)$

\begin{tabular}{|c|c|c|c|c|}
\hline \multirow{2}{*}{ Variable } & \multicolumn{2}{|c|}{ Interval regression } & \multicolumn{2}{|c|}{ Ordered probit regression } \\
\hline & Modified HLL & Modified BL & Modified HLL & Modified BL \\
\hline Age (years) & $\begin{array}{c}0.003 \\
(0.003)\end{array}$ & $\begin{array}{c}0.001 \\
(0.005)\end{array}$ & $\begin{array}{c}0.004 \\
(0.004)\end{array}$ & $\begin{array}{l}-0.001 \\
(0.004)\end{array}$ \\
\hline Gender $(1=$ female $)$ & $\begin{array}{c}0.009 \\
(0.078)\end{array}$ & $\begin{array}{c}0.014 \\
(0.143)\end{array}$ & $\begin{array}{l}-0.008 \\
(0.124)\end{array}$ & $\begin{array}{l}0.030 \\
(0.128)\end{array}$ \\
\hline Education (years) & $\begin{array}{c}0.008 \\
(0.012)\end{array}$ & $\begin{array}{c}-0.045^{* *} \\
(0.023)\end{array}$ & $\begin{array}{c}0.002 \\
(0.020)\end{array}$ & $\begin{array}{c}-0.042 * * \\
(0.020)\end{array}$ \\
\hline Household size (number) & $\begin{array}{l}-0.001 \\
(0.013)\end{array}$ & $\begin{array}{l}-0.021 \\
(0.024)\end{array}$ & $\begin{array}{l}-0.005 \\
(0.020)\end{array}$ & $\begin{array}{l}-0.011 \\
(0.021)\end{array}$ \\
\hline Dependency ratio ${ }^{a}$ & $\begin{array}{l}-0.008 \\
(0.034)\end{array}$ & $\begin{array}{l}-0.069 \\
(0.062)\end{array}$ & $\begin{array}{c}0.019 \\
(0.054)\end{array}$ & $\begin{array}{l}-0.065 \\
(0.056)\end{array}$ \\
\hline District $(1=$ Masaka $)$ & $\begin{array}{c}-0.220 * * * \\
(0.078)\end{array}$ & $\begin{array}{c}0.027 \\
(0.144)\end{array}$ & $\begin{array}{c}-0.388 * * * \\
(0.126)\end{array}$ & $\begin{array}{c}0.056 \\
(0.128)\end{array}$ \\
\hline Quiz test score (number) & $\begin{array}{c}0.111 * * \\
(0.049)\end{array}$ & $\begin{array}{c}0.200 * * \\
(0.092)\end{array}$ & $\begin{array}{c}0.159 * * \\
(0.078)\end{array}$ & $\begin{array}{l}0.130 \\
(0.081)\end{array}$ \\
\hline $\begin{array}{l}\text { Annual per capita household } \\
\text { expenditure }(U G X)^{\mathrm{b}}\end{array}$ & $\begin{array}{l}7.64 \mathrm{e}-08 \\
(1.02 \mathrm{e}-07)\end{array}$ & $\begin{array}{l}4.35 \mathrm{e}-07 * * \\
(1.94 \mathrm{e}-07)\end{array}$ & $\begin{array}{c}1.54 \mathrm{e}-07 \\
(1.62 \mathrm{e}-07)\end{array}$ & $\begin{array}{c}3.98 \mathrm{e}-07 * * \\
(1.73 \mathrm{e}-07)\end{array}$ \\
\hline Total land owned $(\text { acres })^{\mathrm{c}}$ & $\begin{array}{l}0.008 \\
(0.008)\end{array}$ & $\begin{array}{l}-0.005 \\
(0.016)\end{array}$ & $\begin{array}{c}0.010 \\
(0.013)\end{array}$ & $\begin{array}{l}-0.003 \\
(0.014)\end{array}$ \\
\hline $\begin{array}{l}\text { Access to a savings account } \\
\text { (dummy) }\end{array}$ & $\begin{array}{c}0.012 \\
(0.088)\end{array}$ & $\begin{array}{c}0.179 \\
(0.164)\end{array}$ & $\begin{array}{c}0.063 \\
(0.141)\end{array}$ & $\begin{array}{c}0.159 \\
(0.147)\end{array}$ \\
\hline Access to credit (dummy) & $\begin{array}{l}-0.016 \\
(0.076)\end{array}$ & $\begin{array}{c}0.019 \\
(0.140)\end{array}$ & $\begin{array}{l}-0.081 \\
(0.122)\end{array}$ & $\begin{array}{c}0.015 \\
(0.125)\end{array}$ \\
\hline $\begin{array}{l}\text { Order of experiment }(1=\text { first } \\
\text { modified } B L)\end{array}$ & $\begin{array}{c}0.054 \\
(0.076)\end{array}$ & $\begin{array}{l}-0.151 \\
(0.142)\end{array}$ & $\begin{array}{c}0.087 \\
(0.121)\end{array}$ & $\begin{array}{l}-0.135 \\
(0.127)\end{array}$ \\
\hline Winner modified BL (dummy) & $\begin{array}{l}0.255^{*} \\
(0.153)\end{array}$ & & $\begin{array}{l}0.425^{*} \\
(0.244)\end{array}$ & \\
\hline $\begin{array}{l}\text { Winner modified HLL } \\
\text { (dummy) }\end{array}$ & & $\begin{array}{c}0.249 \\
(0.255)\end{array}$ & & $\begin{array}{c}0.183 \\
(0.228)\end{array}$ \\
\hline Constant & $\begin{array}{l}-0.422 * \\
(0.223) \\
\end{array}$ & $\begin{array}{c}0.124 \\
(0.413) \\
\end{array}$ & $\begin{array}{c}-0.443 * * * \\
(0.043) \\
\end{array}$ & $\begin{array}{l}0.107 * \\
(0.063) \\
\end{array}$ \\
\hline Observations & 332 & 332 & 332 & 332 \\
\hline $\mathrm{Chi}^{2}$ & 23.43 & 19.18 & 24.04 & 16.12 \\
\hline Log likelihood & -698.0 & -621.7 & -616.5 & -598.0 \\
\hline Interval observations & 290 & 169 & & \\
\hline Right censored observations & 14 & 122 & & \\
\hline Left censored observations & 19 & 41 & & \\
\hline Uncensored observations & 9 & 0 & & \\
\hline
\end{tabular}

Source: Survey data

Notes: Standard errors in parentheses. $* \mathrm{p}<0.10, * * \mathrm{p}<0.05, * * * \mathrm{p}<0.01$.

Dependent variables: Interval regression: midpoint CRRA coefficients of the modified HL and BL; Ordered probit regression: number of safe choices in the modified HL and BL.

${ }^{a}$ A measure showing the number of dependents (aged 0-14 and over the age of 65) to the number of people (aged 15-64).

$\mathrm{b}$ At the time of the experiments, the exchange rate was approximately $€ 1$ to UGX 3,000.

${ }^{c} 1$ acre $=0.40$ hectare. 


\section{Conclusions}

Smallholder farmers in a rural developing country setting face risky decisions regularly in their daily lives. Thus, a better understanding of farmers' risk attitudes is crucial in order to gain insight of how risk affects their decision behavior, interpreting agricultural outcomes, and designing policies and programs such as insurance instruments and other safety nets that effectively assist farmers. However, several studies quantifying individual risk attitudes showed that results of different elicitation methods may vary and reported relatively high inconsistency rates in individuals' response behavior, which may indicate a low level of comprehension. The comparison of different risk attitude elicitation methods allows insights into which method may be better adapted to assess risk attitudes of farmers in a developing country. In this study, we elicit the risk attitude of Ugandan smallholder farmers using two different methods based on the Holt and Laury (2002) and Brick et al. (2012) lottery tasks, which differ in the variation of probabilities and the fixing of payoffs or vice versa. Brick et al. (2012) assumed that people have more difficulties with varying probabilities than with varying amounts of payoffs. Furthermore, we evaluate the inconsistency rates in the response behavior and investigate whether risk attitudes are influenced by farmers' socio-demographic and socio-economic factors and whether these factors are consistent across the elicitation methods.

Our results show first that farmers, on average, are risk averse. Second, the different categories of risk attitude indicate a statistically significant difference across the two elicitation methods. That means that risk attitude measures are affected by the type of method used, even though the tendency of participants being risk averse is the same. Third, we found a relatively low rate of inconsistent decisions in both lottery-choice experiments. This finding may be an indication that our version and implementation of the modified HLL and the modified BL was well understood by the participants and thus, an appropriate elicitation method within a developing country context. It also shows that in our case people do not have more difficulties with varying probabilities than with varying amounts of payoffs given the low inconsistency rates in both lottery-choice experiments. Fourth, specific socio-demographic and socio-economic factors are significant determinants of risk attitudes: education, district, and annual per capita household expenditure. The factor quiz test score, which we used assess whether farmers have a basic comprehension of probabilities, and the factor winner modified BL, which we used to assess whether winning in the first lottery-choice experiment influences the behavior in the second lottery-choice 
experiment, also have an impact on individuals' risk attitudes. Although these factors are consistent across the two applied regression models, they are not consistent across the two different elicitation methods. This shows that one has to be cautious in making meaningful conclusions about the impact of these factors on risk attitude and therefore policy recommendations.

When interpreting the results, it is important to take into account that our experimental design is abstracted from reality and is considerably simpler than risky situations that would occur in an actual setting. Participants may act differently in the experimental situation than they do in a similar situation in the real world. A common criticism of experiments has to do with whether experimental results are likely to provide reliable inferences outside the experimental setting and can be extrapolated to the real world (Levitt and List 2007; Roe and Just 2009). This lack of external validity is considered to be the major weakness of laboratory experiments (Loewenstein 1999). Nevertheless, we believe that a careful experimental design and implementation, which is adapted to a rural, developing country setting, is essential for a valid measure of individuals' risk attitudes.

Some extensions of the present study might further verify the validity of our results. First, it would be interesting to analyze how the original lottery-choice experiment design with probabilities expressed in percent and the modified lottery-choice experiment design with probabilities expressed in bags of colored balls compares to each other in regard to inconsistency rates in the response behavior. Second, more research is needed in identifying more explanatory factors of risk attitudes and in examining the explanatory power of risk attitude measures in observed actual economic behavior. Third, different risk tasks involving different degrees of difficulty could be considered in order to more carefully address the question of how a participant's ability to reason with numbers and probabilities affects the results of different risk measures. Fourth, another interesting path to be taken would be to test whether farmers in developed countries show similar risk attitudes and inconsistency rates in the two lottery-choice experiments as farmers in developing countries. It would be also worth examining the robustness of our results by conducting the lottery-choice experiments with farmers in another developing country. 


\section{References}

Abdellaoui, M., Driouchi, A., \& L'Haridon, O. (2011). Risk aversion elicitation: Reconciling tractability and bias minimization. Theory and Decision, 71(1), 63-80.

Andersen, S., Harrison G. W., Lau, M. I., \& Rutstroem, E. E. (2006). Elicitation using multiple price list formats. Experimental Economics, 9(4), 383-405.

Anderson, L. R., \& Mellor, J. M. (2009). Are risk preferences stable? Comparing an experimental measure with a validated survey-based measure. Journal of Risk and Uncertainty, 39(2), 137-160.

Bhattamishra, R., \& Barrett, C. B. (2010). Community-based risk management arrangements: A review. World Development, 38(7), 923-932.

Binswanger, H. P. (1980). Attitude toward risk: Experimental measurement in rural India. American Journal of Agricultural Economics, 62(3), 395-707.

De Brauw, A., \& Eozenou, P. (2011). Measuring risk attitudes among Mozambican Farmers. IFPRI Harvest Plus Working Paper 6, Washington DC.

Brick, K., Visser, M., \& Burns, J. (2012). Risk aversion: Experimental evidence from South African fishing communities. American Journal of Agricultural Economics, 94(1), 133-152.

Camerer, C. F., \& Hogarth, R. M. (1999). The effects of financial incentives in experiments: A review and capital-labor-production framework. Journal of Risk and Uncertainty, 19(1-3), 7-42.

Charness, G., \& Viceisza, A., 2011. Comprehension and risk elicitation in the field: Evidence from rural Senegal. IFPRI Discussion Paper 01135, IFPRI Washington DC.

Cohen, A., \& Einav, L. (2007). Estimating risk preferences from deductible choice. The American Economic Review, 97(3), 745-788.

Croson, R., \& Gneezy, U. (2009). Gender differences in preferences. Journal of Economic Literature, 47(2), 448-474.

Dave, C., Eckel, C. C., Johnson, C. A., \& Rojas, C. (2010). Eliciting risk preferences: When is simple better? Journal of Risk and Uncertainty, 41(3), 219-243.

Deck, C., Lee, J., Reyes, J., \& Rosen, C. (2008). Measuring risk attitudes controlling for personality traits. Department of Economics Working Paper 0801, Florida International University.

Doerr, U., Toman, O., \& Schmidt, U. (2011). Overconfidence and risk management of Ethiopian farmers. Department of Economics Working Paper, University of Kiel. 
Dohmen, T., Falk, A., Huffman D., Sunde, U., Schupp, J., \& Wagner, G. (2011). Individual risk attitudes: Measurement, determinants and behavioral consequences. Journal of the European Economic Association, 9, (3), 522-550.

Doss, C., McPeak, J., \& Barrett, C. B. (2008). Interpersonal, intertemporal and spatial variation in risk perceptions: Evidence from East Africa. World Development, 36(8), 1453-1468.

Eckel, C.C., \& Grossman, P. J. (2008). Forecasting risk attitudes: An experimental study using actual and forecast gamble choices. Journal of Economic Behavior and Organization, 68(1), 1-17.

Eckel, C. C., \& Grossman, P. J. (2002). Sex differences and statistical stereotyping in attitudes toward financial risk. Evolution and Human Behavior, 23(4), 281-295.

Engle-Warnick, J. C., Escobal, J., \& Laszlo, S. C. (2011). Ambiguity aversion and portfolio choice in small-scale Peruvian farming. The B:E: Journal of Economic Analysis and Policy, 11(1), 1-54.

Eswaran, M., \& Kotwal, A. (1990). Implications of credit constraints for risk behaviour in less developed economies. Oxford Economic Papers, 42(2), 473-482.

Galarza, F. (2009). Choices under risk in rural Peru. Munich Personal RePec Archive Working Paper 17708, Munich.

Gardner, P. L. (1975). Scales and statistics. Review of Educational Research, 45(1), 43-57.

Gneezy, U., \& Potters, J. (1997). An experiment on risk taking and evaluation periods. The Quarterly Journal of Economics, 112(2), 631-645.

Gollier, C. (2001). The Economics of Risk and Time. MIT Press, Cambridge, UK.

Hallahan, T. A., Faff, R. W., \& Mckenzie, M. D. (2004). An empirical investigation of personal financial risk tolerance. Financial Services Review, 13, 57-78.

Harrison, G. W. (2011). Experimental methods and the welfare evaluation of policy lotteries. The European Review of Agricultural Economics, 38(3), 335-360.

Harrison, G. W., Humphrey, S. J., \& Verschoor, A. (2010). Choice under uncertainty: Evidence from Ethiopia, India and Uganda. The Economic Journal, 120(543), 80104.

Harrison, G. W., Lau, M. I., \& Rutstroem, E. E. (2007). Estimating risk attitudes in Denmark: A field experiment. Scandinavian Journal of Economics, 109(2), 341-368.

Harrison, G. W., Lau, M. I., Rutstroem, E. E., \& Sullivan, M. B. (2005a). Eliciting risk and time preferences using field experiments: Some methodological issues. Field Experiments in Economics. Greenwich, CT: Emerald, 17-50. 
Harrison, G. W., Johnson, E., McInnes, M. M., \& Rutstroem, E. E. (2005b). Risk aversion and incentive effects: Comment. The American Economic Review, 95(3), 897-901.

Hill, R. V. (2009). Using stated preferences and beliefs to identify the impact of risk on poor households. Journal of Development Studies, 45(2), 151-171.

Hill, R. V. (2010). Liberalisation and producer price risk: Examining subjective expectations in the Ugandan coffee market. Journal of African Economies, 19(4), 433-458.

Hill, R. V., \& Viceisza, A. (2012). A field experiment on the impact of weather shocks and insurance on risky investment. Experimental Economics, 15(2), 341-371.

Holm, H. J., Opper, S., \& Nee, V. (2012). Entrepreneurs under uncertainty: An economic experiment. Department of Economics Working Paper 4, (2012), Lund University.

Holt, C. A., \& Laury, S. K. (2002). Risk aversion and incentive effects. The American Economic Review, 92(5), 1644-1655.

Humphrey, S. J., \& Verschoor, A. (2004). Decision-making under risk among small farmers in East Uganda. Journal of African Economies, 13(1), 44-101.

Isaac, R., \& James, D. (2000). Just who are you calling risk averse? Journal of Risk and Uncertainty, 20(2), 177-187.

Jacobson, S., \& Petrie, R. (2009). Learning from mistakes: What do inconsistent choices over risk tell us? Journal of Risk and Uncertainty, 38(2), 143-158.

Kahneman, D., Knetsch, J. L., \& Thaler, R. H. (1990). Experimental tests of the endowment effect and the Coase theorem. Journal of Political Economy, 98(6), 13251348.

Levitt, S. D., \& List, J. A. (2007). What do laboratory experiments measuring social preferences reveal about the real world? The Journal of Economic Perspectives, $21(2), 153-174$.

Loewenstein, G. (1999). Experimental economics from the vantage-point of behavioural economics. The Economic Journal, 109(453), 25-34.

Maart-Noelck, S. C., \& Musshoff, O. (2013). Measuring the risk attitude of decisionmakers: Are there differences between groups of methods and persons? The Australian Journal of Agricultural and Resource Economics, doi: 10.1111/j.14678489.2012.00620.x.

Masclet, D., Colombier, N., Denant-Boemont, L., \& Lohéac, Y. (2009). Group and individual risk preferences: A lottery-choice experiment with self-employed and salaried workers. Journal of Economic Behavior and Organization, 70(3), 470-484. 
Menapace, L., Colson, G., \& Raffaelli, R. (2012). Risk aversion, subjective beliefs, and farmer risk management strategies. American Journal of Agricultural Economics, 95(2), 384-389.

Miyata, S. (2003). Household's risk attitudes in Indonesian villages. Applied Economics, $35(5), 573-583$.

Mosley, P., \& Verschoor, A. (2005). Risk attitudes and the "vicious circle of poverty". The European Journal of Development Research, 17(1), 59-88.

Nielsen, T., Keil, A., \& Zeller, M. (2013). Assessing farmers' risk preferences and their determinants in a marginal upland area of Vietnam: A comparison of multiple elicitation techniques. Agricultural Economics, 44(3), 255-273.

Picazo-Tadeo, A. J., \& Wall, A. (2011). Production risk, risk aversion and the determination of risk attitudes among Spanish rice producers. Agricultural Economics, 42(4), 451-464.

Price, T. J., \& Wetzstein, M. E. (1999). Irreversible investment decisions in perennial crops with yield and price uncertainty. Journal of Agricultural and Resource Economics, 24(1), 173-185.

Purvis, A., Boggess, W. G., Moss, C. B., \& Holt, J. (1995). Technology adoption decisions under irreversibility and uncertainty: "An ex ante" appproach. American Journal of Agricultural Economics, 77(3), 541-551.

Reynaud, A., \& Couture, S. (2012). Stability of risk preference measures: Results from a field experiment on French farmers. Theory and Decision, 73(2), 203-221.

Roe, B. E., \& Just, D. R. (2009). Internal and external validity in economics research: Tradeoffs between experiments, field experiments, natural experiments, and field data. American Journal of Agricultural Economics, 91(5), 1266-1271.

Scheufele, G., \& Bennett, J. (2013). Effects of alternative elicitation formats in discrete choice experiments. The Australian Journal of Agricultural and Resource Economics, $57(2), 214-233$.

Starmer, C. (2000). Developments in non-expected utility theory: The hunt for a descriptive theory of choice under risk. Journal of Economic Literature, 38(2), 332382.

Tanaka, T., Camerer, C., \& Nguyen, Q. (2010). Risk and time preferences: Experimental and household survey data from Vietnam. The American Economic Review, 100(1), 557-571.

Viceisza, A. C. G. (2011). The effects of irrelevant information on adverse selection in a signaling game. IFPRI Discussion Paper 774, IFPRI Washington DC.

Wik, M., Kebede, T., Bergland, O., \& Holden, S. (2004). On the measurement of risk aversion from experimental data. Applied Economics, 36(21), 2443-2451. 
Winter-Nelson, A., \& Amegbeto, K. (1998). Option values to conservation and agricultural price policy: Application to terrace construction in Kenya. American Journal of Agricultural Economics, 80(2), 409-418.

Yesuf, M., \& Bluffstone, R. A. (2009). Poverty, risk aversion, and path dependence in lowincome countries: Experimental evidence from Ethiopia. American Journal of Agricultural Economics, 91(4), 1022-1037. 


\section{General Conclusions}

\section{Conclusions}

\subsection{Summary of findings}

Agricultural food supply systems are undergoing major structural changes, with modern supply chains, vertical integration and private standards gaining in importance. Although this transformation is partly driven by changing consumer preferences, it has profound implications on agricultural production systems in developing countries. Private standards, although voluntary, are becoming a requirement for smallholders to access high-value markets worldwide. Yet smallholder participation and the ability to comply with sustainability oriented certification standards may be affected by various factors that include climatic, institutional, and socio-economic conditions including individual preferences, in particular risk preferences.

While there is consensus in the literature that domestic agricultural food systems in developing countries are profoundly affected by the growth of high-value markets, there is still an ongoing debate on the implications of modern supply chains on the welfare of smallholder farmers. On the one hand, farmers might be excluded from participation in modern supply chains, due to stringent food quality and safety standards. On the other hand, modern supply chains are increasingly viewed as a market based risk management mechanism in which smallholder farmers may benefit through higher prices, access to inputs, credits, extension and more consistent in terms output markets and prices. There is a growing body of literature analyzing the direct and indirect effects of different sustainability standards on the welfare of smallholder farmers in developing countries. Most of these studies show that poor rural households can benefit from modern supply chains through own participation as producers or through labor markets.

In this study, we have contributed to existing literature in three broad ways. In Chapter II, we have analyzed and compared impacts of three sustainability oriented certification schemes - namely, Fairtrade, UTZ, and Organic - on household living standards and poverty. We have used percapita household expenditure as the main variable of interest. We have contributed to extant literature by comparing income and poverty effects of different sustainability standards within the same context, while controlling for selection bias, using propensity score matching. We have shown that farmers complying with all 
three sustainability standards have significantly higher living standards. However, disaggregation by certification scheme shows that Fairtrade certification improves living standards by $30 \%$ and significantly reduces the likelihood of being poor by $50 \%$. However, we have also shown that participation in UTZ and Organic certifications is not associated with higher living standards or lower poverty rates. Much of the observed differences can be explained by the fact that Fairtrade farmers receive minimum guaranteed prices. Furthermore, they have better bargaining power, and process their certified coffee.

In Chapter III, we built on, and advanced the analysis from Chapter II, although the results are not disaggregated by certification standard. We have used 7 day recall data on household food consumption data covering over 100 different food types, which we converted into calories and micronutrients. We have analyzed the impact of sustainability oriented certification on household nutrition, while controlling observed and unobserved factors using an instrumental variable approach. In addition, we have used structural equation modeling to identify the main nutrition impact pathways. We have contributed to the existing literature in two ways. First, by using more comprehensive measures of nutrition - calories and three important micronutrients (iron, zinc and vitamin A) - as measures of undernutrition and dietary quality, respectively. Second, we contribute conceptually to the recent debate on linkages between agriculture, gender, and nutrition. We have shown that compliance with sustainability certification standards is associated with increased consumption of calories and micronutrients. We have also shown that participation in sustainability oriented certification leads to improved household nutrition, through increases in income and a loss in male control of income. Furthermore, these results are also valid, when considering the length of certification.

In Chapter IV, we have compared the performance of two experimental methods in eliciting individual risk attitudes and how well they were understood by farmers. We have contributed to extant literature by comparing two innovative methods - based on the incentive-compatible lotteries used in Holt and Laury (2002) and Brick et al. (2012) - that can be used in eliciting individual risk attitudes. Furthermore, the two methods are modified from the original lottery-choice experiments by replacing probabilities expressed in percent with images of bags of colored balls to represent probabilities of different payoffs in order to apply them to individuals in a rural developing country setting. We have shown that both methods reveal high proportions of farmers who are classified as risk 
averse, which is consistent with literature on risk among smallholder farmers in developing countries.

In the final analysis of the main findings, we can make some general conclusions. Although, we used two different econometric techniques in controlling for selection bias in Chapter II and Chapter III, our results consistently show that certification (as a dummy and not disaggregated by type) positively and significantly affects per-capita household income. In Chapter II, we did not find any significant association between sustainability oriented certification (in general) and the living standards and poverty levels of coffee farmers. However, in Chapter III we do find that farmers that comply with sustainability standards have better household nutrition. In Chapter IV, results of the elicitation methods both confirmed that smallholder coffee farmers in Uganda are generally risk averse.

\subsection{Policy implications}

There are some broader lessons that can be learned from our results. First, when provided with institutional support, smallholder farmers and cooperatives can participate in sustainability oriented certification schemes and be able to comply with stringent food quality and food safety standards. The cooperatives investigated in this study, although operating in one of the poorest countries in the world, have managed to fully comply with the different international standards for more than 5 years. This is an encouraging development and disproves pessimistic views that smallholder farmer will not be able to participate in high-value markets on a sustained basis.

Second, the impact of standards and certification on farmer livelihoods may differ significantly by certification scheme, especially if they are income related. Hence, it is worthwhile to take a closer look. Better understanding impact differences and factors that contribute to these differences may be relevant for all actors along the supply chain, including consumers who may wish to make more informed purchase decisions.

Third, the impacts of standards and certification systems depend to a large extent on institutional factors at the local level, including cooperative performance and management capacity. Certification may be a prerequisite for entering international high-value chains, but for farmers to take full advantage of that opportunity, they need institutional support from public, private, and non-governmental organizations in the form of credit, extension, access to inputs and opportunities to value add their commodities. 
Fourth, market interventions that integrate social components, which go beyond income benefits, as with the case of sustainability standards, have a role to play in improving intrahousehold gender relations and resource allocation. Such components may be replicated and up-scaled, as best-practices, to other similar programs that have been associated with further marginalization of women.

\subsection{Limitations of the study}

The results of this manuscript add to the growing body of literature that assesses welfare implications for smallholder farmers complying with sustainability standards in the context of developing countries. While we find some welfare gains associated with sustainable standards, there are a number of other factors that limit the scope of our study.

First, estimated welfare impacts results rely on cross-sectional data, which does not allow us to consider changes that occur over time. A useful extension of these findings would be following up on the same households over one or several rounds and building up a panel dataset. With panel data, it possible to analyze the evolution of welfare impacts between certified and non-certified farmers over time. Panel data will allow for the estimation of dynamic impacts, both income and non-income that can be used in assessing whether sustainability standards can be sustained over time. If they can, how do the different standards compare over time? Furthermore, panel data could provide a better understanding for policy makers and researchers alike on what happens to households that are certified and those that are non-certified over time. The following questions could be addressed and may be answered: Do certified households continue complying with stringent sustainability standards over time? If there is significant proportion of farmers that stop complying or decertified, what are the factors leading explaining noncompliance? Do non-certified households remain supplying to traditional markets?

In terms of nutrition impacts, our study relied on household consumption data from a single 7-day recall period, which cannot account for seasonal variation in food consumption. Although costly and time consuming, it may be useful to collect household consumption at different intervals of the year that capture variability in supply. Second, the methods we have used to examine the nutrition impacts do not provide insights on intrahousehold food distribution. Collecting additional data consisting of child anthropometrics will be able to provide more in-depth analysis on intra-household undernutrition and dietary quality dynamics. 
With respect to the lottery-choice experiments, it would be interesting to conduct and compare the original lottery-choice experiment design with probabilities expressed in percent and the modified lottery-choice experiment design with probabilities expressed in bags of colored balls using the same sample of subjects, given the low inconsistency rates in the response behavior in the results,. An extension of the present study regarding different sample groups by testing whether farmers in developed countries show similar risk attitudes and inconsistency rates in the two lottery-choice experiments as farmers in developing countries or by conducting the lottery-choice experiments with farmers in another developing country might further verify the validity of the results. 


\section{List of publications}

In Press:

Chiputwa B., Spielman D.J., \& Qaim M. (2015) Food Standards, Certification and Poverty among Coffee farmers in Uganda, World Development: Vol.66, pp.400-412, 2015. http://dx.doi.org/10.1016/j.worlddev.2014.09.006

\section{$\underline{\text { Submitted papers }}$}

Chiputwa, B. and Qaim, M. (2014). Sustainability standards, gender, and nutrition among smallholder farmers in Uganda. Journal: Journal of Development Studies (under review)

Working papers:

Chiputwa, B. and Qaim, M. (2014). Sustainability Standards, Gender and Nutrition among Coffee Farmers in Uganda. GlobalFood Discussion Paper Series No. 52, Transformation of Global Agri-Food Systems: Trends, Driving Forces, and Implications for Developing Countries, Goettingen.

Chiputwa, B., Qaim, M., and Spielman, J.D. (2013). Food Standards, Certification, and Poverty among Coffee Farmers in Uganda. GlobalFood Discussion Paper Series No. 27, Transformation of Global Agri-Food Systems: Trends, Driving Forces, and Implications for Developing Countries, Goettingen.

Ihli, H.J., Chiputwa, B., and Musshoff, O. (2013). Do Changing Probabilities or Payoffs in Lottery-Choice Experiments Matter? Evidence from Rural Uganda. GlobalFood Discussion Paper Series No. 24, Transformation of Global Agri-Food Systems: Trends, Driving Forces, and Implications for Developing Countries, Goettingen.

\section{Conferences:}

Chiputwa, B., Qaim, M., and Spielman, D.J. Food Standards, Certification, and Poverty among Coffee Farmers in Uganda. European Association of Agricultural Economics (EAAE), August 26-29, 2014 in Ljubljana, Slovenia.

Chiputwa, B., Qaim, M., and Spielman, D.J. Food Standards, Certification, and Poverty among Coffee Farmers in Uganda. GlobalFood Symposium 2014, April 25-26, 2014 in Goettingen, Germany.

Ihli, H.J., Chiputwa, B., Bauermeister, F.-G., and Musshoff, O. (2013). Measuring Risk Attitudes of Smallholder Farmers in Uganda: How Consistent Are Results of Different Methods? The Second International Agricultural Risk, Finance, and Insurance Conference (IARFIC), June 16-18, 2013 in Vancouver, Canada. 


\section{Declaration on the proportion of own work performed}

I, hereby, declare the proportion of own work performed in the scientific papers, which are included in this Ph.D. dissertation.

In the first paper titled 'Food Standards, Certification, and Poverty among Coffee Farmers in Uganda', which is co-authored by Prof. Dr. Matin Qaim and Dr. David Spielman, the following parts have been performed by me: conceptualization and design of the household instrument and survey in close cooperation with Prof. Dr. Matin Qaim and Dr. David Spielman, implementation of the survey, analysis and interpretation of the research results in cooperation with all participating authors.

In the second paper titled 'Sustainability Standards, Gender, and Nutrition among Coffee Farmers in Uganda', which is co-authored by Prof. Dr. Matin Qaim, the following parts have been performed by me: conceptualization and design of the household survey in close cooperation with Prof. Dr. Matin Qaim, implementation of the survey, analysis and interpretation of the research results in cooperation with Prof. Dr. Matin Qaim.

In the third paper titled 'Do Changing Probabilities or Payoffs in Lottery-Choice Experiments Affect the Results? Evidence from Rural Uganda', in which I am the second author and which is co-authored by Hanna Ihli and Prof. Dr. Oliver Musshoff, the following parts have been performed by me: conceptualization and design of the experiment by Hanna Ihli and Prof. Dr. Oliver Musshoff, implementation of the experiment by Hanna Ihli, collection of household survey data, analysis and interpretation of the research results in cooperation with Hanna Ihli and Prof. Dr. Oliver Musshoff. 


\section{Declarations}

1. I, hereby, declare that this Ph.D. dissertation has not been presented to any other examining body either in its present or a similar form.

Furthermore, I also affirm that I have not applied for a Ph.D. at any other higher school of education.

Göttingen,

(Signature)

(Name in block capitals)

2. I, hereby, solemnly declare that this dissertation was undertaken independently and without any unauthorised aid.

Göttingen

(Signature)

(Name in block capitals) 


\section{References}

Antle, J. M. (1983). Testing the stochastic structure of production: A flexible momentbased approach. Journal of Business and Economic Statistics, 1(3), 192-201.

Antle, J. M. (1987). Econometric estimation of producers' risk attitudes. American Journal of Agricultural Economics, 69(3), 509-522.

Arnould, E. J., Plastina, A., \& Ball, D. (2009). Does Fair Trade deliver on its core value proposition? Effects on income, educational attainment, and health in three countries. Journal of Public Policy \& Marketing, 28(2), 186-201.

Asfaw, S., Mithöfer, D., \& Waibel, H. (2010a). Agrifood supply chain, private-sector standards, and farmers' health: evidence from Kenya. Agricultural Economics, 41, 251-263.

Asfaw, S., Mithöfer, D., \& Waibel, H. (2010b). What impact are EU supermarket standards having on developing countries' export of high-value horticultural products? Evidence from Kenya. Journal of International Food and Agribusiness Marketing, 22, 252-276.

Beuchelt, \& Zeller, M. (2011). Profits and poverty: Certification's troubled link for Nicaragua's organic and fairtrade coffee producers. Ecological Economics, 70, 13161324.

Binswanger, H. P. (1980). Attitudes toward risk: Experimental measurement in rural India. American Journal of Agricultural Economics, 62, 395-407.

Blackman, A., \& Naranjo, M. (2012). Does eco-certification have environmental benefits? Organic coffee in Costa Rica. Ecological Economics, 83(12), 58-66.

Blackmore, E., Keeley, J., Pyburn, R., Mangus, E., Chen, L., \& Yuhui, . (2012). Pro-poor certification: assessing the benefits of sustainability certification for small-scale farmers in Asia. IIED, London: Natural Resource Issues.

Bolwig, S., Gibbon, P., \& Jones, S. (2009). The economics of smallholder organic contract farming in tropical Africa. World Development, 37(6), 1094-1104.

Brick, K., Visser, M., \& Burns, J. (2012). Risk aversion: Experimental evidence from South African fishing communities. American Journal of Agricultural Economics, 94(1), 133-152.

Calo, M., \& Wise, T. (2005). Revaluing peasant coffee production: Organic and Fair Trade markets in Mexico. Medford, Massachusetts: Global Development and Environment Institute, Tufts University.

Carletto, C., Kirk, A., Winters, P. C., \& Davis, B. (2010). Globalization and smallholders: The adoption, diffusion, and welfare impact of non-traditional export crops in Guatemala. World Development, 38(6), 814-827. 
Colen, L., Maertens, M., \& Swinnen, J. (2012). Private standards, trade and poverty: GlobalGAP and horticultural employment in Senegal. The World Economy, 35(8), 1073-1088.

Dercon, S. (2009). Risk, poverty, and insurance. In M. Vargas, R. Hill Torero (Ed.), Insuring the poor. Washington, DC: IFPRI - International Food Policy Research Institute.

Di Falco, S., Chavas, J. P., \& Smale, M. (2007). Farmer management of production risk on degraded lands: the role of wheat variety diversity in the Tigray region, Ethiopia. Agricultural Economics, 36(2), 147-156.

Di Falco, S., \& Chavas, J.-P. (2009). On crop biodiversity, risk exposure, and food security in the highlands of Ethiopia. American Journal of Agricultural Economics, 91(3), 599-611.

Elfenbein, D. W., \& McManus, B. (2010). A greater price for a greater good? Evidence that consumers pay more for charity-linked products. American Economic Journal: Economic Policy, 2(2), 28-60.

Ellis, K., \& Keane, J. (2008). A review of ethical standards and labels: is there a gap in the market for a new "Good for Development" label? London, UK: Overseas Development Institute (ODI).

Fairtrade. (2013). Powering up smallholder farmers to make food fair: A five point agenda. Fairtrade Foundation. Retrieved August 07, 2013, from http://www.fairtrade.net/fileadmin/user_upload/content/2009/news/2013-05Fairtrade_Smallholder_Report_FairtradeInternational.pdf

FAO, IFAD, \& WFP. (2013). The state of food insecurity in the world. The multiple dimensions of food security 2013. Rome: Food and Agricultural Organization of the United Nations (FAO).

Fort, R., \& Ruben, R. (2008). The impact of Fair Trade on banana producers in northern Peru. In R. Ruben (Ed.), The Impact of Fair Trade (pp. 49-75). The Netherlands.: Wageningen Academic Publishers.

Henson, S., \& Humphrey, J. (2010). Understanding the complexities of private standards in global agri-food chains as they impact developing countries. The Journal of Development Studies, 46(9), 1628-1646.

Henson, S., \& Jaffee, S. (2006). Food safety standards and trade: Enhancing competitiveness and avoiding exclusion of developing countries. The European Journal of Development Research.

Henson, S., Masakure, O., \& Boselie, D. (2005). Private food safety and quality standards for fresh produce exporters: The case of Hortico Agrisystems, Zimbabwe. Food Policy, 30(4), 
Holt, C., \& Laury, S. (2002). Risk aversion and incentive effects. American Economic Review, 92(5), 1644-1655.

Hurley, T. (2010). A review of agricultural production risk in the developing world. Harvest Choice. Retrieved from http://harvestchoice.org/sites/default/files/downloads/publications/Hurley 2010 HC -A Review of Agricultural Production Risk.pdf

IFAD, \& UNEP. (2013). Smallholders, food security and the environment. Rome:International Fund for Agricultural Development (IFAD) and Nairobi: United Nations Environment Program (UNEP).

Jena, P. R., Chichaibelu, B. B., Stellmacher, T., \& Grote, U. (2012). The impact of coffee certification on small-scale producers' livelihoods: a case study from the Jimma Zone, Ethiopia. Agricultural Economics, 43(4), 429-440.

Jones, S., \& Gibbon, P. (2011). Developing agricultural markets in sub-Saharan Africa: organic cocoa in rural Uganda. Journal of Development Studies, 47(10), 1595-1618.

Just, R. E., \& Pope, R. D. (1979). Production function estimation and related risk considerations. American Journal of Agricultural Economics, 61(2), 276-284.

Liu, P., Byers, A., \& Giovannucci, D. (2008). Value-adding standards in the North American food market-trade opportunities in certified products for developing countries. Rome: Trade and Markets Division (FAO).

Maertens, M. (2011). Globalisation and poverty in Senegal: a worst case scenario? European Review of Agricultural Economics: ERAE, 38(1), 1-45.

Maertens, M., \& Swinnen, J. F. M. (2009). Trade, standards, and poverty: Evidence from Senegal. World Development, 37(1), 161-178.

Maertens, M., \& Swinnen, J. F. M. (2012). Gender and modern supply chains in developing countries. Journal of Development Studies, 48(10), 1412-1430.

Mergenthaler, M., Weinberger, K., \& Qaim, M. (2009). The food system transformation in developing countries: a disaggregate demand analysis for fruits and vegetables in Vietnam. Food Policy, 34(5), 426-436.

Minten, B., \& Reardon, T. (2008). Food prices, quality, and quality's pricing in supermarkets versus traditional markets in developing countries. Review of Agricultural Economics, 30(3), 480-490.

Mosley, P., \& Verschoor, A. (2005). Risk attitudes and the "vicious circle of poverty." The European Journal of Development Research, 17(1), 59-88.

Muradian, R., \& Pelupessy, W. (2005). Governing the coffee chain: The role of voluntary regulatory Systems. World Development, 33(12), 2029-2044. 
Narrod, C., Roy, D., Okello, J., Avendaño, B., Rich, K., \& Thorat, A. (2009). Publicprivate partnerships and collective action in high value fruit and vegetable supply chains. Food Policy, 34(1), 8-15.

Pierrot, J., Giovannucci, D., \& Kasterine, A. (2010). Trends in the trade of certified coffees. International Trade Centre, 27551, 1-19.

Rao, E. J. O., Brummer, B., \& Qaim, M. (2012). Farmer participation in supermaket channels of vegetables in Kenya. American Journal of Agricultural Economics, 94(4), 891-912.

Rao, E. J. O., \& Qaim, M. (2013). Supermarkets and agricultural labor demand in Kenya: A gendered perspective. Food Policy, 38, 165-176.

Reardon, T., Barrett, C. B., Berdegué, J. A., \& Swinnen, J. F. M. (2009). Agrifood industry transformation and small farmers in developing countries. World Development, 37(11), 1717-1727.

Reardon, T., Henson, S., \& Berdegue, J. (2007). "Proactive fast-tracking" diffusion of supermarkets in developing countries: implications for market institutions and trade. Journal of Economic Geography, 7(4), 399-431.

Reardon, T., \& Timmer, C. (2007). Transformation of markets for agricultural output in developing countries since 1950: How has thinking changed? In R. E. Evenson, P. Pingali, \& T. P. Schultz (Eds.), Handbook of Agricultural Economics, 3: Agricultural Development: Farmers, Farm Production and Farm Markets (pp. 2808-2855). Amsterdam: Elsevier Press.

Reardon, T., Timmer, C. P., Barrett, C. B., \& Berdegue, J. (2003). The rise of supermarkets in Africa, Asia, and Latin America. American Journal of Agricultural Economics, 85(5), 1140-1146.

Ruben, R., \& Fort, R. (2012). The impact of Fair Trade certification for coffee farmers in Peru. World Development, 40(3), 570-582.

Ruben, R., \& van Schendel, L. (2008). The impact of Fair Trade in banana plantations in Ghana: Income, ownership and livelihoods of banana workers. In R. Ruben (Ed.), The impact of fair trade (pp. 137-153). Wageningen, The Netherlands.: Wageningen Academic Publishers.

Swinnen, J. F. M. (2007). Global supply chains, standards, and the poor restructuring of global supply chains. Public Policy.

Swinnen, J. F. M. (2014). Global agricultural value chains, standards, and development. Badia Fiesolana: Robert Schuman Centre for Advanced Studies.

Swinnen, J. F. M., \& Maertens, M. (2007). Globalization, privatization, and vertical coordination in food value chains in developing and transition countries. Agricultural Economics, 37(1), 89-102. 
Swinnen, J. F. M., \& Vandeplas, A. (2012). Rich consumers and poor producers: quality and rent distribution in global value chains. Journal of Globalization and Development, 2(2), Article 2.

Tanaka, T., Camerer, C. F., \& Nguyen, Q. (2010). Risk and time preferences: linking experimental and household survey data from Vietnam. American Economic Review, $100,557-571$.

Vargas Hill, R. (2009). Using stated preferences and beliefs to identify the impact of risk on poor households. Journal of Development Studies, 45(2), 151-171.

WHO. (2007). The world health report 2007: A safer future. Retrieved from http://www.who.int/whr/2007/en/index.html

Yesuf, M., \& Bluffstone, R. (2009). Poverty, risk aversion, and path dependence in lowincome countries: Experimental evidence from Ethiopia. American Journal of Agricultural Economics, 91, 1022-1037.

Zúñiga-Arias, G., \& Segura, F. (2008). The impact of fair trade in banana production of Costa Rica. In R. Ruben (Ed.), The impact of fair trade. (pp. 99-115). Wageningen, The Netherlands.: Wageningen Academic Publishers. 


\section{Appendix}

\section{Experimental instructions}

\section{Outline}

The experiment session comprises:

1 Sign-in (location and arrival)

2 Introduction and agenda (an introduction of the experimenter, enumerators, assistant experimenter, and the project)

3 Quiz

4 Instructions, practice, and decision making (coin tossing games are randomized)

4.1 Lottery game (1)

4.2 Lottery game (2)

5 Payment

\section{Sign-in (location and arrival)}

- Each participant will present his/her photo ID before he/she will be signed in. The participant will then draw a number out of a bag. This number (personal number of the respondent) randomly determines his/her seat, which is the individual's location throughout the experiment session.

- The experiment will be conducted in sessions of six participants in classrooms in local schools or in a meeting room at the main gathering place of a farmer's group or association.

- Each participant will have his/her own enumerator.

- The typical layout of the room will be as follows:

\begin{tabular}{|l|c|}
\hline \multicolumn{2}{|c|}{ Front of room (experimenter, and white board) } \\
\hline \multicolumn{2}{|l|}{} \\
\hline Seat 1 & Seat 2 \\
\hline Seat 3 & Seat 4 \\
\hline Seat 5 & Seat 6 \\
\hline \multicolumn{2}{|l|}{ Back of room (assistant experimenter/cashier) } \\
\hline
\end{tabular}


Notes:

- $\quad$ Text in italics is not part of the participant instructions.

- $\quad$ The instructions are explained orally by the experimenter in the local language.

- Once all the participants are seated, the explanation will start.

\section{Introduction and agenda}

- Hello and welcome. Thank you for coming to our workshop today.

- The experimenter introduces himself, the enumerators, and the assistant experimenter. The experimenter introduces the institution and the project, typically as follows:

- In Uganda, we are conducting a research project on farmers' decision behavior in risky situations.

- We have been holding discussions with farmers across many parts of Uganda. In particular, we have talked to farmers in ..., but we have not been here before.

- We are very grateful that we can do the workshop in this area today and that you have found some time to participate. Thank you very much for that.

- For the upcoming tasks, you will receive cash payments for the decisions you make. We provide these payments for two purposes:

i. Because you came here today and you are spending your time with us. This is time in which you could be doing something else, so we would like to remunerate this.

ii. Also, we would like you to take this decision seriously, so that it represents your decision making behavior of normal real life decisions.

- Today's workshop will include the following steps:

- First, we explain the instructions of the different tasks on decision making.

- Then, we will do a practice run together to show how it works. Then, you will make your decisions. Today, we will do several types of decisions. In a moment, I will explain all the different tasks on decision making in more detail, one after another.

- Then, you will receive your payment. Payment will be effected in private and in cash at the end of today's workshop.

- I have some additional general comments:

- Please turn off your mobile phones, etc. 
- All decisions you make or answers you give during the workshop are private, confidential, and anonymous.

- Since all decisions and answers are private, please do not talk to each other anymore. If you have questions, please ask us by raising your hand.

- Please do not discuss with your neighbor except for the enumerator next to you. The enumerator next to you will record your answers.

- When making decisions, you should make the decision that you prefer the most as you will receive the cash payment on the basis of that decision, given that you have been selected as a winner. Please make your decisions as if they are real life decisions.

- If there are any questions at any point, please raise your hand and ask.

- Any questions before we start?

\section{Quiz}

- The experimenter hands out the questionnaire to the enumerator. Then, explanation and decision making would start.

- We will start today's workshop with a short quiz.

- The quiz contains several tasks. It is not a test; you do not need to worry if the questions seem difficult.

- Questions are asked with regard to probabilities and percentage calculation. This basically enables the participants to start thinking about the material and the decisions they will be presented with during the workshop. The participants make their choice, and their enumerators record the answers and tick the relevant box.

- Now, we are coming to the first task.

- 1. Imagine, we toss a coin and the 'heads' (emblem) comes up. What comes up if we toss the coin again? (possible answers: $\mathrm{a}=$ heads, $\mathrm{b}=$ tails, $\mathrm{c}=$ one cannot predict exactly)

- Now, we are coming to the second task.

- 2. If the chance of winning a prize is $10 \%$, how many people out of 100 would be expected to get the prize? If you don't know, put an X.

- Now, we are coming to the last task of this quiz.

- 3. When you draw the red ball, you win! Look at the two boxes and mark the correct sentence. (Possible answers: $\mathrm{a}=$ my chance to win is higher if $\mathrm{I}$ choose Box 
A. $b=$ my chance to win is equal, it does not matter which box I choose. $c=$ my chance to win is higher if I choose Box B.)

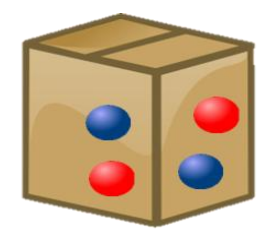

Box A

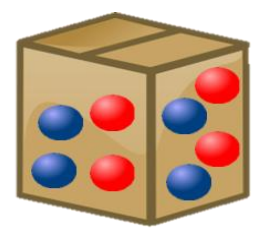

Box B

\section{Instructions and decision making}

\subsection{Lottery game (1)}

- In the first/second session, you are asked to choose between two bags. You will be asked to make a number of repeated choices.

- I will now explain the first session. Then, you will make your decisions in this session.

- Posters are displayed on a large white board at the front of the room. This is used to illustrate the basics of the game as explained below.

- The objective of this task is to win money. There are four possible prizes: 300 UGX, 4,800 UGX, 6,000 UGX, and 11,550 UGX. The four different colored balls represent the four possible prizes. The green ball is worth $300 \mathrm{UGX}$, the blue ball is worth 4,800 UGX, the red ball is worth $6,000 \mathrm{UGX}$, and the yellow ball is worth 11,550 UGX.

- Note that we will randomly select one winner out of you for this task.

- Show poster 1: The picture of the sheet with the lottery game

- Real balls will also be shown.

Choose your preferred bag by marking either Bag $\mathbf{A}$ or $\mathbf{B}$ in each row. 


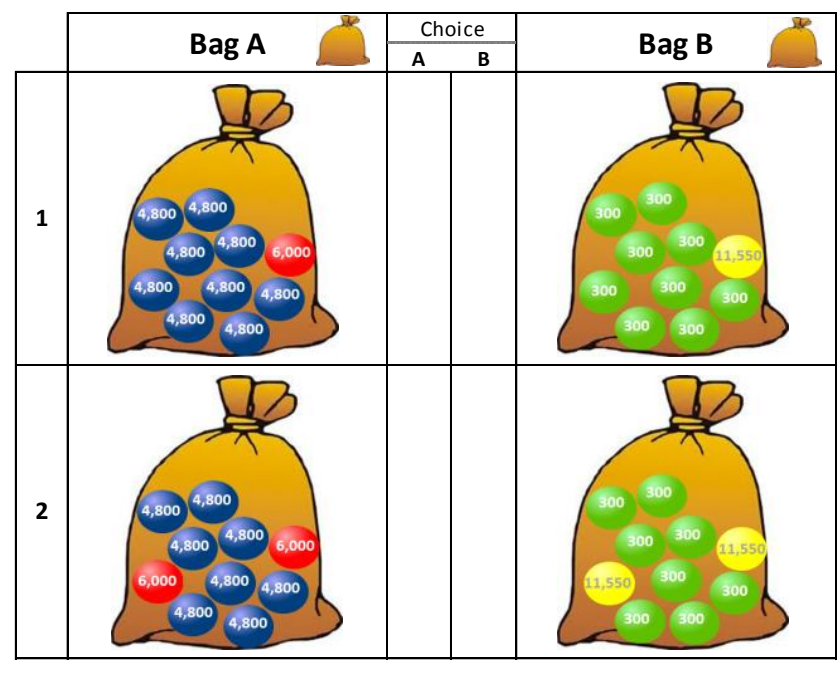

$[\ldots] \quad[\ldots]$

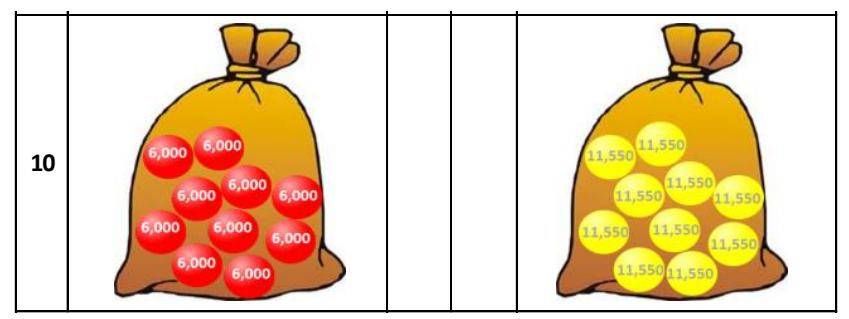

- How are you going to win these prizes?

- To win these prizes, you will first have to choose between two bags, Bag A and Bag B, for each of the 10 rows. How do these two bags differ? Each bag contains 10 balls. The two bags contain differently colored balls (green, blue, red, and yellow) with a different value. We draw only one ball from the selected bag, which will be the prize. If you choose Bag A, you can win a prize of 6,000 UGX (red ball) or a prize of 4,800 UGX (blue ball). And if you choose Bag B, you can win a prize of 11,550 UGX (yellow ball) or a prize of 300 UGX (green ball). We are going to ask you which of these two bags you prefer.

- Note that with Bag A the difference between the prizes is small, while it is large in the case of Bag B.

- In addition, in Bag A the prize of 6,000 UGX is smaller than the prize of 11,550 UGX in Bag B, and the prize of 4,800 UGX in Bag A is greater than the prize of 300 UGX in Bag B.

- Thus, you will choose between Bag A and Bag B in 10 rows, one after another.

- Let's focus on the first row.

- Show poster 2: example for Bag A or Bag B in row one 


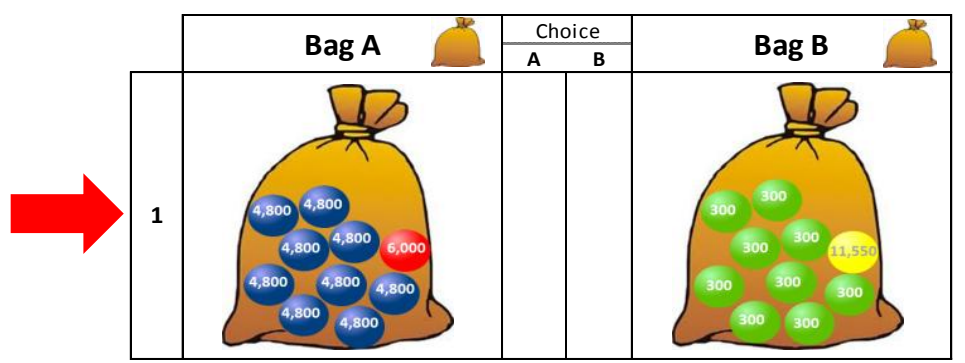

- Bag A:

- Bag A contains nine blue balls and one red ball. Each blue ball is worth 4,800 UGX, and the red ball is worth 6,000 UGX.

- If this bag is selected and the red ball is subsequently drawn, you will win 6,000 UGX. In the case that one of the blue balls is drawn, you will win 4,800 UGX.

- So, if we pick a ball from the bag, it may be blue or red. But, it is more likely that we pick one of the blue balls because there are more blue balls (than red balls) in the bag.

- Bag B:

- Now, let's look at Bag B. What is different about it? Well, this bag contains nine green balls and one yellow ball. Each green ball is worth 300 UGX, and the yellow ball is worth 11,550 UGX.

- If this bag is selected and the yellow ball is subsequently drawn, you will win 11,550 UGX. In the case that one of the green balls is drawn, you will win 300 UGX.

- So, if we pick a ball from the bag, it may be a green or a yellow one. But, it is more likely that we pick one of the green balls because there are more green balls (than yellow balls) in the bag.

- This explains row one. How do the other rows differ from row one?

- Show poster 3: example for Bag A or Bag B in row two 


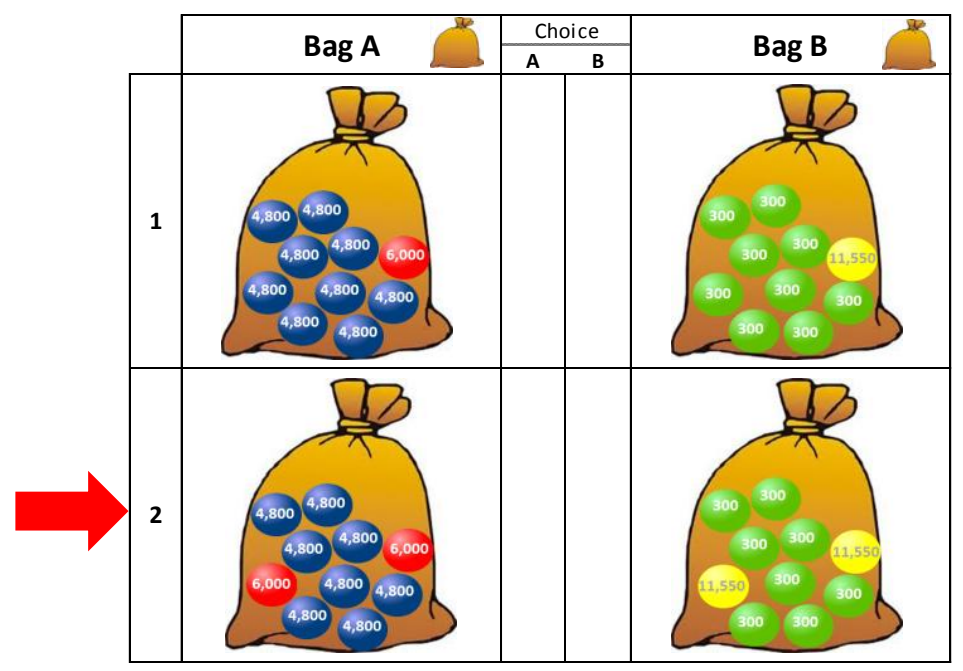

- Note that when we go from row one to row two, the only aspect that changes is the number of red balls in the bags. That is, the value of the balls does NOT change.

- Bag A:

- Bag A contains eight blue balls and two red balls. Each blue ball is worth 4,800 UGX and each red ball is worth 6,000 UGX.

- If this bag is selected and the red ball is subsequently drawn, you will win 6,000 UGX. In the case that one of the blue balls is drawn, you will win 4,800 UGX.

- So, if we pick a ball from the bag, it may be blue or red. But it is more likely that one of the blue balls is drawn because there are more blue balls (than red balls) in the bag.

- Bag B:

- Bag B contains eight green balls (each worth 300 UGX) and two yellow balls (each worth 11,550 UGX). Each green ball is worth 300 UGX, and each yellow ball is worth 11,550 UGX.

- If this bag is selected and the yellow ball is subsequently drawn, you will win 11,550 UGX. In the case that one of the green balls is drawn, you will win 300 UGX.

- So, if we pick a ball from the bag, it may be green or yellow. But, it is more likely that one of the green balls is drawn because there are more green balls (than yellow balls) in the bag.

- Quiz participants for understanding (control questions):

- Now, what happens if we go from row two to row three?

- Show poster 4: example for Bag A or Bag B in row three 


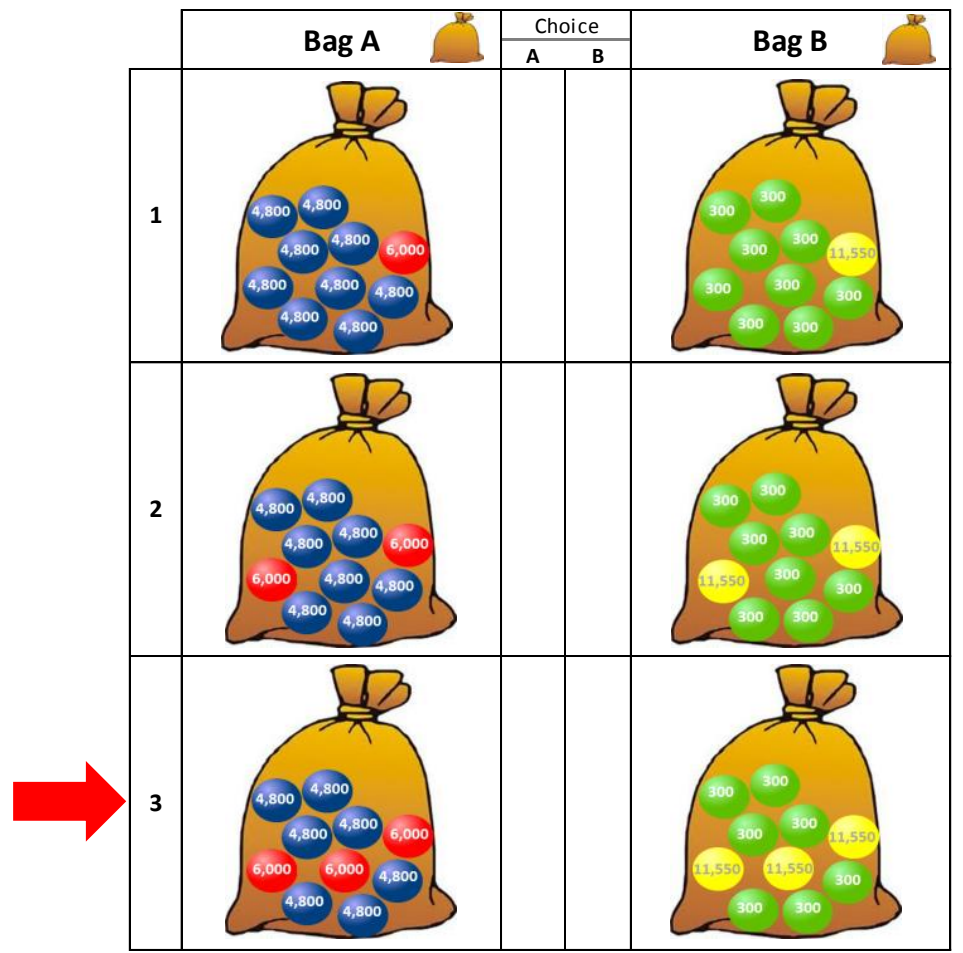

- How many blue and red balls does Bag A contain?

- How many green and yellow balls does Bag B contain?

- Suppose you choose Bag A and the red ball is drawn, how much do you win?

- Suppose you choose Bag B and the yellow ball is drawn, how much is it worth?

- etc.

- So, we are going to ask you to decide for bag A or B in each of the 10 rows.

- Note that your choice should really be guided by your attitudes. There are no wrong or right decisions.

- Then, participants are informed that only one row will be selected for payment and that only one person wins the prize.

- How will we determine the amount of money you will win for participating in this task? Now, we will explain the payment for this game.

- Only one person will receive a payment for one of the choices he/she made in this task. However, you do not know yet for which of the choices the selected person will receive the payment, so you will want to think about each choice very carefully. You will only find out at the end of this task for which of these choices the selected person is going to receive a payment.

- The payment in this game comprises three draws:

- The first draw is to determine the person who wins a prize. Remember, in the beginning of today's workshop, you got a personal number. We will ask one of 
you to draw a number between 1 and 6 out of a bag. The holder of the number that is picked from the bag will be the winner of one of the prizes.

- The second draw is to determine the row for which you will get paid. We will ask the selected person to draw a number between one and 10 out of a bag. The number that is picked from the bag will be the choice that counts for the selected person.

- The third draw is to determine whether the person receives the low or high prize. We will ask the selected person to draw a ball out of Bag A in case he/she chose Bag A or one out of Bag B in case he/she chose Bag B. The ball that is picked from the respective bag will be the choice that counts for him/her.

- Are there any questions before we start?

- $\quad$ Then, decisions will be made.

- Which bag do you choose? Choose your preferred bag by marking either Bag A or $\mathrm{B}$ in each row.

- The enumerators ask their farmers for each of the 10 rows which bag they prefer. The participants make their choice by pointing at the bag they prefer, and their enumerators record the answers and tick the relevant box.

\subsection{Lottery game (2)}

- In the first/second session, you are asked to choose between two bags. You will be asked to make a number of repeated choices.

- I will now explain the second/third session. Then, you will make your decisions in this session.

- Posters are displayed on a large white board at the front of the room. This is used to illustrate the basics of the game as explained below.

- The objective of this task is to win money. The differently coloured balls represent the possible prizes. The red ball is worth 0 UGX, the blue ball is worth 10,000 UGX, and the value of the green ball ranges from 10,000 UGX to 1,000 UGX.

- Note that we will randomly select one winner for this task.

- Show poster 1: The picture of the sheet with the lottery game

- Real balls will also be shown.

Choose your preferred bag by marking either Bag $\mathbf{A}$ or $\mathbf{B}$ in each row. 


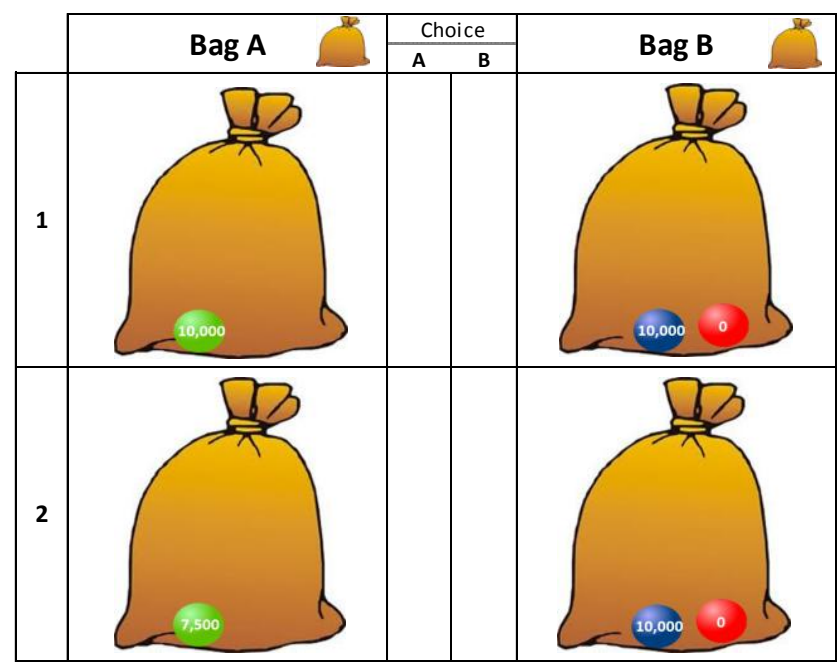

$[\ldots]$

$[\ldots]$

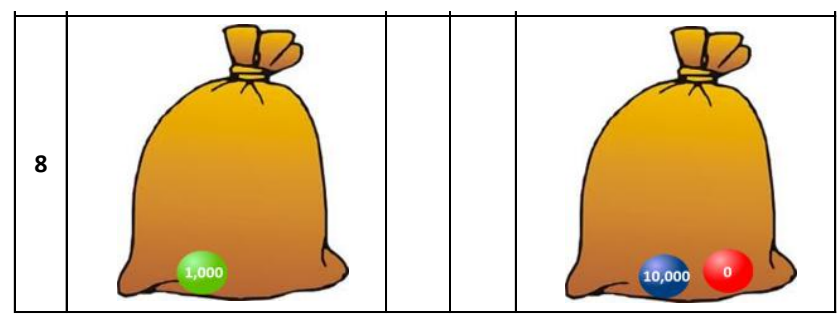

- How are you going to win these prizes?

- To win these prizes, you will first have to choose between two bags, Bag A and Bag B, for each of the 10 rows. How do these two bags differ? The two bags contain differently coloured balls (green, blue, and red). The value of the green ball changes in each decision row, while the values of the blue and the red ball remain the same across the decision rows. We draw only one ball of the selected bag, which will be the prize.

- If you choose Bag A, you can win for sure a certain amount of money (green ball). If you choose Bag B, you can win a prize of 10,000 UGX (blue ball) or nothing (red ball). We are going to ask you which of these two bags you prefer.

- The questions deal with the question of whether you prefer to have a guaranteed smaller amount of money, OR a larger amount of money that involves some risk and you might end up getting nothing. You can never lose any money irrespective of what you choose.

- We will ask you to choose between Bag A and Bag B in eight rows, one after another. 
- Let's focus on the first row.

- Show poster 2: example for Bag A or Bag B in row one

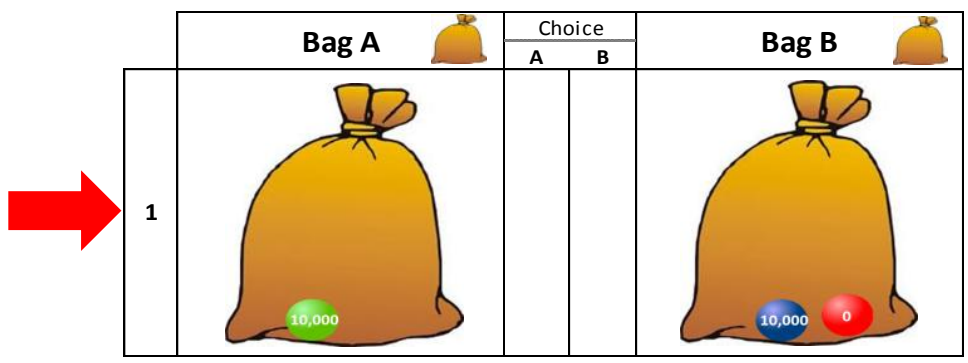

- Bag A:

- Bag A contains one green ball. This ball is worth 10,000 UGX.

- If this bag is selected and the green ball is subsequently drawn, you will win 10,000 UGX.

- So, if you choose bag A, you know what you get for sure.

- Bag B:

- Now, let's look at Bag B. What is different about it? Well, this bag contains one blue ball and one red ball. The blue ball is worth 10,000 UGX and the red is worth nothing.

- If this bag is selected and the blue ball is subsequently drawn, you will win 10,000 UGX. There is also the chance that the red ball is drawn. In this case, you will get nothing.

- This explains row one. How do the other rows differ from row one?

- Show poster 3: example for Bag A or Bag B in row two

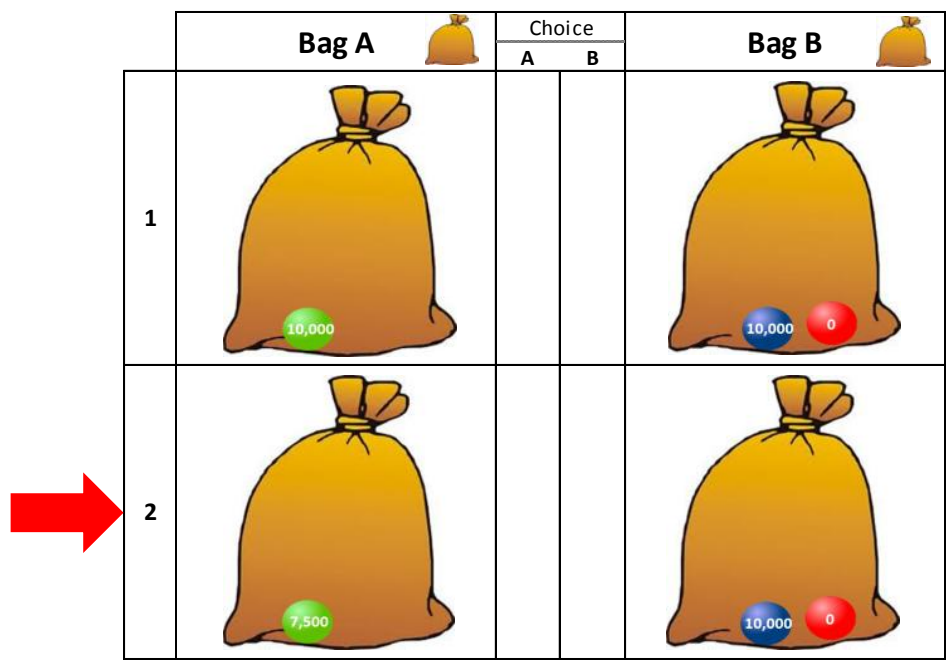

- Note that when we go from row one to row two, the only aspect that changes is the value of the green ball. 
- Bag A:

- Bag A contains one green ball. Now, this ball is worth 7,500 UGX.

- If this bag is selected and the green ball is subsequently drawn, you will win 7,500 UGX.

- So, if you choose bag A, you know what you get for sure.

- Bag B:

- Now, let's look at Bag B. This bag contains one blue ball and one red ball like in the first example. The blue ball is worth 10,000 UGX and the red is worth nothing.

- If this bag is selected and the blue ball is subsequently drawn, you will win 10,000 UGX. There is also the chance that the red ball is drawn. In this case, you will get nothing.

- Quiz participants for understanding. Control questions are asked with regard to the probabilities and earnings.

- Now, what happens if we go from row two to row three?

- Show poster 4: example for Bag A or Bag B in row three

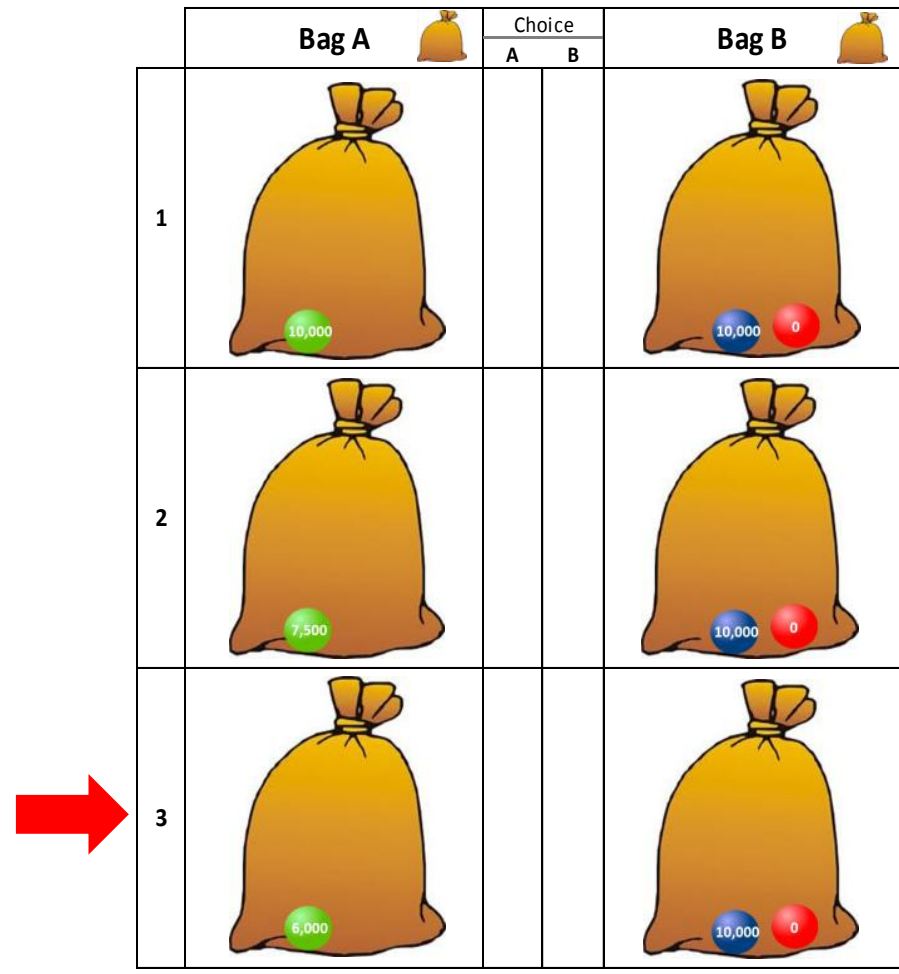

- How many balls does bag A contain?

- What is the value of the green ball?

- How many blue and red balls does Bag B contain? 
- Suppose you choose Bag A and the green ball is drawn, how much do you win?

- Suppose you choose Bag B and the red ball is drawn, how much do you win?

- etc.

- So, we are going to ask you to make a decision for each of the eight rows: Bag A or Bag B.

- Note that your choice should really be guided by your attitudes. There are no wrong or right decisions.

- Then, participants are informed that only one row would be selected for payment and that only one person wins the prize.

- How will we determine the amount of money you will win for participating in this task? Now, we will explain the payment for this task.

- Only one person will receive a payment for one of the choices he/she made in this task. However, you do not know yet for which of the choices the selected person will receive the payment, so you will want to think about each choice very carefully. You will only find out at the end of this task for which of these choices the selected person is going to receive a payment.

- The payment in this game comprises three draws:

- The first draw is to determine the person who wins a prize. Remember, in the beginning of today's workshop, you got a personal number. We will ask one of you to draw a number between one and six out of a bag. The number that is picked from the bag will determine the winner of one of the prizes.

- The second draw is to determine the row for which you will get paid. We will ask the selected person to draw a number between one and eight out of a bag. The number that is picked from the bag will be the choice that counts for $\operatorname{him} /$ her.

- If the person chose bag A, which means he/she decided to take the money for sure, he/she will get that amount of money. If the person chose bag $\mathrm{B}$, he/she will draw a ball out of the bag to determine whether he/she receives 10,000 UGX or nothing. The ball that is picked from the respective bag will be the choice that counts for the selected person.

- $\quad$ Are there any questions before we start?

- $\quad$ Then, decisions will be made.

- Which bag do you choose? Choose your preferred bag by marking either Bag A or $\mathrm{B}$ in each row. 
- The enumerators ask their participants for each of the eight rows which bag they prefer. The participants make their choice by pointing to the bag they prefer, and their enumerators record the choice/tick the relevant box. 
HOUSEHOLD QUESTIONNAIRE 


\section{GlobalFood}

wuw.uni-goettingen.de/globalfood

Georg-August University Göttingen, Germany

Department of Agricultural Economics and Rural Development

\section{Participation in Premium Certified Markets: Small Coffee farmers in Uganda Household Survey Questionnaire}
1 District:
2 County:
3 Subcounty:
4 Parish:
5 Village:
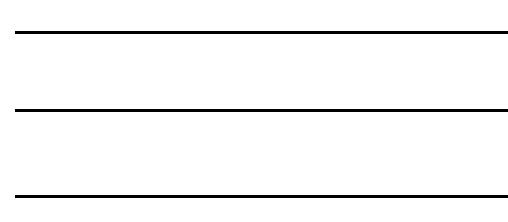

\section{Questionnaire Number}

8 Enumerator:

9 Date of interview

/ / 2012

10 Name of Household Head

11 Time interview Started Ended

5.5 Local Council LC1

GPS COORDINATES AT THE RESIDENCY OF HOUSEHOLD HEAD

\begin{tabular}{lll}
11 North (N)/South(S) & $N$ & $S$ \\
13 EAST & E \\
\hline
\end{tabular}

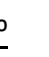

12 Altitude

meters

15 Name of respondent:

17 Is the respondent the HHD?

0. No

1. Yes

16 Phone number of respondent

19 Where is the HHD?

1. Temporarily away

2. Absent from home at least 6 months in a year

20 Sampling

1. Fmr Group + Certified

2. Fmr group but NOT Certified

3. Control G

"We are part of a team from University of Goettingen and working with local organizations like Agro-Eco, NUCAFE and Hanns Nuemann Stiftung and we are conducting this research to assess farmers' access and participation in premium certified markets for Coffee in Uganda. Your help in answering these questions is very much appreciated. The survey should take about 2 hours. Your participation is completely voluntary and your responses will be COMPLETELY CONFIDENTIAL!" 
Section A1: Area and General crops grown

1. Provide the total area owned in both the last 12 months and 5 years ago?

\begin{tabular}{|c|c|c|c|c|c|}
\hline & 1 & 2 & 3 & 4 & 5 \\
\hline & $\begin{array}{l}\text { Provide area for the } \\
\text { following land }\end{array}$ & Current Area (Acres) & $\begin{array}{l}\text { Area in past } 5 \text { years } \\
\text { (Acres) }\end{array}$ & $\begin{array}{l}\text { What atype of title do you } \\
\text { hold for this land }\end{array}$ & $\begin{array}{l}\text { How did you }{ }^{\text {acquire }} \\
\text { this land? }\end{array}$ \\
\hline & Total land & & & & \\
\hline & Land rented-in & & & & \\
\hline & Land rented-out & & & & \\
\hline & Total area cultivated & & & & \\
\hline & Area under Pasture & & & & \\
\hline & Fallowed land & & & & \\
\hline & Area under coffee & & & & \\
\hline Titite & $1=$ Freehold & $2=$ Leasehold $\quad 3=$ Mail & $4=$ Customary rights & $5=$ Bibanja & \\
\hline Acquisatic & $1=$ Purchased & Inherited (family) $3=$ & ted (spouse) 4= Agre & int with land/use rights owner & \\
\hline
\end{tabular}

7. Please provide the following details on ALL crops grown by the household in the last $\mathbf{1 2}$ months?

ENUMERATOR Be sure to capture details for all the crops that are grown in the "Main season and ${ }^{\mathrm{e}} \mathrm{Fly}$ season. In case crops are intercropped, please indicate.

\begin{tabular}{|c|c|c|c|c|c|c|c|c|c|}
\hline & \multirow{3}{*}{\multicolumn{2}{|c|}{\begin{tabular}{|c|}
10 \\
Crops Grown (please \\
list all crops in the past \\
12 months) \\
\end{tabular}}} & \multirow{3}{*}{$\begin{array}{c}11 \\
\begin{array}{c}\text { Total Area grown } \\
\text { (acres or Ha) }\end{array}\end{array}$} & \multirow{3}{*}{$\begin{array}{c}12 \\
\begin{array}{c}\text { Quantity harvested } \\
(\mathrm{kgs})\end{array}\end{array}$} & 13 & 14 & 15 & 16 & 17 \\
\hline & & & & & \multicolumn{2}{|c|}{ Quantity sold and Price/kg } & \multicolumn{3}{|c|}{ Who makes or controls decisions on } \\
\hline & & & & & Quantity (kgs) & Average Price/kg & $\begin{array}{l}\text { Production } \\
\text { acivities }\end{array}$ & Retained harvest & Revenue from sold output \\
\hline \multirow{10}{*}{ 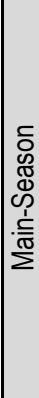 } & & Coffee & & & & & & & \\
\hline & 2 & & & & & & & & \\
\hline & 3 & & & & & & & & \\
\hline & 4 & & & & & & & & \\
\hline & 5 & & & & & & & & \\
\hline & 6 & & & & & & & & \\
\hline & 7 & & & & & & & & \\
\hline & 8 & & & & & & & & \\
\hline & 9 & & & & & & & & \\
\hline & 10 & & & & & & & & \\
\hline \multirow{10}{*}{ 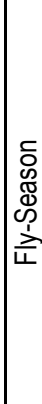 } & 11 & & & & & & & & \\
\hline & 12 & & & & & & & & \\
\hline & 13 & & & & & & & & \\
\hline & 14 & & & & & & & & \\
\hline & 15 & & & & & & & & \\
\hline & 16 & & & & & & & & \\
\hline & 17 & & & & & & & & \\
\hline & 18 & & & & & & & & \\
\hline & 19 & & & & & & & & \\
\hline & 20 & & & & & & & & \\
\hline
\end{tabular}

For Masaka district $=>^{\mathrm{d}}$ Main season was June-July 2011 and ${ }^{\mathrm{e}}$ Fly season was Dec 2011-Jan 2012

For Luwero district $=>$ Main season was in Dec 2011-March 2012 and ${ }^{\mathrm{e}} \mathrm{Fly}$ was in Aug-Oct 2011

\begin{tabular}{|c|c|c|c|c|}
\hline 2. Is the household & to grow coffee? & & $0=$ No $\quad 1=$ & \\
\hline \multirow[b]{2}{*}{ 3. If Yes to $Q 2$} & 6 & 7 & 8 & 9 \\
\hline & ${ }^{\circ}$ Certification type & $\begin{array}{l}\text { Are you 1. fully } \\
\text { certified or 2. In- } \\
\text { transition }\end{array}$ & Area certfied & Year certified \\
\hline & & & & \\
\hline & & & & \\
\hline & & & & \\
\hline & & & & \\
\hline & & & & \\
\hline Total area & & & & \\
\hline
\end{tabular}

CCertification: $1=$ Organic-Utz $\quad 2=$ Fairtrade-Utz $\quad 3=$ Utz $\quad 4=$ Fairtrade $\quad 88=$ Other 


\section{Section A2: Production costs for general crops}

1. For each crop in previous table, provide details on the costs of production for the area indicated in previous table in the past $\mathbf{1 2}$ months.

ENUMERATOR: Please maintain the same order as in previous table. Farmer should answer this table in reference to the area specified.

\begin{tabular}{|c|c|c|c|c|c|c|c|c|c|c|c|c|c|c|c|}
\hline \multirow{3}{*}{\multicolumn{3}{|c|}{\begin{tabular}{|c|c|} 
& 18 \\
\cline { 2 - 3 } & $\begin{array}{c}\text { Crop (please } \\
\text { use list from } \\
\text { previous page) }\end{array}$ \\
\end{tabular}}} & \multicolumn{11}{|c|}{ 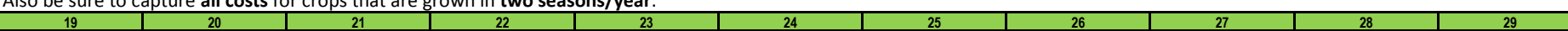 } & \multirow{4}{*}{\multicolumn{2}{|c|}{ List of possible crops }} \\
\hline & & & \multicolumn{2}{|c|}{ Seeds } & \multicolumn{2}{|c|}{ Fertilizer } & \multicolumn{2}{|c|}{ Manure } & \multicolumn{2}{|c|}{ Pesticides $^{\mathrm{a}}$} & Hired labor & Machinery Cost & COther Costs. & & \\
\hline & & & Quantity (kgs) & $\operatorname{Cost}(\mathrm{Shs} / \mathrm{Kg})$ & Quantity (kgs) & $\operatorname{Cost}(\mathrm{Shs} / \mathrm{Kg})$ & Quantity (kgs) & Cost (Shs/Kg) & Quantity (kgs/ltrs) & Cost (Shs/unit) & Cost (Shs) & $(\mathrm{Shs})^{\mathrm{b}}$ & (Shs) & & \\
\hline \multirow{10}{*}{ 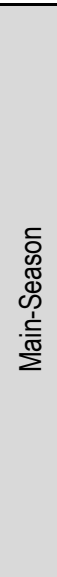 } & & Coffee & & & & & & & & & & & & & \\
\hline & 2 & & & & & & & & & & & & & 1. Coffee & 16. Sukuma \\
\hline & 3 & & & & & & & & & & & & & 2. Matooke & 17. Sugarcane \\
\hline & 4 & & & & & & & & & & & & & 3. Pineapples & 18. Soyabe \\
\hline & 5 & & & & & & & & & & & & & 4. Maize & 19. Pumpkins \\
\hline & 6 & & & & & & & & & & & & & 5. Beans & $\begin{array}{l}\text { 20. Passion } \\
\text { fruits }\end{array}$ \\
\hline & 7 & & & & & & & & & & & & & 6. Swt. potatoes & 21.Cabbages \\
\hline & 8 & & & & & & & & & & & & & 7. Swt. bananas & 22. Vegetable \\
\hline & 9 & & & & & & & & & & & & & 8. Irish potatoes & \\
\hline & 10 & & & & & & & & & & & & & 9. Groundnuts & \\
\hline \multirow{12}{*}{ 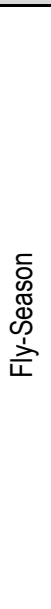 } & 11 & & & & & & & & & & & & & 10. Cowpeas & \\
\hline & 12 & & & & & & & & & & & & & 11. Tomatoes & \\
\hline & 13 & & & & & & & & & & & & & 12. Rice & \\
\hline & 14 & & & & & & & & & & & & & 13 ascava & \\
\hline & 15 & & & & & & & & & & & & & & \\
\hline & & & & & & & & & & & & & & 14. sorgnum & \\
\hline & 10 & & & & & & & & & & & & & 15. Onion & \\
\hline & 17 & & & & & & & & & & & & & & \\
\hline & 18 & & & & & & & & & & & & & & \\
\hline & 19 & & & & & & & & & & & & & & \\
\hline & & & & & & & & & & & & & & & \\
\hline & 20 & & & & & & & & & & & & & & \\
\hline
\end{tabular}

For Masaka district => ${ }^{d}$ Main season was June-July 2011 and ${ }^{\mathrm{E} F l y}$ season was Dec 2011-Jan 2012

For Luwero district $\Rightarrow^{\mathrm{d}}$ Main season was in Dec 2011-March 2012 and ${ }^{\mathrm{e}} \mathrm{Fly}$ was in Aug-Oct 2011

2. On average, how much time (in mins) do you spend walking from your homestead to the NEAREST field?

3. On average, how much time (in mins) do you spend walking from your homestead to the FURTHEST field?

mins mins 


\section{B1: Coffee Production and marketing}

1. How long have you been growing coffee? years.

2. Provide information on your coffee production in the last 12 months

ENUMERATOR: Start with Coffee Gardens that are certified, consistent with column

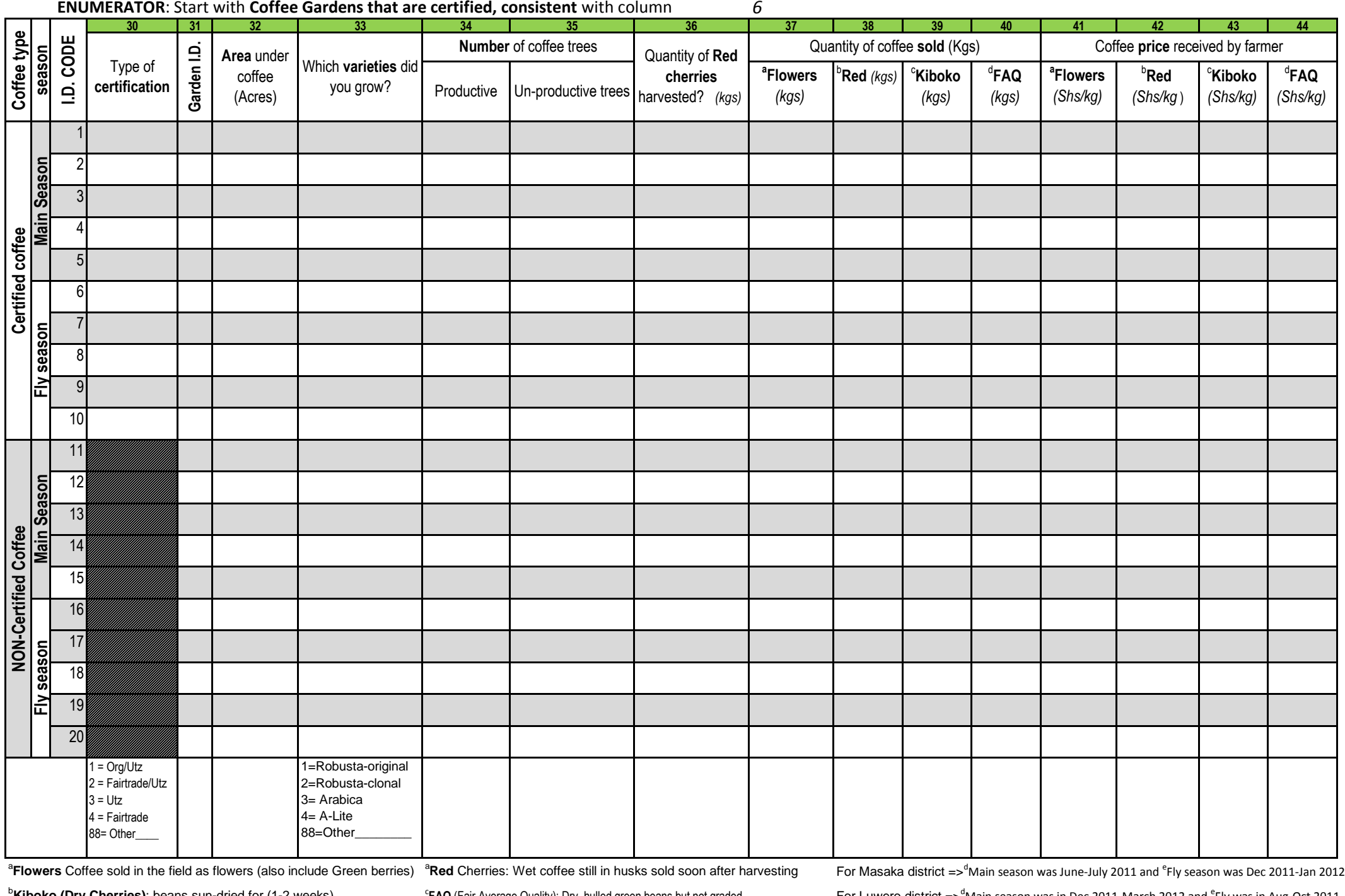

${ }^{b}$ Kiboko (Dry Cherries): beans sun-dried for (1-2 weeks).

CFAQ (Fair Average Quality): Dry, hulled green beans but not graded

For Luwero district $=>^{\mathrm{d}}$ Main season was in Dec 2011-March 2012 and ${ }^{\mathrm{e}}$ Fly was in Aug-Oct 2011

3. What is the Average Age of your current coffee trees (years)

Productive trees:

years

Unproductive trees:

years 


\section{Section B2 Coffee Production Costs}

1. For all the coffee produced, provide details of the cost of production in the past 12 months.

ENUMERATOR: Maintain the same order of coffee list as in the previous table.

ENUMERATOR. Make it clear to respondent that all costs are in reference to the area specified in the previous table.

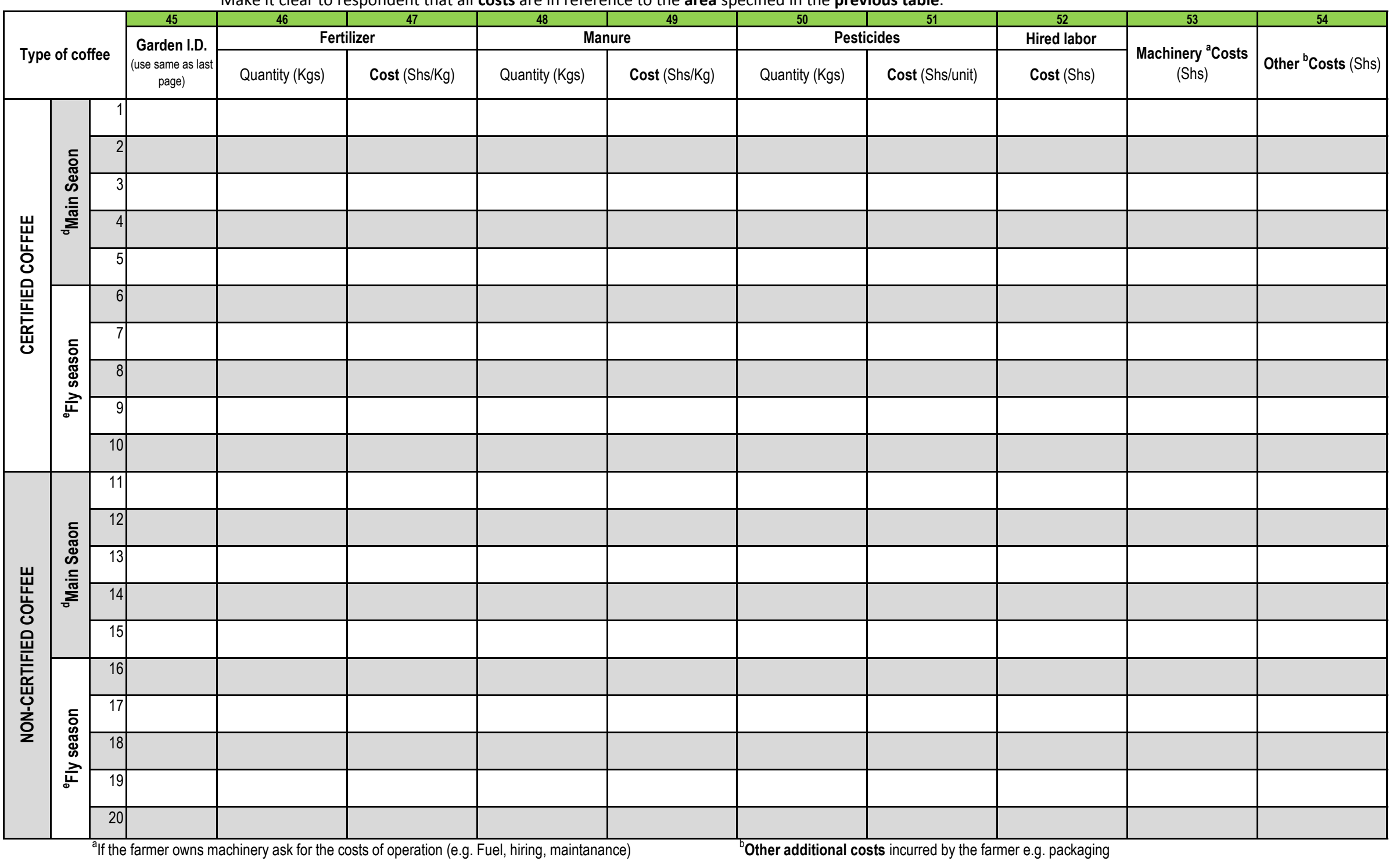

For Masaka district $=>^{\mathrm{d} M a i n}$ season was June-July 2011 and ${ }^{\mathrm{e}}$ Fly season was Dec 2011-Jan 2012

For Luwero district $=>^{\mathrm{d}}$ Main season was in Dec 2011-March 2012 and ${ }^{\mathrm{e}}$ Fly was in Aug-Oct 2011 
Section B3. Gender roles in coffee (CERTIFIED COFFEE)

1. For all the CERTIFIED COFFEE you produce, specify how often the following operations were carried in the past 12 months.

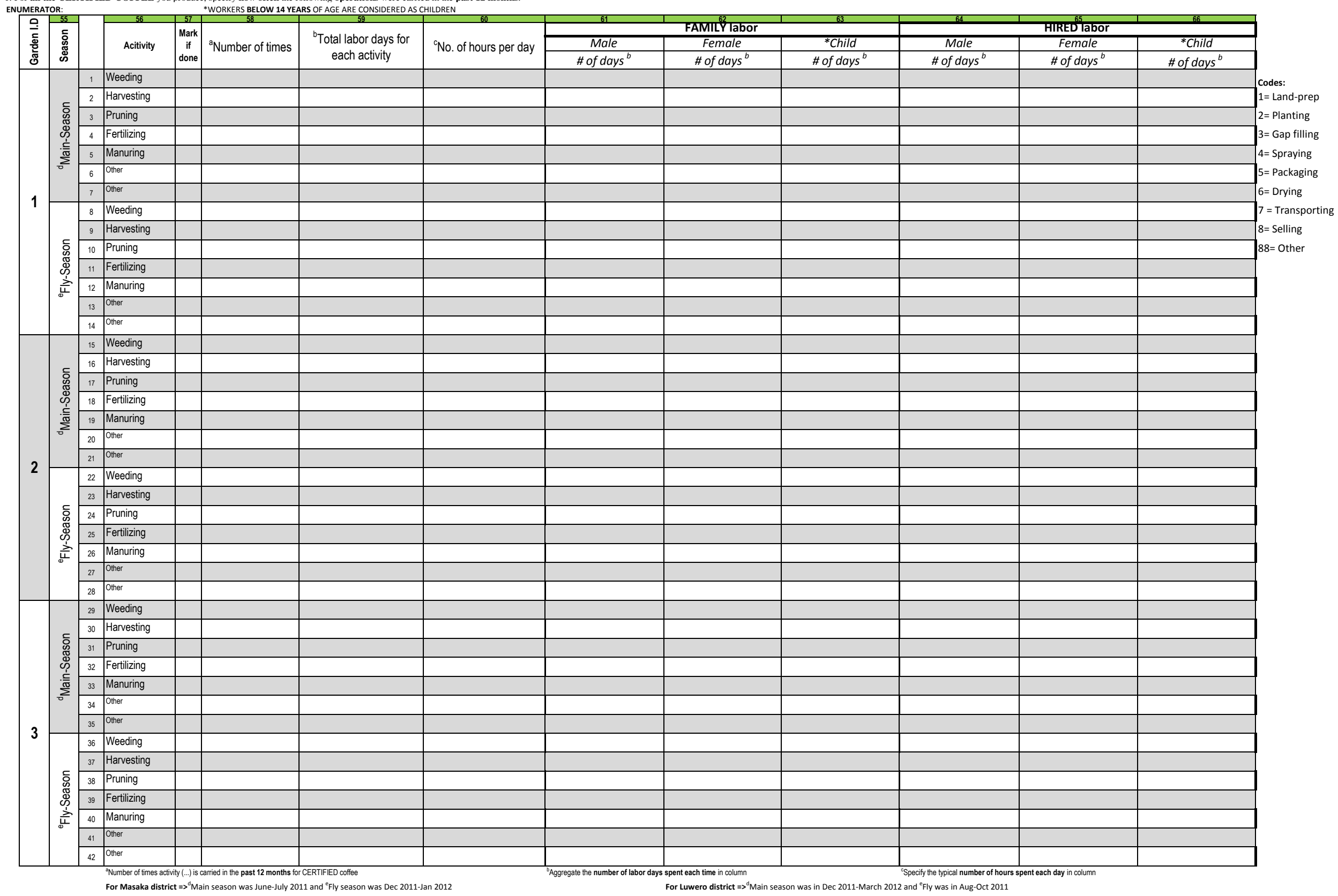


Section B3. Gender roles in coffee (NON-CERTFIED COFFEE)

1. For all the NON-CERTIFIED COFFEE you produce, specify how often the following operations were carried in the past 12 months

\begin{tabular}{|c|c|c|c|c|c|c|c|c|c|c|c|c|c|c|}
\hline \multirow{3}{*}{ 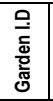 } & \multirow{3}{*}{ 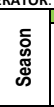 } & \multirow{3}{*}{67} & \multirow{3}{*}{ Acitivity } & \multirow{3}{*}{\begin{tabular}{|c|} 
Mark \\
if \\
done
\end{tabular}} & \multirow{3}{*}{${ }^{\text {anNumber of times }}$} & \multirow{3}{*}{$\begin{array}{l}{ }^{\mathrm{b}} \text { Total labor days for } \\
\text { each activity }\end{array}$} & \multirow{3}{*}{ 'No. of hours per day } & \multicolumn{3}{|c|}{ FAMILY" labor } & \multicolumn{3}{|c|}{ PIRED Jabor } & \\
\hline & & & & & & & & Male & Female & ${ }^{*}$ Child & Male & Female & ${ }^{*}$ Child & \\
\hline & & & & & & & & \# of days ${ }^{b}$ & $\#$ of days ${ }^{b}$ & $\#$ of days ${ }^{b}$ & $\#$ of days ${ }^{b}$ & $\#$ of days ${ }^{b}$ & $\#$ of days ${ }^{b}$ & \\
\hline \multirow{14}{*}{1} & \multirow{7}{*}{ 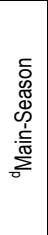 } & 1 & Weeding & & & & & & & & & & & \\
\hline & & 2 & Harvesting & & & & & & & & & & & 1 = Land-prep \\
\hline & & 3 & Pruning & & & & & & & & & & & $2=$ Planting \\
\hline & & 4 & Fertillizing & & & & & & & & & & & $3=$ Gap filling \\
\hline & & \begin{tabular}{|l|}
5 \\
\end{tabular} & Manuring & & & & & & & & & & & $4=$ Spraying \\
\hline & & \begin{tabular}{|l|}
6 \\
\end{tabular} & Other & & & & & & & & & & & $5=$ Packaging \\
\hline & & 7 & Other & & & & & & & & & & & $6=$ Drying \\
\hline & \multirow{7}{*}{ 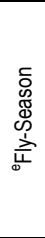 } & 8 & Weeding & & & & & & & & & & & $7=$ Transporting \\
\hline & & \begin{tabular}{|l|}
9 \\
\end{tabular} & Harvesting & & & & & & & & & & & $8=$ Selling \\
\hline & & 10 & Pruning & & & & & & & & & & & $88=$ Other \\
\hline & & \begin{tabular}{|l|}
11 \\
\end{tabular} & Fertilizing & & & & & & & & & & & \\
\hline & & 12 & Manuring & & & & & & & & & & & \\
\hline & & \begin{tabular}{|l|}
13 \\
\end{tabular} & Other & & & & & & & & & & & \\
\hline & & 14 & other & & & & & & & & & & & \\
\hline \multirow{14}{*}{2} & \multirow{7}{*}{ 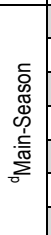 } & 15 & Weeding & & & & & & & & & & & \\
\hline & & 16 & Harvesting & & & & & & & & & & & \\
\hline & & \begin{tabular}{|l|}
17 \\
\end{tabular} & Pruning & & & & & & & & & & & \\
\hline & & \begin{tabular}{|l|}
18 \\
\end{tabular} & Fertilizing & & & & & & & & & & & \\
\hline & & \begin{tabular}{|l|}
19 \\
\end{tabular} & Manuring & & & & & & & & & & & \\
\hline & & \begin{tabular}{|l|}
20 \\
\end{tabular} & Other & & & & & & & & & & & \\
\hline & & \begin{tabular}{|l|}
21 \\
\end{tabular} & Other & & & & & & & & & & & \\
\hline & \multirow{7}{*}{ 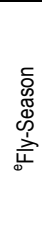 } & 22 & Weeding & & & & & & & & & & & \\
\hline & & 23 & Harvesting & & & & & & & & & & & \\
\hline & & \begin{tabular}{|l|}
24 \\
\end{tabular} & Pruning & & & & & & & & & & & \\
\hline & & \begin{tabular}{|l|}
25 \\
\end{tabular} & Fertilizing & & & & & & & & & & & \\
\hline & & 26 & Manuring & & & & & & & & & & & \\
\hline & & \begin{tabular}{|l|}
27 \\
\end{tabular} & Other & & & & & & & & & & & \\
\hline & & \begin{tabular}{|l|}
28 \\
\end{tabular} & Other & & & & & & & & & & & \\
\hline \multirow{14}{*}{3} & \multirow{7}{*}{ 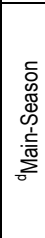 } & 29 & Weeding & & & & & & & & & & & \\
\hline & & \begin{tabular}{|l|l|}
30 \\
\end{tabular} & Harvesting & & & & & & & & & & & \\
\hline & & 31 & Pruning & & & & & & & & & & & \\
\hline & & \begin{tabular}{|l|}
32 \\
\end{tabular} & Fertilizing & & & & & & & & & & & \\
\hline & & \begin{tabular}{|l|}
33 \\
\end{tabular} & Manuring & & & & & & & & & & & \\
\hline & & \begin{tabular}{|l|}
34 \\
\end{tabular} & Other & & & & & & & & & & & \\
\hline & & 35 & other & & & & & & & & & & & \\
\hline & & \begin{tabular}{|l|}
36 \\
\end{tabular} & Weeding & & & & & & & & & & & \\
\hline & & \begin{tabular}{|l|}
37 \\
\end{tabular} & Harvesting & & & & & & & & & & & \\
\hline & 惫 & \begin{tabular}{|l|}
38 \\
\end{tabular} & \begin{tabular}{|l|} 
Pruning \\
\end{tabular} & & & & & & & & & & & \\
\hline & क् & \begin{tabular}{|l|l|l|}
39 \\
\end{tabular} & Fertilizing & & & & & & & & & & & \\
\hline & 츔 & \begin{tabular}{|l|}
40 \\
\end{tabular} & Manuring & & & & & & & & & & & \\
\hline & & \begin{tabular}{|l|}
41 \\
\end{tabular} & Other & & & & & & & & & & & \\
\hline & & \begin{tabular}{|l|}
42 \\
\end{tabular} & Other & & & & & & & & & & & \\
\hline For Ma & asaka dis & ricict $\Rightarrow{ }^{\circ}$ & 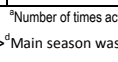 & $\begin{array}{l}\text { ity (...).iscily } \\
\text { une-July }\end{array}$ & 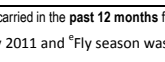 & $\begin{array}{l}\text { or CERTIFIED offiee } \\
\text { Dec 2011-Jan } 2012\end{array}$ & & $\begin{array}{l}\text { gate the number of labc } \\
\text { iwero district }=\Rightarrow^{\mathrm{d}} \mathrm{Ma}\end{array}$ & $\begin{array}{l}\text { ach time in column } \\
\text { sin Dec 2011-Marc }\end{array}$ & ly was in Aug-Oct 2 & the thpical numbe & ch day in column & & \\
\hline $\begin{array}{l}\text { What is } \\
\text { What is }\end{array}$ & $\begin{array}{l}\text { is the typ } \\
\text { s the typl }\end{array}$ & cal num & $\begin{array}{l}\text { mber of hours sp } \\
\text { ily wage rate in }(S \mid\end{array}$ & $\begin{array}{l}\text { on a } 1 \\
\text { for }\end{array}$ & $\begin{array}{l}\text { Men_ } \quad \text { hrslday } \\
\text { Men_Iday }\end{array}$ & $\begin{array}{l}\text { Women__ hrs/day } \\
\text { Women__/day }\end{array}$ & $\begin{array}{l}\text { Children__ hirsday } \\
\text { Children_/dayy }\end{array}$ & & & & & & & \\
\hline
\end{tabular}




\section{Section B4. Coffee Marketing and Certification}

1. Provide answers to the following questions

ENUMERATOR: Specify the type of certified coffee being reffered to in columns

\begin{tabular}{|c|c|c|c|c|c|c|c|}
\hline & \multirow{3}{*}{$\begin{array}{c}\text { Responses (Allow for multiple } \\
\text { answers) }\end{array}$} & 79 & 80 & 81 & 82 & \multirow{3}{*}{ Convetiona } \\
\hline & & & \multicolumn{4}{|c|}{ Certification: $1=$ Organic $\quad 2=\mathrm{FT} \quad 3=\mathrm{Utz} \quad 4=$ Rainforest Alliance $\quad 88=$ Other } & \\
\hline & & & 1= Organic & 2= Fairtrade & $3=U t z$ & & \\
\hline 1 & $\begin{array}{c}\text { Are you aware of certification } \\
\text { schemes like Organic, FT or Utz? }\end{array}$ & $\begin{array}{l}0=\text { No } \quad 1=\text { Yes } \\
\text { Indicate which ones }\end{array}$ & & & & & \\
\hline 2 & $\begin{array}{c}\text { If Yes to Q1, how were you informed of } \\
\text { these certified markets? }\end{array}$ & $\begin{array}{c}1=\text { CO-OP } \quad 2=\text { Farmer Group } \\
3=\text { Neighbor } \quad 4=\text { Media } 88 . \text { Other }\end{array}$ & & & & & \\
\hline 3 & $\begin{array}{l}\text { For each certification scheme, indicate } \\
\text { main challenges of getting certfied? }\end{array}$ & $\begin{array}{c}0=\text { Don' }^{\prime} \text { know } 1=\text { High costs } \\
2=\text { Stringent requirements } \quad 88=\text { Other }\end{array}$ & & & & & \\
\hline 4 & $\begin{array}{c}\text { If given the chance, which certification } \\
\text { scheme would you have first preference } \\
\text { to participate in? }\end{array}$ & $\begin{array}{l}0=\text { None } \quad 1=\text { Organic } \quad 2=F T \\
3=U t z \quad 4=\text { Rainforest } 88=\text { Other }\end{array}$ & & & & & \\
\hline 5 & Why? & & & & & & \\
\hline 6 & \begin{tabular}{|c|}
$\begin{array}{c}\text { What are your main sources for coffee } \\
\text { seedlings/cuttings? }\end{array}$ \\
\end{tabular} & $\begin{array}{c}=\text { Self } \quad 2=\text { Other farmers } \quad 3=\text { Co-op } \\
4=\text { Exporter } \quad 5=\text { Gvt } \quad 88=\text { Other }\end{array}$ & & & & & \\
\hline 7 & How do you dry your coffee? & $\begin{array}{c}\begin{array}{c}0=\text { don't dry } \quad 1=\text { on bare ground } \\
2=\text { on concrete } 3=\text { Tarpaulin } \\
88=\text { Other }\end{array} \\
\end{array}$ & & & & & \\
\hline 8 & $\begin{array}{l}\text { Do you dry it to a certain moisture } \\
\text { content? }\end{array}$ & $\begin{array}{l}0=\text { No } \\
1=\text { Yes }\end{array}$ & & & & & \\
\hline 9 & $\begin{array}{c}\text { If Yes, up to what moisture content to } \\
\text { you Dry your coffee? }\end{array}$ & & & & & & \\
\hline 10 & $\begin{array}{l}\text { How do you ascertain the mositure } \\
\text { content? }\end{array}$ & \begin{tabular}{|c}
$=$ moisture metre $\quad 2=$ biting \\
$3=$ hand shaking $4=$ No of days in \\
Sun $88=$ Other
\end{tabular} & & & & & \\
\hline 11 & $\begin{array}{c}\text { What are the main diseases affecting } \\
\text { your coffee }\end{array}$ & $\begin{array}{l}0=\text { none } \\
1=\text { Coffee wilt disease } \\
3=\text { Coffee blight } \quad 88=\text { Other }\end{array}$ & & & & & \\
\hline 12 & \begin{tabular}{|c|}
$\begin{array}{c}\text { What are the main pests affecting your } \\
\text { coffee }\end{array}$ \\
\end{tabular} & $\begin{array}{c}0=\text { None } \quad 1=\text { Coffee borer } \\
2=\text { Weavil } \quad 88=\text { Other }\end{array}$ & & & & & \\
\hline 13 & $\begin{array}{c}\text { How do you store your coffee after } \\
\text { harvesting? }\end{array}$ & $\begin{array}{c}1=\text { on ground } 2=\text { off the ground } \\
88=\text { Other }\end{array}$ & & & & & \\
\hline
\end{tabular}




\title{
Section B5. Coffee Marketing and Certification
}

1. Provide answers to the following questions

\begin{tabular}{|c|c|c|c|c|c|c|c|c|c|c|}
\hline & 84 & 85 & 86 & 87 & 88 & 89 & 90 & 91 & \multirow{3}{*}{$\begin{array}{l}\text { Codes for Who Buvs } \\
1=\text { Farmer group } \\
2=\text { middlemen }\end{array}$} \\
\hline & & \multicolumn{4}{|c|}{ Certified coffee } & \multicolumn{4}{|c|}{ NON-Certified coffee } & \\
\hline & & Flowers & Red cherries & Kiboko & $F A Q$ & Flowers & Red cherries & Kiboko & $F A Q$ & \\
\hline 1 & $\begin{array}{c}\text { What proportion (\%) of your coffee do you } \\
\text { normally sell as }(\ldots) ?\end{array}$ & & & & & & & & & $\begin{array}{l}3=\text { Kibinge FA } \\
4=\text { IBERO LTD }\end{array}$ \\
\hline 2 & $\begin{array}{l}\text { To }{ }^{\text {a }} \text { whom do you normally sell the } \\
\text { following type of coffee? (allow multiple } \\
\text { respones BUT start with most important)? }\end{array}$ & & & & & & & & & $\begin{array}{l}5=\text { KAWACOM } \\
6=\text { Market in Kampala } \\
7=\text { local Exporter }\end{array}$ \\
\hline \multirow{3}{*}{3} & What are some of the ${ }^{b}$ reasons you sell & & & & & & & & & \multirow{4}{*}{$88=$ Other } \\
\hline & this type of coffee (Start with the most & & & & & & & & & \\
\hline & important)? & & & & & & & & & \\
\hline 4 & $\begin{array}{c}\text { Who in the household negotiates for } \\
\text { coffee prices with buyers? }\end{array}$ & 1. Head & \multicolumn{3}{|c|}{ 2. spouse 3 . Jointly } & 1. Head & 2. spouse 3. Joi & \multicolumn{2}{|c|}{ 88. Other } & \\
\hline
\end{tabular}

2 What are some of the Advantages and Disadvantages of selling your coffee to the following Buyers?

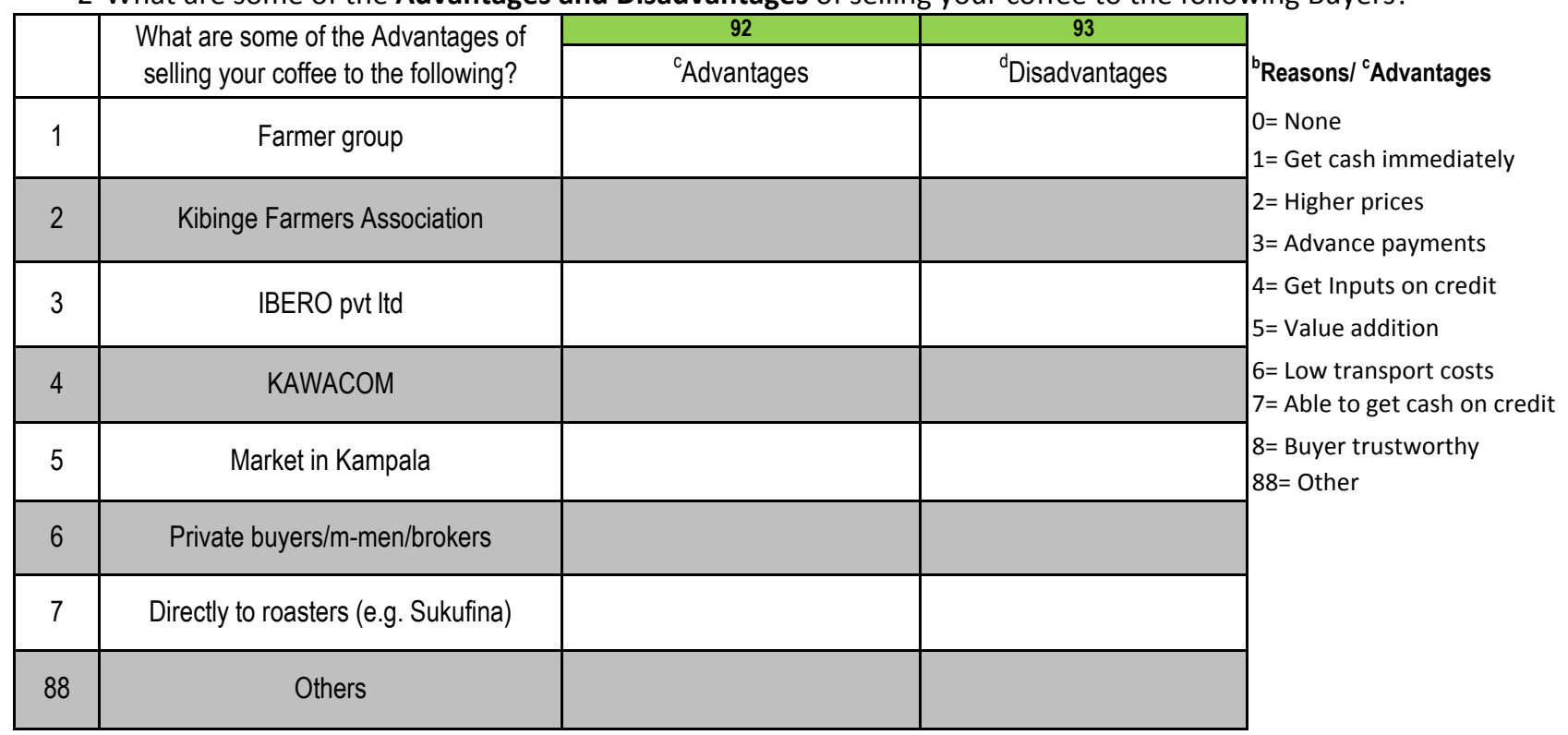

\author{
${ }^{d}$ Disadvantages \\ $0=$ None \\ $1=$ Delayed payment \\ 2= Lower prices \\ $3=$ No Advance payments \\ $4=$ No Inputs on credit \\ $5=$ No Value addition \\ $6=$ High transport costs \\ $7=$ Not able to get cash on credit \\ $8=$ Buyer untrustworthy \\ $88=$ Other
}




\section{Section B6. Coffee Marketing and Certification}

1. FOR ALL FARMERS: Provide answers to the following questions

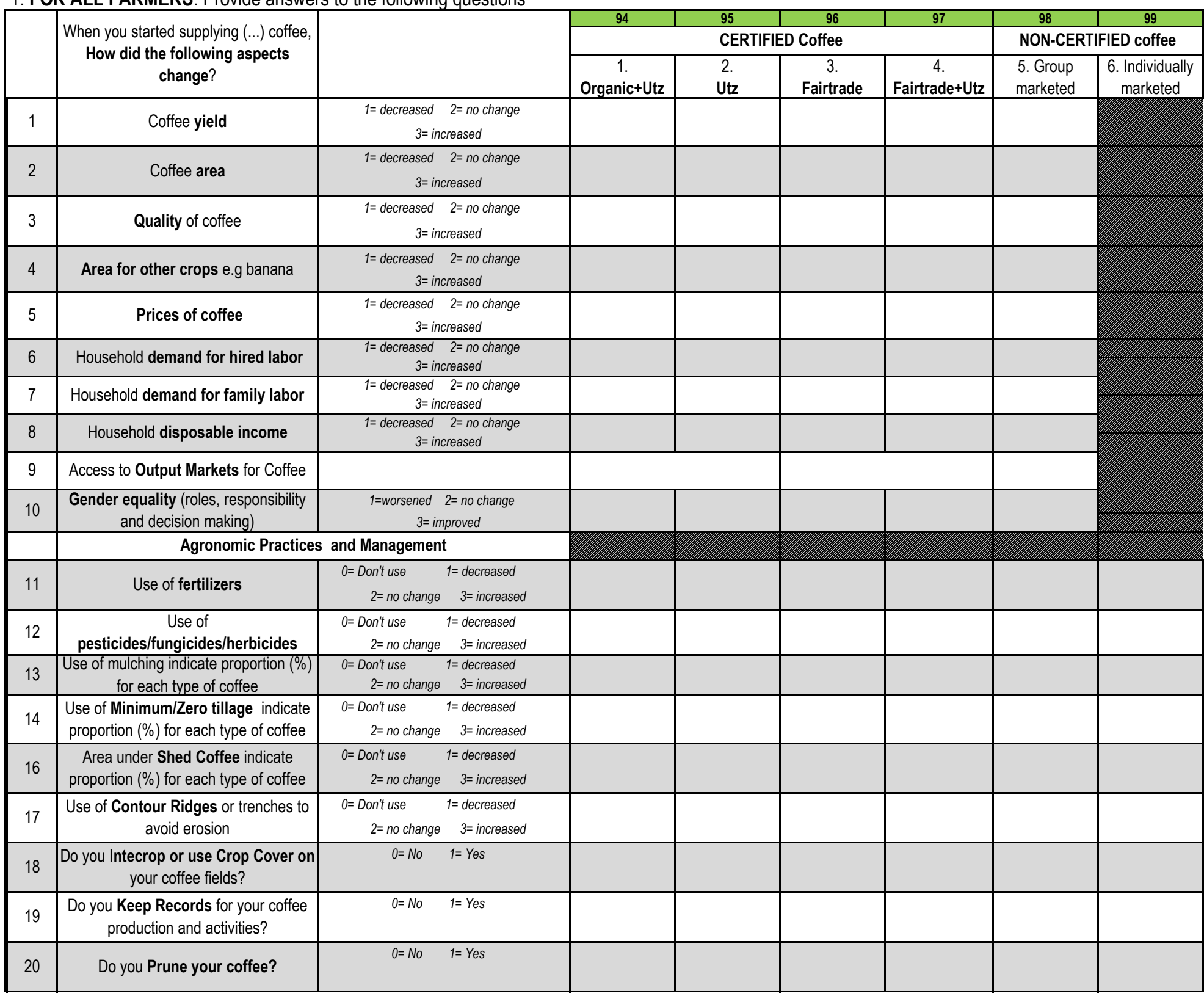




\section{Section C. Livestock production}

1. Provide the following information on livestock owned by your household in the past $\mathbf{1 2}$ months.

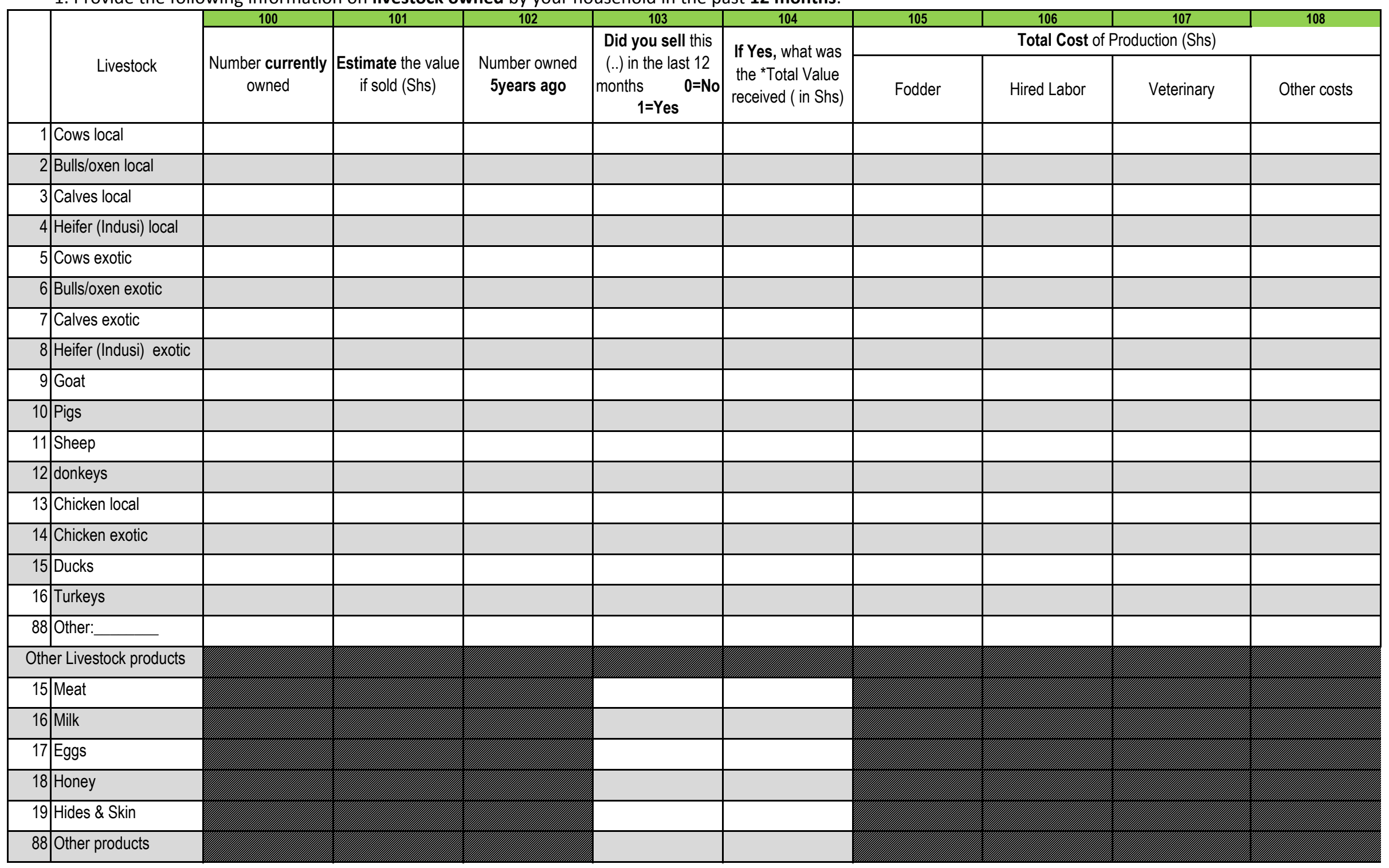

*Value of all livestock and livestock products sold by the household in the past 12 months. 


\section{Section D: Asset Ownership}

1.Provide the following information on assets owned in the past 12 months?

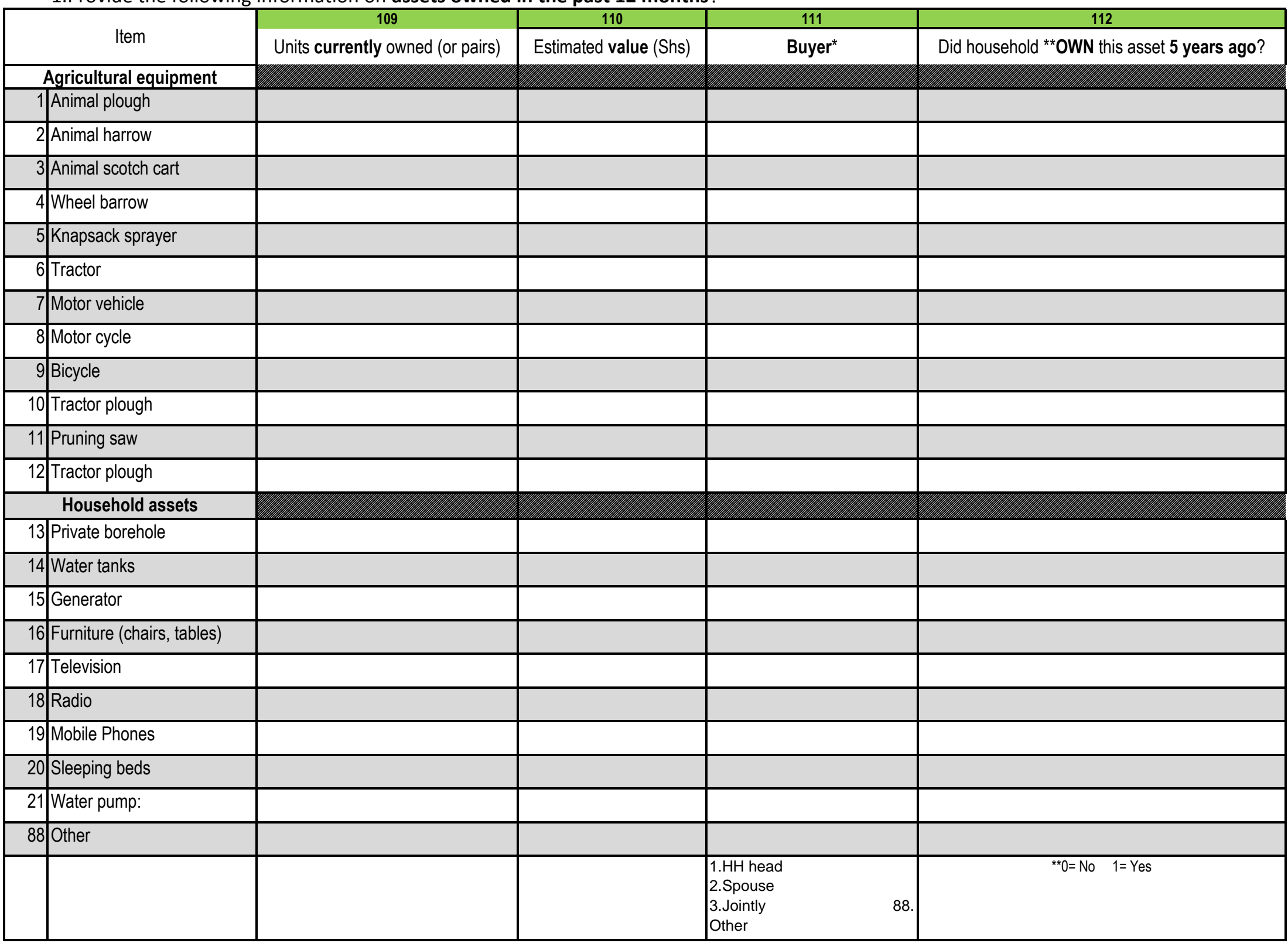




\section{Section D. Household Assets II}

1. Number of years of residence in this community?

2. In which district where you resident before settling in this community?

3. How long have you been involved in farming?

$$
\text { YRES }
$$
years.

DRES

YFARM__ years.

4. Provide answers to the following questions on household assets currently owned as well as $\mathbf{5}$ years ago.

\begin{tabular}{|c|c|c|c|c|}
\hline & 113 & \multirow{2}{*}{114} & \multirow{2}{*}{$\frac{115}{\text { Ownership in the last } 5 \text { years }}$} \\
\hline & & Responses & & \\
\hline 1 & Type of dwelling & $\begin{array}{c}\text { 1= mud hut with grass thatching } \quad 2=\text { Mud hut with asbestors/iron roof } \\
\text { 3= Brick house with grass thatching } \quad 4=\text { Brick house with asbestors/iron roof }\end{array}$ & & \\
\hline 2 & Tenure status of dwelling & $\begin{array}{c}1=\text { Own with title deeds } 2=\text { Own without title deeds } \\
3=\text { Rented } \quad 4=\text { Borrowed without pay } 88 . \text { Other }_{-}\end{array}$ & & \\
\hline 3 & Total number of rooms owned & & & \\
\hline 4 & Type of toilet & $\begin{array}{ccc}1=\text { Bush } & 2=\text { Flush } & 3=\text { Ventilated latrine } \\
4=\text { Pit Latrine } & 88=\text { Other }\end{array}$ & & \\
\hline 5 & Main source of drinking water & $\begin{array}{c}1=\text { Private tap } \quad 2=\text { Public Tap/Borehole } \\
\text { 4= River, stream, lake, pond, well, springs } \quad 5=\text { Rain water } \quad 88=\text { Other }\end{array}$ & & \\
\hline 6 & Main source of lighting & $\begin{array}{c}1=\text { Electric bulbs } \quad 2=\text { Parrafin lantern } \\
4=\text { Wick Lamp }\end{array}$ & & \\
\hline 7 & Main type of cooking fuel & $\begin{array}{l}\begin{array}{l}\text { 1= Charcoal } 2=\text { Firewood } \quad 3=\text { Gas } \quad 4=\text { Electricity } \\
5=\text { Paraffin/Kerosine } \quad 6=\text { Solar } \quad 7=\text { Biogas } \quad 88=\text { other }\end{array}\end{array}$ & & \\
\hline
\end{tabular}




\section{Section E: Household Information}

1. First, I would like to know the number of people who normally live and eat their meals in this household (including servants and other workers).

N/B Tenants who pay rent are NOT considered as members of this household.

Number of $\mathrm{HH}$ members

2. Please provide the list of names of each member in this household starting with the Head, Spouse, his/her children in order of age

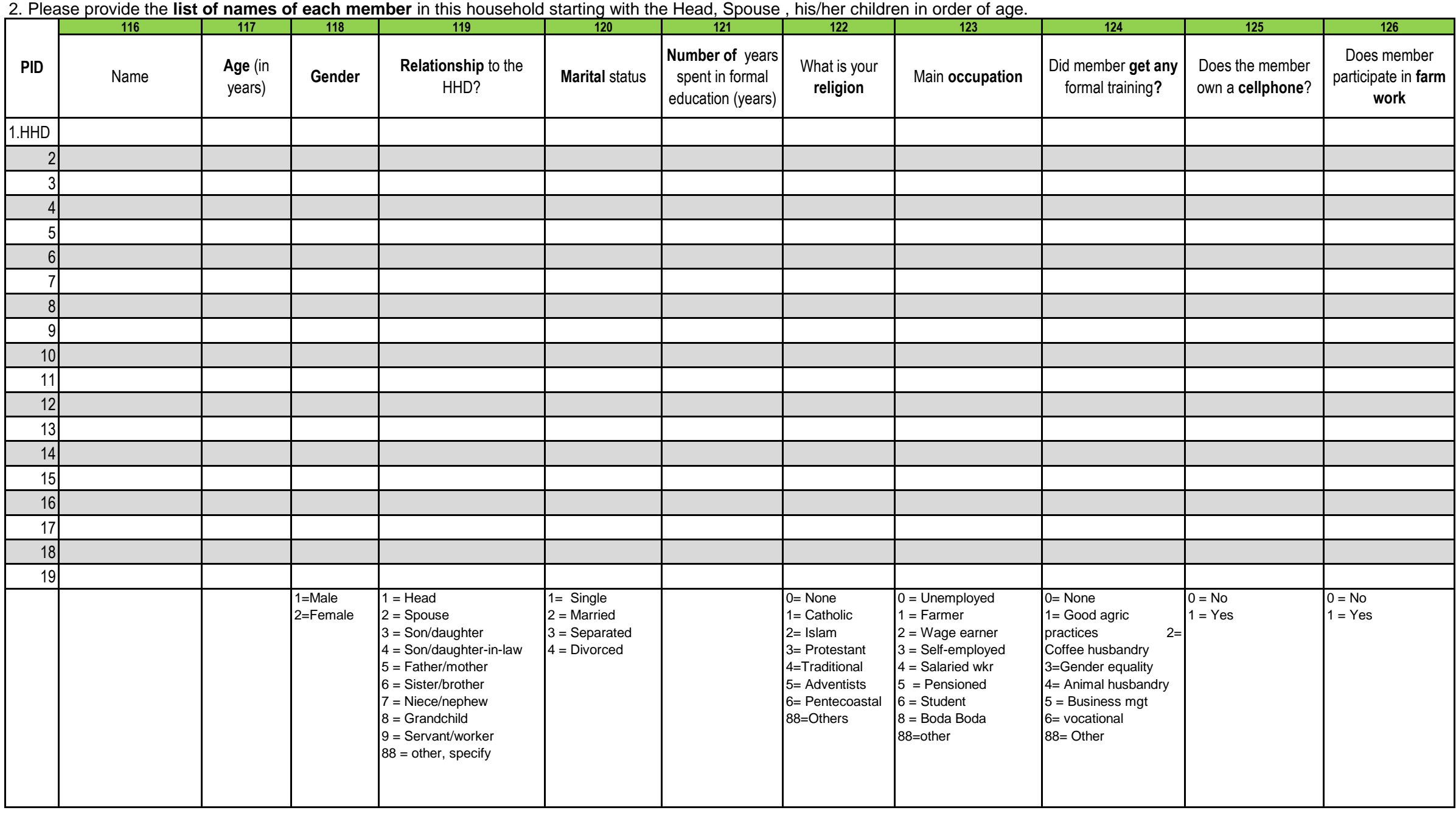




\section{Section F: Off-farm income}

1. Provide information on how much Off-farm income was earned by members of this household in the past 12 months.

PLEASE ENSURE INFORMATION IN THIS TABLE CORRESPONDS TO PREVIOUS TABLE AND COLUMN 88 in particular.

\begin{tabular}{|c|c|c|c|c|c|c|c|c|c|c|c|c|}
\hline & \multirow{3}{*}{ Off-farm income sources } & 127 & 128 & 129 & 130 & 131 & 132 & 133 & 134 & 135 & 136 & 137 \\
\hline & & \multicolumn{11}{|c|}{ Income obtained by household members during the last 12 months (Shs/year) } \\
\hline & & H-Head & Member & Member & Member & Member_ & Member & Member & Member & Member & Member & Member \\
\hline 1 & $\begin{array}{l}\text { Agricultural Wage labour from other } \\
\text { farms }\end{array}$ & & & & & & & & & & & \\
\hline 2 & Wage employment outside Agriculture & & & & & & & & & & & \\
\hline 3 & $\begin{array}{l}\text { Profit from personal business (incl. } \\
\text { retail trade, Boda boda, brickmaking) }\end{array}$ & & & & & & & & & & & \\
\hline 4 & $\begin{array}{l}\text { Revenue from sale of forest products } \\
\text { (tree poles, firewood, charcoal) }\end{array}$ & & & & & & & & & & & \\
\hline 5 & $\begin{array}{l}\text { Wage from machinery service for other } \\
\text { farms }\end{array}$ & & & & & & & & & & & \\
\hline 6 & $\begin{array}{l}\text { Remittances received from family } \\
\text { members and relatives }\end{array}$ & & & & & & & & & & & \\
\hline 7 & $\begin{array}{l}\text { Pensions/retirement package/share } \\
\text { dividends }\end{array}$ & & & & & & & & & & & \\
\hline 8 & Revenue from leasing out land & & & & & & & & & & & \\
\hline 9 & $\begin{array}{l}\text { Income from renting out draft animals or } \\
\text { machinery to other farms }\end{array}$ & & & & & & & & & & & \\
\hline 10 & $\begin{array}{l}\text { Sale of household Assets (land, } \\
\text { furniture) }\end{array}$ & & & & & & & & & & & \\
\hline 11 & Total & & & & & & & & & & & \\
\hline
\end{tabular}


Section G: Food Expenditure I

1. On average, how many people were present in the last 7 days? In this section children are defined as less than 18 years.

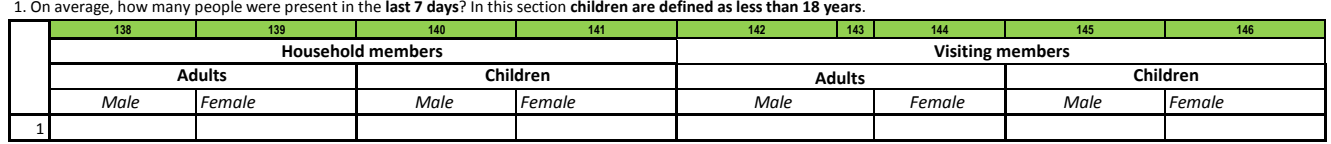

2. In the past 7 days indicate how much of the following food items your household consumed and the value in Shs. (This is for all food consumed, including own-produced, bought, gifts and from food aid programme, by all people living in household)

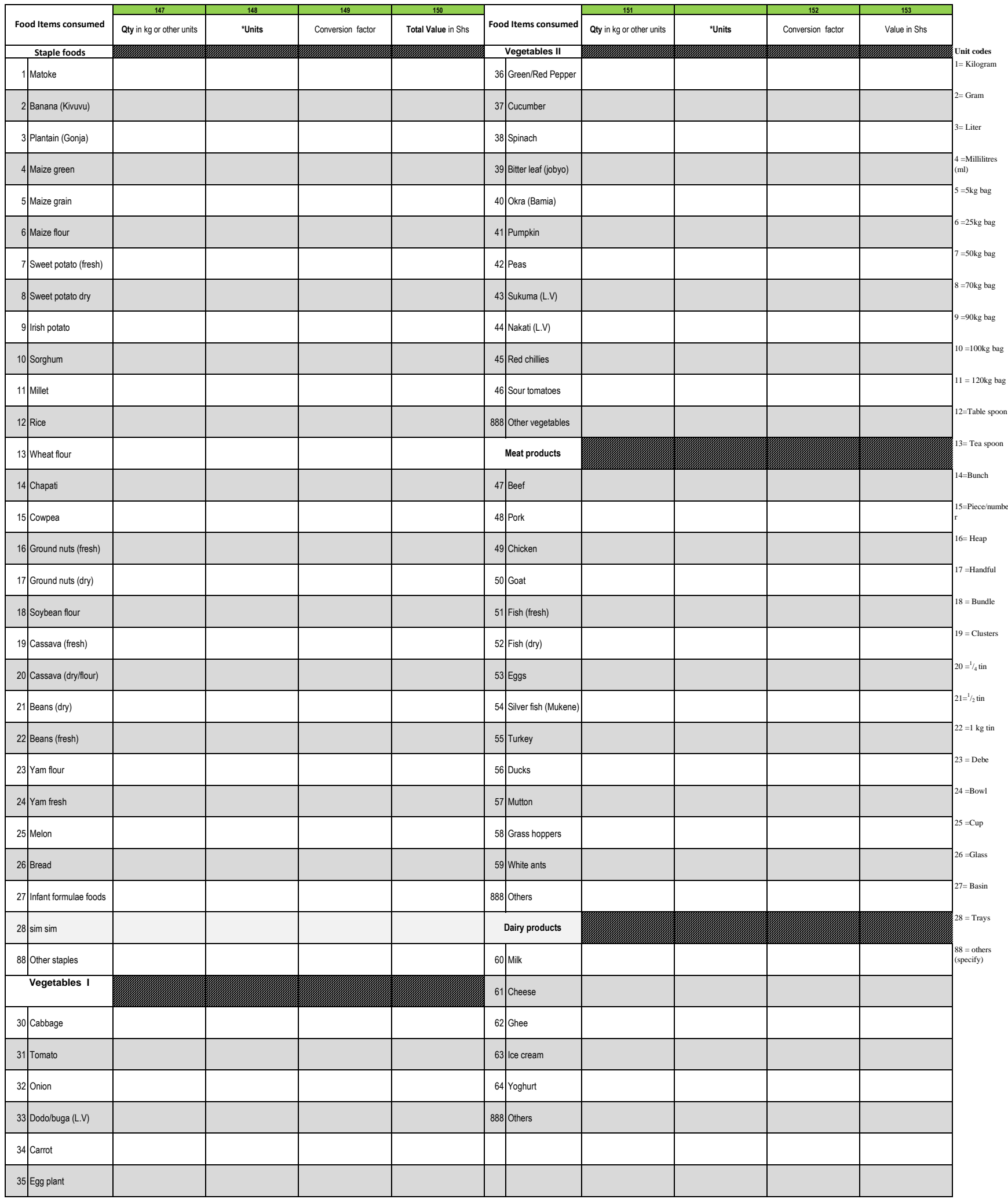


Section G: Food Expenditure II

1. In the past 7 days indicate how much of the following food items your household consumed and the value in Shs. (This is for all food consumed, including own-produced, bought, gifts and from food aid programme, by all people living in household

\begin{tabular}{|c|c|c|c|c|c|c|c|c|c|c|c|c|}
\hline \multirow{2}{*}{\multicolumn{2}{|c|}{ Food Items consumed }} & 154 & \multirow{2}{*}{$\begin{array}{c}155 \\
\text { *Units }\end{array}$} & \multirow{2}{*}{$\begin{array}{c}156 \\
\text { Conversion } \\
\text { factor }\end{array}$} & \multirow{2}{*}{$\begin{array}{c}157 \\
\text { Value in Shs }\end{array}$} & \multirow{2}{*}{\multicolumn{2}{|c|}{ Food Items consumed }} & \multirow{2}{*}{\begin{tabular}{|c|}
158 \\
$\begin{array}{c}\text { Qty in kg or other } \\
\text { units }\end{array}$
\end{tabular}} & \multirow{2}{*}{$\begin{array}{l}159 \\
* \text { Units }\end{array}$} & \multirow{2}{*}{\begin{tabular}{|c|}
159 \\
Conversion factor
\end{tabular}} & \multirow{2}{*}{$\begin{array}{c}160 \\
\text { Value in Shs }\end{array}$} & \multirow[b]{3}{*}{ *Unit codes } \\
\hline & & $\begin{array}{c}\text { Qty in kg or other } \\
\text { units }\end{array}$ & & & & & & & & & & \\
\hline & Fruits & & & & & & ndiments etc & & & & & \\
\hline $55 s$ & Sweett bananas & & & & & 79 & Royco & & & & & 1 = Kilogram \\
\hline 56 & Bogoya & & & & & 80 & Salt & & & & & $2=$ Gram \\
\hline $57 \mathrm{~F}_{\mathrm{F}}$ & Pineapples & & & & & 81 & Curry & & & & & $3=$ Liter \\
\hline $58 \mathrm{~F}$ & Pawpaws & & & & & 82 & Oatmeal & & & & & $4=$ Millilitres \\
\hline 59 & Mangoes & & & & & 83 & Ginger & & & & & $5=5 \mathrm{~kg}$ bag \\
\hline $60 \mid A-r a t a$ & Apples & & & & & 84 & Other spices & & & & & $6=25 \mathrm{~kg} \mathrm{bag}$ \\
\hline $61 \mathrm{~F}$ & Passion fruits & & & & & 85 & Sugar and sweets & & & & & $7=50 \mathrm{~kg} \mathrm{bag}$ \\
\hline 62 & Guavas & & & & & 86 & Sugar & & & & & $8=10 \mathrm{~kg}$ bag \\
\hline $63 \mathrm{~s}$ & Sugar cane & & & & & 87 & Chocolate & & & & & $9=90 \mathrm{~kg} \mathrm{bag}$ \\
\hline $64 \mathrm{C}$ & Oranges & & & & & 88 & Other sweets & & & & & $10=100 \mathrm{~kg}$ bag \\
\hline $65 \mid \mathrm{J}$ & Jack Fruit & & & & & 89 & Cooking oil/fat & & & & & $11=120 \mathrm{~kg} \mathrm{ba}$ \\
\hline 888 & Other fruits & & & & & 90 & Peanut butter oil & 年 & & & & $\begin{array}{l}12=\text { Table } \\
\text { spoon }\end{array}$ \\
\hline & Beverages & & & & & 91 & Sheer butter oil & & & & & $13=$ Tea spoon \\
\hline $64 C$ & Coffee & & & & & 92 & Margarine/Butter & & & & & |14=Bunch \\
\hline 657 & Tea & & & & & 93 & Ghee & & & & & $\begin{array}{l}15=\text { =iece/numb } \\
\text { er }\end{array}$ \\
\hline $66 \mathrm{~s}$ & Soft drinks & & & & & 94 & Other oil & & & & & $16=$ heap \\
\hline $67 \mathrm{~F}$ & Fruit juices & & & & & 95 & Snacks & & & & & | 17 =Handful \\
\hline 68 & Carbonated Drinks & & & & & 96 & Popcorn & & & & & 18=Pakaacha \\
\hline 69 & Other juice & & & & & 97 & Biscuit & & & & & $19=$ Gorogoro \\
\hline $70 \mid \mathrm{E}$ & Bottled beer & & & & & 98 & Cashew nut & & & & & $20=1 / 4$ tin \\
\hline $71 \mathrm{~L}$ & Local beer (opaque) & & & & & 99 & Other snacks & & & & & $21=1 / 2 \operatorname{tin}$ \\
\hline $72 \mathrm{~V}$ & Wine & & & & & 100 & Cashew nut & & & & & $22=1 \mathrm{~kg}$ tin \\
\hline $73 \mathrm{~s}$ & Spirits & & & & & 888 & Other snacks & & & & & $23=$ Debe \\
\hline $74 \mid \mathrm{K}$ & Kayinja/Musa & & & & & & & & & & & $24=$ Bowl \\
\hline 75 & Ciggarettes & & & & & & & & & & & $25=$ Cup \\
\hline 76 & Other Tobacco & & & & & & & & & & & $26=$ Glass \\
\hline 888 & Other beverages & & & & & & & & & & & $\begin{array}{l}88=\text { othe } \\
\text { (specify) }\end{array}$ \\
\hline
\end{tabular}


1. During the past $\mathbf{7}$ Days, did any of the household members eat food away from home? $\quad \mathbf{0}=$ No $\quad \mathbf{1}=$ Yes

2. If Yes to Q1, indicate the number of times they ate food away and the value of meals in the past 7 days.

\begin{tabular}{|c|c|c|c|c|c|c|c|c|c|c|c|}
\hline & \multirow{3}{*}{$\begin{array}{l}\text { Food eaten away from home in the past } \\
7 \text { days (e.g. In schools, restaurants, during } \\
\text { ceremonies) }\end{array}$} & 161 & 162 & 163 & 164 & 165 & 166 & 167 & 168 & 169 & 170 \\
\hline & & \multicolumn{10}{|c|}{ Member of household (maintain members and sequence as in Table E1. } \\
\hline & & $\mathrm{HHD}$ & Member 2 & Member 3 & Member 4 & Member 5 & Member 6 & Member 7 & Member 8 & Member 9 & Member 10 \\
\hline 1 & Number of times & & & & & & & & & & \\
\hline 2 & Value of meals & & & & & & & & & & \\
\hline 3 & Which *Foods does member normally eat & & & & & & & & & & \\
\hline
\end{tabular}

Which *Foods does member normally eat

\begin{tabular}{|c|c|c|c|c|c|c|c|c|c|c|c|}
\hline \multirow{3}{*}{\multicolumn{2}{|c|}{$\begin{array}{c}\text { Food eaten away from home in the past } \\
\text { 7days (e.g. In schools, restaurants, during } \\
\text { ceremonies) }\end{array}$}} & 171 & 172 & 173 & 174 & 175 & 176 & 177 & 178 & 179 & 180 \\
\hline & & \multicolumn{10}{|c|}{ 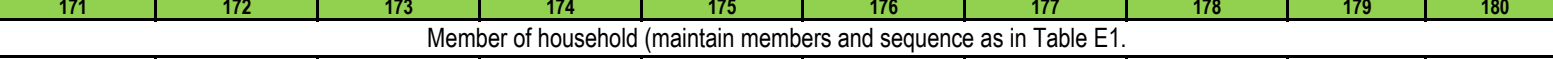 } \\
\hline & & Member 11 & Member 12 & Member 13 & Member 14 & Member 15 & Member 16 & Member 17 & Member 18 & Member 19 & Member 20 \\
\hline 1 & Number of times & & & & & & & & & & \\
\hline 2 & Value of meals & & & & & & & & & & \\
\hline 3 & Which *Foods does member normally eat & & & & & & & & & & \\
\hline
\end{tabular}

SECTION H: Non-food expenditure I

1. How much does your household spend on the items listed in a typical month or year (whichever is easier)?

\begin{tabular}{|c|c|c|c|c|c|c|}
\hline \multirow{2}{*}{\multicolumn{2}{|c|}{$\begin{array}{c}\text { CONSUMED IN TYPICAL MONTH } \\
\text { READ OUT }\end{array}$}} & 161 & 162 & \multirow{2}{*}{$\begin{array}{c}\text { CONSUMED IN TYPICAL } \\
\text { MONTH } \\
\text { READ OUT }\end{array}$} & 163 & 164 \\
\hline & & $\begin{array}{c}\text { Value of spending on [ITEM] in a } \\
\text { typical month? }\end{array}$ & $\begin{array}{c}\text { Value of spending on [ITEM] in } \\
\text { a typical year? }\end{array}$ & & $\begin{array}{l}\text { Value of spending on [ITEM] in } \\
\text { a typical month? }\end{array}$ & $\begin{array}{l}\text { Value of spending on } \\
\text { [ITEM] in a typical year? }\end{array}$ \\
\hline \multicolumn{2}{|r|}{$\begin{array}{l}\text { ENTER ZERO IF NOTHING IS CONSUMED } \\
\text { ENTER } 99 \text { IF THEY DON'T KNOW }\end{array}$} & VALUE IN Shs & VALUE IN Shs & $\begin{array}{c}\text { ENTER ZERO IF NOTHING IS } \\
\text { CONSUMED } \\
\text { ENTER 99 IF THEY DON'T KNOW }\end{array}$ & VALUE IN Shs & VALUE IN Shs \\
\hline & Rentals (house, land) & & & $\begin{array}{l}\text { 8. Telephone Bills (including } \\
\text { mobile) }\end{array}$ & & \\
\hline 2 & Kitchen utensils (pots, pans, plates, cutlery) & & & $\begin{array}{l}\text { 9. Ceremonies (church, } \\
\text { weddings, festivals, burials) }\end{array}$ & & \\
\hline 3 & Household furniture (beds, tables, chairs) & & & 10. Firewood/ Charcoal & & \\
\hline & $\begin{array}{l}\text { Clothing and footwear (fabric, clothes, towels, } \\
\text { shoes) }\end{array}$ & & & $\begin{array}{l}\text { 11. Remittances or transfers to } \\
\text { other individuals }\end{array}$ & & \\
\hline & $\begin{array}{l}\text { Electricity, Gas, Parafin, Biogas (for cooking and } \\
\text { light) }\end{array}$ & & & $\begin{array}{l}\text { 12. Repairs of machinery, } \\
\text { equipment, housing }\end{array}$ & & \\
\hline 6 & Education, books, schoolfees, uniforms & & & $\begin{array}{l}\text { 13. Amount paid as interest, } \\
\text { other fees, amagoba }\end{array}$ & & \\
\hline & $\begin{array}{l}\text { Health care(consultation fees, medicines, } \\
\text { spectacles) }\end{array}$ & & & $\begin{array}{l}\text { 14. Public transport (Boda-boda, } \\
\text { taxi, bus) }\end{array}$ & & \\
\hline 15 & $\begin{array}{l}\text { Membership fees (COOP, Fmr groups, Burial } \\
\text { socities, }\end{array}$ & & & $\begin{array}{l}\text { 88. Other major non-food items } \\
\text { (SPECIFY) }\end{array}$ & & \\
\hline
\end{tabular}




\section{Section I: Social networks I}

1. Provide answers to the following questions.

\begin{tabular}{|c|c|c|c|c|c|c|}
\hline & & \begin{tabular}{|c|}
165 \\
\end{tabular} & 166 & & 167 & 168 \\
\hline & Type of service & $\begin{array}{c}\text { Do you have access to } \\
\text { this service? } \\
0=\text { No } \quad 1=\text { Yes } \\
\end{array}$ & $\begin{array}{r}\text { Distance to nearest } \\
\text { source/service }(\mathrm{km})\end{array}$ & Type of service & $\begin{array}{c}\text { Do you have access to } \\
\text { this service? } \\
0=\text { No } \quad 1=\text { Yes }\end{array}$ & $\begin{array}{r}\text { Distance to nearest } \\
\text { source/service }(\mathrm{km})\end{array}$ \\
\hline 1 & Financial credit & & & 12. Tarred road & & \\
\hline 2 & Hospital, clinic or Doctor & & & 13. Bus connection to Kampala & & \\
\hline 3 & Input market for coffee & & & 14. Watering Source (livestock) & & \\
\hline 4 & $\begin{array}{l}\text { Output market for coffee } \\
\text { (different from farm-gate) }\end{array}$ & & & 15. Electricity & & \\
\hline 5 & Coffee collection centre & & & 16. Water source for Household use & & \\
\hline 6 & Extension office/r & & & 17.Access to phone (public/private) & & \\
\hline 7 & Access to a Primary school & & & 18. Access to Internet & & \\
\hline 8 & Access to a Secondary school & & & 19. Access to a University & & \\
\hline 9 & Source of coffee seedlings & & & 20. Religous association & & \\
\hline 10 & Access to a Commercial Bank & & & $\begin{array}{l}\text { 21. Access to a coffee nurserie run by } \\
\text { fellow farmers }\end{array}$ & & \\
\hline 11 & $\begin{array}{l}\text { Access to a Promoter Lead } \\
\text { farmer for coffee }\end{array}$ & & & 22. Micro-credit and saving facility & & \\
\hline
\end{tabular}

2. Provide information to the following questions

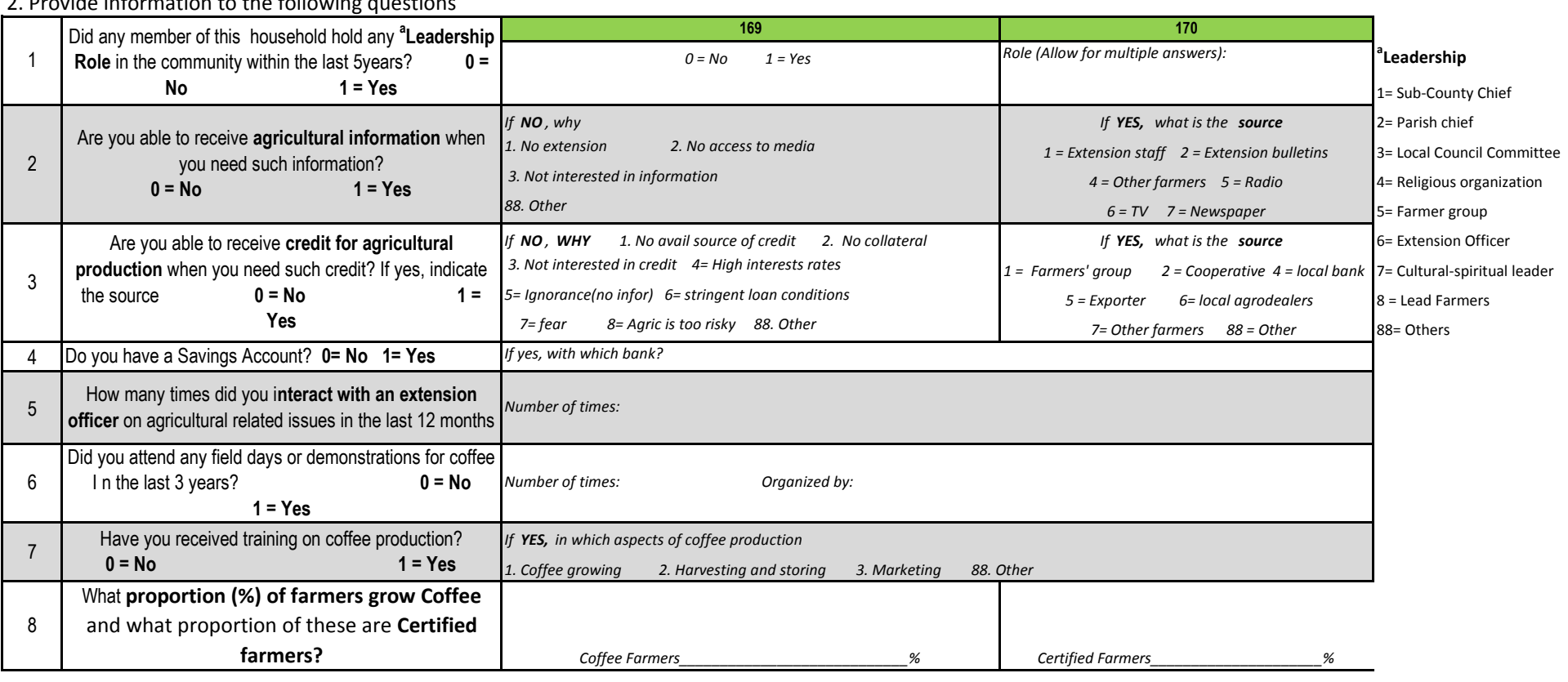


SECTION I: Social networks, cooperatives and certification II

1. Provide the following information on the participation and membership in social networks by members of this household.

\begin{tabular}{|c|c|c|c|c|c|c|c|c|c|}
\hline & \multirow{3}{*}{ Type of organization } & 171 & 172 & 173 & 174 & \multirow{3}{*}{\begin{tabular}{|c|}
175 \\
Women's group \\
\end{tabular}} & \multirow{3}{*}{$\begin{array}{c}176 \\
\text { Credit and } \\
\text { Savings group }\end{array}$} & \multirow{3}{*}{\begin{tabular}{|c|}
177 \\
$\begin{array}{c}\text { Health/Nuitrition } \\
\text { program }\end{array}$
\end{tabular}} & \multirow{3}{*}{$\begin{array}{c}178 \\
\text { Others }\end{array}$} \\
\hline & & \multicolumn{4}{|c|}{ Specifically for Coffee } & & & & \\
\hline & & Farmer group & $\begin{array}{l}\text { Farmers' } \\
\text { Cooperative }\end{array}$ & $\begin{array}{c}\text { Farmers' } \\
\text { Association }\end{array}$ & Farmers' Alliance & & & & \\
\hline 1 & $\begin{array}{l}\text { porticipate in the folllowing } \\
\text { p=No } 1=V_{0 s}\end{array}$ & & & & & & & & \\
\hline 2 & Name of the group & & & & & & & & \\
\hline 3 & a Who in the household is a member & & & & & & & & \\
\hline 4 & $\begin{array}{l}\text { For how long have they been a } \\
\text { member (years) }\end{array}$ & & & & & & & & \\
\hline 5 & $\begin{array}{l}\text { bLeadership role of member in this } \\
\text { organization } \quad 0=\text { No } \quad 1=\text { Yes }\end{array}$ & & & & & & & & \\
\hline 6 & $\begin{array}{l}\text { Are any of your relatives also } \\
\text { members } 0=\text { No } 1=\text { Yes }\end{array}$ & & & & & & & & \\
\hline 7 & $\begin{array}{l}\text { Are any of your neighbors also } \\
\text { members } 0=\text { No } 1=\text { Yes }\end{array}$ & & & & & & & & \\
\hline 9 & $\begin{array}{l}\text { What 'Services do you receive from } \\
\text { this association? }\end{array}$ & & & & & & & & \\
\hline 10 & $\begin{array}{l}\text { How did you get to know }{ }^{d} \text { about this } \\
\text { group }\end{array}$ & & & & & & & & \\
\hline & & & $\begin{array}{l}\text { a'Codes: } \\
\text { 1) HH head } \\
\text { 2) Spouse } \\
\text { 3) Jointly } \\
\text { 4) Parent } \\
\text { 5) Child } \\
\text { 88) Other }\end{array}$ & & $\begin{array}{l}\text { bPosition: } \\
\text { 1) Chairman } \\
\text { 2) Secretary } \\
\text { 3) Treasurer } \\
\text { 4 Group leader } \\
\text { 88) Other (Specify) }\end{array}$ & $\begin{array}{l}\text { 'Type of service: } \\
\text { 1) Information on Co } \\
\text { 2) Bulk marketing of } \\
\text { 3) Credit provision } \\
\text { 4) Access to markets } \\
\text { 5) Extension services } \\
\text { 6) Cash advances on } \\
\text { 7) Information on oth } \\
\text { 88) Other } \\
\end{array}$ & $\begin{array}{l}\text { fee } \\
\text { offee } \\
\text { and training } \\
\text { roduce } \\
\text { er crops } \\
\end{array}$ & $\begin{array}{l}\text { 'Source: } \\
\text { 1) Extensn staff } \\
\text { 2) other farmers } \\
\text { 3) Media } \\
\text { 4) Farmer group } \\
\text { 88) Other }\end{array}$ & \\
\hline
\end{tabular}

2. Provide the following information about coffee farmers that you know.

\begin{tabular}{|c|c|r|r|}
\hline \multirow{2}{*}{1} & Are you aware of any relative, neighbor or farmer that \\
produces Certified coffee. & $0=$ No $1=$ Yes & 180 \\
\cline { 3 - 4 } 2 & $\begin{array}{c}\text { If YES, do you interact with any of these farmer/s? } \\
0=\text { No } \\
1=\text { Yes }\end{array}$ & $\begin{array}{c}\text { If YES, what is the distance in (Km) to the } \\
\text { certified farmer that you interact with? }\end{array}$ & $\begin{array}{r}\text { What type of information do you } \\
\text { exchange with this CERTIFIED farmer } \\
\text { (Use the c codes above) }\end{array}$ \\
\hline 3 & $\begin{array}{c}\text { Please list 3-4 farmers living around this neighbourhood } \\
\text { that are NON-CERTIFIED and NOT part of any Farmer } \\
\text { group }\end{array}$ & & \\
\hline
\end{tabular}

THANK YOU VERY MUCH FOR TAKING TIME TO TALK TO US! 
DATE:

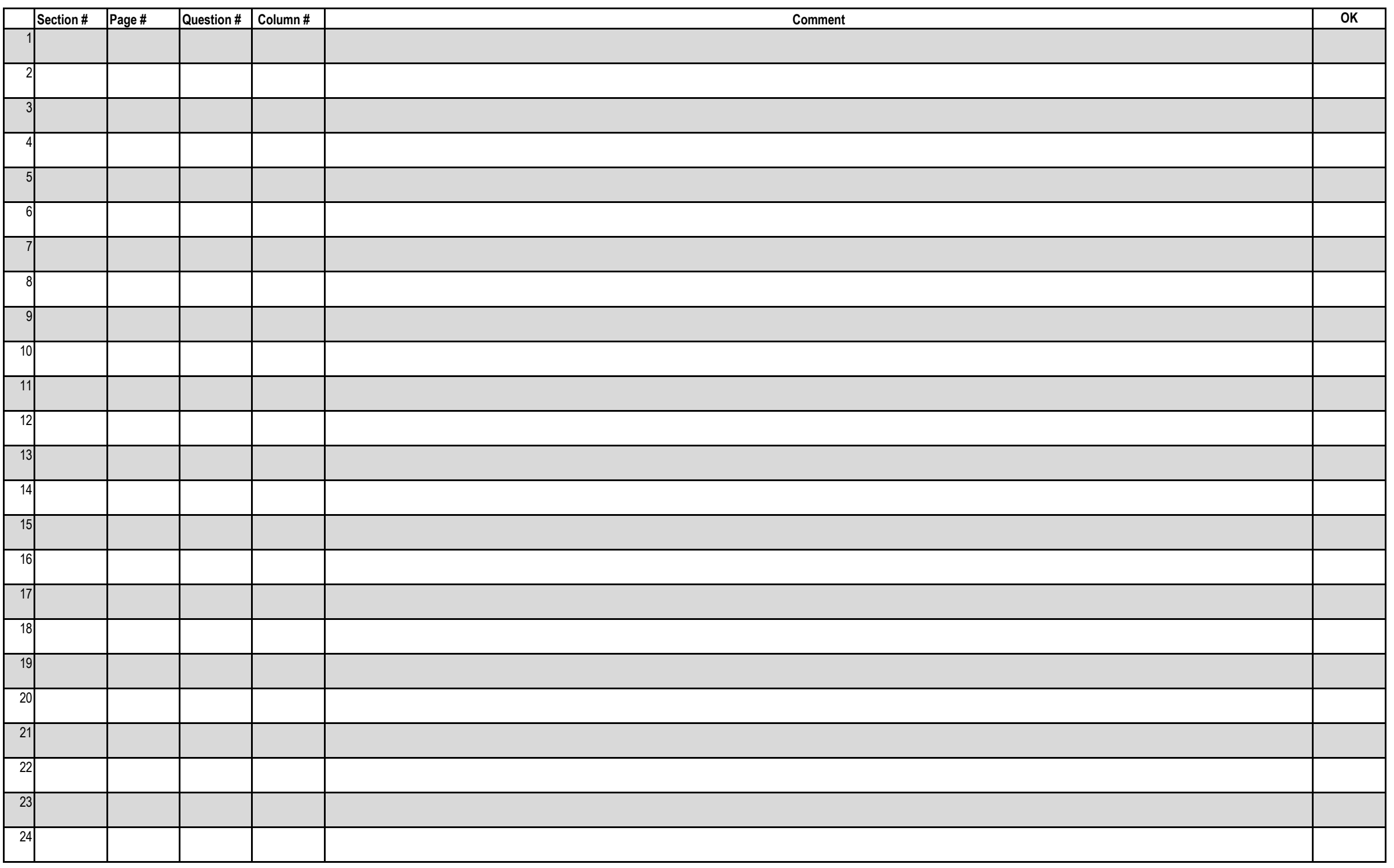

